\title{
Evaluating the function of the Aryl Hydrocarbon Receptor in CNS autoimmunity
}

\author{
Doctoral Thesis \\ for the award of the degree \\ “Doctor rerum naturalium" (Dr. rer. nat.) \\ in the Neuroscience Program \\ at the Georg August University Göttingen, \\ Faculty of Biology
}

submitted by

Erika Avendaño Guzmán

born in

Tlalnepantla de Baz, México

Göttingen 2018 


\section{Members of the Committee Meeting}

Supervisor (reviewer): Prof. Dr. med Wolfgang Brück

Institute for Neuropathology, University Medical Center Göttingen

$2^{\text {nd }}$ Referee: Prof. Dr. Klaus-Armin Nave

Department of Neurogenetics, Max Planck Institute for Experimental Medicine

$3^{\text {rd }}$ Referee: Prof. Dr. Alexander Flügel

Department of Neuroimmunology, Institute for Multiple Sclerosis Research

$4^{\text {th }}$ Referee: Prof. Dr. Holger Reichardt

Institute of Cellular and Molecular Immunology, University Medical Center Göttingen

\section{Further members of the Examination Board}

Prof. Hannelore Ehrenreich

Clinical Neuroscience, Max Planck Institute of Experimental Medicine

Prof. Fred Wouters

Institute for Neuropathology, University Medical Center Göttingen

Date of oral examination: $\underline{17.10 .18}$ 
I hereby declare that my dissertation entitled "Evaluating the function of the Aryl Hydrocarbon Receptor in CNS autoimmunity" has been written independently with no other sources and aids than quoted.

Erika Avendaño Guzmán

Göttingen, August 2018 


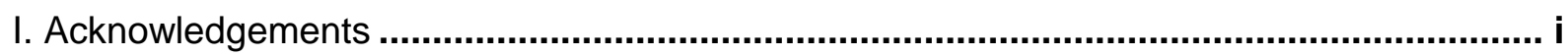

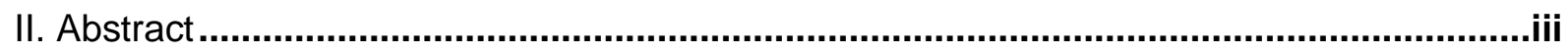

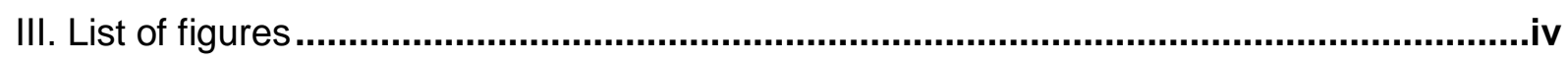

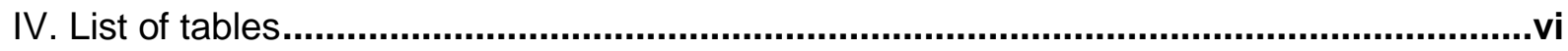

V. Abbreviations .....................................................................................................

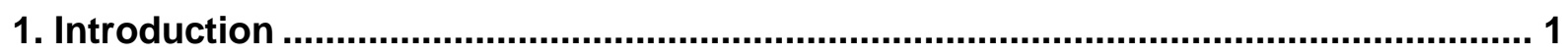

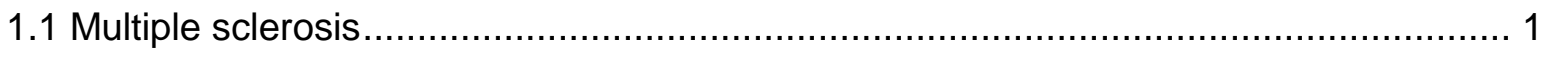

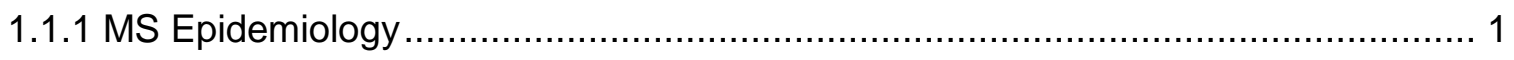

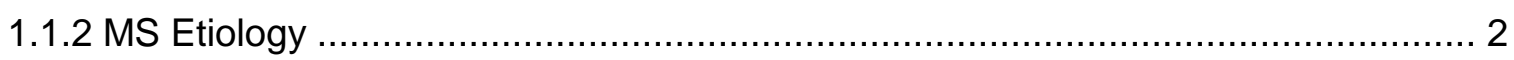

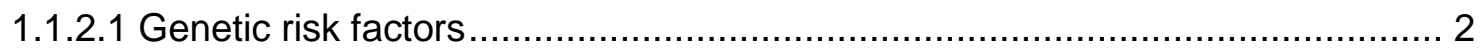

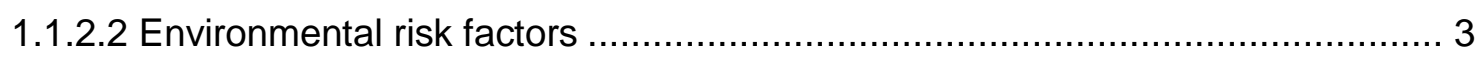

1.2 Experimental Autoimmune Encephalomyelitis ..................................................... 5

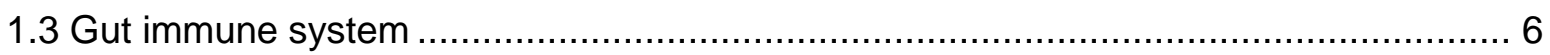

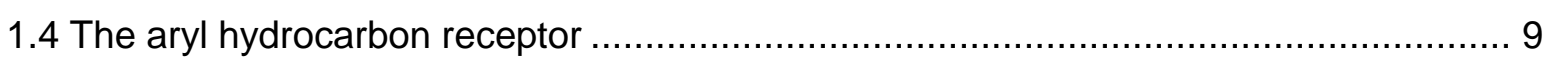

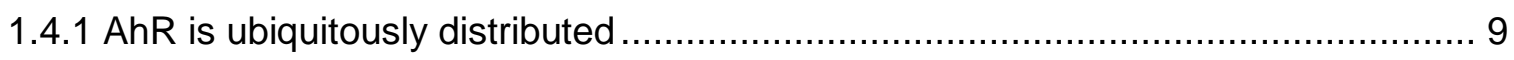

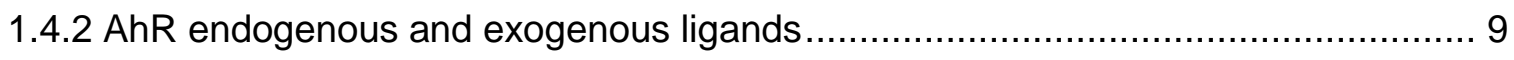

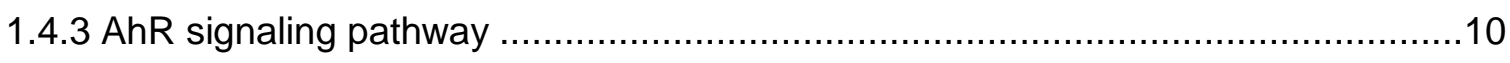

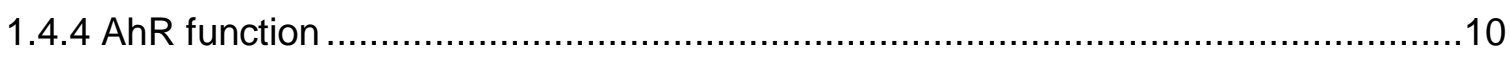

1.4.5 AhR knock out animals ........................................................................... 11

1.4.6 AhR modulates the crosstalk between the intestinal immune system, diet and

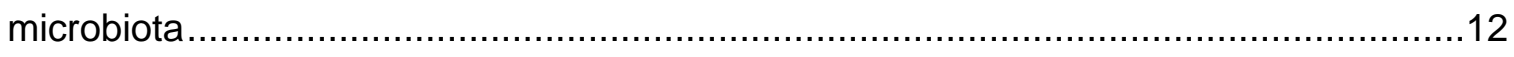

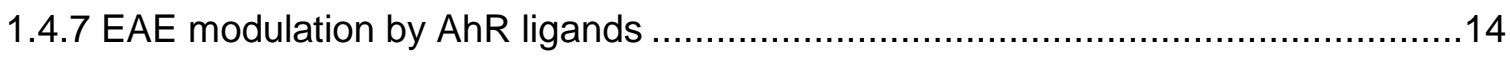

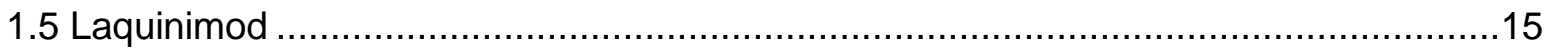

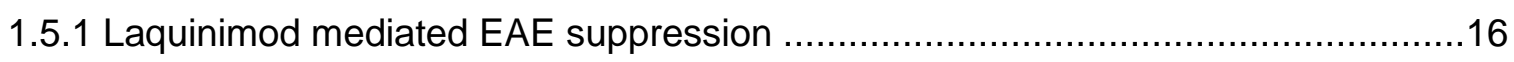

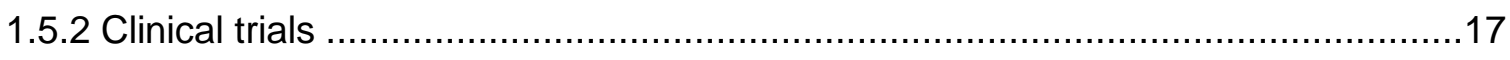

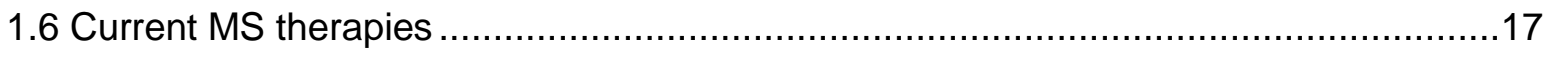

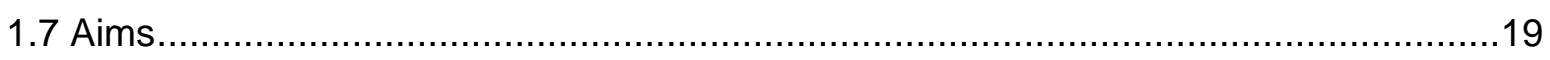

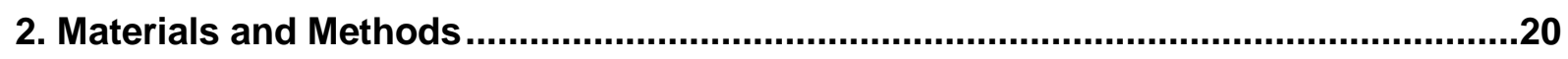

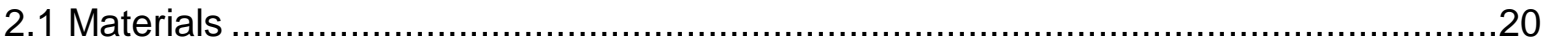

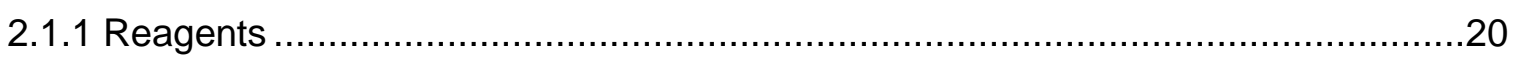

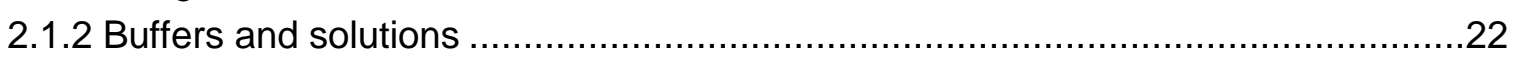

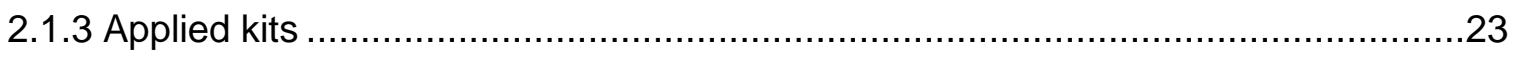

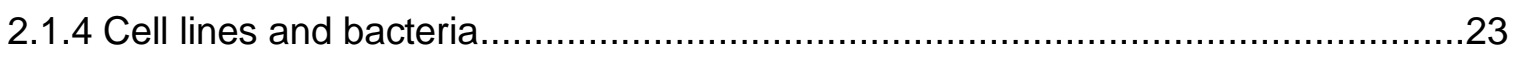

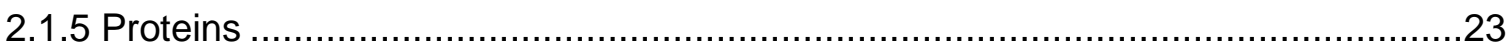




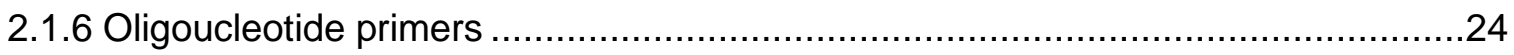

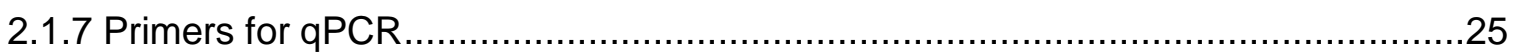

2.1.8 Secondary anti-mouse HRP tagged antibodies used for ELISA ...........................25

2.1.9 Primary antibodies used in paraffin embedded sections ......................................25

2.1.10 Secondary antibodies used in paraffin embedded sections................................25

2.1.11 Fluorophore tagged monoclonal antibodies used for flow cytometry ..................26

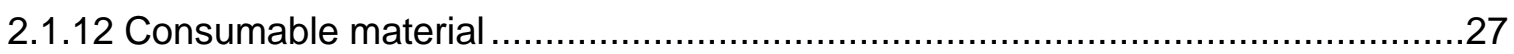

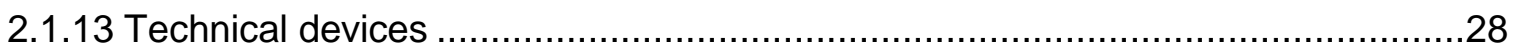

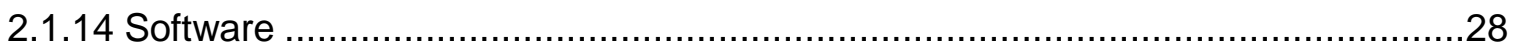

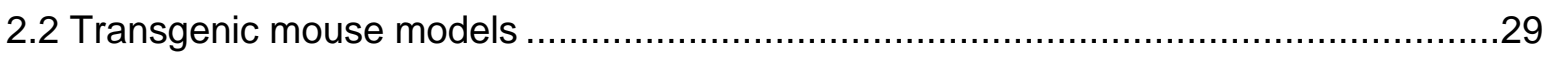

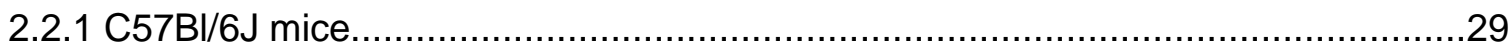

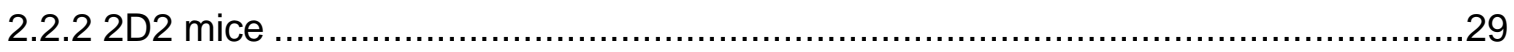

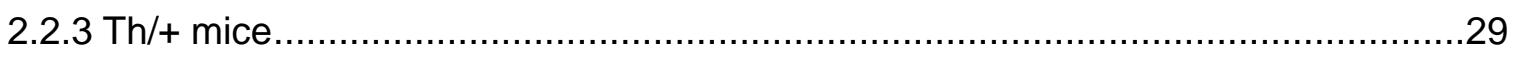

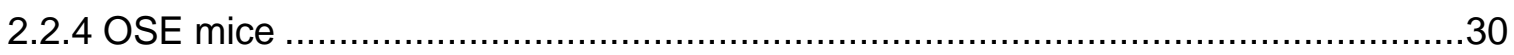

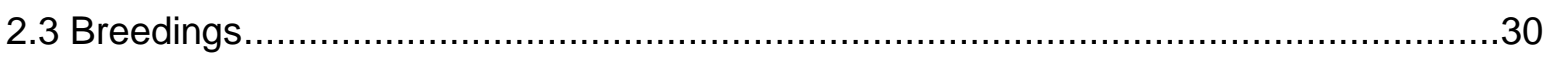

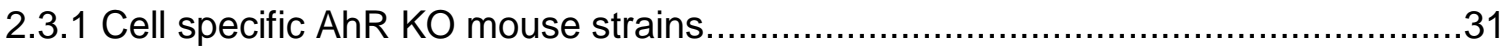

2.3.2 $\mathrm{AhR}^{\mathrm{fl} /+} \mathrm{CD} 11 \mathrm{c}^{\mathrm{Cre}+} \mathrm{R} 26^{\mathrm{eYFP}}$ mice (CD11c specific AhR KO) ...................................31

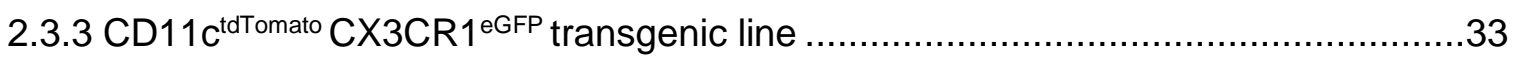

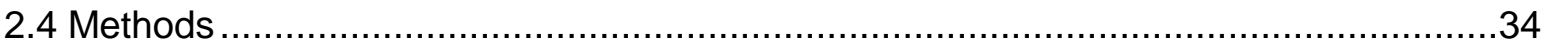

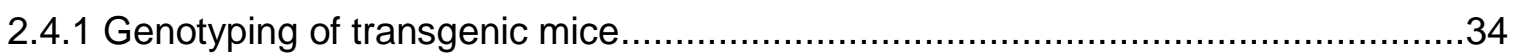

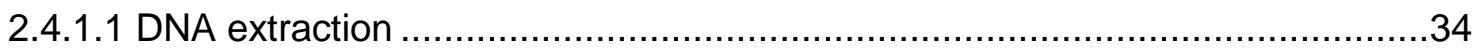

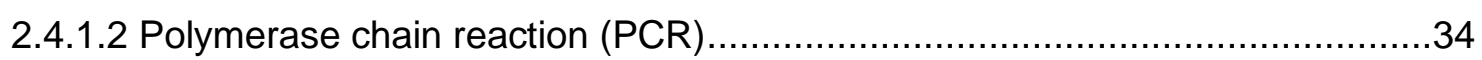

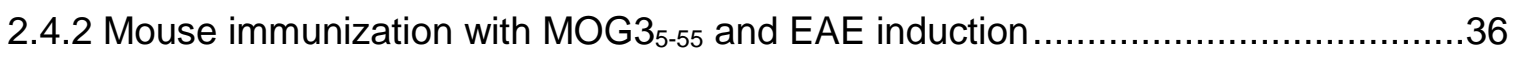

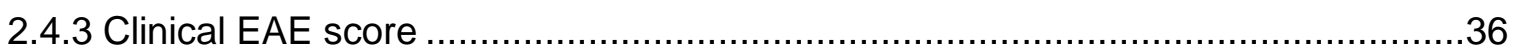

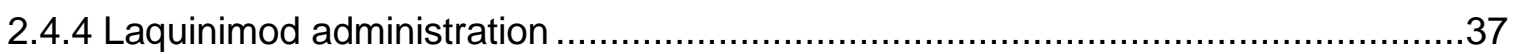

2.4.5 Preparation of single cell suspensions from the spleen for ex vivo analysis ..........37

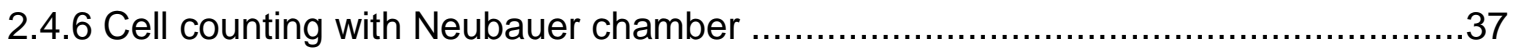

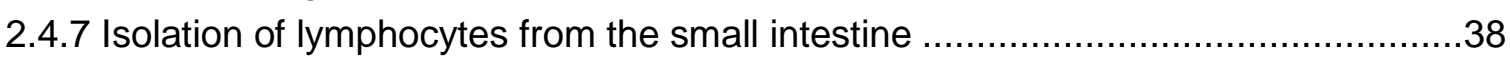

2.4.7.1 Isolation of lymphocytes from the Peyer patches .........................................38

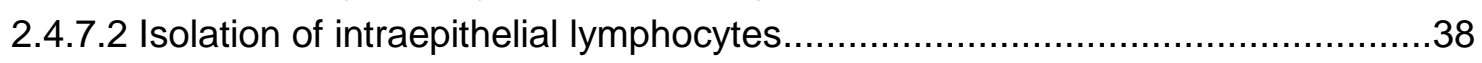

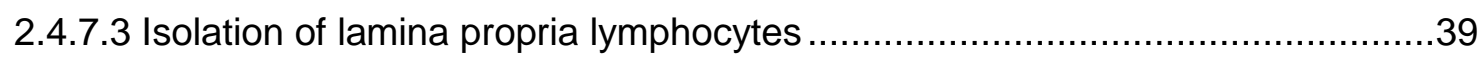

2.4.7.4 Separation of lymphocytes using a Percoll gradient....................................40

2.4.8 Flow cytometry staining and analysis .......................................................... 41

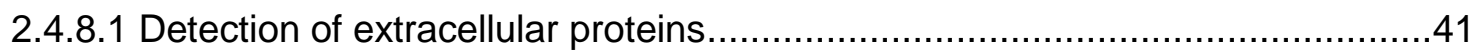

2.4.8.2 Intracellular detection of FoxP3 ................................................................ 41

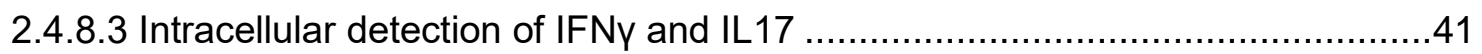

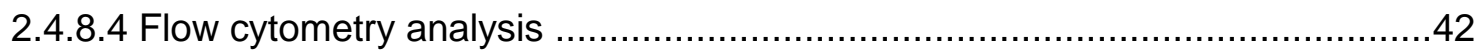

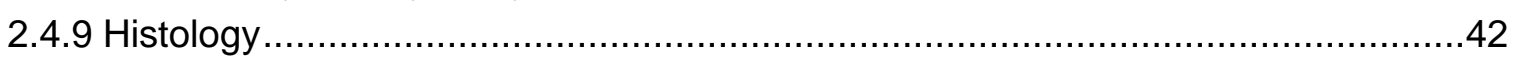

2.4.9.1 Preparation of mouse tissue for immunohistochemistry ............................. 42

2.4.9.2 Deparaffinization and dehydration of small intestine sections ......................43

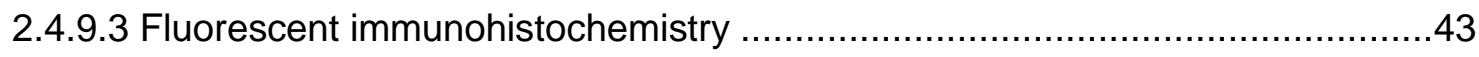

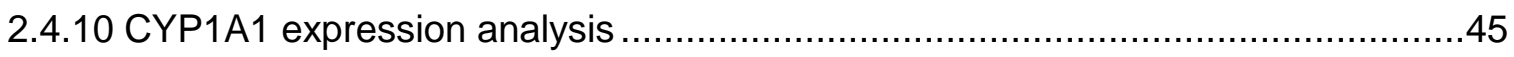

2.4.10.1 Purification of dendritic cells ............................................................. 45 
2.4.10.2 Quantitative real time PCR analysis of CYP1A1 expression ........................45

2.4.11 B16F10 melanoma cell culture and passaging ................................................46

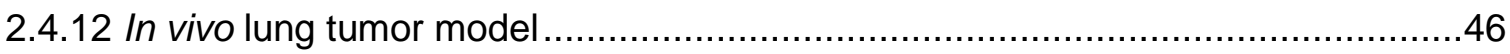

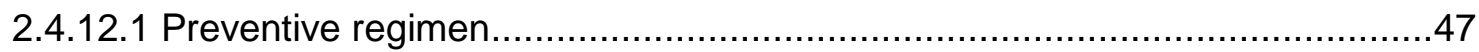

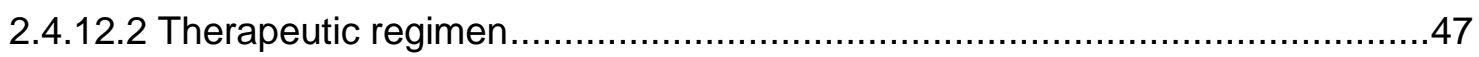

2.4.12.3 Lung isolation and metastasis quantification ......................................... 47

2.4.13 Preparation of serum samples for MOG antibody quantification..........................47

2.4.14 Indol-3-carbinol enriched diet regimen .......................................................48

3. Results

3.1 Physiological AhR ligands reduce spontaneous CNS autoimmunity by acting on dendritic cells

3.1.1 Diet supplementation with an AhR ligand suffices to modify the EAE incidence in OSE mice

3.1.2 AhR deficiency in CD4+ T cells and astrocytes does not influence spontaneous EAE in the OSE mouse model. .50

3.1.3 AhR deficiency in DC significantly increases the incidence of spontaneous EAE..51

3.2 AhR deficiency in DC alters the phenotype of APCs in the lamina propria of OSE mice

3.2.1 OSE $A h R^{\Delta D C}$ mice present increased numbers of $\mathrm{FNNY}^{+}$transgenic $\mathrm{T}$ cells in the lamina propria of the small intestine.

3.2.2 OSE $A h R^{\triangle D C}$ mice have significantly higher MOG specific IgG2a antibody titers...59

3.3 AhR competent DC are relevant for Laquinimod to suppress $E A E$ .59

3.3.1 Laquinimod's therapeutic effect cannot be attributed to a single AhR competent cell type 60

3.3.2 AhR competent DC contribute to Laquinimod's protection against EAE..... .62

3.3.3 Laquinimod treatment reduces the percentage of $\mathrm{CD} 11 \mathrm{C}^{+} \mathrm{MHCI}{ }^{\text {high }} \mathrm{DC}$ cells in $\mathrm{AhR}^{\triangle \mathrm{DC}}$ mice

3.3.4 Laquinimod requires AhR competent $D C$ to reduce the frequency of Th17 cells ...67 3.3.5 The AhR-IDO-1 axis does not mediate Laquinimod's protective effect in the EAE model .69

3.3.6 Laquinimod increases CD25 ${ }^{+}$FoxP3 $^{+} \mathrm{T}$ cells in $\mathrm{AhR}^{\triangle \mathrm{CD} 4}$ and $\mathrm{AhR}^{\Delta \mathrm{Treg}}$ mice ...........70

3.3.7 NK cell activation by Laquinimod is independent of AhR expression on DC and CD4+ T cells .72

3.3.8 Laquinimod reduces pulmonary B16F10 metastases .74

4. Discussion . .76

4.1 AhR deletion in DC doubles disease incidence in the OSE mouse model .78

4.2 Evaluation of intestinal APCs in the OSE $A H R^{\triangle D C}$ mice. .79

4.3 OSE $A H R^{\triangle D C}$ mice produce higher amounts of IgG2a MOG antibody titers and IFNy..81

4.4 AhR effect on $\mathrm{T}$ cell differentiation .82

4.5 AhR repercussions on astrocytes .82 
4.6 EAE incidence can be altered by modifying AhR ligands in the diet .83

4.7 AhR mediated effect of Laquinimod on EAE. .84

4.7.1 Laquinimod effect on NK cell cytotoxicity

4.7.2 Final remarks on AhR mediated Laquinimod's effect

5. Outlook .88

6. Conclusions .90

7. References. 92

8. Curriculum Vitae. 110 
A mi madre 


\section{ACKNOWLEDGEMENTS}

This work wouldn't be possible without the help from many people. Therefore, I would like to express my gratitude to all that contributed to the present dissertation:

To Dr. Stefan Nessler for the insightful comments on this thesis, the lab training at the bench, the tireless work and input to the project and the relentless supervision.

To Prof. Dr. Christine Stadelmann for all the support during the last four years.

To Prof. Dr. Wolfgang Brück for letting me join the Neuropathology department and for all valuable comments during my progress reports and committee meetings.

To Prof. Dr. Klaus-Armin Nave, Prof. Dr. Alexander Flügel and Prof. Dr. Holger Reichardt for being in my thesis advisory meetings and for all suggestions and discussions that enriched the project. I'm also thankful to Prof. Hannelore Ehrenreich and to Prof. Fred Wouters for being part of the extended committee board.

To the excellent team of technical assistants: Brigitte, Jasmin, Heidi, Angela, Elke, Uta and Olga. Special thanks to Katja for her great help in immunohistochemistry and performing the genotypings of the different transgenic mouse lines.

To Jana and Anne for their helpful feedback on this manuscript and to my colleagues: Claudia, Franzi, Nielsen, Patrick, Alonso, Susi, Nasrin, Carolin, Darius, Sandra, Silke, Jasmin and Sebastian for their scientific advice.

To the Neuroscience Program IMPRS and the deeply committed coordination team led by Prof. Dr. Michael Hörner and Sandra Drube for guidance provided since I came to Germany in 2012. Many thanks for always keeping an open door for me and for letting this whole adventure begin.

To Heidi and Cynthia for the administrative help and to Bernd for the IT support and for lending me his quiet office to write my dissertation. 
Last but not least to my family and friends which always supported me and deserve a special mention in Spanish, my mother language:

\section{AGRADECIMIENTOS}

Antes que nada, le dedico esta tesis a mi madre, por motivarme a luchar por alcanzar mis sueños, aún si eso significa vivir a más de 10 mil kilómetros de distancia de mis seres queridos. Por enseñarme que lo importante es el viaje no el destino y por hacerme sentir tan querida en cada etapa de mi vida.

A mis abuelos Irma y Alfonso por ser un ejemplo de honradez, trabajo y esfuerzo.

A mi life-couch Poncho por nunca dejar de creer en mí.

A Beto por todo su apoyo y por regalarme la tranquilidad de que he dejado a mi madre bien acompañada.

A mi tía Rebeca por ser ejemplo e inspiración tras la tremenda batalla que le ha dado a la neuromielitis óptica.

A mi tía Blanquita que con sus cartas y detalles siempre está al pendiente de mí.

A mis primos Rebeca, Julián, Chuchito y Carolina por recordarme, cada uno a su manera, el legado de superación y entrega que nos dejaron nuestros padres.

A toda mi familia y amigos en el DF y Göttingen porque sin su ayuda y apoyo no estaría aquí.

¡A todos mil gracias! 
The aryl hydrocarbon receptor $(\mathrm{AhR})$ is a ligand activated transcription factor highly expressed within the immune and nervous system. Structurally diverse endogenous and synthetic ligands activate AhR, including dietary, microbial and physiological compounds, suggesting a potential crosstalk between AhR's signaling, diet, microbiome, and immune system. The aim of the present thesis was to evaluate if endogenous AhR ligands influence the development of spontaneous CNS autoimmunity. For this purpose, double transgenic opticospinal (OSE) mice carrying myelin oligodendrocyte glycoprotein (MOG) specific $T$ and $B$ cell receptors were generated with or without AhR competent dendritic cells (DC), CD4 ${ }^{+} \mathrm{T}$ cells, regulatory $\mathrm{T}$ cells $\left(T_{\text {regs }}\right)$ or astrocytes. The spontaneous EAE incidence significantly increased in OSE animals with $\mathrm{AhR}$ deleted in $\mathrm{DC}\left(\mathrm{OSE} A h \mathrm{R}^{\Delta \mathrm{DC}}\right.$ ), but not in OSE mice devoid of $\mathrm{AhR}$ in $\mathrm{CD}^{+} \mathrm{T}$ cells, $\mathrm{T}_{\text {regs }}$ or astrocytes. OSE $A h R^{\triangle D C} \mathrm{CX} 3 \mathrm{CR} 1^{\mathrm{EGFP} /+}$ reporter mice were generated in order to assess the antigen presenting cells (APCs) of the lamina propria (LP), where MOG specific CD4+ cells are likely activated in the OSE mouse model. AhR deficiency of DC increased the frequency of CX3CR $1^{\text {int }} \mathrm{DC}$ and correspondingly decreased the frequency of CX3CR1- DC. The presence of $C X 3 C R 1^{\text {int }} D C$ and $C X 3 C R 1^{-} D C$ was confirmed by immunohistochemistry in the LP of CD11 $\mathrm{c}^{\text {tdTomato }} \mathrm{CX} 3 \mathrm{CR} 1^{\text {eGFP }}$ reporter mice. CX3CR1 ${ }^{\text {int }} \mathrm{DC}$ showed higher MHCII expression than CX3CR1 - DC. Thus, might be better equipped to initiate the activation of MOG specific naïve T cells. Compared to OSE $A h R^{\mathrm{fl} / f \mathrm{l}}$ control littermates, OSE $A h R^{\Delta D C}$ mice showed higher frequencies of IFNY+ transgenic $\mathrm{CD}^{+}{ }^{+} \mathrm{T}$ cells in the LP and increased MOG specific $\lg 2 \mathrm{a}$ antibodies in the sera. Furthermore, supplementing a single AhR ligand to the diet of OSE mice, spontaneous EAE was almost completely abolished. Finally, it was aimed to define the relevant cellular players mediating the therapeutic efficacy of the presumed and clinically relevant $A h R$ agonist, Laquinimod, against EAE. Laquinimod significantly protected $A h R^{\Delta D C}$, $A h R^{\Delta C D 4}, A h R^{\Delta T r e g}$ and $A h R^{\Delta A s t r o}$ mice, but its protective effect was less sustained in $A h R^{\Delta D C}$ mice. In summary, this work provides evidence showing that the physiological concentrations of AhR ligands modulate CNS autoimmunity via AhR competent DC. 
Figure Name

1 Structure of Laquinimod and Roquinimex

2 Breeding strategy used to produce four different cell specific AhR KO mouse strains that develop spontaneous EAE Breeding strategy used to generate $\mathrm{AhR}^{\mathrm{fl} /+} \mathrm{CD} 11 \mathrm{c}^{\mathrm{Cre}+} \mathrm{R} 26^{\mathrm{eYFP}}$ and $\mathrm{AhR}^{\mathrm{fl} /-}$

$3 \quad \mathrm{CD} 11 \mathrm{c}^{\mathrm{Cre}+} \mathrm{R} 26^{\mathrm{YYFP}}$ control mice

Schematic representation of the tubes containing 40 and $80 \%$ Percoll

$4 \quad$ phases before and after the Percoll gradient centrifugation Indol-3-carbinol enriched diet abrogates spontaneous EAE development in OSE mice AhR deficiency in $\mathrm{CD}^{+} \mathrm{T}$ cells and astrocytes does not influence

6 spontaneous CNS autoimmunity in OSE mice AhR deficiency in DC increases the incidence of spontaneous EAE in OSE mice

9 The percentage of $\mathrm{CX}_{3} \mathrm{CR} 1^{\text {int }} \mathrm{DC}$ increases in OSE $\mathrm{AhR}^{\Delta \mathrm{DC}} \mathrm{CX}{ }_{3} \mathrm{CR} 1^{\mathrm{EGFP} /+}$ mice compared to OSE $\mathrm{AhR}^{\mathrm{fl/fl}} \mathrm{CX}_{3} \mathrm{CR} 1^{\mathrm{EGFP} /+}$ transgenic animals

10 Visualization of intestinal APCs using the CD11c ${ }^{\text {tdTomato }}$ CX3CR 1 eGFP transgenic mice

11 DC might sample luminal antigens by small transepithelial dendrites

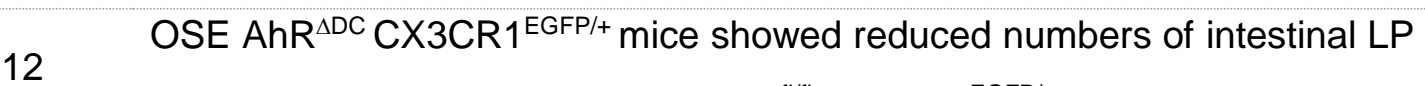
macrophages compared to OSE $\mathrm{AhR}^{\mathrm{fl/fl}} \mathrm{CX} 3 \mathrm{CR} 1^{\mathrm{EGFP} /+}$ control animals

13 Quantification of CYP1A1 expression in YFP+ AhR competent and AhR deficient DC

14 OSE AhR ${ }^{\triangle D C}$ mice have significantly higher frequencies of IFN $\gamma$ producing MOG specific $T$ cells in the lamina propria of the small intestines Quantification of MOG specific antibody titers in the sera of OSE AhR ${ }^{\triangle D C}$ and OSE $A H R^{f / / f l}$ mice by ELISA 
Figure Name

16 The Laquinimod mediated EAE incidence decrease is less sustained in $\mathrm{AhR}^{\Delta \mathrm{DC}}$ mice

Expression of $\mathrm{AhR}$ on $\mathrm{DC}, \mathrm{T}_{\text {regs }}$ and astrocytes is not essential for

17 Laquinimod mediated decrease of EAE severity

63

18 Laquinimod's effect on $\mathrm{AhR}^{\Delta \mathrm{Astro}}$ and $\mathrm{AhR}^{\Delta \mathrm{DC}}$

19 Laquinimod decreases the percentage of CD11c ${ }^{+} M H C I^{\text {high }} \mathrm{DC}$ in $\mathrm{AhR}^{\Delta \mathrm{DC}}$ mice

Laquinimod fails to decrease IL17 producing $C D 4^{+} \mathrm{T}$ cells in $\mathrm{AhR}^{\Delta \mathrm{DC}}$ mice

20 but not in $\mathrm{AhR}^{\triangle \mathrm{CD} 4}$ and $\mathrm{AhR}^{\triangle \mathrm{Astro}}$

21 The lack of IDO-1 does not impair Laquinimod's protection against EAE

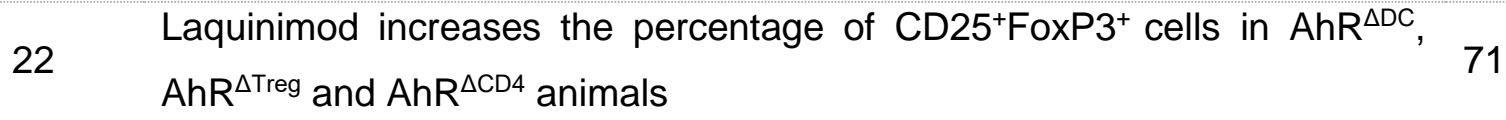

23 Laquinimod activates NK cells in the absence of AhR competent CD4 ${ }^{+} \mathrm{T}$ cells or DC

Preventive and therapeutic approaches used to study the efficacy of

24 Laquinimod to suppress B16F10 melanoma metastases in vivo Laquinimod reduces the number of pulmonary B16F10 metastases if given preventively and without AhR deletion in DC 
$1 \quad$ First and second line approved drugs for MS treatment 18

2 Reagents used in the different experimental procedures. 20

3 Buffers, cell culture media and solutions used for immunization, cell isolation

3 and flow cytometry stainings

$4 \quad$ Applied kits 23

$5 \quad$ Cell lines and bacteria 23

$6 \quad$ Proteins, enzymes and inhibitors 23

$7 \quad$ Oligonucleotide primers used for transgenic mice genotyping 24

$8 \quad$ TaqMan qPCR primers $\quad 25$

$9 \quad$ Polyclonal antibodies used for ELISA 25

10 Primary antibodies used in paraffin embedded sections 25

11 Secondary antibodies used in paraffin embedded sections 25

12 Fluorophore tagged monoclonal antibodies used for flow cytometry 26

$\begin{array}{lll}13 & \text { Laboratory consumables } & 27\end{array}$

14 Technical devices and special equipment 28

$15 \quad$ List of software used for data acquisition and analysis 28

16 Transgenic mouse models used for breeding, in vivo and in vitro experiments 30

17 Transgenic mouse lines used to generate AhR specific knock out mice 33 through the Cre/Lox system

$18 \quad$ Composition of PCR reactions used for transgenic mice genotyping 34

196 step PCR programs used in the T3 thermocycler for transgenic mice genotyping

$20 \quad$ Scoring scale for EAE clinical monitoring 36

21 Deparaffinization and rehydration series of paraffin embedded sections 43

22 EAE incidence, maximum disease score and EAE onset 60 


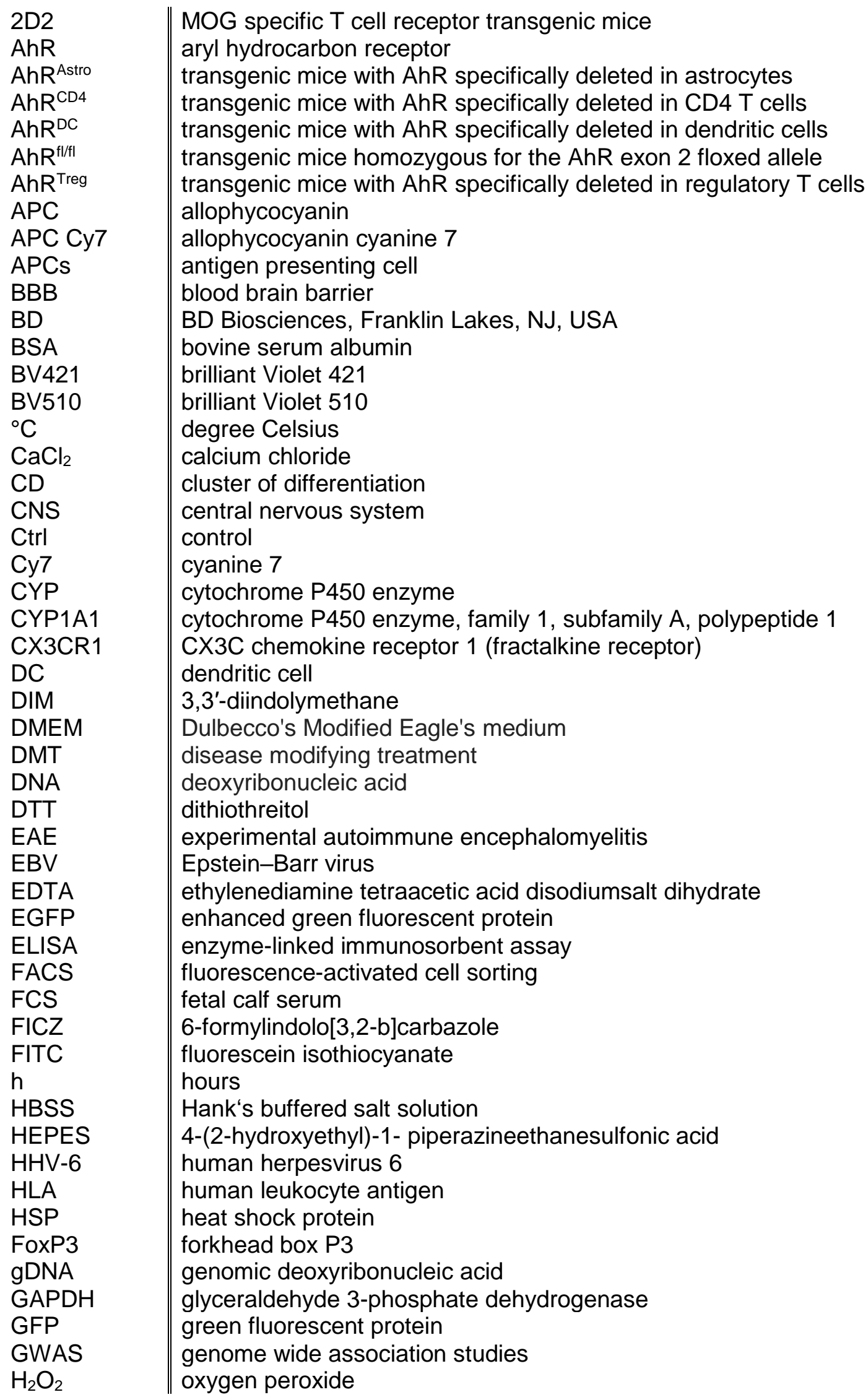




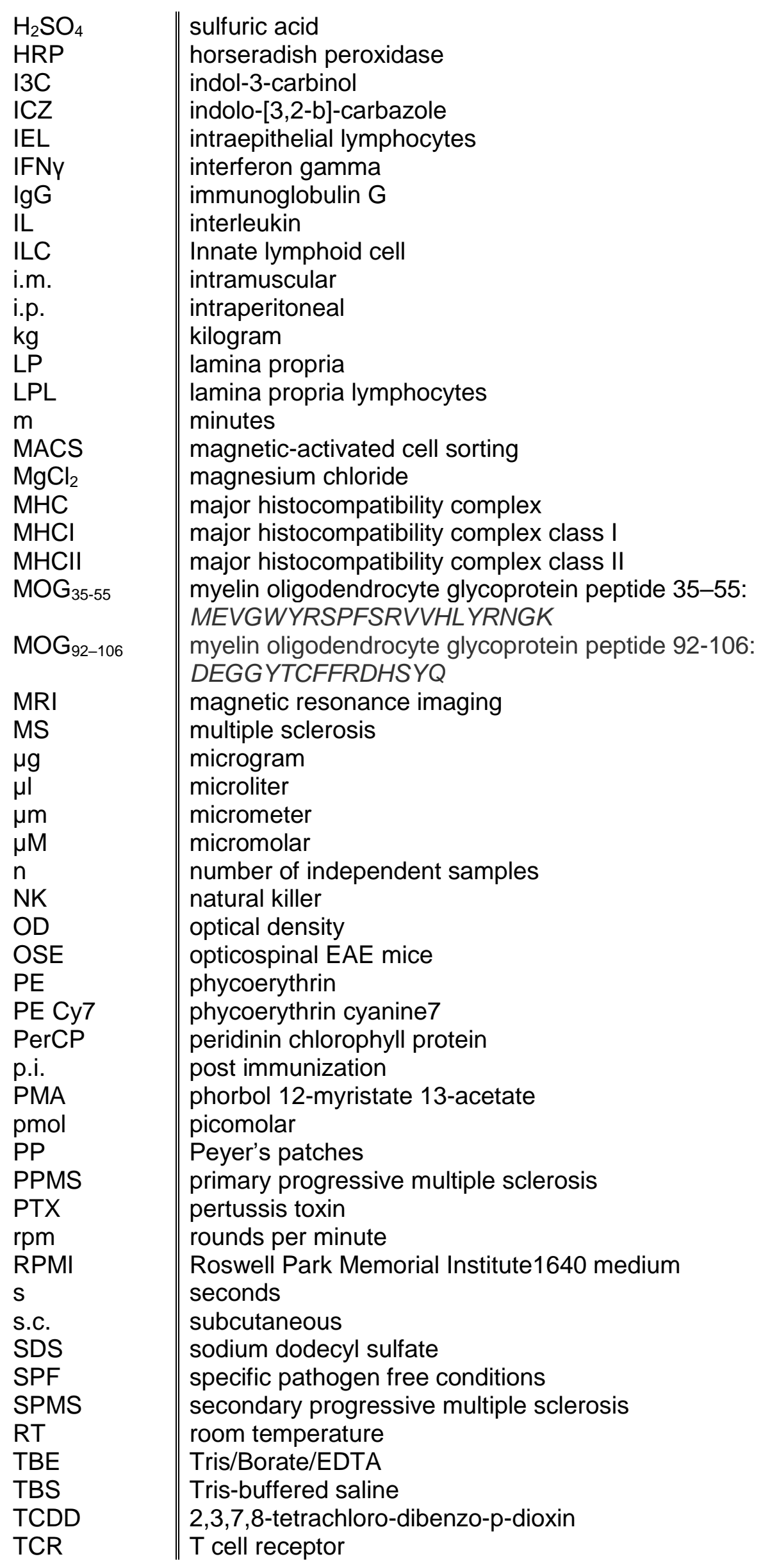




\begin{tabular}{l||l} 
Th cell & T helper cell \\
Th17 cell & T helper 17 cell \\
Th/+ mice & MOG specific B cell receptor transgenic mice \\
TMB & $3,3^{\prime}, 5,5^{\prime}$-tetramethylbenzidine \\
T $_{\text {regs }}$ & regulatory T cells \\
TSA & tyramide signal amplification \\
UMG & University medical center Göttingen \\
UV & ultraviolet \\
VDR & vitamin D receptor \\
WT & wild type \\
YFP & yellow fluorescent protein
\end{tabular}




\subsection{Multiple sclerosis}

Multiple sclerosis (MS) is a currently incurable chronic inflammatory and demyelinating disease of the central nervous system (CNS). It is considered autoimmune in nature and its cause remains unknown. MS is characterized by lymphocytic and monocyte/macrophage infiltrates wreaking havoc to the myelin sheaths and oligodendrocytes ${ }^{1}$. Inflammatory demyelination is associated with axonal and neuronal pathology, which are considered the major pathological determinants of irreversible neurological disability.

Around $80 \%$ of MS patients start with a relapsing remitting (RRMS) clinical course, which is characterized by episodes of neurological dysfunction followed by recovery periods. Patients typically present initially vision problems, numbness and or muscle weakness ${ }^{2}$. With time, $65 \%$ of the RRMS patients enter a secondary progressive (SPMS) stage of the disease, characterized by a gradual physical decline with no noticeable remissions. A primary progressive (PPMS) disease course can be found in $15-20 \%$ of the MS cases and usually starts in male patients after the age of $40^{3}$.

\subsubsection{MS Epidemiology}

MS is the most frequent inflammatory demyelinating disorder with a prevalence that varies considerably between regions with high rates in North America and Europe (less than 100 per 100000 inhabitants) and low rates in eastern Asia and sub-Saharan Africa (2 per 100 000). In addition, MS is considered the most frequent non-traumatic disorder leading to neurological disability in young adults ${ }^{4}$.

As the most prevalent inflammatory disorder of the CNS, MS affects more than 2 million people worldwide ${ }^{5}$. The highest prevalence occurs in Europe where more than half of the diagnosed MS patients live $e^{6,7}$. Just in Germany, there are an estimated 100 to 140 thousand MS patients, which are generally diagnosed around the age of 35 years $^{8}$. 
2 Introduction

Similar to other autoimmune disorders, MS is more prevalent in women than men; suggesting a role of sexual hormones, as well as gender differences in genes, development and function of the immune and nervous system ${ }^{3,9}$. The female-male ratio has significantly increased in the last decades (2.3-3.5:1). This significant increase of MS in women could be caused by environmental changes and nutrition ${ }^{10}$.

\subsubsection{MS Etiology}

Since Jean-Martin Charcot first described MS in 1868, its etiology has been extensively studied in order to design possible therapies that allow us to treat and ultimately cure the disease ${ }^{11}$. However, MS remains incurable up to now and the precise factors initiating the development of the disease are unclear.

Like most autoimmune diseases, MS is considered a multifactorial disorder with genetic and environmental risk factors. Furthermore sex, age, race, cultural and socio-economic conditions might enter the intricate interaction of elements triggering the disease ${ }^{12}$. MS complexity probably resides in the fact that none of these factors is essential or sufficient to trigger or at least, to predict the disease.

\subsubsection{Genetic risk factors}

Recent studies conclude that genetic variation might be accountable for about $50 \%$ of the individual differences in MS susceptibility ${ }^{13,14}$. Different population-based studies have shown MS concordance rates for monozygotic twins ( $25 \%)$, dizygotic twins $(\sim 5.4 \%)$ and siblings $(\sim 3 \%)^{15-20}$.

Having a first degree relative with MS increases the risk up to $2-4 \%$, which is already $20-40$ times higher than the $0.1 \%$ prevalence in the general population ${ }^{21}$. The likelihood to develop MS increases around 5- fold when both parents have the disease (12.2\%) compared to one parent affected $(2.5 \%)^{22-27}$.

The first identified MS genetic risk locus was the major histocompatibility complex $(\mathrm{MHC})$ on chromosome $6 \mathrm{p} 21$, specifically the human leukocyte antigen HLA-DR2 or 
DRB1*1501-DQB1*0602 extended haplotype. This extremely polymorphic region has shown the most consistent association with MS by genome wide association studies (GWAS) and case-control studies.

Carrying one copy of the HLA-DRB1 ${ }^{*} 1501$ haplotype increases the risk to develop MS 2-3 fold, while carrying two copies elevates the risk by 6 -fold ${ }^{15,28-30}$. Interestingly, other HLA alleles have been confirmed as MS protective factors including HLA-C554, HLA-DRB1*11, HLA $A^{*} 02$ and HLA B*4402 3 ,31.

At present, more than 50 non-HLA genetic risk factors for MS have been discovered and most belong to genes affecting the immune response. Namely, interleukin 2 receptor $\alpha$ chain (IL2RA), interleukin 7 receptor $\alpha$ chain (IL7RA), CD58, C-Type Lectin Domain Containing 16A (CLEC16A), nuclear receptor NR1.H3 and enzyme 1a-hydroxylase CYP27B1 (involved in vitamin D metabolism) are additional susceptibility genes for $\mathrm{MS}^{32-36}$.

\subsubsection{Environmental risk factors}

Since Charcot detected the variability in the incidence of MS around the world in 1877, plenty of evidence has been gathered regarding the environmental factors that could make an individual more susceptible to develop $\mathrm{MS}^{37}$. More than two decades ago, Kurtzke defined prevalence regions due to the geographically asymmetric distribution of $\mathrm{MS}^{38,39}$.

Nowadays, latitudinal gradients have been identified in Europe, North America, Australia and Asia concerning MS geoepidemiology $y^{6,40-46}$. The greater number of MS cases in higher latitudes compared to lower ones supports the importance of environmental factors modulating MS onset. For instance, vitamin D assimilation, exposure to ultraviolet (UV) radiation, smoking and pathogens have been related to the risk of developing $\mathrm{MS}^{47}$.

\subsubsection{Vitamin $D$}

Due to the inverse correlation between MS prevalence and sunlight exposure and given the fact that UV light is essential for vitamin $D_{3}$ (cholecalciferol) synthesis in the skin, vitamin $D$ deficiency has been long considered a modifiable risk factor for $\mathrm{MS}^{48-50}$. Vitamin $\mathrm{D}$ and solar 
4 Introduction

radiation have been shown to play differential effects on the immune cells located in the skin $^{51,52}$. The vitamin D receptor (VDR) is expressed in most cells of the human body, is involved in numerous cell processes and protects against autoimmune diseases ${ }^{36,53-56}$.

Even though the most important source of vitamin $D$ is induced by sun exposure in the skin, this fat soluble steroid can be also obtained from the diet and supplements ${ }^{57}$. The precise role of the vitamin D, as well as the diet's impact on MS susceptibility have not been fully elucidated, however both have been suggested to play a role in the disease since the early 50 's 58,59

\subsubsection{Diet}

Diet habits have been long associated to MS, particularly the fat ${ }^{60,61}$, salt ${ }^{62-64}$ and fiber consumption ${ }^{65-67}$. A large longitudinal study from 2012 reported that the Mediterranean diet prevents white matter lesions and cognitive decline by protecting small vessels in the brain ${ }^{68}$. This type of diet has been associated with reduced MS risk because it involves a high intake of fruits, vegetables, fish, whole grains, legumes and nuts ${ }^{69-71}$.

Although there is no particular diet recommended for MS patients, following a healthy nutritional scheme has been positively associated with the composition of gut bacteria and the immune system homeostasis ${ }^{67,72-78}$. Besides nutritional status, obesity ${ }^{79-81}$, malnutrition ${ }^{82}$ and related disorders, such as dyslipidemia ${ }^{83}$ and hypertension ${ }^{84}$ have been connected with MS.

\subsubsection{Viral infections}

Among the environmental factors, viral infections caused by herpesviruses, namely the human herpesvirus 6 (HHV-6) and Epstein-Barr virus (EBV), have been associated to MS pathogenesis. The former is linked to MS due to a greater appearance of HHV-6 in MS lesions compared to MS normal appearing white matter possibly indicating that HHV-6 can be reactivated during MS relapses ${ }^{85,86}$.

EBV is implicated in the pathogenesis of MS due to universal seropositivity and high anti-EBV antibody levels compared to age matched controls ${ }^{85,87-89}$. Furthermore, defective 
5 Introduction

control of EBV infection by cytotoxic $\mathrm{CD}^{+} \mathrm{T}$ cells might predispose to MS by allowing EBVinfected autoreactive B cells to accumulate in the central nervous system ${ }^{87,90}$.

Another hypothesis postulates that after viral infection, activated T cells recognize CNS antigens due to molecular similarity or mimicry. Nevertheless, this hypothesis extends to T cells primed in the periphery by any other infectious antigen or superantigen ${ }^{91,92}$.

Despite the fact no single environmental factor has been proven to cause MS, all mentioned environmental factors are able to directly or indirectly modulate immune responses and to influence protein and gene expression possibly affecting the likelihood to develop MS.

\subsection{Experimental Autoimmune Encephalomyelitis}

Experimental autoimmune encephalomyelitis (EAE) is the most commonly used animal model for MS. It can be induced by active immunization with myelin proteins/peptides emulgated in complete Freund's adjuvant (CFA) or by the adoptive transfer of myelin specific $T$ cells into syngenic recipients ${ }^{92,93}$.

Active $\mathrm{EAE}$ is achieved by immunization with myelin peptides depending on the mouse strain $^{94}$. For example, the proteolipid peptide (PLP) is used for SJL/J mice immunization ${ }^{95}$, myelin oligodendrocyte glycoprotein (MOG) for C57BL/6 mice ${ }^{96,97}$ and myelin basic protein (MBP) for B10.PL mice ${ }^{98}$.

In order to increase disease incidence, pertussis toxin is often administered at the time of the immunological challenge and two days later ${ }^{99}$. On the other hand, passive EAE is induced by adoptive transfer of encephalitogenic T cells, which can be in vitro manipulated before being inoculated to the recipients. The autoreactive $\mathrm{T}$ cells could be also labeled to follow their localization and interactions with other cells ${ }^{100}$.

Alternatively, spontaneous EAE can be observed in myelin specific T cell receptor transgenic mice. The frequency of spontaneous EAE can be significantly increased in animal strains less prone to EAE development such as $\mathrm{C} 57 \mathrm{BL} / 6$ mice by generating MOG specific $\mathrm{T}$ and $\mathrm{B}$ cell receptor transgenic mice such as the opticospinal (OSE) mice. In contrast to single 
6 Introduction

transgenic animals, around $50 \%$ of the OSE mice develop spontaneous EAE in the first 10 weeks of age depending on the housing conditions ${ }^{101,102}$.

Environmental factors vary depending on the animal facility and shape the microbiota composition, propensity to develop infections and immune responses. It is thought that external stimuli could trigger the autoimmune conversion of innocuous progenitors to pathogenic immune cells, leading to the combined attack of pathogenic $T$ and $B$ cells that potentially prompt spontaneous EAE development in the OSE mice ${ }^{103}$.

The EAE model is considered a $\mathrm{CD}^{+}$or $\mathrm{T}$ helper (Th) cell mediated autoimmune disease that resembles MS features. For instance, $\mathrm{CD}^{+} \mathrm{T}$ cell and mononuclear cell infiltration with subsequent demyelination and clinical signs. CD4 ${ }^{+}$Th1 and Th17 cells are primed outside the CNS before crossing the blood brain barrier (BBB). Besides microglia activation and other inflammation mediators' attraction, IFNy production by Th1 cells and IL 17 by Th17 cells causes damage in the myelin covering the axons ${ }^{92}$.

Activation of MOG specific $T$ cells in the gut-associated lymphatic tissue (GALT) is necessary for spontaneous EAE development in the relapsing remitting (RR) mice (SJL/J strain). According to Berer and colleagues ${ }^{103}$ the commensal microbiota could provide innate immune signals or peptides that share similarities with MOG epitopes. Their observations in germ free (GF) mice demonstrated full protection through life against spontaneous EAE in the $\mathrm{RR}$ mice, supporting a central role of commensal microbiota shaping $\mathrm{CD} 4^{+} \mathrm{T}$ cell priming at the GALT.

In general, no animal model recapitulates all features and underlying mechanisms of any human disorder. However, the EAE experimental model has been widely used to identify therapeutic targets and molecular pathways relevant in MS pathophysiology ${ }^{104}$.

\subsection{Gut immune system}

The gastrointestinal tract is the largest mucosal surface that separates the organism from the external environment. It comprises trillions of microorganisms termed the gut microbiome, 
which have co-evolved with the host over millennia in a symbiotic relationship ${ }^{105}$. The microbiota composition differs between individuals and performs essential functions to maintain the gut homeostasis, metabolism and immune system ${ }^{106}$.

The microbial community contains between 1000 to 1500 species depending on environmental and genetic factors. Most of them are Bacteroides and Firmicutes (92\%), that offer different metabolic benefits to the host and vice versa ${ }^{107}$. For instance, the host provides a nutritive milieu and a suitable niche for colonization, whereas the gut microbiota contributes to the assimilation of nutrients, development of the epithelium and immune system, as well as modulation of innate and adaptive immune responses, among many others ${ }^{108}$.

The intestinal wall is covered by finger-like protrusions called villi, whose major function is nutrient absorption and transport through its network of blood vessels. Nevertheless, these structures and the underlying tissues are also hosting the largest population of immune cells in mammals. The gut immune system coordinates a delicate balance directing immune responses against invading pathogens and providing tolerance to harmless microbes and food to avoid autoimmunity ${ }^{109}$.

The gut mucosa is formed by a single layer epithelium and the connective tissue beneath, which is known as the lamina propria (LP). The epithelial cells or enterocytes line up the lumen of the intestines and together with the overlying mucus are the first point of contact with food and microbes. Enterocytes are intercalated by intraepithelial lymphocytes (IEL), with about one lymphocyte for every four to nine epithelial cells ${ }^{110}$.

IEL comprise roughly equal numbers of $\alpha \beta$ and $\gamma \delta T$ cells. They are a very heterogeneous group that includes: natural IEL, activated during development in the thymus in the presence of self-antigens and induced IEL, activated post-thymically in response to peripheral antigens. Both express activation markers such as $\mathrm{CD}_{69}{ }^{+}$and $\mathrm{CD} 44^{+111}$.

Natural IEL are either CD8 $\alpha \alpha^{+}$or CD8 $\alpha \alpha^{-}$T cells that express $\gamma \delta$ or $\alpha \beta$ TCR but do not express $\mathrm{CD}^{+}$or $\mathrm{CD} 8 \mathrm{a} \beta^{+}$(CD8- CD4- double negative cells), whereas induced IELs arise from 
8 Introduction

conventional $\alpha \beta$ TCR CD4 $4^{+}$or $C D 8 \alpha \beta^{+} T$ cells. The natural IEL are the dominant $T$ cell population in unchallenged mice. These cells enter the small intestine directly after maturation ${ }^{110-112}$

Secondary lymphoid structures are scattered along the gut mucosa and embedded in the LP forming the gut associated lymphoid tissue (GALT). Most of the GALT encloses dispersed leukocytes in diffuse masses under the gut epithelium. In some cases, leukocytes are arranged in more organized structures such as the Peyer's patches (PP). These domelike organs are surrounded by a follicle-associated epithelium containing B cell follicles with germinal centers and interfollicular T cell areas ${ }^{113}$.

PP are considered gut immune sensors because of their ability to transport luminal antigens and bacteria through specialized phagocytic $M$ (microfold) cells ${ }^{114}$. The matrix of the PP comprises $T$ cells and the three major APCs types: macrophages, B cells and DC, increasing the probability of antigen uptake right after its release by $M$ cells. Another mechanism of luminal sampling is executed by DC in the PP and LP, which extend their processes across the epithelial layer into the gut lumen. Once a DC has engulfed a bacterial antigen, it will then migrate through the lymphatic circulation to the closest mesenteric lymph node to present its antigenic cargo ${ }^{70}$.

Pattern recognition receptors (PRR) activate DC and define the type of cytokines that they produce. These cytokines will then modulate the differentiation of naïve $\mathrm{T}$ cells into proinflammatory or regulatory lineages. Most intestinal CD4 ${ }^{+} \mathrm{T}$ cells are located in the LP. Even though they are activated by DC via antigen recognition in the context of MHCII, specific microbial stimulus can activate diverse differentiation programs characterized by particular transcription factors: Th1 (T-bet), Th2 (Gata-3), Th17 (Roryt) or $T_{\text {regs }}$ (FoxP3) ${ }^{108,115,116 .}$

Proinflammatory stimuli can be exerted by different pathogens. For example, Bacteroides fragilis has been shown to induce $\mathrm{T}$ cell differentiation into Th1 cells that secrete IFNy ${ }^{117}$. Extracellular parasites promote a Th2 response with IL4, IL5 and IL13 secretion. Certain extracellular pathogens, such as segmented filamentous bacteria (SFB), stimulate 
9 Introduction

Th17 differentiation leading to IL17, IL17F and IL22 production ${ }^{118,119}$. Conversely, it was shown that colonization with Clostridium spp. of the large intestine favors $T_{\text {regs }}$ differentiation, which maintains a tolerogenic state by producing IL10, IL35 and TGF $\beta^{120,121 .}$

\subsection{The aryl hydrocarbon receptor}

One putative MS therapeutic target is the aryl hydrocarbon receptor (AhR), which is a ligand activated transcription factor widely expressed in the immune and nervous system. Despite the fact it is best known for mediating the toxic effects of chemical pollutants its evolutionary conservation suggests that binding toxins might not be its primary function. As part of the basic helix-loop-helix/Per-Arnt-Sim (PAS) homology superfamily, the AhR is a promiscuous receptor that can be activated by structurally diverse agonists found in the environment or endogenously produced ${ }^{122,123}$.

\subsubsection{AhR is ubiquitously distributed}

Consistent with its role as environmental sensor, $A h R$ is expressed in the liver and barrier tissues, such as gut, skin and lungs ${ }^{124,125}$. Within the nervous system it is found in neurons and glia, showing particularly high levels in astrocytes ${ }^{126,127}$. In the immune system, it is expressed in hematopoietic, innate, B and T cells ${ }^{128}$.

High AhR expression has been reported in plasma cells, Th17, yס T cells, innate lymphoid cells type 3 (ILC3), monocytes, macrophages, mast cells, dendritic cells (DC) and Langerhans cells ${ }^{76,129-135}$. In contrast, AhR expression is significantly weak in the kidneys, secretory glands, muscle and stromal cells ${ }^{123,124}$.

\subsubsection{AhR endogenous and exogenous ligands}

The AhR has been extensively studied in the toxicology field for its role during the biotransformation of different environmental pollutants. For example, the 2,3,7,8-tetrachlorodibenzo-p-dioxin (TCDD) is the best known AhR xenobiotic ligand. However, a vast diversity of AhR ligands have been identified, including not only environmental toxins, but also dietary (obtained from vegetables, fruits and teas), commensal microflora and physiological 
compounds. Some of the reported physiological AhR ligands are 6-formylindolo[3,2b]carbazole (FICZ), kynurenine and indoles ${ }^{136-139}$

\subsubsection{AhR signaling pathway}

As an inactive protein, the AhR is located in the cytoplasm binding actin filaments and forming a multiprotein complex with the heat shock protein 90 (HSP 90), AhR-interacting protein (AIP), c-SRC protein kinase and the cochaperone p23. Upon ligand binding, the AhR undergoes a conformational change that allows it to bind importin $\beta$, to translocate into the nucleus and to release the complex ${ }^{123,136}$.

In the active form, the AhR heterodimerizes with its interaction partner, AhR nuclear translocator (ARNT) and binds genomic regions containing the dioxin response element (DRE) motif. Hence, AhR induces the transcription of certain target genes, for example, AhR repressor (AhRR), indoleamine 2,3-dioxygenase 1 (IDO1), and enzymes corresponding to the cytochrome P450 (CYP) family, such as CYP1A1, CYP1A2 and CYP1B1 ${ }^{137,140,141 .}$

\subsubsection{AhR function}

The AhR is considered a key regulator of gene expression networks underlying homeostasis, developmental processes, physiological and immune responses. Exerting its effect in a wide range of tissues, the AhR expression is tightly regulated and its functions are cell specific and diverse ${ }^{128}$.

Depending on the ligand, AhR stimulation can activate different pathways producing different effects in the EAE model. For example, it can strongly influence the development of proinflammatory Th17 or anti-inflammatory regulatory $T$ cells $\left(T_{\text {regs }}\right)^{142}$, maintain gut epithelial barrier integrity ${ }^{69,125}$ and modulate NK cell activation, innate lymphocyte cell (ILC) homeostasis and IL22 production ${ }^{72,143,144}$. At large, activation of the AhR pathway can modulate CNS inflammation integrating immunological, metabolical and environmental stimuli ${ }^{126,145}$. 


\subsubsection{AhR knock out animals}

In order to elucidate $A h R$ functions and to provide a sensible animal model for this environmental sensor, three AhR knock out (KO) strains have been developed. During the 90's, independent groups from Spain, Japan and the USA generated separately AhR KO mice by gene targeting of exons 1 and 2 of the AhR locus. Different strategies were used to disable the murine AhR locus in vivo producing mice yielding some, though minor, dissimilarities in their phenotypes ${ }^{136}$.

The group of Prof. Frank Gonzalez inactivated the AhR gene by replacing the exon 1 containing DNA binding sites with a neomycin resistance gene ${ }^{146} \cdot 40-50 \%$ of these mice die postnatally. Furthermore, they often have lower splenocyte numbers, eosinophilia and lymphocyte infiltration of various organs. In addition, the liver of this mutant demonstrated glycogen depletion, hepatic fibrosis and inflammation of the bile ducts ${ }^{147}$.

A second AhR null mutant was generated by Prof. Fujii-Kuriyama's group replacing part of the exon 1 with the bacterial galactosidase gene ${ }^{148}$. These animals exhibit the highest postnatal lethality of all AhR KO mice (50\%).

The most widely used AhR KO strain was developed by Prof. Bradfield and collaborators (AhR $\left.{ }^{\mathrm{tm} 1 \mathrm{Bra}}\right)$. They targeted exon 2, which encodes the basic/helix-loop-helix domain, known to be required for DNA recognition and dimerization with ARNT ${ }^{149}$. Even though this strain has shown very low postnatal lethality, it presents other immune and hepatic defects such as smaller periarteriolar lymphatic sheets (PALS), larger spleens, prolonged extramedullary hematopoiesis and impaired hepatic fat metabolism ${ }^{150,151 .}$

In a comparison between the three AhR deficient mutant lines published by Prof. Esser, they all share some features including liver pathology, decreased fertility, slower growth rate, elevated retinoic acid levels, TCDD resistance, a patent ductus venosus, and failure to induce CYP1A1 and CYP1A2. Noteworthy, AhR KO mice present a spectrum of hepatic defects due to the crucial role of $\mathrm{AhR}$ in liver growth and development. For instance, liver size is 
dramatically reduced to approximately half of the size of WT mice. Fibrosis is frequently observed and liver tumors develop in a proportion of the animals ${ }^{150}$.

The AhR KO mouse strains have been crucial to elucidate AhR's immunomodulatory functions that go beyond its role as an environmental sensor, including repercussions in development, reproduction, immunology and gut-microbiome interactions derived from AhR signaling ${ }^{122,152}$. For example, AhR KO mice helped to describe AhR's role in peripheral myelination. AhR ablation in mice causes locomotor defects, induces thinner myelin sheaths and causes dysregulation of myelin gene expression and developmental markers in the peripheral nervous system ${ }^{153}$.

\subsubsection{AhR modulates the crosstalk between the intestinal immune system, diet and microbiota}

In the last decade, most attention on AhR research focused on its functions as master regulator of peripheral immunity affecting CNS inflammation and integrating environmental signals. AhR activity can be regulated by dietary components derived from cruciferous vegetables such as broccoli and Brussels sprouts ${ }^{69,76,154}$.

The majority of dietary AhR ligands are plant derived compounds including flavonoids, glucosinolates, stilbenes, carotenoids and some indoles ${ }^{155}$. For example, indole-3-carbinol (I3C) uptake from ingested cruciferous vegetables leads to high affinity AhR ligands production in the stomach, such as indolo-[3,2-b]-carbazole (ICZ) and 3,3'-diindolymethane (DIM) ${ }^{156,157}$.

Most of these ligands are able to enter AhR expressing cells forming the intestinal epithelium and immune system. They trigger AhR nuclear translocation and targeted gene expression, including CYP1A1 and CYP1A2 $2^{158}$.

It has been shown that natural AhR ligands modulate Th17 cell differentiation in vivo and in vitro ${ }^{159}$. AhR signaling is required in Th17 T cells obtained from C57BL/6J mice to produce IL22 ${ }^{130,160,161}$. CD4 ${ }^{+} \mathrm{T}$ cells from AhR KO mice can develop Th17 cells but when confronted with AhR ligands fail to produce IL22 $2^{130}$. 
In humans, AhR mediates IL22 production in Th22 cells ${ }^{162}$. IL22 is expressed at barrier surfaces by mouse and human cells and its signaling plays an important role in antimicrobial immunity, maintenance and inflammation of the bowel ${ }^{163}$.

Another major source of IL22 is produced by cells from the ILC family, including NK and lymphoid tissue inducer ( $\mathrm{LTi}$ ) cells. In this way, AhR ligands derived from the diet or microbiota not only regulate IL22 production, but also the maintenance, survival and proliferation of Roryt+ ILC in the gut and other mucosal barriers ${ }^{75,164,165}$.

AhR expression in ILC3 has been relatively well studied in the gut because of its repercussions in other immune compartments. For instance, deletion of AhR in ILC3 impairs IL22 production decreasing the gut epithelial cells production of antimicrobial peptides. This proinflammatory stimulus leads to an increase of segmented filamentous bacteria (SFB) and induces Th17 responses ${ }^{143,144}$.

AhR mediates the interaction between ILC3 and microbiota. Animals lacking caspase recruitment domain family member 9 (CARD9) present altered microbiota and are unable to metabolize tryptophan into AhR ligands. The catabolism of the essential amino acid tryptophan into kynurenine by the tryptophan 2,3-dioxygenase (TDO) or indoleamine 2,3-dioxygenase (IDO) provides a major source of AhR ligands. Therefore an impairment of tryptophan metabolism in the microbiota causes a decrease in the ILC3 and consequently, in IL22 production $^{140,166,167}$.

IDO1 can be induced in intestinal macrophages, epithelial and DC by different stimuli such as proinflammatory cytokines, toll like receptor ligands and interactions with costimulatory molecules. During infectious diseases IDO1 activity controls pathogen growth and $\mathrm{T}_{\text {regs }}$ expansion by metabolizing the available tryptophan into kynurenine. IDO1 response could either inhibit bacteria proliferation through amino acid - deprivation or modulate T cell response by generating tryptophan metabolites and AhR ligands ${ }^{168}$. 
AhR's genomic activity via tryptophan derived ligands could lead to IDO1 transcription via AhR responsive elements binding ${ }^{169}$. Besides acting as a transcription factor, AhR can act as $E 3$ ubiquitin ligase and assemble with cullin $4 B$ to form the ubiquitin ligase CUL4B ${ }^{A H R}$ complex. Different proteins are targeted by this complex for proteasomal degradation, such as IDO1 $^{141}, \beta$ catenin $^{170}$, estrogen and androgen receptors ${ }^{171,172}$.

AhR expression is essential for tertiary lymphoid tissue formation such as cryptopatches and intestinal lymphoid follicles ${ }^{155}$ and is involved in the proliferation of colonic crypt stem cells. Therefore, AhR deficiency has a significant impact on the gut immune system leading to ILC3 and IEL loss, impairment of IL22 secretion, disruption of the intestinal epithelium and dysregulation of intestinal bacteria ${ }^{136,173}$.

\subsubsection{EAE modulation by AhR ligands}

AhR activation during EAE induction has different repercussions in the immune system depending on the ligand. Stimulation at the time of EAE induction with the endogenous AhR agonist FICZ increased the number of IL17 and IL22 producing CD4+ ${ }^{+}$cells quantified in the spinal cord of $\mathrm{C} 57 \mathrm{BL} / 6 \mathrm{~J}$ mice. In contrast, $\mathrm{MOG}_{35-55}$ immunized AhR KO animals showed a reduced production of IL17 and no IL22 was detectable regardless of FICZ stimulation ${ }^{130,160,161 .}$

Differently from FICZ stimulation, AhR activation by $2-\left(1^{\prime} \mathrm{H}-\right.$ indole-3'-carbonyl)thiazole-4-carboxylic acid methyl ester (ITE) suppressed EAE in $M \mathrm{G}_{35-55}$ immunized C57BL/6J mice. Daily administration of ITE from the day of immunization induced tolerogenic $\mathrm{DC}$ that supported the differentiation of $\mathrm{FoxP}^{+} \mathrm{T}_{\text {regs }}{ }^{174}$.

Besides the non-toxic endogenous ligands (FICZ and ITE), the high-affinity AhR agonist TCDD has been tested in the EAE model. A single TCDD i.p. injection on the day before $\mathrm{MOG}_{35-55}$ immunization inhibited $\mathrm{EAE}$ inducing $\mathrm{T}_{\text {regs }}$ expansion, decreasing IL17 secretion and producing higher levels of TGF $\beta$. TCDD oral administration also prevented EAE development and had a dose dependent effect on EAE induction ${ }^{142}$. 
AhR regulates inflammation by affecting different components of the immune system. AhR, as well as its target gene CYP1B1, are upregulated in astrocytes through type I interferons (IFN-I) signaling after active immunization with $\mathrm{MOG}_{35-55}$. Astrocytes stimulated with IFN $\beta$ activate the JAK1-STAT signaling pathway and induce AhR expression. Furthermore, the knock down of IFN-I in astrocytes reduced the AhR expression and induced EAE worsening, suggesting a role of interferons limiting CNS inflammation through AhR signaling ${ }^{126}$.

Additionally, certain quinolone-3-carboximide based drugs intended for the treatment of autoimmune diseases and tested in the EAE model are effective AhR activators ${ }^{175}$. The protective effect of Laquinimod, Tasquinimod and Paquinimod against EAE is mediated by AhR and affect AhR battery genes in a distinct manner ${ }^{176,177}$.

\subsection{Laquinimod}

Laquinimod is an orally active quinoline-3-carboximide with AhR agonistic properties formulated as a potential DMT for $\mathrm{MS}^{178-181}$. It has been modified form its predecessor roquinimex (linomide) to increase efficacy in EAE models and improve its toxicological profile $^{182-185}$. As a small synthetic molecule, Laquinimod has the ability to freely cross the BBB without requiring further active transport. It has a high bioavailability $(80-90 \%)$ and a low rate of total clearance. It is quickly absorbed in the gut reaching its maximum concentration in the plasma within two hours after administration. Laquinimod is normally eliminated in the urine after being metabolized by the cytochrome P450 (CYP) isoenzyme, CYP3A4 in the liver microsomes ${ }^{180,186-188}$.<smiles>CCN(C(=O)c1c(O)c2c(Cl)cccc2n(C)c1=O)c1ccccc1</smiles>

Laquinimod

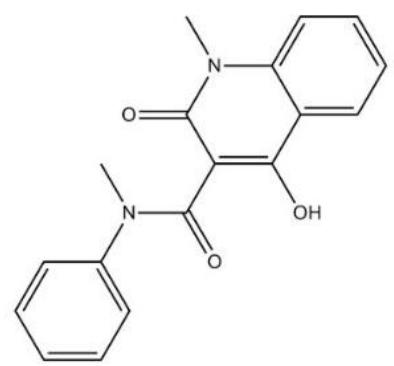

Roquinimex

Figure 1. Structure of Laquinimod and Roquinimex. Laquinimod (5-chloro-N-ethyl-4-hydroxy-1methyl-2-oxo-N-phenyl-1,2-dihydroquinoline-3-carboxamide), also known as ABR-215062 or nerventra, is structurally related to roquinimex (linomide). 


\subsubsection{Laquinimod mediated EAE suppression}

Preclinical studies demonstrated that Laquinimod treatment inhibits acute and chronic relapsing EAE in C57BL/6 and SJL/J mice, respectively. Inflammatory cell infiltration, spinal cord demyelination and axonal loss were significantly reduced by daily oral administration of Laquinimod from the day of immunization (preventive regimen) in $\mathrm{MOG}_{35-55}$ immunized C57BL/6 mice mis,189. $^{18}$.

Moreover, VLA-4 mediated cell adhesion and proinflammatory cytokine production by Th1/Th17 responses were downmodulated in treated mice ${ }^{190}$. Laquinimod was shown to modulate the adaptive $T$ cell response via its effect on the antigen presenting cell (APCs) compartment $^{182}$.

Similarly, EAE was abolished in SJL/N mice immunized with mouse spinal cord homogenate $(\mathrm{MSCH})$ using daily oral dosage of Laquinimod ${ }^{183}$. Laquinimod was also shown to inhibit EAE in Lewis rats, preventing $\mathrm{CD} 4^{+} \mathrm{T}$ cells and macrophages to infiltrate into the CNS and favoring Th2/Th3 cytokines ${ }^{191,192}$. Using different EAE protocols, Laquinimod has shown immunomodulatory properties affecting different immune cells, for instance APCs and T cell compartments $^{188}$.

Experiments using AhR KO animals showed that Laquinimod's therapeutic effect is completely abolished in the absence of $\mathrm{AhR}^{193}$. In addition, bone marrow chimera experiments demonstrated that $\mathrm{AhR}$ deletion in the immune system completely revokes the therapeutic effect of Laquinimod, while AhR deletion in the CNS partially affects Laquinimod's protective effect in the EAE model ${ }^{194}$. These results suggest that Laquinimod might have additional neuroprotective properties.

Besides its immunomodulatory effect, Laquinimod has shown neuroprotective actions such as brain-derived neurotrophic factor (BDNF) modulation ${ }^{195,196}$ and axonal protection ${ }^{189,197}$ in the EAE model and MS patients. In the cuprizone induced demyelination model, Laquinimod prevented demyelination, oligodendroglial apoptosis, astrocytic activation and microglia infiltration ${ }^{189}$. 


\subsubsection{Clinical trials}

In phase II placebo - controlled trials, Laquinimod showed a tolerable safety profile in patients. Daily treatment led to a reduction in the number of enhancing MRI lesions compared to placebo ${ }^{198,199}$, leading to further studies. Thereafter, orally administered Laquinimod (0.6 or 1.2 mg per day) was tested in three randomized phase III clinical trials, namely ALLEGRO, BRAVO and CONCERTO studies, all of them multinational, multicenter, double blind, and placebocontrolled.

The first two, ALLEGRO (Assessment of OraLLaquinimod in PrEventing ProGRession in Multiple SclerOsis) and BRAVO (Benefit-Risk Assessment of AVonex and LaquinimOd) trials, revealed Laquinimod's clinical efficacy, including reduction of disability progression, relapse rate and the number of gadolinium enhancing lesions ${ }^{200-203}$.

In a third study, CONCERTO ${ }^{204}$, the primary endpoint of significant treatment effect on 3-month-confirmed disability progression was not achieved. However, from baseline to month 15 and compared to placebo, Laquinimod significantly reduced the risk for the first relapse $(28 \%)$, relapse rate $(25 \%)$ and brain volume change (40\%).

\subsection{Current MS therapies}

MS patients can be treated by corticosteroids, plasma exchange and disease modifying therapies (DMT). Oral or intravenous corticosteroids including methylprednisolone, dexamethasone, prednisone, prednisolone and betamethasone are commonly prescribed to MS patients primarily to manage acute exacerbations or relapses through their rapid antiinflammatory properties ${ }^{205}$.

Plasma exchange or immune adsorption can be used in the short term to treat severe exacerbations if steroids are ineffective or contraindicated ${ }^{206,207}$. Disease modifying therapies (DMT) are prescribed to MS patients in order to reduce the number and the severity of relapses $^{208}$. The currently accepted DMT are summarized in table 1. 


\begin{tabular}{|c|c|c|c|c|c|c|}
\hline \multicolumn{2}{|c|}{$\begin{array}{c}\text { DMT (commercial } \\
\text { name) }\end{array}$} & $\begin{array}{l}\text { Dosage/ } \\
\text { Route/ } \\
\text { Frequency }\end{array}$ & $\begin{array}{l}\text { Efficacy in } \\
\text { clinical } \\
\text { trials }\end{array}$ & References & $\begin{array}{l}\text { Mechanism of } \\
\text { action }\end{array}$ & $\begin{array}{l}\text { Drug } \\
\text { class }\end{array}$ \\
\hline \multirow{4}{*}{ IFN $\beta$} & $\begin{array}{c}-1 \mathrm{a} \\
(\text { Avonex })\end{array}$ & $\begin{array}{l}30 \mathrm{mcg} / \\
\text { i.m. / } \\
\text { weekly }\end{array}$ & $\begin{array}{c}\downarrow 18 \% \text { ARR } \\
\text { and } \downarrow 44 \% \\
\text { CCDMS }\end{array}$ & $\begin{array}{l}\text { CHAMPS }{ }^{209} \\
\text { CHAMPIONS }^{210}\end{array}$ & $\begin{array}{l}\text { Different immuno- } \\
\text { modulatory } \\
\text { effects } 211\end{array}$ & First line \\
\hline & $-1 a$ (Rebif) & $\begin{array}{l}44 \mathrm{mcg} / \\
\text { s.c. / } 3 \text { x } \\
\text { week }\end{array}$ & $\begin{array}{c}\downarrow 32 \% \text { ARR } \\
\text { and } \downarrow 45 \% \\
\text { CCDMS }\end{array}$ & ETOMS 212 & $\begin{array}{l}\text { Different immuno- } \\
\text { modulatory } \\
\text { effects }{ }^{213}\end{array}$ & First line \\
\hline & $\begin{array}{c}-1 \mathrm{~b} \\
\text { (Betaseron) }\end{array}$ & $\begin{array}{l}250 \text { mcg / } \\
\text { s.c. / every } \\
\text { other day }\end{array}$ & $\begin{array}{c}\downarrow 34 \% \text { ARR, } \\
\downarrow 30 \% \text { DP } \\
\text { and } \downarrow 50 \% \\
\text { CCDMS }\end{array}$ & BENEFIT198,214 & $\begin{array}{c}\text { Different } \\
\text { immunomodulator } \\
\text { y effects }^{215}\end{array}$ & First line \\
\hline & $\begin{array}{c}-1 \mathrm{~b} \\
\text { (Extravia) }\end{array}$ & $\begin{array}{l}0.25 \mathrm{mg} / \\
\text { s.c. / every } \\
\text { other day }\end{array}$ & $\begin{array}{l}\downarrow 42 \% \text { ARR, } \\
\downarrow 16 \% \text { DP } \\
\text { and }\end{array}$ & $216-218$ & $\begin{array}{l}\text { Immuno- } \\
\text { modulatory } \\
\text { therapy for RRMS } \\
\text { and SPMS }\end{array}$ & First line \\
\hline \multicolumn{2}{|c|}{$\begin{array}{l}\text { Glatiramer acetate } \\
\text { (Copaxone) }\end{array}$} & $\begin{array}{l}20 \mathrm{mg} / \mathrm{s} . \mathrm{c} . \\
\text { / every day }\end{array}$ & $\begin{array}{c}\downarrow 29 \% \text { ARR } \\
\text { and } \downarrow 45 \% \\
\text { CCDMS }\end{array}$ & $\begin{array}{c}{ }^{219-221} \\
\text { PreCISe }^{222} \\
\text { GLACIER }^{223}\end{array}$ & $\begin{array}{l}\text { Induces and } \\
\text { activates T- } \\
\text { lymphocyte } \\
\text { suppressor cells }\end{array}$ & First line \\
\hline \multicolumn{2}{|c|}{$\begin{array}{l}\text { Teriflunomide } \\
\text { (Aubagio) }\end{array}$} & $\begin{array}{l}14 \text { mg / } \\
\text { oral / daily }\end{array}$ & $\begin{array}{c}\downarrow 31 \%-36 \% \\
\text { ARR, } \\
\downarrow 26 \%-32 \% \\
\text { DP }\end{array}$ & $\begin{array}{l}\text { TEMSO } 224,225 \\
\text { TOPIC } \\
\text { TOWER } \\
\text { TOW }\end{array}$ & $\begin{array}{l}\text { Pyrimidine } \\
\text { synthesis } \\
\text { inhibition in } \\
\text { lymphocytes }\end{array}$ & First line \\
\hline \multicolumn{2}{|c|}{$\begin{array}{l}\text { Dimethyl fumarate } \\
\text { (Tecfidera) }\end{array}$} & $\begin{array}{l}240 \mathrm{mg} / \\
\text { oral / } 2 \mathrm{x} \\
\quad \text { day }\end{array}$ & $\begin{array}{c}\downarrow 44 \%-53 \% \\
\text { ARR, } \\
\downarrow 38 \% \text { DP }\end{array}$ & $\begin{array}{l}\text { CONFIRM }^{228}, \\
\text { DEFINE }^{229}, \\
\text { ENDORSE }^{230}, \\
\text { ESTEEM }^{231}\end{array}$ & $\begin{array}{l}\text { Induces apoptosis } \\
\text { in activated T } \\
\text { cells through Th2 } \\
\text { cytokines }\end{array}$ & First line \\
\hline \multicolumn{2}{|c|}{$\begin{array}{l}\text { Natalizumab } \\
\text { (Tysabri) }\end{array}$} & $\begin{array}{l}300 \mathrm{mg} / \\
\text { i.v. / } \\
\text { monthly }\end{array}$ & $\begin{array}{l}\downarrow 68 \% \text { ARR, } \\
\downarrow 42 \% \text { DP }\end{array}$ & $\begin{array}{l}\text { SENTINEL } 232, \\
\text { TIMER }^{233} \\
\text { AFFIRM }^{234,235}\end{array}$ & $\begin{array}{c}\text { Blockade of } \\
\text { adhesion } \\
\text { molecules that } \\
\text { inhibit T cell traffic } \\
\text { across the BBB }\end{array}$ & $\begin{array}{l}\text { Second } \\
\text { line }\end{array}$ \\
\hline \multicolumn{2}{|c|}{$\begin{array}{l}\text { Fingolimod } \\
\text { (Gilenya) }\end{array}$} & $\begin{array}{l}0.5 \mathrm{mg} / \\
\text { oral / daily }\end{array}$ & $\begin{array}{c}\downarrow 48 \%-54 \% \\
\text { ARR, } \downarrow 30 \% \\
\text { DP }\end{array}$ & $\begin{array}{c}\text { TRANSFORMS } \\
236-239, \\
\text { FREEDOMS } \\
240,241 \\
\text { FREEDOMS } \\
\|^{242}\end{array}$ & $\begin{array}{l}\text { S1PR receptor } \\
\text { modulator and } \\
\text { Immuno- } \\
\text { suppressant }\end{array}$ & First line \\
\hline \multicolumn{2}{|c|}{$\begin{array}{l}\text { Alemtuzumab } \\
\text { (Lemtrada) }\end{array}$} & $\begin{array}{c}30 \mathrm{mg} \mathrm{x} \\
\text { day / i.v. / } 3 \\
\text { x week for } \\
12 \text { weeks }\end{array}$ & $\begin{array}{l}\downarrow 49 \%-55 \% \\
\text { ARR } \\
\downarrow 42 \% \text { DP }\end{array}$ & 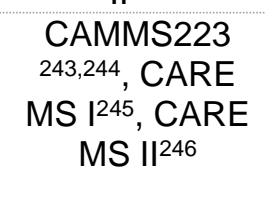 & $\begin{array}{c}\text { Anti-CD52 } \\
\text { monoclonal } \\
\text { antibody that } \\
\text { depletes T and B } \\
\text { lymphocytes }\end{array}$ & $\begin{array}{l}\text { Second } \\
\text { line }\end{array}$ \\
\hline \multicolumn{2}{|c|}{$\begin{array}{l}\text { Mitoxantrone } \\
\text { (Novantrone) }\end{array}$} & $\begin{array}{c}12 \mathrm{mg} / \mathrm{m}^{2} \mathrm{x} \\
3 \mathrm{months} \\
\text { or } 8 \mathrm{mg} / \mathrm{m}^{2} \\
\text { monthly / } \\
\text { i.v. }\end{array}$ & $\begin{array}{c}\downarrow 65 \% \\
\text { relapse risk } \\
\text { and } \downarrow 66 \% \\
\text { DP }\end{array}$ & $247-249$ & $\begin{array}{l}\text { DNA intercalator } \\
\text { and } \\
\text { topoisomerase II } \\
\text { enzyme activity } \\
\text { inhibitor }\end{array}$ & $\begin{array}{l}\text { Second } \\
\text { line }\end{array}$ \\
\hline
\end{tabular}

Table 1. First and second line approved drugs for MS treatment. Abbreviations: $\downarrow$ : reduction; $\uparrow:$ increase; ARR: Annualized relapse rate; CCDMS: conversion to clinically definite multiple sclerosis; DMT: disease modifying treatment, DP: disability progression; INF: interferon; i.m.: intramuscular; i.v.: intravenous; s.c.: subcutaneous.

The escalating and the induction therapies are the two major treatment approaches for MS. Mildly or moderately affected MS patients usually receive a first line therapy with moderate 
efficacy but high safety profile before changing to a second line medication with more safety risks (escalating approach). The induction approach is the initial use of a highly effective second line treatment in order to obtain a rapid remission of a highly active disease $250,251$.

\subsection{Aims}

The AhR molecular pathway is activated by different environmental factors affecting the immune system. Contradicting results have been obtained using $\mathrm{MOG}_{35-55}$ immunized C57BL/6J mice by stimulation with different high affinity AhR agonists such as FICZ, ITE and $\operatorname{TCCD}^{130,142,174}$. It remains unknown if physiological concentrations of AhR ligands in the regular diet have immunomodulatory properties influencing spontaneous EAE incidence and severity and if so, which cell type is the most relevant player for AhR mediated modulation of the CNS autoimmunity.

The central aim of this project is to evaluate the function of AhR in CNS autoimmunity and its modulation through physiological ligands found in the diet. In order to get an insight through the AhR's mechanistic regulation, the present work intends to elucidate which cellular players are required to mediate the immunomodulatory effect of the clinically relevant AhR agonist, Laquinimod.

In detail, the present thesis aims:

a) To assess if EAE incidence and severity can be influenced by increasing the AhR ligands of cruciferous vegetables in the diet of OSE mice.

b) To evaluate AhR's immunomodulation in $\mathrm{DC}, \mathrm{CD}^{+} \mathrm{T}$ cells and astrocytes by generating cell specific AhR KO mice in the OSE mouse model using the Cre-Lox system.

c) To investigate how clinically relevant cell specific AhR deficiencies in OSE mice affect APCs activation, antibody production and T cell activation.

d) To identify relevant AhR targets that mediate the therapeutic efficacy of the putative AhR ligand, Laquinimod, in CNS autoimmunity. 


\section{MATERIALS AND METHODS}

\subsection{Materials}

\subsubsection{Reagents}

\begin{tabular}{|c|c|}
\hline Reagent & Supplier \\
\hline Agarose & StarLab GmbH, Hamburg, Germany \\
\hline BD FACS Clean & BD Biosciences, Franklin Lakes, NJ, USA \\
\hline BD FACS Flow & BD Biosciences, Franklin Lakes, NJ, USA \\
\hline BD FACS Lysing Solution, 10x & BD Biosciences, Franklin Lakes, NJ, USA \\
\hline BD FACS Shutdown Solution & BD Biosciences, Franklin Lakes, NJ, USA \\
\hline BD Pharm Lyse, 10x & BD Biosciences, Franklin Lakes, NJ, USA \\
\hline$\beta$-Mercaptoethanol & Sigma Aldrich, St. Louis, MO, USA \\
\hline Boric acid & Merck Millipore, Darmstadt, Germany \\
\hline $\mathrm{CaCl}_{2}$ (calcium chloride) & Sigma Aldrich, St. Louis, MO, USA \\
\hline Chloral hydrate & Merck Millipore, Darmstadt, Germany \\
\hline Cytofix & BD Biosciences, Franklin Lakes, NJ, USA \\
\hline Cytofix/Cytoperm & BD Biosciences, Franklin Lakes, NJ, USA \\
\hline (DAPI) Diamidino-2-phenylindole, 1 mg/ml & Thermo Scientific, Waltham, MA, USA \\
\hline DMEM (Dulbecco's Modified Eagle's medium) & Sigma Aldrich, St. Louis, MO, USA \\
\hline dNTP (desoxynucleoside triphosphate) mix & Thermo Scientific, Waltham, MA, USA \\
\hline DTT (Dithiothreitol) & Sigma Aldrich, St. Louis, MO, USA \\
\hline EDTA (ethylenediamine tetraacetic acid) & Carl Roth, Karlsruhe, Germany \\
\hline FCS (fetal calf serum) & Sigma Aldrich, St. Louis, MO, USA \\
\hline Fluorescence mounting medium & Dako, Deutschland GmbH, Hamburg \\
\hline FoxP3 Fixation/Permeabilization Concentrate & eBioscience, San Diego, CA, USA \\
\hline FoxP3 Fixation/Permeabilization Diluent & eBioscience, San Diego, CA, USA \\
\hline FoxP3 Permeabilization buffer, 10x & eBioscience, San Diego, CA, USA \\
\hline GelRed nucleic acid gel stain, 10 000x & Biotium, Fremont, CA, USA \\
\hline GeneRuler, 100 base pairs (bp) DNA ladder plus & Thermo Scientific, Waltham, MA, USA \\
\hline Go-Taq DNA polymerase buffer, $5 x$ & Promega, Madison, WI, USA \\
\hline HBSS (Hank's buffered salt solution) & Sigma Aldrich, St. Louis, MO, USA \\
\hline $\mathrm{HCl}$ (hydrochloric acid) & Merck Millipore, Darmstadt, Germany \\
\hline $\begin{array}{l}\text { HEPES (4-(2-hydroxyethyl)-1- } \\
\text { piperazineethanesulfonic acid) }\end{array}$ & Sigma Aldrich, St. Louis, MO, USA \\
\hline $\mathrm{H}_{2} \mathrm{O}_{2}$ (oxygen peroxide) & Sigma Aldrich, St. Louis, MO, USA \\
\hline $\mathrm{H}_{2} \mathrm{SO}_{4}$ (sulfuric acid) & Sigma Aldrich, St. Louis, MO, USA \\
\hline
\end{tabular}




\begin{tabular}{|c|c|}
\hline Reagent & Supplier \\
\hline Ionomycin & Sigma Aldrich, St. Louis, MO, USA \\
\hline Isopropyl alcohol & Merck Millipore, Darmstadt, Germany \\
\hline Laquinimod & $\begin{array}{l}\text { Teva pharmaceutical industries Ltd., Netanya, } \\
\text { Israel }\end{array}$ \\
\hline L-glutamine & Sigma Aldrich, St. Louis, MO, USA \\
\hline Mannide monooleate & Sigma Aldrich, St. Louis, MO, USA \\
\hline $\begin{array}{r}\text { MEM (minimum essential medium) non-essential } \\
\text { amino acids, } 100 x\end{array}$ & Sigma Aldrich, St. Louis, MO, USA \\
\hline $\mathrm{MgCl}_{2}$ (magnesium chloride) & Promega, Madison, WI, USA \\
\hline $\mathrm{NaCl}$ (sodium chloride) & Carl Roth, Karlsruhe, Germany \\
\hline Paraffin oil & Carl Roth, Karlsruhe, Germany \\
\hline PBS (phosphate buffered salt solution) & Sigma Aldrich, St. Louis, MO, USA \\
\hline Penicillin, 10000 units/streptomycin, $10 \mathrm{mg} / \mathrm{ml}$ & Sigma Aldrich, St. Louis, MO, USA \\
\hline Percoll & Sigma Aldrich, St. Louis, MO, USA \\
\hline Permeabilization/Wash buffer, 10x & BD Biosciences, Franklin Lakes, NJ, USA \\
\hline PMA (phorbol 12-myristate 13-acetate) & Sigma Aldrich, St. Louis, MO, USA \\
\hline PFA (paraformaldehyde) & Merck Millipore, Darmstadt, Germany \\
\hline QIAzol Lysis Reagent & Qiagen, Maryland, MD, USA \\
\hline $\begin{array}{r}\text { RPMI } 1640 \text { (Roswell Park Memorial Institute } \\
1640)\end{array}$ & Sigma Aldrich, St. Louis, MO, USA \\
\hline SDS (sodium dodecyl sulfate) & Sigma Aldrich, St. Louis, MO, USA \\
\hline Sodium pyruvate, $100 \mathrm{mM}$ & Sigma Aldrich, St. Louis, MO, USA \\
\hline $\begin{array}{r}\text { TMB }\left(3,3^{\prime}, 5,5^{\prime} \text {-tetramethylbenzidine) }\right. \\
\text { substrate } \\
\text { solution }\end{array}$ & eBioscience, San Diego, CA, USA \\
\hline Tris (tris(hydroxymethyl)aminomethane) & Carl Roth, Karlsruhe, Germany \\
\hline Trypan blue & Sigma Aldrich, St. Louis, MO, USA \\
\hline Xylene & $\begin{array}{l}\text { Chemsolute, Th. Geyer GmbH \& Co. KG, } \\
\text { Renningen, Germany }\end{array}$ \\
\hline
\end{tabular}

Table 2. Reagents used in the different experimental procedures. 


\subsubsection{Buffers and solutions}

\begin{tabular}{|c|c|}
\hline Solution & Components \\
\hline $80 \%$ Percoll solution & $80 \%$ Percoll in DMEM high-Glu \\
\hline \multirow[t]{2}{*}{ Agarose gel } & $2 \%$ agarose in TBE (Tris/Borate/EDTA) buffer \\
\hline & $85 \%$ paraffin oil \\
\hline \multirow[t]{2}{*}{ CFA (Complete Freund's Adjuvant) } & $15 \%$ mannide monooleate \\
\hline & $6.7 \mathrm{mg} / \mathrm{ml}$ mycobacterium tuberculosis H37R \\
\hline Chloral hydrate $14 \%$ anesthesia & $14 \mathrm{~g}$ chloral hydrate in $100 \mathrm{ml}$ bidistilled $\mathrm{H}_{2} \mathrm{O}$ \\
\hline \multirow{2}{*}{ 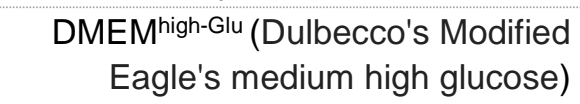 } & $4500 \mathrm{mg} / \mathrm{L}$ glucose \\
\hline & $2 \%$ FCS in DMEM \\
\hline ELISA blocking buffer & $5 \%$ BSA in PBS \\
\hline ELISA wash buffer & $0.05 \%$ Tween 20 in PBS \\
\hline ELISA stop solution & $1 \mathrm{~N} \mathrm{H}_{2} \mathrm{SO}_{4}$ in $\mathrm{H}_{2} \mathrm{O}$ \\
\hline FACS buffer & $2 \%$ FCS in PBS \\
\hline Fixation buffer & 4\% paraformaldehyde (PFA) in PBS \\
\hline Immunization emulsifier & $\begin{array}{l}1: 1(\mathrm{v} / \mathrm{v} \text { ) mixture of CFA (supplemented with } 5 \mathrm{mg} / \mathrm{ml} \\
\mathrm{H} 37 \mathrm{Ra} \text { ) and } 2 \mathrm{mg} / \mathrm{ml} \mathrm{MOG}_{35-55} \text { in PBS }\end{array}$ \\
\hline Master mix (40\% Percoll solution) & 40\% Percoll in DMEM ${ }^{\text {high-Glu }}$ \\
\hline \multirow{2}{*}{ MACS buffer } & $0.5 \% \mathrm{BSA}$ \\
\hline & 2 mM EDTA in PBS \\
\hline \multirow{3}{*}{ Percoll gradient medium } & 40 or $80 \%$ Percoll \\
\hline & $2 \%$ FCS \\
\hline & DMEM, high glucose (4.5 g/L D-glucose) \\
\hline \multirow{7}{*}{$\begin{array}{l}\text { RPMI complete (Roswell Park Memorial } \\
\text { Institute } 1640 \text { medium complete) }\end{array}$} & RPMI 1640 \\
\hline & $10 \%$ FCS \\
\hline & $1 \mathrm{mM}$ sodium pyruvate $1 \mathrm{x}$ \\
\hline & $1 \mathrm{x}$ non-essential amino acids \\
\hline & $50 \mu \mathrm{M} \beta$-mercaptoethanol \\
\hline & $0.1 \mathrm{mg} / \mathrm{ml}$ streptomycin \\
\hline & 2 mM L-glutamine \\
\hline \multirow{5}{*}{ Small intestine digestion solution } & $100 \mu \mathrm{l}$ collagenase $\mathrm{D}(100 \mathrm{mg} / \mathrm{ml})$ \\
\hline & $100 \mu \mathrm{l}$ DNase I (100 mg/ml) \\
\hline & $10 \%$ FCS \\
\hline & $10 \mathrm{mM} \mathrm{CaCl} 2$ \\
\hline & $20 \mathrm{ml}$ DMEM \\
\hline \multirow{4}{*}{ Small intestine predigestion solution } & $1 \mathrm{mM}$ DTT \\
\hline & $5 \mathrm{mM}$ EDTA \\
\hline & $10 \%$ FCS \\
\hline & $500 \mathrm{ml} \mathrm{HBSS}$ \\
\hline \multirow{4}{*}{ Tail Lysis Buffer } & $0.1 \mathrm{M}$ Tris- $\mathrm{HCl}$ \\
\hline & $200 \mathrm{mM} \mathrm{NaCl}$ \\
\hline & $0.2 \%$ SDS (sodium dodecyl sulfate) \\
\hline & $5 \mathrm{mM}$ EDTA in bidistilled $\mathrm{H}_{2} \mathrm{O}$, adjusted $\mathrm{pH}=8.5$ \\
\hline \multirow{3}{*}{ TBE (Tris/Borate/EDTA) buffer } & $90 \mathrm{mM}$ Tris, \\
\hline & $90 \mathrm{mM}$ boric acid \\
\hline & 2 mM EDTA in bidistilled $\mathrm{H}_{2} \mathrm{O}$ \\
\hline
\end{tabular}

Table 3. Buffers, cell culture media and solutions used for immunization, cell isolation and flow cytometry stainings. 


\subsubsection{Applied kits}

\begin{tabular}{r||l} 
Kit & Supplier \\
Hranscription Kit with RNase Inhibitor & Life Technologies GmbH, Darmstadt, Germany \\
NucleoSpin RNA XS Kit & Macherey-Nagel GmbH, Düren Germany \\
Pan Dendritic Cell Isolation Kit (mouse) & Miltenyi Biotec, Bergisch Gladbach, Germany \\
qPCR Core Kit & Eurogentec, Liège, Belgium \\
\hline Tyramide SuperBoost Alexa Fluor 488 kit & Invitrogen, Life Technologies, USA
\end{tabular}

Table 4. Applied kits.

\subsubsection{Cell lines and bacteria}

\begin{tabular}{|c|c|}
\hline Organism & Supplier \\
\hline B16F10 melanoma cell line & $\begin{array}{l}\text { Generous gift from Prof. Evelyn Ullrich, Children's } \\
\text { Hospital, Department of Pediatric Hematology and } \\
\text { Oncology, Goethe-University, Frankfurt, Germany }\end{array}$ \\
\hline $\begin{array}{r}\text { Mycobacterium tuberculosis H37RA, } \\
\text { non-viable }\end{array}$ & DIFCO, Detroit, MI, USA \\
\hline
\end{tabular}

\subsubsection{Proteins}

\begin{tabular}{r||l} 
Proteins / enzymes & Supplier \\
BSA (bovine serum albumin) & SERVA Electrophoresis GmbH, Heidelberg, Germany \\
Collagenase D & Roche, Basel, Switzerland \\
Golgi Stop & BD Biosciences, Franklin Lakes, NJ, USA \\
Go-Taq DNA polymerase & Promega, Madison, WI, USA \\
Ionomycin & Sigma Aldrich, St. Louis, MO, USA \\
DNase I & Roche, Basel, Switzerland \\
glycoprotein amino acids 35-55) & Göttingen, Germany \\
Proteinase K & Roche, Basel, Switzerland \\
PTX (Pertussis toxin) & List biological laboratories, Campbell, CA, USA \\
Trypsin, 0.05\% & Gibco/Invitrogen, Carlsbad, CA, USA
\end{tabular}

Table 6. Proteins, enzymes and inhibitors. 


\subsubsection{Oligoucleotide primers}

\begin{tabular}{|c|c|c|c|}
\hline Mouse line & Name & Oligonucleotide sequence ( $\left.5^{\prime}->3^{\prime}\right)$ & Gene \\
\hline \multirow{2}{*}{ 2D2 } & olMR6711 & $\begin{array}{c}\text { CCC GGG CAA GGC TCA GCC ATG CTC } \\
\text { CTG }\end{array}$ & TCR Va3.2 \\
\hline & olMR6712 & $\begin{array}{c}\text { GCG GCC GCA ATT CCC AGA GAC ATC } \\
\text { CCT CC }\end{array}$ & TCR Ja18 \\
\hline \multirow{2}{*}{$A h R^{f / / f l}$} & Ahrtm3.1Bra-forward & GGT ACA AGT GCA CAT GCC TGC & \multirow{2}{*}{ AhR exon 3} \\
\hline & Ahrtm3.1Bra-reverse & CAG TGG GAA TAA GGC AAG GA & \\
\hline \multirow{2}{*}{$A h R^{\Delta D C}$} & $\begin{array}{l}\text { CD11 } c^{\text {Cre trans- }} \\
\text { forward }\end{array}$ & ACT TGG CAG CTG TCT CCA AG & \multirow{2}{*}{ CD11c Cre } \\
\hline & $\begin{array}{l}\text { CD11c }{ }^{\text {Cre }} \text { trans- } \\
\text { reverse }\end{array}$ & GCG AAC ATC TTC AGG TTC TG & \\
\hline \multirow{2}{*}{$\mathrm{AhR}^{\Delta \mathrm{CD} 4}$} & $\begin{array}{l}\text { CD4 Cre trans- } \\
\text { forward }\end{array}$ & GCG GTC TGG CAG TAA AAA CTA TC & \multirow{2}{*}{ CD4 } \\
\hline & $\begin{array}{l}\text { CD4Cre trans- } \\
\text { reverse }\end{array}$ & GTG AAA CAG CAT TGC TGT CAC TT & \\
\hline \multirow{2}{*}{ AhR $R^{\triangle A s t r o}$} & 859 -forward & GTG AAA CAG CAT TGC TGT CAC TT & \multirow{2}{*}{ GFAPCre } \\
\hline & 860-reverse & GCG GTC TGG CAG TAA AAA CTA TC & \\
\hline \multirow{4}{*}{$\mathrm{AhR}^{\Delta \mathrm{Treg}}$} & WT-forward & CCT AGC CCC TAG TTC CAA CC & \multirow{4}{*}{ FoxP3Cre } \\
\hline & WT-reverse & AAG GTT CCA GTG CTG TTG CT & \\
\hline & Mutant-forward & $\begin{array}{c}\text { AGG ATG TGA GGG ACT ACC TCC TGT } \\
\text { A }\end{array}$ & \\
\hline & Mutant-reverse & TCC TTC ACT CTG ATT CTG GCA ATT T & \\
\hline \multirow{4}{*}{$\mathrm{Th} /+$} & 8.18C5-forward & TGA GGA CTC TGC CGT CTA TTA CTG T & \multirow{2}{*}{$\begin{array}{l}\text { Anti-MOG } \\
\lg \mathrm{H}\end{array}$} \\
\hline & 8.18C5-reverse & GGA GAC TGT GAG AGT GGT GCC T & \\
\hline & $\mathrm{mlgH}$-forward & $\begin{array}{c}\text { ATT GGT CCC TGA CTC AAG AGAAGA } \\
\text { TG }\end{array}$ & \multirow{2}{*}{ Igh-J } \\
\hline & mlgH-reverse & TGG TGC TCC GCT TAG TCA AA & \\
\hline \multirow{3}{*}{ CX3CR1EGFP/+ } & $\begin{array}{l}\text { CX3CR1 WT- } \\
\text { reverse }\end{array}$ & CAG TGA TGC TGG GCT TCC & \multirow{3}{*}{ CX3CR1 } \\
\hline & CX3CR1-forward & TCA GTG TTT TCT CCC GCT TGC & \\
\hline & $\begin{array}{l}\text { CX3CR1-KI- } \\
\text { reverse }\end{array}$ & GTA GTG GTT GTC GGG CAG & \\
\hline
\end{tabular}

Table 7. Oligonucleotide primers used for transgenic mice genotyping. All primers were purchased from Eurofins MWG, Ebersberg, Germany. Abbreviations: 2D2 mice: MOG specific T cell receptor transgenic mice; CX3CR1: CX3C chemokine receptor 1 (fractalkine receptor); GFAP: Glial fibrillary acidic protein; FoxP3: forkhead box P3; Itgax: integrin alpha X; IgH: murine immunoglobulin heavy chain; hybridoma clone $8.18-\mathrm{C} 5$ used to subclone the $1.7 \mathrm{~kb}$ genomic region containing a rearranged $\mathrm{V}_{\mathrm{H}} \mathrm{D} \mathrm{J}_{\mathrm{H}}$ gene and denominated Th gene; MOG: myelin oligodendrocyte glycoprotein; Th/+ mice: MOG specific $\mathrm{B}$ cell receptor transgenic mice. 


\subsubsection{Primers for qPCR}

\begin{tabular}{|c|c|c|c}
\hline Primer number & $\begin{array}{c}\text { RNA } \\
\text { specificity }\end{array}$ & $\begin{array}{c}\text { Reference } \\
\text { sequence }\end{array}$ & Supplier \\
\hline Mm99999915_g1 & GAPDH & NM_001289726.1 & $\begin{array}{c}\text { Life Technologies GmbH, } \\
\text { Darmstadt, Germany }\end{array}$ \\
\hline Mm00487218_m1 & CYP1A1 & NM_001136059.2 & .
\end{tabular}

Table 8. TaqMan qPCR primers. Abbreviations: GAPDH: glyceraldehyde 3-phosphate dehydrogenase; CYP1A1: cytochrome P450 enzyme, family 1, subfamily A, polypeptide 1.

\subsubsection{Secondary anti-mouse HRP tagged antibodies used for ELISA}

\begin{tabular}{|c|c|c|c|c|}
\hline Name & Antigen & Dilution & Host & Supplier \\
\hline IgG1 STAR132P & $\operatorname{lgG1}$ & $\begin{array}{c}1: 4000 \text { in } \\
0.5 \% \text { BSA in } \\
\text { PBS }\end{array}$ & goat & $\begin{array}{c}\text { Bio-Rad AbD Serotec } \\
\text { GmbH, Puchheim, Germany }\end{array}$ \\
\hline IgG2a STAR133P & $\operatorname{lgG} 2 \mathrm{~A}$ & $\begin{array}{c} \\
\text { PB }\end{array}$ & &
\end{tabular}

Table 9. Polyclonal antibodies used for ELISA. Horseradish peroxidase (HRP) tagged antibodies used to measure MOG antibody concentrations in blood serum samples.

\subsubsection{Primary antibodies used in paraffin embedded sections}

\begin{tabular}{c|c|c|c|c|}
\hline Name & Antigen & Dilution & Host & Supplier \\
\hline $\begin{array}{c}\text { Anti-RFP polyclonal } \\
\text { (\#600-401-379S) }\end{array}$ & RFP & $1: 100$ & & $\begin{array}{c}\text { Rockland Immunochemicals, Inc., } \\
\text { PA, USA }\end{array}$ \\
$\begin{array}{c}\text { Anti-GFP polyclonal } \\
\text { (\#PABG1-100) }\end{array}$ & GFP & $1: 2000$ & rabbit & $\begin{array}{c}\text { ChromoTek GmbH, Planegg- } \\
\text { Martinsried, Germany }\end{array}$ \\
\hline
\end{tabular}

Table 10. Primary antibodies used in paraffin embedded sections.

2.1.10 Secondary antibodies used in paraffin embedded sections

\begin{tabular}{|c|c|c|c|}
\hline Name & Dilution & Host & Supplier \\
\hline $\begin{array}{c}\text { Anti-rabbit IgG }(\mathbf{H}+\mathrm{L})- \\
\text { biotinylated (\#111-065-144) }\end{array}$ & $1: 500$ & goat & $\begin{array}{c}\text { Dianova GmbH, Hamburg, } \\
\text { Germany }\end{array}$ \\
$\begin{array}{c}\text { Anti-rabbit IgG (H+L)- Cy3 } \\
\text { conjugated (\#111-165-144) }\end{array}$ & $1: 100$ & & \\
\hline
\end{tabular}

Table 11. Secondary antibodies used in paraffin embedded sections. 


\subsubsection{Fluorophore tagged monoclonal antibodies used for flow cytometry}

\begin{tabular}{|c|c|c|c|}
\hline Fluorochrome & Antigen & Clone & Supplier \\
\hline . & CD16/32 & 93 & BioLegend, San Diego, CA, USA \\
\hline \multirow{5}{*}{ APC } & CD25 & PC61.5 & eBioscience, San Diego, CA, USA \\
\hline & CD80 & $1 \mathrm{G} 10$ & Molecular Probes, OR, USA \\
\hline & CD64 & $X 54-5 / 7.1$ & \multirow{6}{*}{ BioLegend, San Diego, CA, USA } \\
\hline & IFNy & XMG1.2 & \\
\hline & IL17 & TC11-18H10.1 & \\
\hline \multirow{3}{*}{ APC-Cy7 } & CD19 & $6 \mathrm{D} 5$ & \\
\hline & CD45 & $30-\mathrm{F} 11$ & \\
\hline & CD86 & GL-1 & \\
\hline \multirow{5}{*}{ PE } & CD4 & RM4-5 & BD Biosciences, Franklin Lakes NJ, USA \\
\hline & FoxP3 & FJK-16s & eBioscience, San Diego, CA, USA \\
\hline & CD11c & N418 & \multirow{6}{*}{ BioLegend, San Diego, CA, USA } \\
\hline & $\mathrm{F} 4 / 80$ & BM8 & \\
\hline & IL10 & Jess-16E3 & \\
\hline \multirow{4}{*}{ Pe-Cy7 } & CD3 & $145-2 \mathrm{C} 11$ & \\
\hline & CD11b & $\mathrm{M} 1 / 70$ & \\
\hline & IFNy & XMG1.2 & \\
\hline & IL17 & eBio17B7 & eBioscience, San Diego, CA, USA \\
\hline \multirow{3}{*}{ PerCP } & CD4 & RMG1.2 & BD Biosciences, Franklin Lakes NJ, USA \\
\hline & CD19 & ID3 & \multirow{2}{*}{ BioLegend, San Diego, CA, USA } \\
\hline & CD45 & $30 \mathrm{~F} 11$ & \\
\hline \multirow{3}{*}{ FITC } & CD19 & eBio1D3 & eBioscience, San Diego, CA, USA \\
\hline & $\mathrm{MHCll}$ & M5/114.15.2 & \multirow{9}{*}{ BioLegend, San Diego, CA, USA } \\
\hline & $\operatorname{Va} 3.2$ & RR3-16 & \\
\hline \multirow{3}{*}{ BV421 } & CD3 & $145-2 \mathrm{C} 11$ & \\
\hline & CD11c & N418 & \\
\hline & NK1.1 & PK136 & \\
\hline \multirow{4}{*}{ BV510 } & CD8 & $53-6.7$ & \\
\hline & CD19 & $6 \mathrm{D} 5$ & \\
\hline & CD69 & $\mathrm{H} 1.2 \mathrm{~F} 3$ & \\
\hline & MHCII & M5/114.15.2 & \\
\hline
\end{tabular}

Table 12. Fluorophore tagged monoclonal antibodies used for flow cytometry. All antibodies were diluted 1:200 in FACS buffer; except for the anti-CD16/CD32 (Fc Block), which was diluted 1:100 and used in all FACS stainings to avoid nonspecific binding. 


\subsubsection{Consumable material}

\section{Consumable Supplier}

\begin{tabular}{|c|c|}
\hline Bottle top filter, $0.2 \mu \mathrm{m}$ & Sarstedt, Nümbrecht, Germany \\
\hline $\begin{array}{r}\text { BRAND seripettor pro bottle-top dispenser, } \\
10 \mathrm{ml}\end{array}$ & Merck KGaA, Darmstadt, Germany \\
\hline Butterfly Winged Infusion Set (25G) & Hospira UK Ltd, UK \\
\hline Cell culture flask, $75 \mathrm{~cm} 2$ & Greiner bio-one, Kremsmuenster, Austria \\
\hline $\begin{array}{r}\text { Cell culture plates, flat bottom (6 well, } 24 \\
\text { well, } 96 \text { well) }\end{array}$ & Greiner bio-one, Kremsmuenster, Austria \\
\hline Cell strainer $(70 \mu \mathrm{m}, 40 \mu \mathrm{m})$ & BD Biosciences, Franklin Lakes, NJ, USA \\
\hline Cryogenic tubes & Thermo Scientific, Waltham, MA, USA \\
\hline FACS tubes $(5 \mathrm{ml}$ & BD Biosciences, Franklin Lakes, NJ, USA \\
\hline Feather disposable scalpel (No. 11, No. 21) & PFM medical AG, Köln, Germany \\
\hline GEM Scientific Razor Blades & Alpha Biotech Ltd., Glasgow, UK \\
\hline LS columns for MACS separation & Miltenyi Biotec, Bergisch Gladbach, Germany \\
\hline Needles (18G, 23G) & BD Biosciences, Franklin Lakes, NJ, USA \\
\hline Nunc MaxiSorp 96 well ELISA plate & Thermo Scientific, Waltham, MA, USA \\
\hline $\begin{array}{r}\text { Nunc MicroWell Plates, round bottom } 96 \text { well } \\
\text { plate }\end{array}$ & Thermo Scientific, Waltham, MA, USA \\
\hline StatMatic II 8 channel Microplate Washer & $\begin{array}{l}\text { Gardner Denver Thomas GmbH, Fürstenfeldbruck, } \\
\text { Germany }\end{array}$ \\
\hline Syringes ( $1 \mathrm{ml}, 5 \mathrm{ml}, 10 \mathrm{ml}, 20 \mathrm{ml}$ ) & BD Biosciences, Franklin Lakes, NJ, USA \\
\hline Tubes (50 ml, $10 \mathrm{ml}, 2 \mathrm{ml}, 1,5 \mathrm{ml}, 0.2 \mathrm{ml}$ ) & Sarstedt, Nuembrecht, Germany \\
\hline
\end{tabular}

Table 13. Laboratory consumables. Abbreviations: ELISA: enzyme-linked immunosorbent assay; FACS: fluorescence-activated cell sorting; G: gauge. 


\subsubsection{Technical devices}

\begin{tabular}{|c|c|}
\hline Devices & Supplier \\
\hline Beurer IL11 Infrared Lamp & Beurer GmbH, Ulm, Germany \\
\hline Centrifuge $5415 \mathrm{R}$ & Eppendorf, Hamburg, Germany \\
\hline Centrifuge $5810 \mathrm{R}$ & Eppendorf, Hamburg, Germany \\
\hline Excelsior AS automated tissue processor & Life Technologies GmbH, Darmstadt, Germany \\
\hline FACS Canto II & BD Biosciences, Franklin Lakes, NJ, USA \\
\hline $\begin{array}{r}\text { Fluorescence/light microscope, Olympus BX51, } \\
\text { equipped with DP71 digital and XM10 } \\
\text { monochrome camera }\end{array}$ & Olympus, Hamburg, Germany \\
\hline Hera cell 150 incubator & Heraeus, Hanau, Germany \\
\hline iQ5 Real Time PCR Detection System & Bio-Rad, Munich, Germany \\
\hline iMark microplate reader & Bio-Rad, Munich, Germany \\
\hline Leica SM2000 R sliding microtome & Leica Biosystems Newcastle Ltd., UK \\
\hline MEDITE TES Valida paraffin embedding system & MEDITE GmbH, Burgdorf, Germany \\
\hline Neubauer chamber & $\begin{array}{l}\text { Superior Marienfeld, Lauda-Koenigshofen, } \\
\text { Germany }\end{array}$ \\
\hline Power Pac 300 & Bio-Rad, Munich, Germany \\
\hline QuadroMACS separator & Miltenyi Biotec, Bergisch Gladbach, Germany \\
\hline Thermocycler & Biometra TRIO, Jena, Germany \\
\hline Thermomixer comfort UV & Eppendorf, Hamburg, Germany \\
\hline UV transluminator & Vilber Lourmat, Eberhardzell, Germany \\
\hline
\end{tabular}

Table 14. Technical devices and special equipment.

\subsubsection{Software}

\begin{tabular}{c|c|c}
\hline Software & Application & Supplier \\
\hline $\begin{array}{c}\text { BD FACS Diva } \\
\text { Software 6.1.2 }\end{array}$ & $\begin{array}{c}\text { Flow cytometry data } \\
\text { acquisition and analysis }\end{array}$ & BD Biosciences, Franklin Lakes, NJ, USA \\
\hline FlowJo 7.6.1 & Flow cytometry data analysis & Tree Star Inc., Ashland, OR, USA \\
\hline GraphPad Prism 6 & Statistical analysis & GraphPad software Inc., La Jolla, CA, USA \\
\hline
\end{tabular}

Table 15. List of software used for data acquisition and analysis. 


\subsection{Transgenic mouse models}

All transgenic mice were housed at the animal facility of the University Medical Center Göttingen (UMG) under specific pathogen free (SPF) conditions. Animals were exposed to constant $12 \mathrm{~h} / 12 \mathrm{~h}$ dark/light cycles and supplied with food and water ad libitum. All mice transported from outside the animal facility or to a new room (inside the bioterium) received one week of acclimation before the experiment started.

Animal experiments were performed in agreement with the European Communities Council Directive of 24 November 1986 (86/EEC) and were approved by the Government of Lower Saxony, Germany. All genetically modified mice used for breeding, in vivo and ex vivo experiments are summarized in tables 16 and 17.

\subsubsection{C57BI/6J mice}

6-8 weeks old female C57BI/6J mice were purchased from Charles River laboratories, Sulzfeld, Germany or from the animal facility of the University Medical Center Göttingen.

\subsubsection{D2 mice}

MOG specific T cell receptor (TCR) transgenic mice, which are also known as TCR ${ }^{\mathrm{MOG}}$. Bettelli and colleagues developed the transgenic mouse model by using a $\mathrm{CD}^{+}{ }^{+} \mathrm{MOG}_{35-55}$ specific $\mathrm{T}$ cell clone called 2D2, which expresses a TCR conformed by a Va3.2 and V $\beta 11$ chains. Approximately $30 \%$ of the 2D2 mice spontaneously develop optic neuritis without showing clinical or histological signs of EAE. 2-4\% of the mice develop spontaneous EAE.

\subsubsection{Th/+ mice}

Knock in mice also referred as $\mathrm{IgH}^{\mathrm{MOG}}$, were developed by Litzenburger and collaborators by inserting a transgenic $\mathrm{IgH}$ chain variable gene of the $8.18 \mathrm{C} 5 \mathrm{MOG}$ specific monoclonal antibody. Around $30 \%$ of all $\mathrm{B}$ cells in bone marrow and periphery are MOG specific. Consequently, high titers of MOG specific IgM antibodies are present in the sera of these mice. In contrast to 2D2 mice, the Th/+ transgenic mouse line does not spontaneously develop EAE. Upon active immunization or the adoptive transfer of MOG specific T cells, MOG specific 
antibodies are switched to $\lg G 1$ and $\lg G 2 a$ isotypes leading to an earlier disease onset, increased EAE incidence and severity compared to non-transgenic animals ${ }^{252}$.

\subsubsection{OSE mice}

Krishnamoorthy and colleagues generated a double transgenic mouse model that spontaneously develops CNS demyelinating disease. They were named OSE or opticospinal EAE mice because the CNS lesions are located almost exclusively in the optic nerve and spinal cord. The mouse strain was generated by crossing the previously described 2D2 mice with $\mathrm{Th} / \mathrm{Th}+$ double transgenic mice on a C57BL/6 background. As a result, $50 \%$ of these mice express both, MOG specific T and B cells. OSE mice develop spontaneous EAE under specific pathogen free (SPF) conditions with a frequency of $30-50 \%$ depending on the animal facility ${ }^{101}$.

\begin{tabular}{|c|c|c|c|}
\hline $\begin{array}{l}\text { Mouse } \\
\text { model }\end{array}$ & Expression method & Developer / Reference & $\begin{array}{l}\text { Donating } \\
\text { researcher }\end{array}$ \\
\hline 2D2 & $\begin{array}{l}\text { Transgene insertion: } V \alpha 3.2 \mathrm{Ja} 18 \\
\text { region of TCRa and V } \beta 11 \mathrm{DJ} \beta 1,1 \\
\text { region of TCRb from the 2D2 T } \\
\text { cell clone inserted into TCR } \\
\text { expression cassettes }\end{array}$ & $\begin{array}{l}\text { Esther Bettelli, Brigham and } \\
\text { Women's Hospital and } \\
\text { Harvard Medical School }{ }^{253}\end{array}$ & $\begin{array}{l}\text { Generous gift } \\
\text { from the group of } \\
\text { Prof. Vijay K. } \\
\text { Kuchroo, Harvard } \\
\text { Medical School }\end{array}$ \\
\hline $\mathrm{Th} / \mathrm{Th}+$ & $\begin{array}{l}\text { Targeted insertion of the } \\
\text { rearranged VDJ gene of the H } \\
\text { chain from the MOG specific } \\
\text { hybridoma 8.18-C5 }\end{array}$ & $\begin{array}{l}\text { Tobias Litzenburger, Max } \\
\text { Plank Institute of } \\
\text { Neurobiology } 252\end{array}$ & $\begin{array}{l}\text { Generous gift } \\
\text { from the group of } \\
\text { Prof. Hartmut } \\
\text { Wekerle }\end{array}$ \\
\hline OSE & $\begin{array}{c}\text { Double transgenic mice (derived } \\
\text { from } 2 \mathrm{D} 2 \text { and } \mathrm{Th} /+ \text { mice } \\
\text { breeding) }\end{array}$ & $\begin{array}{c}\text { Gurumoorthy Krishnamoorthy, } \\
\text { Max Plank Institute of } \\
\text { Neurobiology }\end{array}$ & Crossbreeding \\
\hline
\end{tabular}

Table 16. Transgenic mouse models used for breeding, in vivo and in vitro experiments. Abbreviations: OSE: opticospinal EAE.

\subsection{Breedings}

All transgenic mice were generated from in-house breeding colonies at the UMG animal facility and backcrossed to C57BL/6 for more than 12 generations. Animals were mated between 6 and 8 weeks of age. 


\subsubsection{Cell specific AhR KO mouse strains}

To examine the repercussions of AhR signaling in certain immune players, a variety of cell specific Cre lines $\left(C D 11 c^{\text {Cre }}\right.$, FoxP3 ${ }^{\text {Cre }}$, GFAPCre and $\left.C D 4^{\mathrm{Cre}}\right)$ were crossed to $\mathrm{AhR}^{\mathrm{fl} / \mathrm{fl}}$ mice (table 17 ) to specifically delete $\mathrm{AhR}$ in $\mathrm{DC}, \mathrm{T}_{\text {regs, }}$, astrocytes and $\mathrm{CD} 4^{+} \mathrm{T}$ cells. The generated $A h R^{\Delta D C}, A h R^{\Delta T r e g}, A h R^{\Delta A s t r o}$ and $A h R^{\Delta C D 4}$ mice were used in the context of actively induced EAE, by immunization with $\mathrm{MOG}_{35-55}$ and $\mathrm{CFA}$ as described in 2.4.2.

On the other hand, the same transgenic lines were bred to $2 \mathrm{D} 2$ and $\mathrm{Th} / \mathrm{Th}+$ mice to obtain: OSE $A h R^{\mathrm{fl} / \mathrm{fl}}$, OSE $A h R^{\Delta C D 4}$, OSE $A h R^{\Delta T r e g}$, OSE $A h R^{\Delta A s t r o}$ and OSE $A h R^{\Delta D C}$. Using the breeding strategy depicted in figure 2 , the repercussions of a cell specific AhR deletion on a spontaneous EAE model were studied.

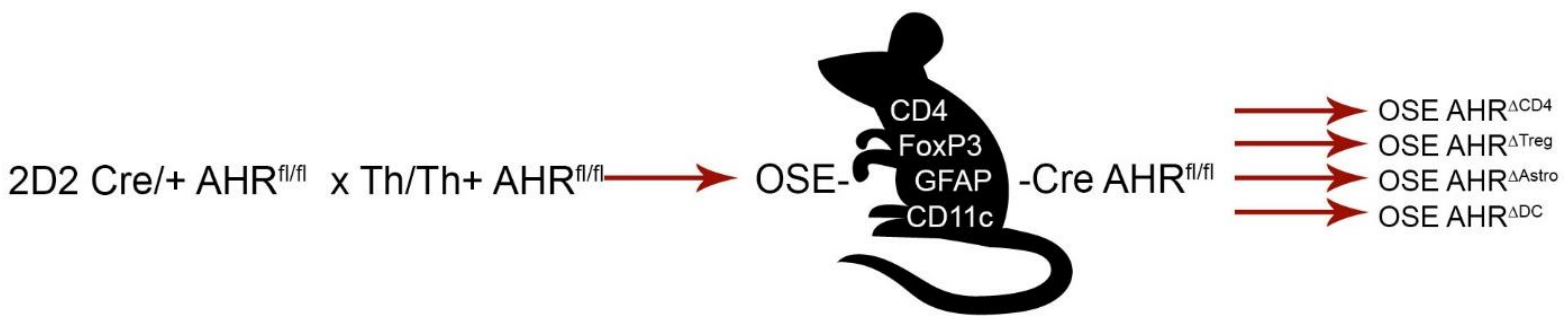

Figure 2. Breeding strategy used to produce four different cell specific AhR KO mouse strains that develop spontaneous EAE. The different strains are double transgenic (opticospinal or OSE) mice generated by crossing 2D2 and Th/Th+ animals: OSE AhR ${ }^{\Delta C D 4}$, OSE $A h R^{\Delta T r e g}$, OSE $A h R^{\triangle A s t r o}$ and OSE $A h R^{\triangle D C}$. Taking advantage of the Cre/Lox system, cell specific AhR KO were produced by breeding $A_{h R^{f / f l l}}$ mice with animals expressing an active Cre recombinase controlled by a defined promoter (CD4Cre, FoxP3 ${ }^{\text {Cre }}$, GFAPCre and CD11c Cre).

To further characterize the APCs compartment of the OSE mice, reporter animals expressing an enhanced green fluorescent protein (EGFP) under the control of a CX3CR1 promoter were bred to the $\mathrm{OSE} A h \mathrm{R}^{\Delta \mathrm{DC}}$ or $\mathrm{OSE} \mathrm{AhR}^{\mathrm{fl} / \mathrm{fl}}$ control littermates generating $\mathrm{OSE}$ $\mathrm{AhR}^{\triangle \mathrm{DC}} \mathrm{CX} 3 \mathrm{CR} 1^{\mathrm{EGFP} /+}$ and OSE $\mathrm{AhR}^{\mathrm{fl/fl}} \mathrm{CX} 3 \mathrm{CR} 1^{\mathrm{EGFP} /+}$ control mice.

\subsection{2 $\mathrm{AhR}^{\mathrm{fl} /+} \mathrm{CD}_{11 c^{\mathrm{Cre}+}} \mathrm{R26}^{\mathrm{eYFP}}$ mice (CD11c specific AhR KO)}

To investigate AhR deletion in CD11 $\mathrm{C}^{+} \mathrm{DC}$ cells, AhR competent $\left(\mathrm{AhR}^{+/+}\right)$or $\mathrm{AhR} \mathrm{KO}\left(\mathrm{AhR}^{-{ }^{--}}\right)$ $\mathrm{CD} 11 \mathrm{c}^{\mathrm{Cre}}$ mice were bred with $A h R^{\mathrm{fl} / \mathrm{fl}}$ animals to generate $A h \mathrm{R}^{\mathrm{fl} /+} \mathrm{CD} 11 \mathrm{c}^{\mathrm{Cre+}}$ controls and $A h R^{\mathrm{fl} /-}$ CD11 $\mathrm{C}^{\mathrm{Cre}+}$ offspring. The $\mathrm{CD} 11 \mathrm{c}^{\mathrm{Cre}+}$ transgenic mice are described in table 17 and harbor Cre recombinase under the control of a CD11c promoter ${ }^{254}$. 
The $A h R^{f / f f l}$ animals were previously crossed to $\mathrm{R} 26^{\mathrm{eYFP}}$ transgenic mice carrying an enhanced yellow fluorescent protein (eYFP) inserted into the Gt(ROSA)26Sor locus and blocked by an upstream loxP flanked STOP sequence ${ }^{255}$. The breeding of $A_{h} R^{f / f l l} R 26^{\text {eYFP }}$ animals with $\mathrm{AhR}^{+-} \mathrm{CD} 11 \mathrm{c}^{\mathrm{Cre}+}$ led to the deletion of the $\mathrm{AhR}$ targeted gene in one allele of CD11 $\mathrm{c}^{+}$cells. Cre recombinase activation deleted the STOP sequence in CD11 $\mathrm{c}^{+}$cells and was reported by eYFP expression.

The generated mice $\left(A h R^{\mathrm{fl} /+} \mathrm{CD} 11 c^{\mathrm{Cre}+} \mathrm{R} 26^{\mathrm{eYFP}}\right.$ and $\left.A h R^{\mathrm{fl} /-} \mathrm{CD} 11 c^{\mathrm{Cre}+} \mathrm{R} 26^{\mathrm{YYFP}}\right)$ offered the advantage that eYFP ${ }^{+}$AhR competent or AhR deficient $\mathrm{DC}$ can be sorted ex vivo for further analysis and its generation is depicted in figure 3.
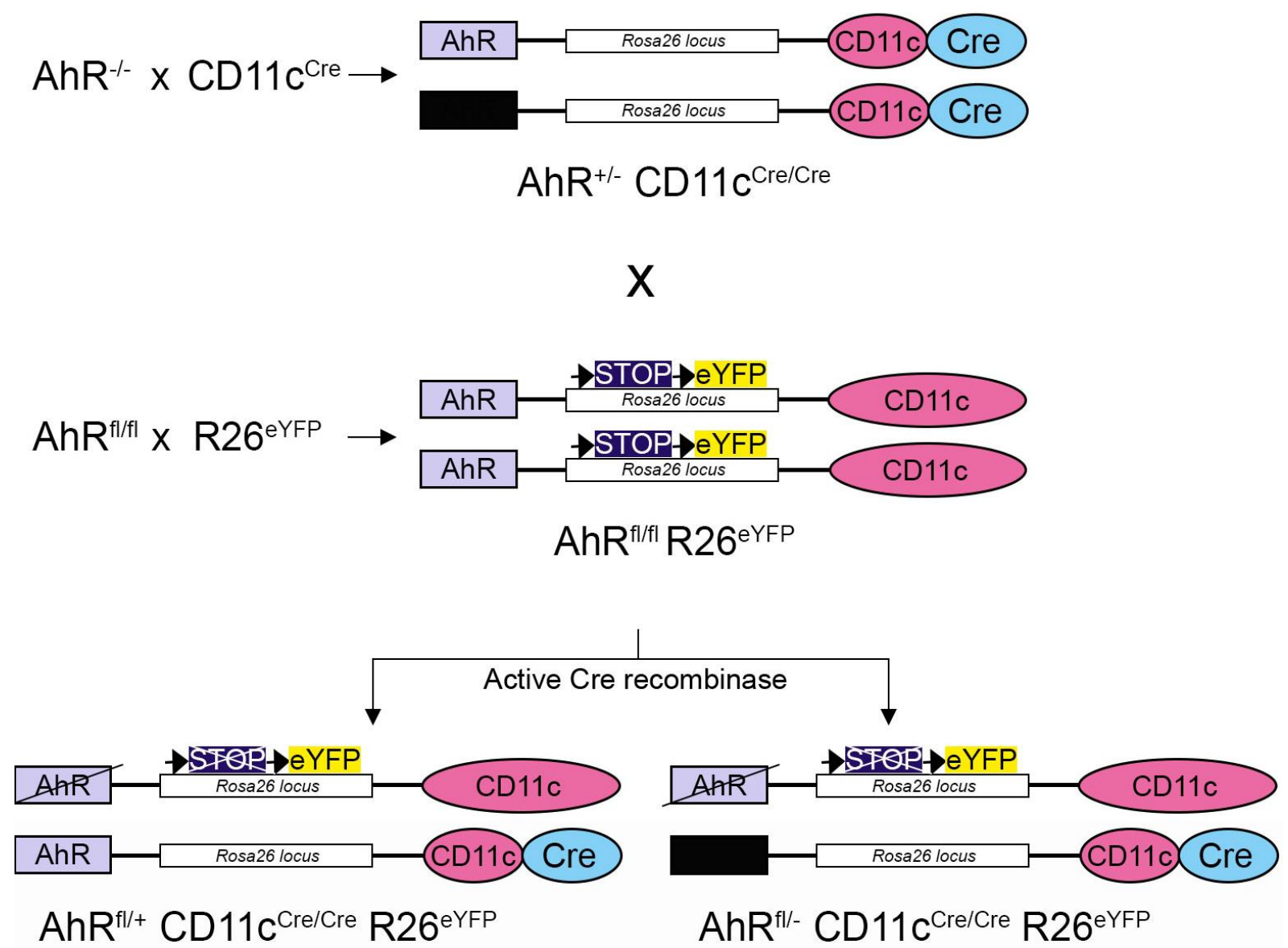

Figure 3. Breeding strategy used to generate $A h R^{\mathrm{fl} /+} \mathrm{CD}_{11 c^{\mathrm{Cre}+}} \mathrm{R}^{\mathrm{eYFP}}$ and $A h R^{\mathrm{fl} /-} \mathrm{CD} 11 \mathrm{c}^{\mathrm{Cre}+}$ R26 ${ }^{\text {YFP }}$ control mice. The transgenic animals carry a Cre recombinase active under the control of a CD11c promoter and a Cre dependent eYFP reporter gene that labels CD11c cells upon Cre recombinase activation. AhR ${ }^{\mathrm{fl} /} \mathrm{CD} 11 \mathrm{c}^{\mathrm{Cre}+} \mathrm{R} 26^{\mathrm{eYFP}}$ lack $\mathrm{AhR}$ in $\mathrm{DC}$ cells and $\mathrm{AhR}^{\mathrm{fl} / \mathrm{C}} \mathrm{CD} 11 \mathrm{c}^{\mathrm{Cre}+} \mathrm{R} 26^{\mathrm{eYFP}}$ are $\mathrm{AhR}^{+/-}$in $\mathrm{CD} 11 \mathrm{c}^{+}$cells. 


\subsubsection{CD11 tdTomato $^{\text {CX3CR1 }}{ }^{\text {eGFP }}$ transgenic line}

To evaluate the different intestinal APCs populations CX3CR $1^{\text {eGFP }}$ mice were bred with the $\mathrm{CD} 11 \mathrm{C}^{\mathrm{Cre}}$ and R26 $6^{\text {tdTomato }}$ transgenic strains. The R26 ${ }^{\text {tdTomato }}$ mice harbor a loxP flanked STOP cassette designed to prevent transcription of the red fluorescent protein variant. When they were bred to the $\mathrm{CD} 11 \mathrm{c}^{\mathrm{Cre}}$ mice that express Cre recombinase under the control of a CD11c promoter, the resulting offspring deleted the STOP cassette in $\mathrm{CD}_{11 \mathrm{c}^{+}}$cells marking them with tdTomato fluorescence. Because this CAG promoter driven reporter construct is inserted into the Gt(ROSA)26Sor locus, robust tdTomato expression is determined by the CD11c Cre recombinase.

\begin{tabular}{|c|c|c|c|}
\hline Target gene & Expression method & Developer / Reference & Supplier \\
\hline$A h R^{\operatorname{tm} 1}$ & Targeted (knock out) & $\begin{array}{l}\text { Christopher A Bradfield, University } \\
\text { of Wisconsin-Madison }{ }^{149}\end{array}$ & $\begin{array}{l}\text { Jackson } \\
\text { Laboratory }\end{array}$ \\
\hline $\mathrm{AhR}^{\mathrm{tm} 1.2}$ & Targeted (knock out) & $\begin{array}{c}\text { Taconic in collaboration with CXR } \\
\text { Biosciences }\end{array}$ & Taconic \\
\hline $\begin{array}{c}\mathrm{AhR}^{\mathrm{tm} 3.1 \mathrm{Bra} /} \\
\mathrm{AhR}^{\mathrm{fl/fl}}\end{array}$ & $\begin{array}{l}\text { Targeted mutation } 3.1 \\
\text { (floxed) }\end{array}$ & $\begin{array}{l}\text { Christopher A Bradfield, University } \\
\text { of Wisconsin-Madison } 256\end{array}$ & \multirow{5}{*}{$\begin{array}{l}\text { Jackson } \\
\text { Laboratory }\end{array}$} \\
\hline CD11c Cre & $\begin{array}{l}\text { Transgenic } \\
\text { (Recombinase } \\
\text { expressing) }\end{array}$ & $\begin{array}{l}\text { Boris Reizis, Columbia University } \\
\text { Medical Center } 254\end{array}$ & \\
\hline CD4Cre & $\begin{array}{c}\text { Transgenic insertion } 1 \\
\text { (Recombinase } \\
\text { expressing) }\end{array}$ & $\begin{array}{c}\text { Christopher B. Wilson, University } \\
\text { of Washington } 257,258\end{array}$ & \\
\hline CX3CR1 1 EGFP/+ & $\begin{array}{l}\text { Transgene insertion } \\
\text { 4097, (Recombinase } \\
\text { expressing) }\end{array}$ & $\begin{array}{l}\text { Dr. Dan R. Littman, New York } \\
\text { University Medical Center } 259\end{array}$ & \\
\hline FoxP3 YFP Cre & $\begin{array}{l}\text { Targeted mutation } 4, \\
\text { (Recombinase } \\
\text { expressing) }\end{array}$ & $\begin{array}{l}\text { Alexander Rudensky, Memorial } \\
\text { Sloan Kettering Cancer Center } 260\end{array}$ & \\
\hline GFAPCre & $\begin{array}{c}\text { Transgene insertion } \\
\text { 73.12, (Recombinase } \\
\text { expressing) }\end{array}$ & $\begin{array}{l}\text { Michael V Sofroniew, University of } \\
\text { California Los Angeles }\end{array}$ & $\begin{array}{l}\text { Charles River } \\
\text { Laboratories, } \\
\text { Sulzfeld, } \\
\text { Germany. }\end{array}$ \\
\hline R26 tdTomato & Targeted mutation 9 & $\begin{array}{l}\text { Hongkui Zeng, Allen Institute for } \\
\text { Brain Science }\end{array}$ & \multirow{2}{*}{$\begin{array}{l}\text { Jackson } \\
\text { Laboratory }\end{array}$} \\
\hline R26 YYFP & $\begin{array}{l}\text { Targeted mutation } 1 \\
\text { (eYFP reporter gene) }\end{array}$ & $\begin{array}{l}\text { Frank Costantini, Columbia } \\
\text { University Medical Center } 255\end{array}$ & \\
\hline
\end{tabular}

Table 17. Transgenic mouse lines used to generate AhR specific knock out mice through the Cre/Lox system. Abbreviations: CX3CR1: chemokine receptor 1; EGFP: enhanced green fluorescent protein; FoxP3: forkhead box P3; GFAP: glial fibrillary acidic protein; Itgax: integrin alpha X; TM: targeted mutation; R26: rosa 26 locus; YFP: yellow fluorescence protein. 


\subsection{Methods}

\subsubsection{Genotyping of transgenic mice}

PCR based genotyping of all transgenic mouse lines was performed by Ms. Katja Schulz (Department of Neuropathology, University Medical Center Göttingen).

\subsubsection{DNA extraction}

Genomic DNA was isolated from tail biopsies of $\mathrm{AhR}^{\mathrm{fl|fl}}, \mathrm{AhR}^{\Delta \mathrm{CD} 4}, \mathrm{AhR}^{\Delta T r e g}, \mathrm{AhR}^{\Delta \mathrm{Astro}}$ and $\mathrm{AhR}^{\Delta \mathrm{DC}}, 2 \mathrm{D} 2, \mathrm{Th} /+$, OSE $A h R^{\mathrm{fl} / \mathrm{fl} l}$, OSE $\mathrm{AhR}^{\Delta \mathrm{CD} 4}$, OSE $A h R^{\Delta T r e g}$, OSE $A h R^{\Delta A s t r o}$, OSE $A h R^{\Delta \mathrm{DC}}$, OSE AhR ${ }^{\triangle D C} \mathrm{CX} 3 C R 1^{\mathrm{EGFP} /+}$ and OSE $A h R^{\mathrm{fl/fl}} \mathrm{CX} 3 \mathrm{CR} 1^{\mathrm{EGFP} /+}$ mice at 3 weeks of age.

In order to isolate genomic DNA, the tails were digested using a mixture of $20 \mu$ l Proteinase $\mathrm{K}$ and $350 \mu \mathrm{l}$ tail lysis buffer in a thermomixer at $350 \mathrm{rpm}$ and $56^{\circ} \mathrm{C}$ overnight. Samples were centrifuged for $5 \mathrm{~min}$ at $13200 \mathrm{rpm}$ and the supernatants were collected into new tubes. Each tube received $350 \mu \mathrm{l}$ of isopropyl alcohol to precipitate the DNA.

All samples were carefully mixed, centrifuged and the supernatants were discarded. Subsequently, $350 \mu \mathrm{l}$ of $70 \%$ ethanol were added before the last centrifugation step. The DNA pellet was dried for $10-15$ min at $45^{\circ} \mathrm{C}$ in a speed vacuum concentrator and resuspended in $100 \mu$ l bidistilled $\mathrm{H}_{2} \mathrm{O}$.

\subsubsection{Polymerase chain reaction (PCR)}

\begin{tabular}{|c|c|c|c|c|c|c|c|c|}
\hline Gene & 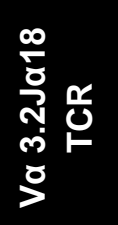 & 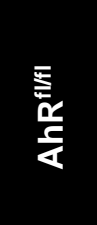 & $\begin{array}{l}\frac{0}{0} \\
\frac{0}{5} \\
\frac{0}{0}\end{array}$ & $\begin{array}{l}\stackrel{\circ}{\bar{\Xi}} \\
\stackrel{8}{8}\end{array}$ & $\frac{\substack{0 \\
\frac{0}{0}}}{\frac{1}{0}}$ & $\begin{array}{l}\frac{0}{0} \\
\stackrel{0}{0} \\
\frac{0}{x} \\
口\end{array}$ & 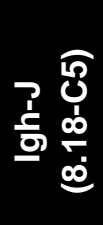 & 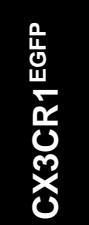 \\
\hline Buffer & 4 & 4 & 4 & 4 & 2,5 & 4 & 4 & 4 \\
\hline dNTPs & 0.4 & 0.4 & 1 & 1 & 0.15 & 0.5 & 0.4 & 1 \\
\hline Primers & $\begin{array}{c}0.5 \\
\text { each }\end{array}$ & $\begin{array}{r}0.5 \\
\text { each }\end{array}$ & $\begin{array}{c}1 \\
\text { each }\end{array}$ & $\begin{array}{c}0.5 \\
\text { each }\end{array}$ & $\begin{array}{l}0.25 \\
\text { each }\end{array}$ & $\begin{array}{l}0.5 \\
\text { each }\end{array}$ & $\begin{array}{c}0.5 \\
\text { each }\end{array}$ & $\begin{array}{r}0.5 \\
\text { each }\end{array}$ \\
\hline $\begin{array}{c}\text { DNA } \\
\text { polymerase }\end{array}$ & 0.1 & 0.1 & 0.1 & 0.1 & 0.1 & 0.1 & 0.1 & 0.1 \\
\hline Bidistilled $\mathrm{H}_{2} \mathrm{O}$ & 9.5 & 9.4 & 7.9 & 7 & 8.9 & 8.9 & 9.4 & 8.4 \\
\hline Genomic DNA & 2 & 2 & 2 & 2 & 2 & 2 & 2 & 2 \\
\hline $\mathrm{MgCl}_{2}(25 \mathrm{mM})$ & -- & -- & -- & 1 & 0.5 & 0.5 & -- & -- \\
\hline
\end{tabular}

Table 18. Composition of PCR reactions used for transgenic mice genotyping. A mixture of GoTaq DNA polymerase buffer (5x), deoxynucleotide triphosphates (dNTPs), reverse and forward primers, Go-Taq DNA polymerase, bidistilled $\mathrm{H}_{2} \mathrm{O}$ and genomic DNA was used for all reactions. Primers were used at a concentration of $10 \mathrm{mM}$; except for GFAP (100 pmol) and dNTPs at concentration of 2,5 mM; except for FoxP3 and GFAP (10 mM). All quantities are given in microliters $(\mu \mathrm{l})$. 
The PCR reaction components are listed on table 18 for each of the transgenic mouse lines and all primers are described in table 7. PCR reactions were run in a T3 thermocycler and the specific cycling conditions are described in table 19. Ethidium bromide stained PCR products were separated by electrophoresis on agarose gel at 120 volts for $60-90$ minutes and the product length was evaluated using a 100 base pairs (bp) DNA ladder under UV light.

\begin{tabular}{|c|c|c|c|c|c|c|c|c|c|c|c|c|}
\hline Step & \multicolumn{3}{|c|}{ 2D2 } & \multicolumn{3}{|c|}{$A h R^{f / f i}$} & \multicolumn{3}{|c|}{ CD11c ${ }^{\text {Cre }}$} & \multicolumn{3}{|c|}{ CD4 ${ }^{\text {Cre }}$} \\
\hline & ${ }^{\circ} \mathrm{C}$ & time & & ${ }^{\circ} \mathrm{C}$ & time & & ${ }^{\circ} \mathrm{C}$ & time & & ${ }^{\circ} \mathrm{C}$ & time & \\
\hline $\begin{array}{c}\text { 1.Pre- } \\
\text { denaturation }\end{array}$ & 95 & $2 \mathrm{~m}$ & & 94 & $3 \mathrm{~m}$ & & 94 & $3 \mathrm{~m}$ & & 94 & $3 \mathrm{~m}$ & \\
\hline 2.Denaturation & 95 & $1 \mathrm{~m}$ & \multirow{3}{*}{$\begin{array}{c}30 \\
\text { cycles }\end{array}$} & 94 & $30 \mathrm{~s}$ & \multirow{3}{*}{$\begin{array}{c}35 \\
\text { cycles }\end{array}$} & 94 & $30 \mathrm{~s}$ & \multirow{3}{*}{$\begin{array}{c}35 \\
\text { cycles }\end{array}$} & 94 & $30 \mathrm{~s}$ & \multirow{3}{*}{$\begin{array}{c}35 \\
\text { cycles }\end{array}$} \\
\hline 3. Annealing & 58 & $1 \mathrm{~m}$ & & 60 & $20 \mathrm{~s}$ & & 60 & $1 \mathrm{~m}$ & & 51,7 & $1 \mathrm{~m}$ & \\
\hline 4. Elongation & 72 & $1 \mathrm{~m}$ & & 72 & $20 \mathrm{~s}$ & & 72 & $1 \mathrm{~m}$ & & 72 & $1 \mathrm{~m}$ & \\
\hline $\begin{array}{l}\text { 5. Final } \\
\text { elongation }\end{array}$ & 72 & $\begin{array}{l}10 \\
m\end{array}$ & & 72 & $2 \mathrm{~m}$ & & 72 & $2 \mathrm{~m}$ & & 72 & $2 \mathrm{~m}$ & \\
\hline 6.Storage & 10 & hold & & 10 & hold & & 10 & hold & & 10 & hold & \\
\hline $\begin{array}{l}\text { Product size } \\
\text { (bp) }\end{array}$ & \multicolumn{3}{|c|}{ Transgene: $\sim 700$} & \multicolumn{3}{|c|}{$\begin{array}{l}\text { WT: } 106 \\
\text { Homozygous: } 140 \\
\text { Heterozygous: } \\
106+140\end{array}$} & \multicolumn{3}{|c|}{ Transgene: 313} & \multicolumn{3}{|c|}{ Transgene: $~ 100$} \\
\hline Step & \multicolumn{3}{|c|}{ GFAPCre } & \multicolumn{3}{|c|}{ FoxP3 ${ }^{\text {Cre }}$} & \multicolumn{3}{|c|}{ Th/t } & \multicolumn{3}{|c|}{ CX3CR1 ${ }^{\mathrm{EGFP} /+}$} \\
\hline & ${ }^{\circ} \mathrm{C}$ & time & & ${ }^{\circ} \mathrm{C}$ & time & & ${ }^{\circ} \mathrm{C}$ & time & & ${ }^{\circ} \mathrm{C}$ & time & \\
\hline $\begin{array}{c}\text { 1.Pre- } \\
\text { denaturation }\end{array}$ & 98,5 & $3 \mathrm{~m}$ & & 94 & $2 \mathrm{~m}$ & & 95 & $2 \mathrm{~m}$ & & 94 & $3 \mathrm{~m}$ & \\
\hline 2. Denaturation & 98,5 & $30 \mathrm{~s}$ & \multirow{3}{*}{$\begin{array}{c}35 \\
\text { cycles }\end{array}$} & 94 & $30 \mathrm{~s}$ & \multirow{3}{*}{$\begin{array}{c}28 \\
\text { cycles }\end{array}$} & 95 & $1 \mathrm{~m}$ & \multirow{3}{*}{$\begin{array}{c}30 \\
\text { cycles }\end{array}$} & 94 & $30 \mathrm{~s}$ & \multirow{3}{*}{$\begin{array}{c}35 \\
\text { cycles }\end{array}$} \\
\hline 3. Annealing & 65 & $45 \mathrm{~s}$ & & 61 & $20 \mathrm{~s}$ & & 61 & $1 \mathrm{~m}$ & & 60 & $30 \mathrm{~s}$ & \\
\hline 4. Elongation & 72 & $1 \mathrm{~m}$ & & 72 & $20 \mathrm{~s}$ & & 72 & $1 \mathrm{~m}$ & & 72 & $1 \mathrm{~m}$ & \\
\hline $\begin{array}{l}\text { 5. Final } \\
\text { elongation }\end{array}$ & 72 & $2 \mathrm{~m}$ & & 72 & $2 m$ & & 72 & $\begin{array}{l}10 \\
\mathrm{~m}\end{array}$ & & 72 & $\begin{array}{l}10 \\
\mathrm{~m}\end{array}$ & \\
\hline 6.Storage & 10 & hold & & 10 & hold & & 10 & hold & & 10 & hold & \\
\hline $\begin{array}{l}\text { Product size } \\
\text { (bp) }\end{array}$ & \multicolumn{3}{|c|}{ Transgene: 100} & \multicolumn{3}{|c|}{$\begin{array}{l}\text { WT: } 322 \\
\text { Homozygous:346 } \\
\text { Heterozygous: } \\
322+346\end{array}$} & \multicolumn{3}{|c|}{$\begin{array}{l}\text { WT: } 150 \\
\text { Homozygous: } 100 \\
\text { Heterozygous: } \\
150+100\end{array}$} & \multicolumn{3}{|c|}{$\begin{array}{l}\text { WT: } 400 \\
\text { Homozygous: } 800 \\
\text { Heterozygous: } 400 \\
+800\end{array}$} \\
\hline
\end{tabular}

Table 19. 6 step PCR programs used in the T3 thermocycler for transgenic mice genotyping. Abbreviations: m: minutes; s: seconds.

For the genotyping of $A h R^{f / f 1}, A h R^{\Delta C D 4}, A h R^{\Delta T r e g}, A h R^{\Delta A s t r o}$ and $A h R^{\Delta D C}$ two PCR reactions were performed: one for the $A \mathrm{AR}^{\mathrm{fl} / \mathrm{fl}}$, gene and one for the corresponding Cre transgene under control of a CD11c, CD4, FoxP3 or GFAP promoter. For the OSE $\mathrm{AhR}^{\Delta \mathrm{DC}}$, OSE $A h R^{\Delta C D 4}$, OSE $A h R^{\Delta T r e g}$, OSE $A h R^{\Delta A s t r o}$ and OSE $A h R^{f / / f l}$ CX3CR1 $1^{E G F P /+}$ two additional 
reactions were performed one to detect the Va3.2Ja18 TCR gene (2D2 mice) and one for the Igh-J gene (Th/+ mice)

\subsubsection{Mouse immunization with MOG3 ${ }_{5-55}$ and EAE induction}

$A h R^{\Delta D C}, A h R^{\Delta T r e g}, A h R^{\Delta A s t r o}, A h R^{\Delta C D 4}$ and $A h R^{f / / f l}$ control mice were actively immunized with a subcutaneous (s.c.) injection of $50 \mu \mathrm{l}$ of $\mathrm{MOG}_{35-55}$ emulsified in complete Freund's adjuvant (CFA, composition detailed in table 3) per groin and per axilla (200 $\mu \mathrm{g} \mathrm{MOG}$ 35-55/animal). The s.c. inoculation was accompanied by an intraperitoneal (i.p.) injection of $400 \mathrm{ng}$ of pertussis toxin (PTX) on the day of immunization and two days later.

\subsubsection{Clinical EAE score}

All animals were observed after immunization and scored daily based on a scale of disease severity. The scale ranges from 0 (healthy) to 5 (death) as shown in table 20 . Ethical standards dictate that animals reaching 3.5 should be immediately sacrificed. The animals that died because of EAE were scored 5 and the ones sacrificed for ethical reasons were documented with the last given score until the experiment ended.

\begin{tabular}{|c|c|c|}
\hline Score & Clinical signs & Description \\
\hline 0 & Healthy & No neurological deficits \\
\hline 0.5 & Partially limp tail & The distal part of the tail is weak or paralyzed \\
\hline 1 & Tail paralysis & The complete tail is flaccid and hanging loosely \\
\hline 2 & $\begin{array}{l}\text { Impair righting reflex, hind } \\
\text { limbs weakness }\end{array}$ & $\begin{array}{l}\text { Positive flip test: The mouse struggles to roll back onto its } \\
\text { feet when laid on its back }\end{array}$ \\
\hline 2.5 & $\begin{array}{l}1 \text { or } 2 \text { hind limbs } \\
\text { incomplete paralysis }\end{array}$ & Hind limbs are unsteady producing wobbling when walking \\
\hline 3 & $\begin{array}{l}\text { Hind limbs complete } \\
\text { paralysis }\end{array}$ & $\begin{array}{l}\text { Front paws are very active for grasping. The mouse can } \\
\text { easily support its own weight using only the fore paws. }\end{array}$ \\
\hline 3.5 & $\begin{array}{l}\text { Hind limbs and abdomen } \\
\text { paralysis }\end{array}$ & $\begin{array}{l}\text { The mouse lacks the strength to hang on the grid and it is not } \\
\text { able to reach the water bottle and food located on the lid. }\end{array}$ \\
\hline 4 & Fore limbs weakness & Inactive behavior, loss of muscular tone of all limbs \\
\hline 4.5 & Moribund & $\begin{array}{l}\text { The paralysis extends to the fore limbs, altered breathing and } \\
\text { usually prostrated. }\end{array}$ \\
\hline 5 & Dead & \\
\hline
\end{tabular}

Table 20. Scoring scale for EAE clinical monitoring. Detailed description of the clinical signs that characterized each stage of disease severity according to the followed EAE scale. 


\subsubsection{Laquinimod administration}

Laquinimod was dissolved in water and administered daily to the mice by oral gavage at a dosage of $25 \mathrm{mg} / \mathrm{kg}_{\text {body weight }}$ for MOG immunized mice and $50 \mathrm{mg} / \mathrm{kg}_{\text {body weight }}$ for animals transferred with B16F10 melanoma cells. Every week the animals were weighted and the dosages were adjusted accordingly. The control animals received the same volume of tap water. Laquinimod was a generously provided by Teva Pharmaceutical Industries, Ltd., Netanya, Israel.

Laquinimod treatment was started on the day of immunization and continued daily for 10 days if immunological analyses were performed or for 30 days to follow the clinical disease course.

\subsubsection{Preparation of single cell suspensions from the spleen for ex vivo analysis}

Laquinimod or vehicle treated animals were sacrificed by cervical dislocation after anesthesia. Spleens were dissected and transferred into a $10 \mathrm{ml}$ tube with cold $\mathrm{RPMI}_{\text {complete. This procedure }}$ was performed under the hood for the sterile acquisition of splenocytes. Unless stated otherwise, cells were washed with $10 \mathrm{ml}$ of cold $\mathrm{RPMI}_{\text {complete }}$ and centrifuged for 10 minutes at $300 \times g$ and $4^{\circ} \mathrm{C}$.

Mechanical dissociation was used to disrupt the spleens, which were pressed through a $70 \mu \mathrm{m}$ strainer using the plunger end of a syringe. The remaining cells were washed through the strainer, collected into $50 \mathrm{ml}$ tubes and centrifuged. The pellet was resuspended in $1 \mathrm{ml}$ of BD Pharm lyse solution ( $1: 10$ diluted in bidistilled $\mathrm{H}_{2} \mathrm{O}$ ) and incubated for $3 \mathrm{~min}$ at $37^{\circ} \mathrm{C}$ to lyse erythrocytes. The reaction was stopped by adding $20 \mathrm{ml}$ of cold $\mathrm{RPMI}_{\text {complete }}$ and the cells were washed twice.

\subsubsection{Cell counting with Neubauer chamber}

Before being plated for FACS staining, the cells were stained with trypan blue to test cell viability and counted in a Neubauer chamber. Living cells with intact cell membranes exclude dyes such as trypan blue allowing us to differentiate between dead and viable cells. 
Therefore, $10 \mu \mathrm{l}$ of the cell suspension were diluted 1:10 in trypan blue (previously diluted 1:10 in PBS) and transferred to the capillary gap between the chamber bottom and the cover glass. The cell concentration was determined by counting the number of cells in the four outer squares of $1 \mathrm{~mm}^{2}$ of area and $1 \mu \mathrm{l}$ of volume using the $10 \mathrm{x}$ objective of the light microscope.

The concentration of cells was then calculated according to the following formula:

$$
\text { Concentration }(\text { cells } / \mathrm{ml})=\frac{\text { Number of cells } \times 10000}{\text { Number of squares } \times \text { dilution }}
$$

\subsubsection{Isolation of lymphocytes from the small intestine}

6 to 8 weeks old OSE $A h R^{\Delta D C}$, OSE $A h R^{f / / f 1}$, OSE $A h R^{\triangle D C} C X 3 C R 1^{E G F P /+}$ and OSE $A h R^{f / / 1 /}$ $\mathrm{CX} 3 \mathrm{CR} 1^{\mathrm{EGFP} /+}$ animals were used to isolate lymphocytes from the gut. The small intestine was dissected leaving approximately $0.5 \mathrm{~cm}$ separation below the stomach and $0.5 \mathrm{~cm}$ above the caecum, transferred to a Petri dish with cold PBS and cut in $\sim 5 \mathrm{~cm}$ long pieces. Each segment was cleaned from the remaining connective tissue, fat and blood vessels. The faeces were rinsed from the intestine pieces using a $10 \mathrm{ml}$ syringe filled with cold PBS and 18G needle. The intestinal lumen was flushed with approximately $40 \mathrm{ml}$ per mouse or until no remaining fecal matter was observed.

\subsubsection{Isolation of lymphocytes from the Peyer patches}

5 to 10 Peyer's patches (PP) per mouse were removed from the intestines of each mouse using small scissors and curved tweezers to hold tight these structures. After excision, all PP were transferred into a $50 \mathrm{ml}$ tube with cold $\mathrm{RPMI}_{\text {complete }}$ and remained on ice until further treatment. The content of the tube with the PP was filtered through a $70 \mu \mathrm{m}$ strainer and the tissue was disrupted by mechanical dissociation using the plunger of a $5 \mathrm{ml}$ syringe. The strainer was flushed with $10 \mathrm{ml}$ cold $\mathrm{RPMI}_{\text {complete. }}$

\subsubsection{Isolation of intraepithelial lymphocytes}

After removing the PP, the intestine segments were opened longitudinally and further cut in $0.5 \mathrm{~cm}$ pieces. The sections obtained were washed 3 times with cold PBS using a metallic 
sieve and transferred into a $50 \mathrm{ml}$ tube with $10 \mathrm{ml}$ prewarmed predigestion solution. This buffer contains EDTA (cation chelant) and DTT (reducing agent), which have been shown to increase intestinal intraepithelial lymphocytes (IEL) isolation purity ${ }^{263}$.

The tissue was vigorously mixed using a tube rotator at maximum speed for 10 to 15 minutes at $37^{\circ} \mathrm{C}$ and vortexed for 15 seconds. Subsequently, the $10 \mathrm{ml}$ content containing detached IEL was filtered through a $70 \mu \mathrm{m}$ strainer and collected into a $50 \mathrm{ml}$ tube. The strainer was rinsed with $5 \mathrm{ml}$ cold PBS and the tissue was transferred into a new tube with fresh $15 \mathrm{ml}$ prewarmed predigestion solution. The tube was placed again inside the warming chamber and the same procedure was repeated 3 times until collecting a final volume of $45 \mathrm{ml} \mathrm{IEL}$ suspension.

\subsubsection{Isolation of lamina propria lymphocytes}

The remaining predigested tissue was washed 3 times with cold PBS, cut into smaller pieces and transferred into a $50 \mathrm{ml}$ tube with $5 \mathrm{ml}$ prewarmed digestion solution. The dissociation buffer contains collagenase D and DNase I for enzymatic degradation of the connective tissue forming the lamina propria (LP) underneath the intestinal epithelium.

Samples were mixed using a rocking platform at $190 \mathrm{rpm}$ for 15 to 20 minutes at $37^{\circ} \mathrm{C}$, and vortexed for 20 seconds. The $5 \mathrm{ml}$ content was filtered through a $40 \mu \mathrm{m}$ strainer and collected into a $50 \mathrm{ml}$ tube. $5 \mathrm{ml}$ of cold RPMI complete were used to rinse the strainer. Next, the tissue was transferred into a new tube with fresh $5 \mathrm{ml}$ prewarmed digestion solution and placed again on the rocking platform. The same procedure was repeated 4 times, generating a final volume of $40 \mathrm{ml}$ containing the isolated lamina propria lymphocytes (LPL).

Cells obtained from OSE AhR ${ }^{\Delta \mathrm{DC}} \mathrm{CX} 3 \mathrm{CR} 1^{\mathrm{EGFP} /+}$ and OSE $A h R^{\mathrm{fl/fl}} \mathrm{CX} 3 \mathrm{CR} 1^{\mathrm{EGFP} /+}$ animals were always protected from light exposure. During incubation periods the cells always remained on ice and centrifugations ran for 10 minutes at $400 \times g$ at $4^{\circ} \mathrm{C}$ if not stated differently. 


\subsubsection{Separation of lymphocytes using a Percoll gradient}

The IEL and LPL obtained from the predigestion and digestion steps were centrifuged and resuspended in $10 \mathrm{ml} \mathrm{DMEM}^{\text {high-Glu }}$. After an additional centrifugation, cells were resuspended in $8 \mathrm{ml}$ master mix (40\% Percoll solution), thoroughly mixed and gently added onto $5 \mathrm{ml}$ of $80 \%$ Percoll solution, which was previously poured into a $15 \mathrm{ml}$ tube as shown in figure 4 . The tubes containing 40 and $80 \%$ Percoll phases corresponding to either IEL or LPL (2 per mouse) were centrifuged for 25 minutes at $400 \times g$ at $20^{\circ} \mathrm{C}$ without break and deceleration.

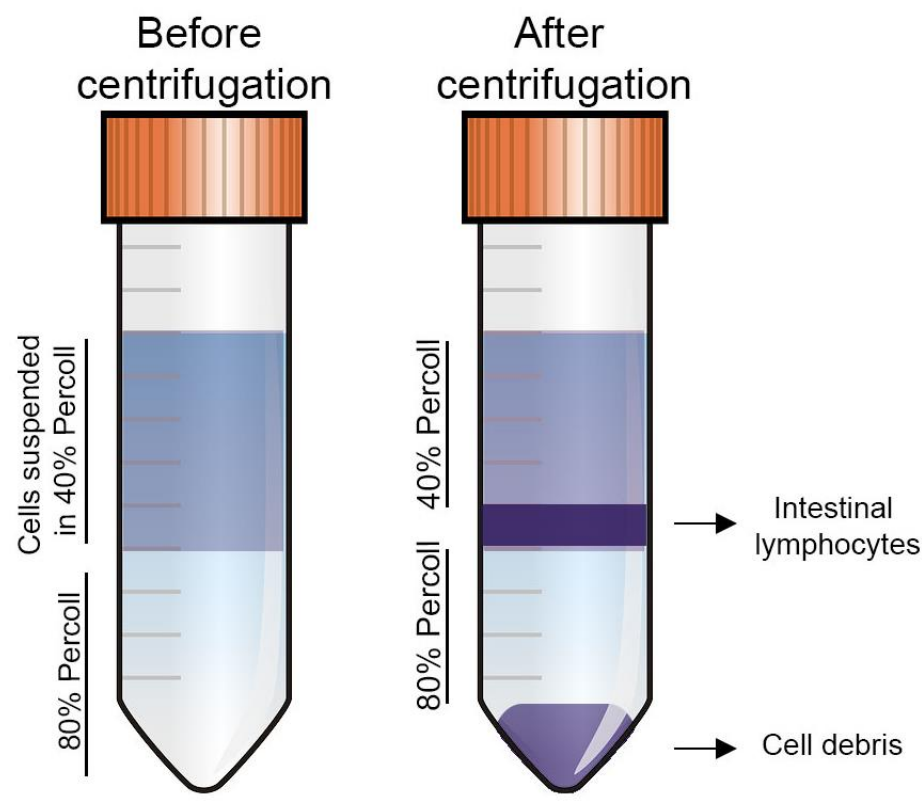

Figure 4. Schematic representation of the tubes containing $\mathbf{4 0}$ and $80 \%$ Percoll phases before and after the Percoll gradient centrifugation. This procedure was used to separate either intraepithelial or lamina propria lymphocytes from the small intestines.

After the Percoll gradient centrifugation, a fraction of the $40 \%$ Percoll upper layer was removed using a glass pipette connected to a vacuum pump in order to have better access to the layer beneath comprising the intestinal lymphocytes. Using a $1 \mathrm{ml}$ micropipette, the intestinal lymphocytes from the Percoll interphase were transferred into a new tube containing $10 \mathrm{ml}$ of FACS buffer.

The 3 tubes obtained from each mouse (containing IEL, PP and LP lymphocytes) were centrifuged and resuspended in FACS buffer. Cells were counted as described in section 2.4.6 
and plated in 96 well plates (500 000 cells per well) before proceeding to extra and intracellular FACS stainings.

\subsubsection{Flow cytometry staining and analysis}

Once the cell concentration was determined, single cell suspensions were transferred to round bottom 96 well plates $\left(0.5-1 \times 10^{6}\right.$ cells per well), centrifuged and washed twice. Unless stated otherwise, cells were washed with $200 \mu \mathrm{l}$ of cold FACS buffer per well and centrifuged for 10 minutes at $300 \times g$ and $4^{\circ} \mathrm{C}$.

\subsubsection{Detection of extracellular proteins}

For extracellular FACS stainings a master mix was prepared beforehand with 8 fluorochrome labeled antibodies diluted 1:200 and BD Fc block (anti-CD16/CD32) diluted 1:100 in FACS buffer (table 12). $50 \mu$ of staining solution was added per well. Cells were incubated with the master mix in the dark for 12 minutes at $4^{\circ} \mathrm{C}$, centrifuged and washed twice.

\subsubsection{Intracellular detection of FoxP3}

Intracellular detection of the transcription factor FoxP3 was performed after staining all surface molecules as described in the previous section. Subsequently, cells were incubated and fixed in FoxP3 fixation concentrate diluted 1:4 in the dilution buffer for 1 hour. After centrifugation, cells were washed twice with FoxP3 permeabilization buffer diluted 1:10 in bidistilled $\mathrm{H}_{2} \mathrm{O}$. After centrifugation, cells were resuspended with the anti-FoxP3 antibody diluted 1:100 in permeabilization buffer and incubated for 30 minutes at $4^{\circ} \mathrm{C}$ in darkness. Next, $100 \mu \mathrm{l}$ of staining solution were added per well. Cell suspensions were centrifuged and washed twice.

\subsubsection{Intracellular detection of IFNY and IL17}

Ionomycin is a calcium ionophore and PMA is a small organic compound that freely diffuses through the cell membrane. They stimulate cytokine secretion by activating calcium release and protein kinase $C(P K C)$ signaling, respectively ${ }^{264-267}$. In order to quantify $\mathrm{CD}^{+}{ }^{+} \mathrm{T}$ cell production of IFNy and IL17 and before proceeding to the staining protocol, cells were stimulated with $25 \mathrm{ng} / \mathrm{ml}$ phorbol 12-myristate 13-acetate (PMA) and $1 \mu \mathrm{g} / \mathrm{ml}$ ionomycin in 
$\mathrm{RPMI}_{\text {complete }}$ for at least 6 hours at $37^{\circ} \mathrm{C}$ and $5 \% \mathrm{CO}_{2}$ in round bottom 96 well plates. After the first hour of incubation, cytokine secretion was blocked adding Golgi Stop protein transport inhibitor (monensin) 1:1000 to the medium.

After stimulation with PMA and ionomycin, cell surface molecules were detected as described in section 2.4.8.1 and using FACS buffer with Golgi Stop diluted 1:1000. All FACS extra and intracellular stainings were performed under the hood in sterile conditions to avoid contamination of the stock antibodies.

For intracellular staining of cytokines, cell suspensions were fixed with Cytofix/Cytoperm for 1 hour, washed twice with Perm/Wash buffer diluted 1:10 in bidistilled $\mathrm{H}_{2} \mathrm{O}$ and incubated with anti-IL17 and anti-IFNy antibodies diluted 1:50 in Perm/Wash buffer in the dark for 30 minutes at $4^{\circ} \mathrm{C} .50 \mu$ of staining solution was added per well.

\subsubsection{Flow cytometry analysis}

Cell suspensions were centrifuged and washed twice. Flow cytometry analysis was performed using a FACS Canto II device able to detect an eight color panel using FITC, PE, PerCP-Cy5.5, PE-Cy7, APC, APC-Cy7, AmCyan, and Pacific Blue fluorophores. Different combinations of the eight fluorophore labeled antibodies (listed in table 12) were used for FACS stainings. BD FACSDiva Software 6.1.2 was used to preview and record data from all samples.

\subsubsection{Histology}

\subsubsection{Preparation of mouse tissue for immunohistochemistry}

CD11 $\mathrm{c}^{\text {tdTomato }}, \mathrm{CX} 3 \mathrm{CR} 1^{\mathrm{eGFP}}$ and double transgenic CD11 $\mathrm{c}^{\text {tdTomato }} \mathrm{CX} 3 \mathrm{CR} 1^{\text {eGFP }}$ mice were sacrificed by cervical dislocation after anesthesia and transcardially perfused with PBS. Small intestines were dissected leaving approximately $0.5 \mathrm{~cm}$ separation below the stomach as described in section 2.4.7. The mesenteric fat and blood vessels were carefully removed and the intestinal content was flushed with cold PBS using a $10 \mathrm{ml}$ syringe and $18 \mathrm{G}$ needle. 
The small intestine samples were fixed overnight in 4\% PFA and incubated 1 day in PBS, loaded in cassettes, dehydrated and immersed in paraffin using an Excelsior AS automated tissue processor. Tissues were embedded in paraffin blocks using a MEDITE TES Valida paraffin embedding system and cut in 2 to $4 \mu \mathrm{m}$ sections using a Leica SM2000 R sliding microtome.

\subsubsection{Deparaffinization and dehydration of small intestine sections}

Before further immunohistochemistry methods, all sections were heated in an oven at paraffin melting point $\left(56-58^{\circ} \mathrm{C}\right)$ for at least 1 hour, gradually deparaffinized in xylene and rehydrated in graded isopropyl alcohol series as shown in table 21.

\begin{tabular}{|c|c|c|}
\hline Reagent & Repetitions & Function \\
\hline Xylene & $4 \times 5$ minutes & Deparaffinization \\
\hline Isopropyl alcohol/Xylene & $1 \times 2$ minutes & \\
\hline Isopropyl alcohol (100\%) & $2 \times 3$ minutes & \\
\hline Isopropyl alcohol (90\%) & $1 \times 3$ minutes & Rehydration \\
\hline Isopropyl alcohol (70\%) & $1 \times 3$ minutes & \\
Isopropyl alcohol (50\%) & $1 \times 3$ minutes & \\
Distilled water to rinse & 30 seconds & \\
\hline
\end{tabular}

Table 21. Deparaffinization and rehydration series of paraffin embedded sections. Before proceeding to any immunostaining protocol all slides were deparaffinized and rehydrated.

\subsubsection{Fluorescent immunohistochemistry}

CD11 $\mathrm{c}^{\text {tdTomato }} \mathrm{CX} 3 \mathrm{CR} 1^{\text {eGFP }}$ transgenic mice were used to visualize $\mathrm{CD} 11 \mathrm{c}^{+}$and $\mathrm{CX} 3 \mathrm{CR} 1^{+}$cells in the small intestines. To enhance the fluorescence intensity, immunohistochemistry with antiGFP and anti-RFP antibodies was performed.

To avoid antigen masking after PFA fixation, citrate buffer antigen retrieval was performed before the immunohistochemical staining 268,269 . The citrate based solution is designed to break the protein cross-links, hence unmask the antigens and epitopes in paraffin embedded tissue sections, enhancing the intensity of antibodies. 
The sections were incubated in preheated sodium citrate buffer $10 \mathrm{mM}, \mathrm{pH}=6$ in a steamer at $95-100^{\circ} \mathrm{C}$ for 30 minutes. If not stated otherwise, the next part of the protocol was performed at room temperature and the washing steps were repeated 3 times for 5 minutes using PBS.

After washing, the slides were incubated with $3 \%$ hydrogen peroxidase solution for 60 minutes in order to block endogenous peroxidase activity, $1 \%$ triton for 20 minutes and $10 \%$ goat serum for 30 minutes to reduce nonspecific hydrophobic binding. Washing steps were performed between the incubations.

All sections were washed and incubated overnight with a polyclonal anti-GFP primary antibody (\#PABG1-100) diluted 1:2000 (table 10). To enhance the immunohistochemical detection of eGFP, tyramide signal amplification was performed on paraffin embedded sections $^{270}$ using the Tyramide SuperBoost Alexa Fluor 488 kit (table 4). This kit is based on the activation of Alexa Fluor tyramids by horseradish peroxidase (HRP), resulting in the formation of tyramide radicals that covalently bind to tyrosine residues in close proximity of the HRP.

The Tyramide SuperBoost Alexa Fluor 488 kit was used according to the manufacturer instructions. Briefly, the next day the slides were washed and incubated with a biotinylated anti-rabbit IgG antibody (\#111-065-144) diluted 1:500 (table 11) for 1 hour. After washing, the slides were developed in tyramide working solution and the reaction was monitored using a fluorescence microscope. After 10 minutes the reaction was stopped using the Reaction Stop Reagent.

Subsequently, the slides were washed and incubated overnight with a polyclonal antiRFP antibody (\#600-401-379S) diluted 1:100 (table 10) at $4^{\circ} \mathrm{C}$. The next day, the sections were washed and stained with a Cy3 conjugated anti-rabbit IgG antibody (\#111-165-144) diluted 1:100 (table 11) for 2 hours in darkness. 
After washing, nuclei were counterstained with DAPI (1:10 000 in PBS) for 10 minutes. Slides were washed again, rinsed once in distilled water and mounted using fluorescence mounting medium.

\subsubsection{CYP1A1 expression analysis}

In order to analyze expression of the AhR targeted gene CYP1A1, dendritic cells were isolated from the spleens of $A h R^{\mathrm{fl} /+}$ CD11c $\mathrm{C}^{\mathrm{Cre}+} \mathrm{R} 26^{\mathrm{eYFP}}$ and $A h R^{\mathrm{fl} /-} \mathrm{CD} 11 c^{\mathrm{Cre}+} \mathrm{R} 26^{\mathrm{eYFP}}$ transgenic mice (depicted in figure 3). Single cell suspensions were prepared and counted using a Neubauer chamber as described in sections 2.4.5 and 2.4.6.

\subsubsection{Purification of dendritic cells}

Dendritic cells were purified by depletion of non-target cells (negative selection) using magnetic activated cell sorting (MACS). Single cell suspensions were centrifuged for 10 minutes at $300 \times g$ and $4^{\circ} \mathrm{C}$ and resuspended in $10 \mathrm{ml}$ of MACS buffer. Cells were flushed through a $40 \mu \mathrm{m}$ cell strainer and then rinsed with an equal volume of MACS buffer passed through the filter.

The Pan Dendritic Cell Isolation Kit (mouse), LS columns and the QuadroMACS separator were used according to the manufacturer's instructions. After MACS separation, cells were resuspended in $200 \mu \mathrm{l}$ of FACS buffer and YFP+ DC were further purified using a BD FACS Aria II cell sorter.

\subsubsection{Quantitative real time PCR analysis of CYP1A1 expression}

AhR deficient $\left(A h R^{\mathrm{fl} /-} \mathrm{CD} 11 \mathrm{c}^{\mathrm{Cre}+} \mathrm{R} 26^{\mathrm{YYFP}}\right)$ and AhR competent $\left(\mathrm{AhR}^{\mathrm{fl} /+} \mathrm{CD} 11 \mathrm{c}^{\mathrm{Cre}+} \mathrm{R}^{\mathrm{P}} 6^{\mathrm{eYFP}}\right) \mathrm{DC}$ were cultured in round bottom 96 well plates at a concentration of 250000 cells per well and were ex vivo stimulated with $250 \mathrm{nM}$ of FICZ, high affinity agonist of AhR, for 24 hours.

After FICZ stimulation, the supernatant was removed and the DC were lysed in QIAzol Lysis Reagent. Subsequently, RNA was isolated using the NucleoSpin RNA XS Kit following the manufacturer's protocol for cultured cells and transcribed into cDNA using the HighCapacity RNA-to-cDNA Kit according to the instructions provided. 
Quantitative PCR was performed in the iQ5 Real Time PCR Detection System using the qPCR Core Kit obtained from Eurogentec. The following FAM labeled primers/probes (TaqMan Gene Expression Assays) were selected to be intron spanning from Life Technologies: GAPDH (Mm99999915 g1) and CYP1A1 (Mm00487218 m1).

\subsubsection{B16F10 melanoma cell culture and passaging}

B16F10 melanoma cells ${ }^{271,272}$ were cultured in $75 \mathrm{~cm}$ cell culture flasks using $\mathrm{RPMI}_{\text {complete. }}$ Cultures were routinely split (1:10) every second to third day when confluence was reached. For cell passaging, the medium was discarded and non-adherent cells were removed by washing with $10 \mathrm{ml}$ PBS before cell dissociation. $1.5 \mathrm{ml}$ of prewarmed $0.01 \%$ trypsin solution in PBS was added and cells were incubated at $37^{\circ} \mathrm{C}$ for $5-7$ minutes to ensure cell detachment.

To inactivate the trypsin enzymatic action, $8.5 \mathrm{ml}$ 10\% FCS containing media

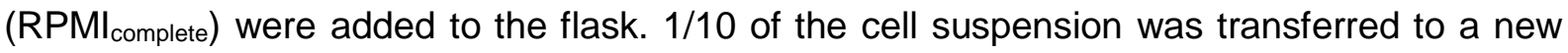
flask with fresh $\mathrm{RPMI}_{\text {complete }}$ and maintained in a humidified $37^{\circ} \mathrm{C}, 5 \% \mathrm{CO}_{2}$ incubator until confluent growth and subsequent cell passage or until needed for i.v. inoculation.

\subsubsection{In vivo lung tumor model}

Low density melanoma cell cultures were used for i.v. transfer, which are known to efficiently form lung tumor colonies ${ }^{273}$. Approximately $\leq 50 \%$ confluent B16F10 melanoma cells were trypsinized as described in 2.4.11 and washed with $10 \mathrm{ml} \mathrm{RPMI}$ complete. Cells were counted with a Neubauer chamber as explained in section 2.4.6.

B16F10 cells were resuspended in 0.5\% EDTA in PBS and pipetted thoroughly before every injection to avoid cell clumping. Cell suspensions were i.v. injected into the lateral tail veins using $27 \mathrm{G}$ needles and $1 \mathrm{ml}$ syringes. All animals were immobilized using a restrainer and the tail veins were dilated under an infrared lamp. 


\subsubsection{Preventive regimen}

C57BL/6 and AhR KO mice received Laquinimod $50 \mathrm{mg} / \mathrm{kg}_{\text {body weight }}$ or vehicle by oral gavage for 14 days. After 3 days of treatment animals were i.v. transferred with $0.5 \times 10^{6} \mathrm{~B} 16 \mathrm{~F} 10$ melanoma cells. At day 11 after tumor inoculation the mice were sacrificed to obtain the lungs.

\subsubsection{Therapeutic regimen}

C57BL/ 6 were injected in the lateral tail vein with $0.2 \times 10^{6} \mathrm{~B} 16 \mathrm{~F} 10$ melanoma cells. Melanoma cells take 5-10 days to establish and form tumors ${ }^{274}$. Therefore, treatment with vehicle or Laquinimod $50 \mathrm{mg} / \mathrm{kg}_{\text {body weight }}$ was initiated at day 11 after i.v. injection once the melanoma cells have established in the lungs. After 1 week of treatment with Laquinimod or water (day 19), all mice were sacrificed and the lungs were isolated.

\subsubsection{Lung isolation and metastasis quantification}

After following the preventive or therapeutic treatment the mice from all experimental groups were sacrificed by a lethal i.p. injection of $14 \%$ chloral hydrate. The lungs were carefully dissected, weighted, rinsed with cold PBS and fixed overnight in 4\% PFA buffer. Samples were washed with PBS and the number of metastatic colonies were counted under the stereoscopic microscope with an ocular morphometric grid.

\subsubsection{Preparation of serum samples for MOG antibody quantification}

Blood samples were collected from WT, OSE $A h R^{\Delta D C}$ and OSE $A h R^{f / / f l}$ mice older than 100 days. Mice were restrained using the scruffing technique and 100 to $200 \mu \mathrm{L}$ of blood were drawn from the submandibular vein using a 23G needle. After collection, samples were allowed to clot and centrifuged at $300 \times g$ for 10 minutes at $4^{\circ} \mathrm{C}$. After centrifugation the resulting supernatant or serum was carefully transferred into a new tube. Serum samples were stored at $-20^{\circ} \mathrm{C}$ until further use.

Anti-MOG antibody titers were determined in the serum samples of OSE $A h R^{\triangle D C}$ and OSE AhR $R^{\mathrm{fl} / \mathrm{fl}}$ mice by an enzyme-linked immunosorbent assay (ELISA). Sera obtained from WT 
mice were used as a negative control. For this purpose, sterile 96 well ELISA plates were coated with $100 \mu \mathrm{l}$ per well of $\mathrm{MOG}_{1-125}(8 \mu \mathrm{g} / \mathrm{ml})$ diluted in PBS at $4^{\circ} \mathrm{C}$ overnight.

The next part of the assay was performed at RT. If not stated otherwise, the washing steps were repeated 5 times by adding ELISA wash buffer with an 8 channel microplate washer connected to a top bottle dispenser. The plates were dried by tapping the inverted plates against paper towels. $250 \mu \mathrm{l}$ of ELISA blocking buffer were added per well and incubated for 2 hours. Plates were washed and $100 \mu \mathrm{l}$ of the serum diluted in blocking buffer were added per well. 5-fold serum dilutions (1:500, 1:2500, 1:12500, 1:62500 and 1:312500) were incubated for 1.5 hours at RT.

Once more blots were washed and $100 \mu \mathrm{l}$ of polyclonal anti - mouse $\lg \mathrm{G} 1$ and $\lg \mathrm{G} 2 \mathrm{~A}$ HRP secondary antibodies (1:4000) were added per well and incubated 1 hour in the dark. The last washing step was repeated 7 times and $100 \mu \mathrm{l}$ per well of TMB substrate premixed with hydrogen peroxide $\left(\mathrm{H}_{2} \mathrm{O}_{2}\right)$ were added. The colorimetric reaction formed a soluble blue product obtained from the TMB oxidation in the presence of the HRP conjugates and $\mathrm{H}_{2} \mathrm{O}_{2}$. The reaction was stopped with $50 \mu \mathrm{l}$ per well of ELISA stop solution to stabilize color development, which turns yellow upon addition. The optical density was measured at $450 \mathrm{~nm}$ with $540 \mathrm{~nm}$ wavelength as reference using the iMark microplate reader. Samples were run in triplicates used to calculate the average absorbance values at different dilutions and the average background OD was subtracted to each value.

\subsubsection{Indol-3-carbinol enriched diet regimen}

To investigate the effect of AhR ligands ingested in the diet using a spontaneous EAE model, OSE mice were submitted to a chemically defined diet (E1500) enriched or not with $2 \mathrm{mg} / \mathrm{kg}$ of indol-3-carbinol (I3C $\left.\mathrm{C}^{2 \mathrm{mg} / \mathrm{kg}}\right)$. At birth, all mothers of OSE mice received free access to the food corresponding to its experimental group.

Animals were randomly assigned to either I3C enriched diet or control group and food was continuously provided. The spontaneous disease development was monitored for 100 days after birth. 


\section{RESULTS}

\subsection{Physiological AhR ligands reduce spontaneous CNS autoimmunity by acting on dendritic cells}

Multiple endogenous and dietary ligands are known to activate AhR signaling in different immune compartments. An abundant source of indole - based AhR agonists can be found among members of the Brassica genus consumed in the diet; including broccoli, cauliflower, Brussel sprouts and cabbages. Indol-3-carbinol (I3C) is one dietary indole derivative product which is transformed by non-enzymatic acid condensation into AhR agonists. The microbiota in the gut has the ability to convert such precursors (I3C) into immune regulatory metabolites, controlling T cell dependent inflammation; for example in the EAE model ${ }^{275,276}$.

In order to test the effect of AhR ligands consumed in the diet in the context of autoimmunity and using a spontaneous EAE model, OSE mice were submitted to a chemically

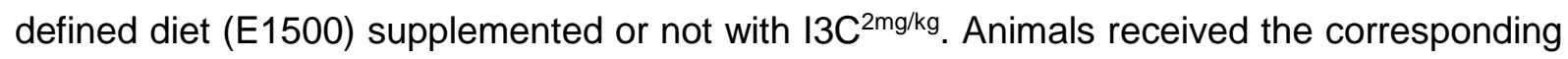
diet from birth and the EAE incidence was recorded during the first hundred days of life.

Control mice received the same diet without the $13 \mathrm{C}$ enrichment. The mothers received matching diets to their pups from the day they gave birth. The pups remained their whole life with the same diet and the mothers were changed back to regular chow after weaning.

\subsubsection{Diet supplementation with an AhR ligand suffices to modify the EAE incidence in OSE mice}

Adding one AhR ligand precursor to the chemically defined diet composition, the EAE incidence significantly dropped during the first three months of age, when most of the OSE mice spontaneously develop the first symptoms. $35.7 \%$ (15/42) of the OSE mice fed with the chemically defined diet spontaneously developed EAE, whereas only $3.1 \%(1 / 32)$ of the mice receiving the $\mathrm{I} 3 \mathrm{C}$ enriched diet presented clinical signs (figure $5 \mathrm{~A}$ ). 
The OSE mice fed from birth with the supplemented diet count with all necessary elements to mount an effective immune response and are fully susceptible to EAE induction. $\mathrm{MOG}_{35-55}$ immunized OSE mice under the $\mathrm{I}^{3 \mathrm{C}}$ enriched diet were fully capable of developing EAE within the two following weeks postimmunization (figure 5B).

A

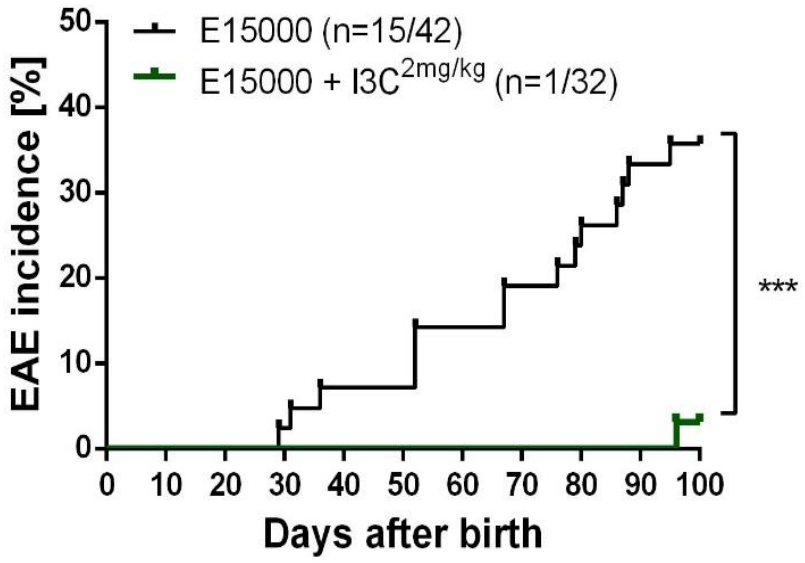

$B$

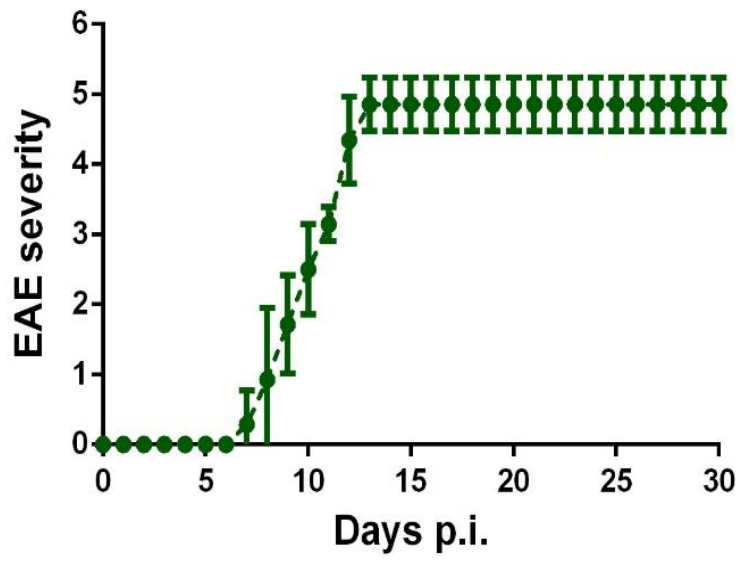

Figure 5. Indol-3-carbinol enriched diet abrogates spontaneous EAE development in OSE mice. (A) EAE incidence curves using the Kaplan-Meier estimator. OSE mice were fed with the chemically

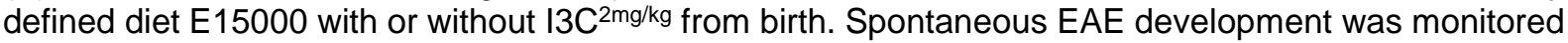
for 100 days. Comparison of EAE incidence curves by log-rank (Mantel-Cox) test. ${ }^{* * *} p=0.0007$. (B) OSE mice fed with the I3C enriched diet are fully susceptible to develop EAE if immunized. OSE mice $(n=7)$, which remained healthy for 100 days and were fed with $13 \mathrm{C}$ were immunized with $\mathrm{MOG}_{35-55}$ and the EAE course was monitored for 30 days p.i.

Since the addition of AhR ligands to the diet seemed to suppress EAE development, this work aimed to study which cell types expressing AhR exerted immunoregulatory actions and promoted disease suppression in the EAE model.

\subsubsection{AhR deficiency in CD4+ T cells and astrocytes does not influence spontaneous EAE in the OSE mouse model}

Among immune cells, the AhR is highly expressed in $\mathrm{CD}^{+} \mathrm{T}$ (helper) cells and dendritic cells $(D C)^{123,128}$. In the CNS, it is strongly expressed in astrocytes ${ }^{126}$. The aforementioned three cell populations contribute to the neuroinflammatory disease process in CNS autoimmune diseases at multiple levels ${ }^{92,277}$. Furthermore, $\mathrm{DC}$ and $\mathrm{CD} 4^{+} \mathrm{T}$ cells are important regulators of immune surveillance and host - microbe homeostasis in the intestines via AhR signaling pathway ${ }^{137,139}$ 
In order to study AhR repercussions in a cell specific manner and taking advantage of the Cre-Lox system, AhR was deleted in CD4+ ${ }^{+}$cells (OSE $A h R^{\Delta C D 4}$ ), DC (OSE $A h R^{\Delta D C}$ ) or astrocytes (OSE $\left.A h R^{\triangle A s t r o}\right)$ of OSE mice and monitored every other day for EAE symptoms for 100 days. AhR competent controls (OSE $\left.A h R^{f \mid / f l}\right)$ did not differ from their OSE $\operatorname{AhR}^{\triangle A s t r o}$ and OSE $A h R^{\Delta C D 4}$ littermates in EAE onset (figure $6 A$ and $D$ ), EAE severity course (6B and $E$ ) and maximum disease scores $(6 \mathrm{C}$ and $\mathrm{F})$ respectively.
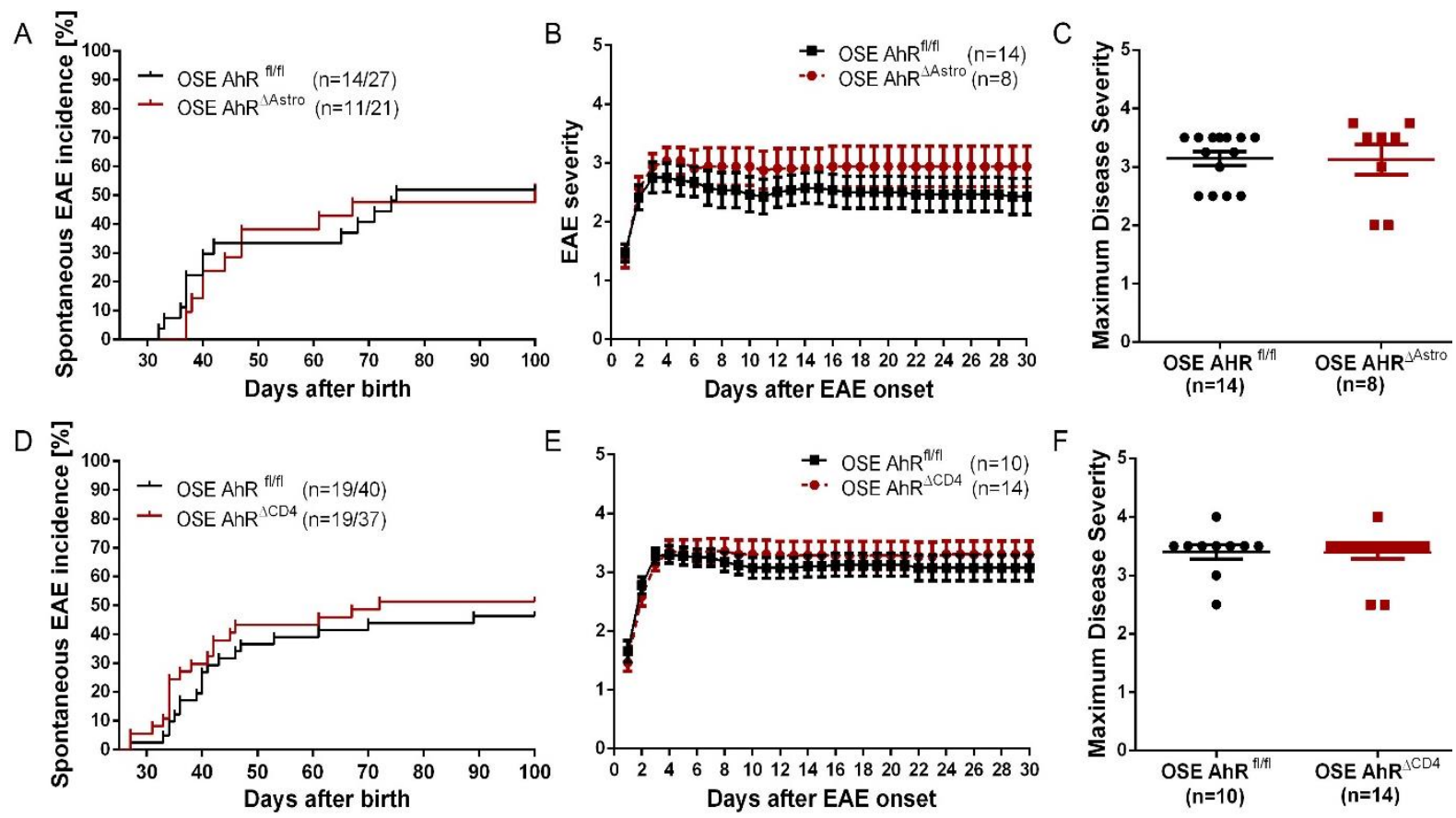

Figure 6. AhR deficiency in $\mathrm{CD}^{+}{ }^{+} \mathrm{T}$ cells and astrocytes does not influence spontaneous CNS autoimmunity in OSE mice. Kaplan-Meier curves are shown to depict spontaneous EAE incidence and were compared using log-rank (Mantel-Cox) test. EAE severity was monitored for 30 days from the day of EAE onset. Severity curves were analyzed using multiple $t$ tests. Scatter dot plots represent the maximum disease severity, shown as mean \pm SEM and compared using unpaired t test. No difference was found in the EAE incidence, severity and maximum disease severity between OSE $\operatorname{AhR}^{\triangle G F A P}(A, B$ and $C$ ) and OSE $A h R^{\triangle C D 4}\left(D, F\right.$ and $G$ ) with respect of OSE $A h R^{f / f / 1}$ control animals. The number of mice is indicated for each graph.

\subsubsection{AhR deficiency in DC significantly increases the incidence of spontaneous EAE}

Given the fact that AhR expression in DC plays a central role in their differentiation and function and that DC are the most potent activators of naïve T cells; AhR specific ablation in DC was fundamental to evaluate AhR function in a T cell mediated model such as EAE. AhR deletion in DC doubled the incidence of spontaneous EAE in OSE mice compared to AhR competent littermates (figure $7 A,{ }^{\star * \star *} p<0.0001$ ). 

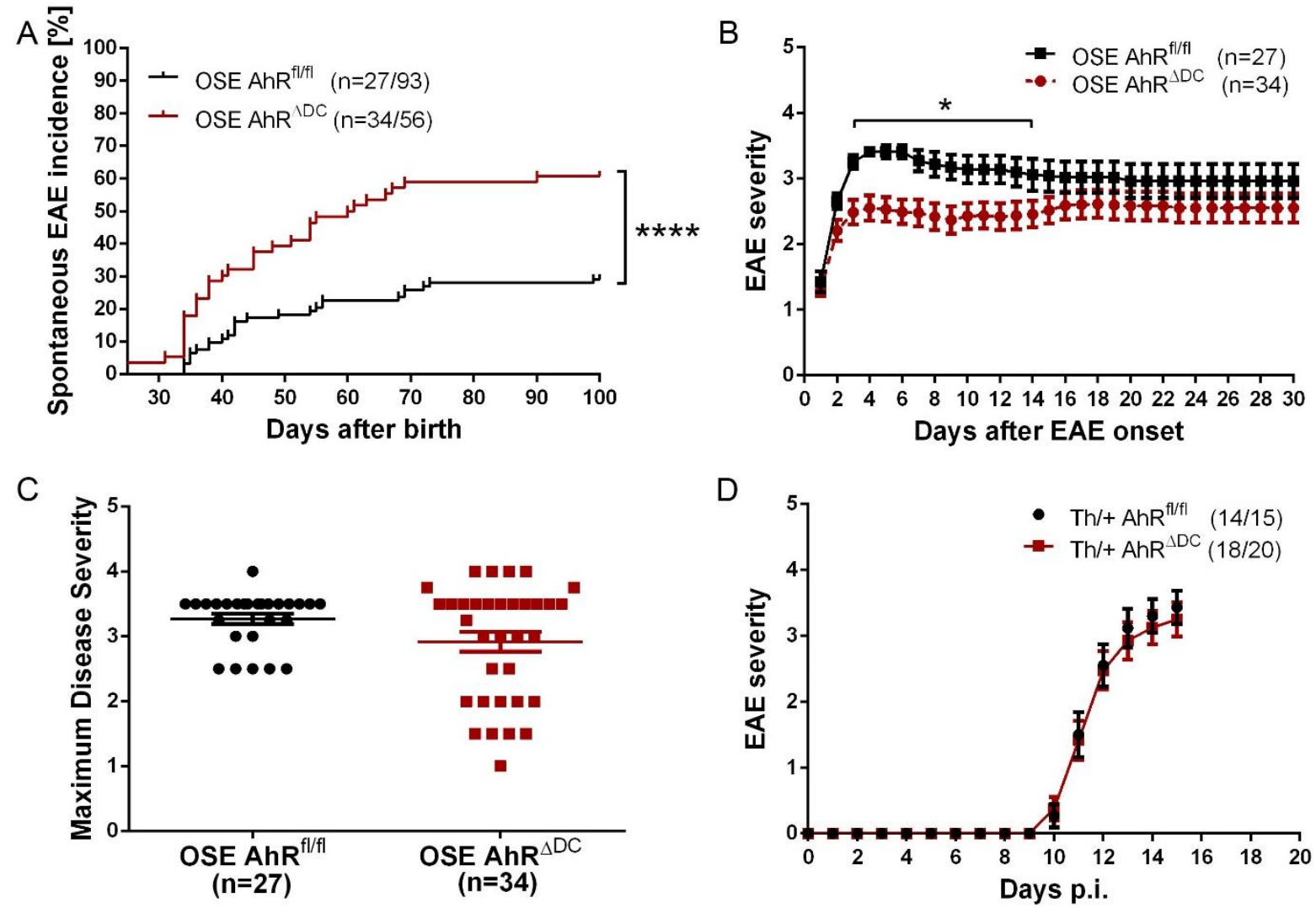

Figure 7. AhR deficiency in DC increases the incidence of spontaneous EAE in OSE mice. (A) Spontaneous EAE incidence curves were compared by log-rank (Mantel-Cox) test. ${ }^{* * *} p<0.001$. (B) EAE disease severity was monitored for 30 days from the day of EAE onset. Severity curves were analyzed using multiple t tests. ${ }^{*} p<0.05$. (C) The number of mildly affected cases increased in OSE AhR ${ }^{\triangle D C}$ mice

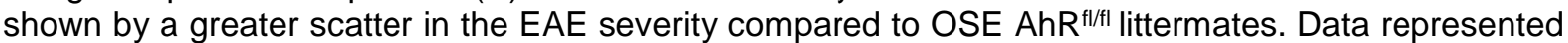
as mean \pm SEM and analyzed by unpaired $t$ test. (D) The EAE severity of $T h /+A h R^{\triangle D C}$ is not influenced if the mice are actively immunized using $M O_{1-125}$. The severity curves were analyzed using multiple $t$ tests and showed no significant difference. The number of mice varies and is indicated in each graph.

Compared to OSE $A h R^{f / / f l}$ control mice, the OSE $A h R^{\Delta D C}$ strain was less severely affected during the first fourteen days after EAE onset $\left({ }^{*} \mathrm{p}<0.05\right)$ and was equally sick at later time points (figure 7B). The scattered distribution of the maximum disease severity of OSE $A h R^{\Delta D C}$ mice revealed that this group contains more diseased mice that are mildly affected. In comparison, most OSE $\mathrm{AhR}^{\mathrm{fl} / \mathrm{fl}}$ mice presented high scores and a lower dispersion of the maximum EAE severity values (figure $7 \mathrm{C}$ ).

Besides using a spontaneous EAE model, DC specific AhR deletion was also evaluated in Th/+ mice immunized with $\mathrm{MOG}_{1-125}$ emulgated in CFA. AhR deficiency in DC did not alter the $\mathrm{EAE}$ incidence or severity in the presence of strong immunostimulants such as CFA (figure 7D, $p>0.05$ using multiple t tests). 


\subsection{AhR deficiency in DC alters the phenotype of APCs in the lamina propria of}

\section{OSE mice}

In order to explain the higher incidence of OSE $A R^{\Delta D C}$ compared to OSE $A h R^{1 / f / 1}$ mice the $D C$ and macrophage compartments were analyzed in the LP of OSE mice, where T cell activation might take place in the OSE animal model ${ }^{278}$.

To discriminate better between DC and macrophages, OSE $A h R^{\Delta D C}$ and OSE $A h R^{f / 1 / 1}$ were crossed to CX3CR1 ${ }^{\text {EGFP }}$ reporter mice. Leukocytes from the small intestine were then isolated from OSE AhR ${ }^{\triangle D C} \mathrm{CX} 3 \mathrm{CR}^{\mathrm{EGFP} /+}$ and OSE $A h R^{1 / 1 / 1} \mathrm{CX} 3 \mathrm{CR} 1^{\mathrm{EGFP} /+}$ animals as described in section 2.4.7 and analyzed ex vivo by flow cytometry as explained in 2.4.8.

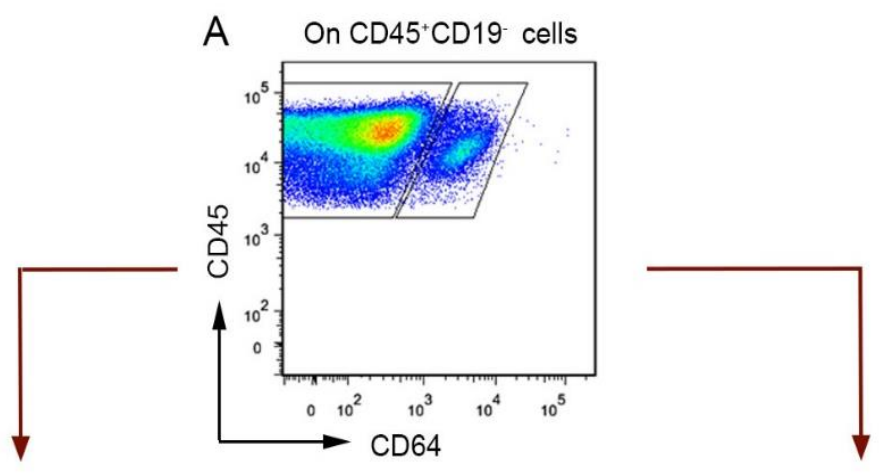

B

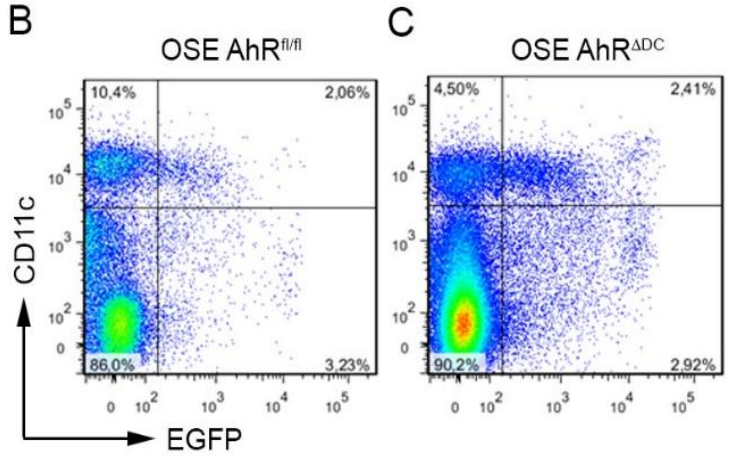

D OSEAhR ${ }^{\text {nIt/ }}$ E

E OSE AhR'DOC
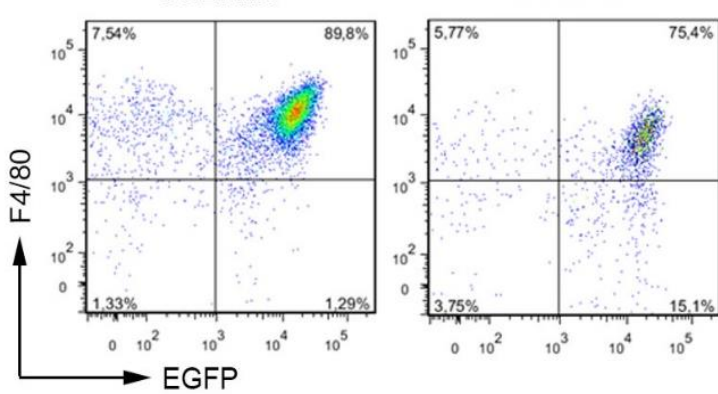

Figure 8. Gating strategy to assess intestinal APCs. (A) Representative flow cytometry analysis of $\mathrm{CD}_{4} 5^{+}$intestinal leukocytes divided into the $(B, C) \mathrm{DC}$ and $(\mathrm{D}, \mathrm{E})$ macrophage compartments. Leukocytes were isolated from the small intestines of OSE $A h R^{\Delta D C} C X_{3} C R 1^{E G F P /+}$ and OSE $A h R^{f / / 11}$ $\mathrm{CX}_{3} \mathrm{CR} 1 \mathrm{EGFP} /+$ mice. EGFP expression was measured ex vivo in intestinal LP CD11 ${ }^{+} \mathrm{CD} 64-\mathrm{DC}$ and CD11 $\mathrm{C}^{-} \mathrm{CD} 64^{+} \mathrm{F} 4 / 80^{+}$macrophages by flow cytometry. 
OSE AHR ${ }^{\triangle D C}$ CX3CR1 $1^{E G F P /+}$ animals showed a significantly higher percentage of CD45+ CD11 ${ }^{+}$CD64- DC intermediately expressing CX3CR1 $\left(\% C X 3 C R 1^{\text {int }}\right.$ DC $\left.=29.4 \% \pm 2.8\right)$ compared to OSE $\mathrm{AHR}^{\mathrm{f} / \mathrm{fl} \mathrm{l}} \mathrm{CX} 3 \mathrm{CR} 1^{\mathrm{EGFP} /+}$ mice $(18.5 \% \pm 1.6)$ as shown in figure $9 \mathrm{~A}$ and $\mathrm{B}$ $\left({ }^{*} \mathrm{p}=0.03\right)$.

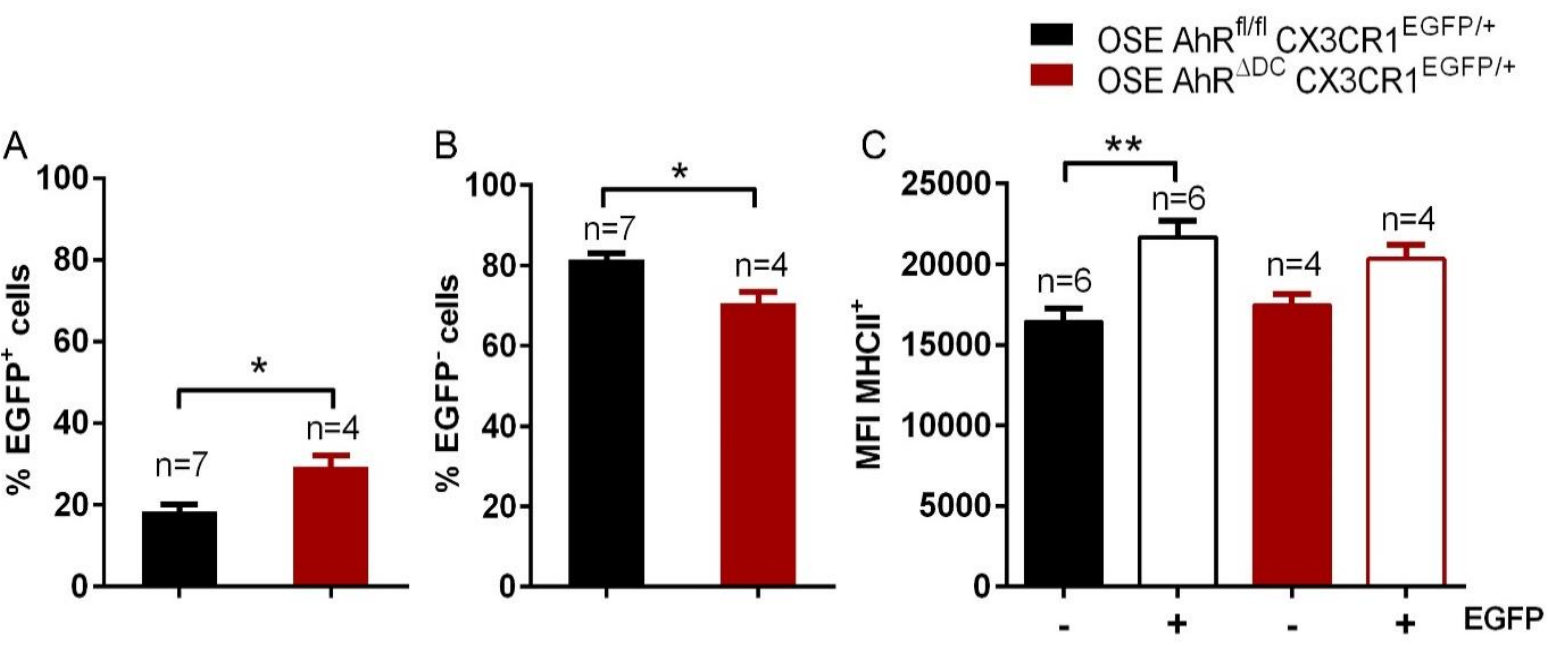

Figure 9. The percentage of $C X_{3} C R 1^{\text {int }} D C$ increases in OSE $A h R^{\triangle D C} C X_{3} C R 1^{E G F P /+}$ mice compared to OSE AhR ${ }^{\text {fl/fi }} \mathbf{C X}_{3} \mathrm{CR}^{\mathrm{EGFP} /+}$ transgenic animals. (A, B) Quantification of EGFP+ and (A) EGFP- DC cell frequencies. (C) MHCll expression (MFI) on EGFP+ or EGFP- DC in OSE AhR ${ }^{\triangle \mathrm{DC} C} \mathrm{CX}_{3} \mathrm{CR} 1^{\mathrm{EGFP} /+}$ and OSE $\mathrm{AhR}^{\mathrm{tl} / \mathrm{fl}} \mathrm{CX}_{3} \mathrm{CR} 1_{\mathrm{EGFP} /+}$ transgenic animals. Data are presented as mean $\pm \mathrm{SEM}$. Data are pooled from at least four independent experiments. ${ }^{*} p<0.05,{ }^{* *} p<0.01$, Mann-Whitney U-test.

MHCII expression was analyzed in CX3CR $1^{\text {int }}$ and CX3CR1 $1^{-}$CD45 $5^{+}$CD11 ${ }^{+}$CD64- DC of both OSE AhR ${ }^{\triangle \mathrm{DC}} \mathrm{CX} 3 \mathrm{CR} 1^{\mathrm{EGFP} /+}$ and OSE $\mathrm{AHR}^{\mathrm{fl} / \mathrm{fl}} \mathrm{CX} 3 \mathrm{CR} 1^{\mathrm{EGFP} /+}$ mice by flow cytometry analysis. Higher MHCII MFI was observed on CX3CR1+ DC compared to CX3CR1- DC (figure $9 \mathrm{C} ;{ }^{* *} \mathrm{p}=0.0025$ in OSE $A H R^{\mathrm{fl/fl}} \mathrm{CX} 3 \mathrm{CR} 1^{\mathrm{EGFP} /+}$ mice), suggesting that $\mathrm{CX} 3 \mathrm{CR} 1^{+} \mathrm{DC}$ might be better APCs for CD4+ $\mathrm{T}$ cells compared to CX3CR1- DC.

Furthermore, the presence of LP CX3CR1 ${ }^{+}$and CX3CR1- DC was detected in paraffin embedded sections of the small intestines of CD11 $\mathrm{c}^{\text {tdTomato }} \mathrm{CX} 3 \mathrm{CR} 1^{\text {eGFP }}$ reporter mice (figure 10). Some DC, which might extend transepithelial dendrites into the lumen of the small intestine were detected by immunohistochemistry (figure 11). 

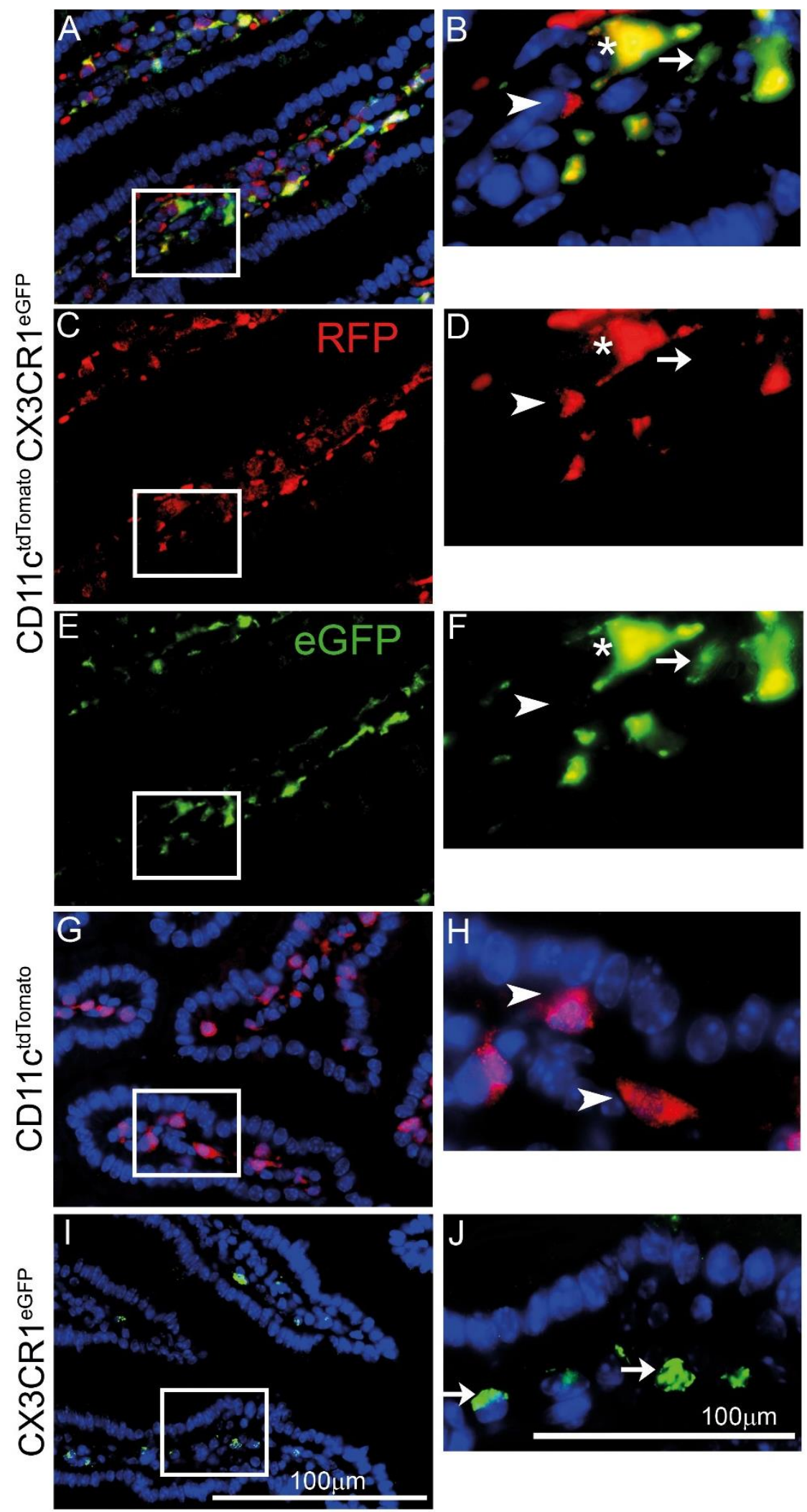

Figure 10. Visualization of intestinal APCs using the CD11 $c^{\text {tdTomato }} \mathrm{CX} 3 \mathrm{CR} 1^{\mathrm{eGFP}}$ transgenic mice. Mice carrying an eGFP reporter gene under the control of the CX3CR1 promoter and a Cre dependent R26tdTomato gene that labels $\mathrm{CD} 11 \mathrm{c}^{+}$cells upon Cre recombinase activation. Asterisks indicate $\mathrm{CD} 11 \mathrm{C}^{+} \mathrm{CX} \mathrm{X}_{3} \mathrm{CR} 1^{+}$double positive cells, $\mathrm{CD} 11 \mathrm{C}^{+}$cells are marked with arrow heads and $\mathrm{CX}_{3} \mathrm{CR} 1^{+}$cells with arrows. (A, B) overlay, $(C, D)$ tdTomato $C D 11 c^{+}$cells, red. (E, F) eGFP CX3CR $11^{+}$cells, green. $(G$, H) CD11 $\mathrm{c}^{\text {tdTomato }}$ and $(\mathrm{I}, \mathrm{J}) \mathrm{CX}_{3} \mathrm{CR} 1^{\mathrm{eGFP}}$ single transgenic mice are shown as controls. A, C, E, G and I were acquired using $400 \mathrm{x}$ magnification. $\mathrm{B}, \mathrm{D}, \mathrm{F}$ and $\mathrm{H}$ are the corresponding insets at $1000 \mathrm{x}$ magnification. 

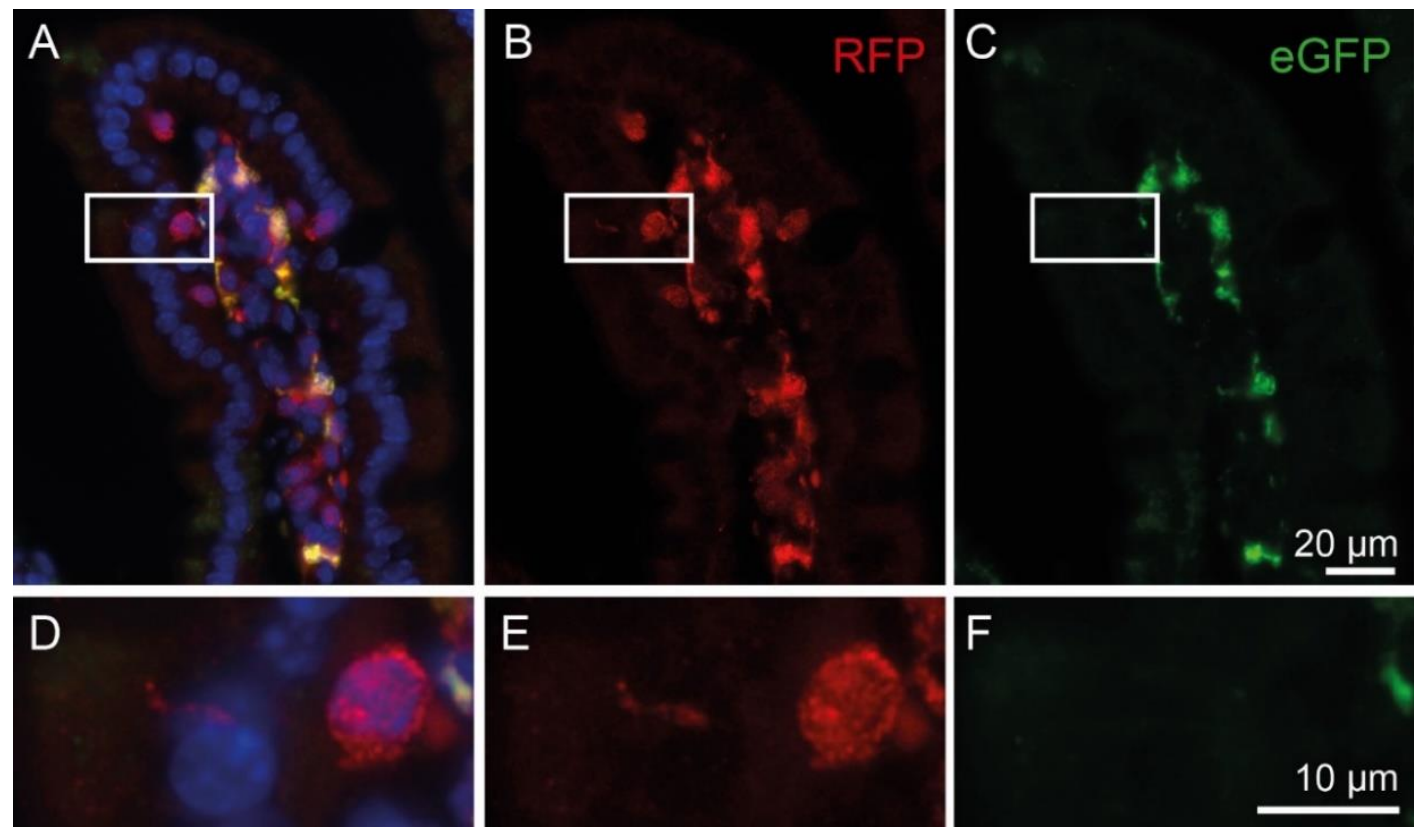

Figure 11. DC might sample luminal antigens by small transepithelial dendrites. Intestinal sections of CD11 $\mathrm{c}_{\text {tdTomato }} \mathrm{CX} 3 \mathrm{CR} 1 \mathrm{eGFP}^{\mathrm{G}}$ reporter mice. $(\mathrm{A}, \mathrm{D})$ overlay, $(\mathrm{B}, \mathrm{E})$ tdTomato $\mathrm{CD} 11 \mathrm{C}^{+}$cells, red. $(\mathrm{C}, \mathrm{F})$ eGFP CX3CR $1+$ cells, green. $A, B$ and $C$ were acquired using $400 x$ magnification. $D, E$ and $F$ are the corresponding insets at $1000 x$ magnification.

As shown in figure $8 \mathrm{D}$ and $\mathrm{E}$ and quantified in figure $12 \mathrm{~A}$ fewer cells in the lamina propria of OSE $A h R^{\triangle D C} C X 3 C R 1^{E G F P /+}$ mice compared to OSE $A H R^{f / / f l}$ control littermates were bona fide macrophages defined as $\mathrm{CD} 45^{+} \mathrm{CD} 64^{+} \mathrm{F} 4 / 80^{+} \mathrm{CX} 3 \mathrm{CR} 1^{\text {high }}$. Interestingly, also the macrophage population in OSE $A h R^{\triangle D C} C X 3 C R 1^{E G F P /+}$ compared to the macrophage population in OSE $\mathrm{AHR}^{\mathrm{fl} / \mathrm{fl}}$ mice harbored a more activated phenotype as suggested by downregulation of $\mathrm{F} 4 / 80$ (figure $8 \mathrm{D}$ and $\mathrm{E}$ ) and upregulation of $\mathrm{MHCll}$ (figure 12B, MFI=20333 \pm 865 in OSE $\mathrm{AHR}^{\triangle \mathrm{DC}} \mathrm{CX} 3 \mathrm{CR} 1^{\mathrm{EGFP} /+}$ mice compared to $\mathrm{MFI}=17467 \pm 706$ in control mice).
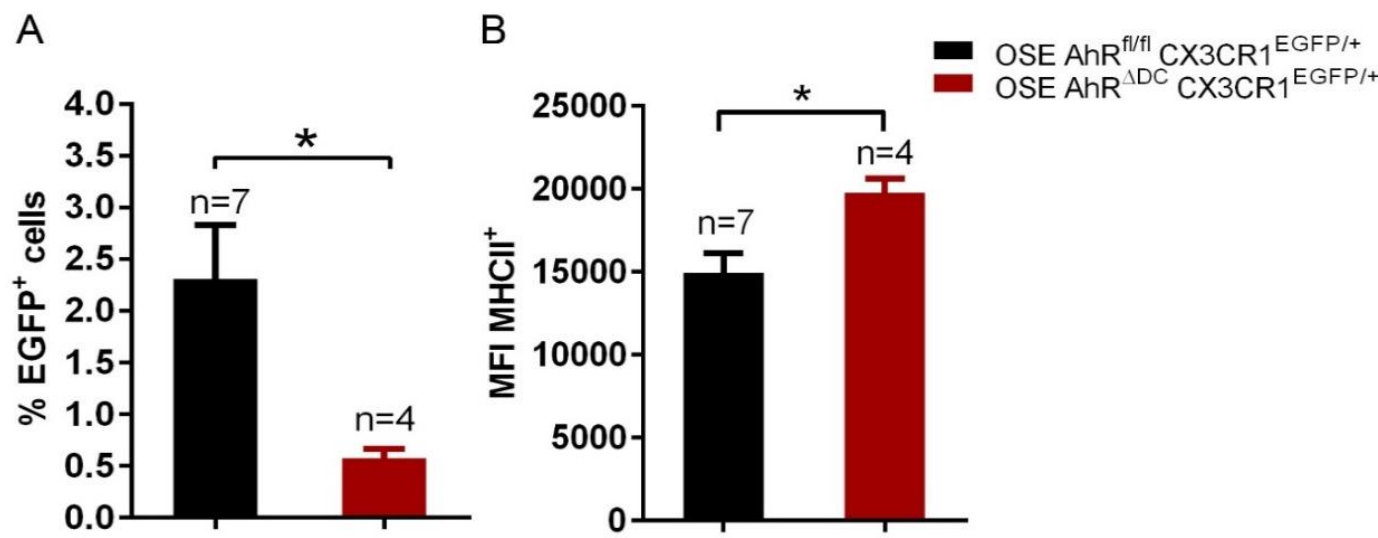

Figure 12. OSE $A h R^{\triangle D C} C X 3 C R 1^{E G F P /+}$ mice showed reduced numbers of intestinal $L P$ macrophages compared to OSE AhR $^{\mathrm{fl} / \mathrm{fl}} \mathrm{CX3CR}^{\mathrm{EGFP} /+}$ control animals. (A) Percentage of CD64 ${ }^{+}$ $\mathrm{F} 4 / 80^{+} \mathrm{CX} 3 \mathrm{CR} 1$ high macrophages among CD45+ leukocytes in the LP of OSE AhR ${ }^{\triangle \mathrm{DC}} \mathrm{CX} 3 \mathrm{CR} 1 \mathrm{EGFP} /+$ compared to OSE AhR ${ }^{\mathrm{fl} / \mathrm{fl}} \mathrm{CX} 3 \mathrm{CR} 1 \mathrm{EGFP/+}$ mice (B) MHCll MFI of CD64+ $\mathrm{F} 4 / 80^{+} \mathrm{CX} 3 \mathrm{CR} 1$ high $\mathrm{LP}$ macrophages. Data are shown as mean \pm SEM. ${ }^{*} p<0.1$, Mann-Whitney U-test. 
To improve the tools to dissect the difference between AhR competent and AhR deficient DC, $A h R^{\mathrm{fl} /+} \mathrm{CD} 11 \mathrm{c}^{\mathrm{Cre}+} \mathrm{R} 26 \mathrm{R}^{\mathrm{eYFP}}$ and $A h \mathrm{R}^{\mathrm{fl} /-} \mathrm{CD} 11 \mathrm{c}^{\mathrm{Cre}+} \mathrm{R} 26 \mathrm{R}^{\mathrm{eYFP}}$ mice were generated. The former mice have YFP tagged AhR competent DC and the latter YFP tagged AhR deficient DC.

High frequencies of $\mathrm{YFP}^{+}$cells were observed among the DC purified from the spleens of both transgenic strains using MACS separation (figure 13B and C). An upregulation of the AhR reporter gene, CYP1A1, was observed in $\mathrm{YFP}^{+} \mathrm{AhR}$ competent $\mathrm{DC}$ in response to the potent AhR agonist, FICZ, while no changes were observed in $\mathrm{YFP}^{+} \mathrm{AhR}$ deficient DC.

Thus, these preliminary experiments suggest that the $A h R^{\mathrm{fl} /+} \mathrm{CD} 11 c^{\mathrm{Cre}+} \mathrm{R}^{26 \mathrm{R}^{\mathrm{eYFP}}}$ and $A h R^{\mathrm{fl} / /} \mathrm{CD} 11 \mathrm{c}^{\mathrm{Cre}+} \mathrm{R} 26 \mathrm{R}^{\mathrm{eYFP}}$ mice might be valuable tools to purify AhR competent and AhR deficient DC ex vivo for functional studies.
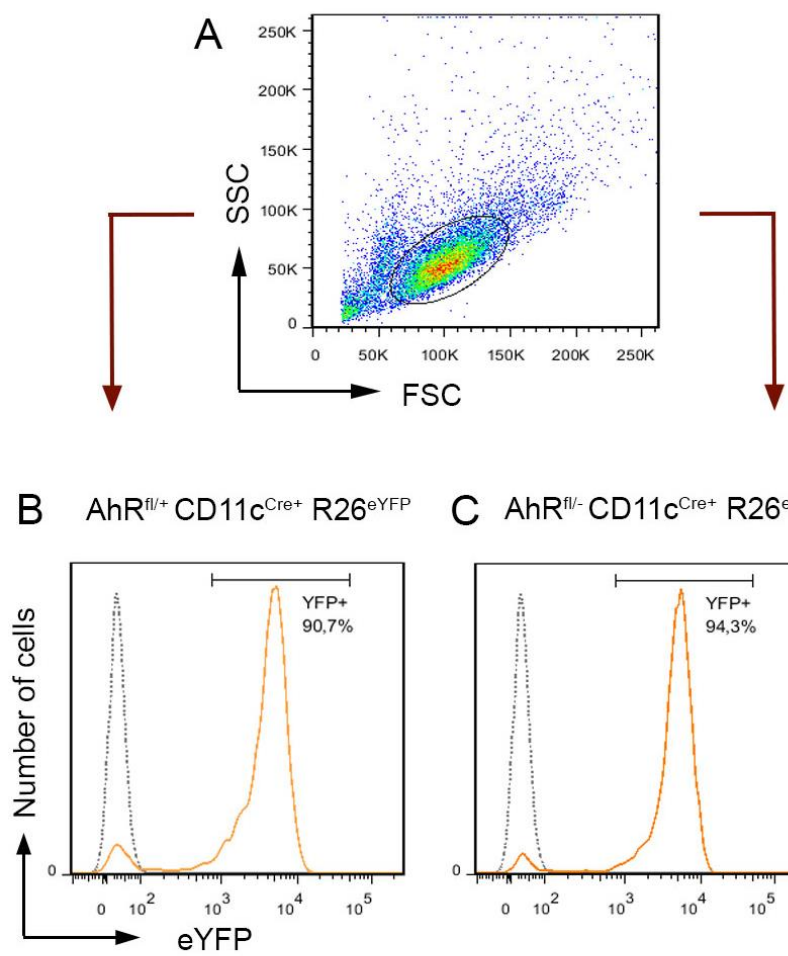

C $\mathrm{AhR}^{\mathrm{fl} /-} \mathrm{CD} 11 \mathrm{c}^{\mathrm{Cre}+} \mathrm{R} 26^{\mathrm{eYFP}}$
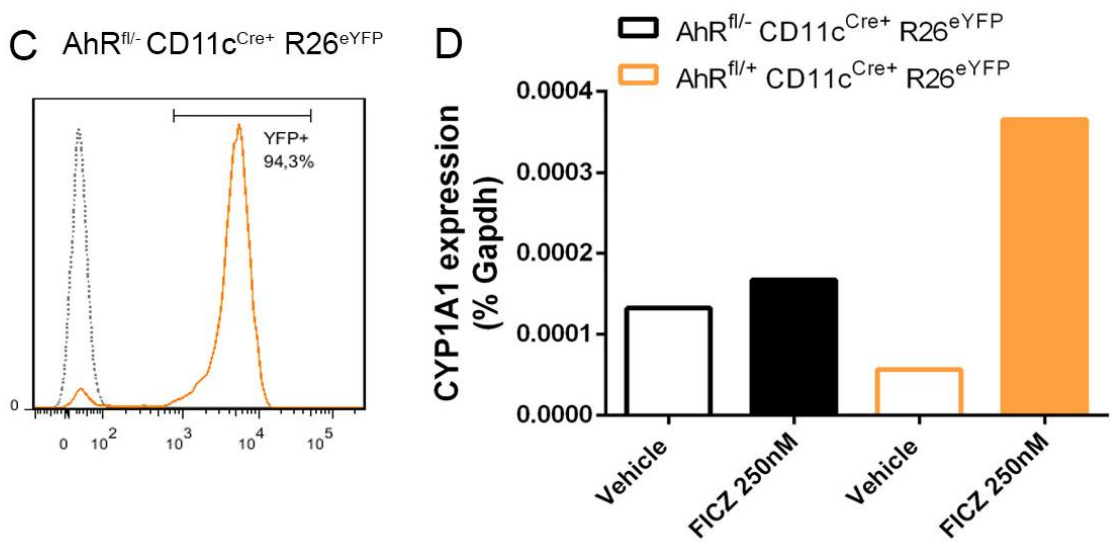

Figure 13. Quantification of CYP1A1 expression in YFP+ AhR competent and AhR deficient DC. (A) Representative FACS dot plot of the forward and side scatter of the splenic cells obtained from the transgenic lines. (B) YFP expression of DC purified from $A h R^{\mathrm{fl} / \mathrm{+}} \mathrm{CD} 11 \mathrm{c}^{\mathrm{Cre}}+\mathrm{R} 26 \mathrm{R}^{\mathrm{eYFP}}$ and $(\mathrm{C}) \mathrm{AhR} \mathrm{R}^{\mathrm{fl} /-}$ CD11 $c^{\mathrm{Cre}+} \mathrm{R} 26 \mathrm{R}^{\mathrm{eYFP}}$ mice was analyzed by flow cytometry. (D) Expression of CYP1A1 was quantified by qPCR after FICZ stimulation. 


\subsubsection{OSE AhR ${ }^{\triangle D C}$ mice present increased numbers of IFNy ${ }^{+}$transgenic $\mathrm{T}$ cells in the lamina propria of the small intestine}

In order to test if the higher percentage of $\mathrm{CX} 3 \mathrm{CR} 1^{\text {int }} \mathrm{DC}$ in OSE $A h \mathrm{R}^{\triangle \mathrm{DC}} \mathrm{CX} 3 \mathrm{CR} 1^{\mathrm{EGFP} /+}$ compared to OSE $A h R^{\mathrm{fl} / f l} \mathrm{CX} 3 \mathrm{CR} 1^{\mathrm{EGFP} /+}$ mice translates into higher frequencies of cytokine producing $\mathrm{CD}^{+} \mathrm{T}$ cells, intestinal leukocytes were isolated from the lamina propria and stimulated with PMA and ionomycin (figure 14B and D). Unstimulated cells were used as controls (14A and C).

\section{On $\mathrm{CD} 45^{+} \mathrm{CD} 19-\mathrm{CD} 3^{+} \mathrm{CD} 4^{+} \mathrm{V} \alpha 3.2^{+}$cells}
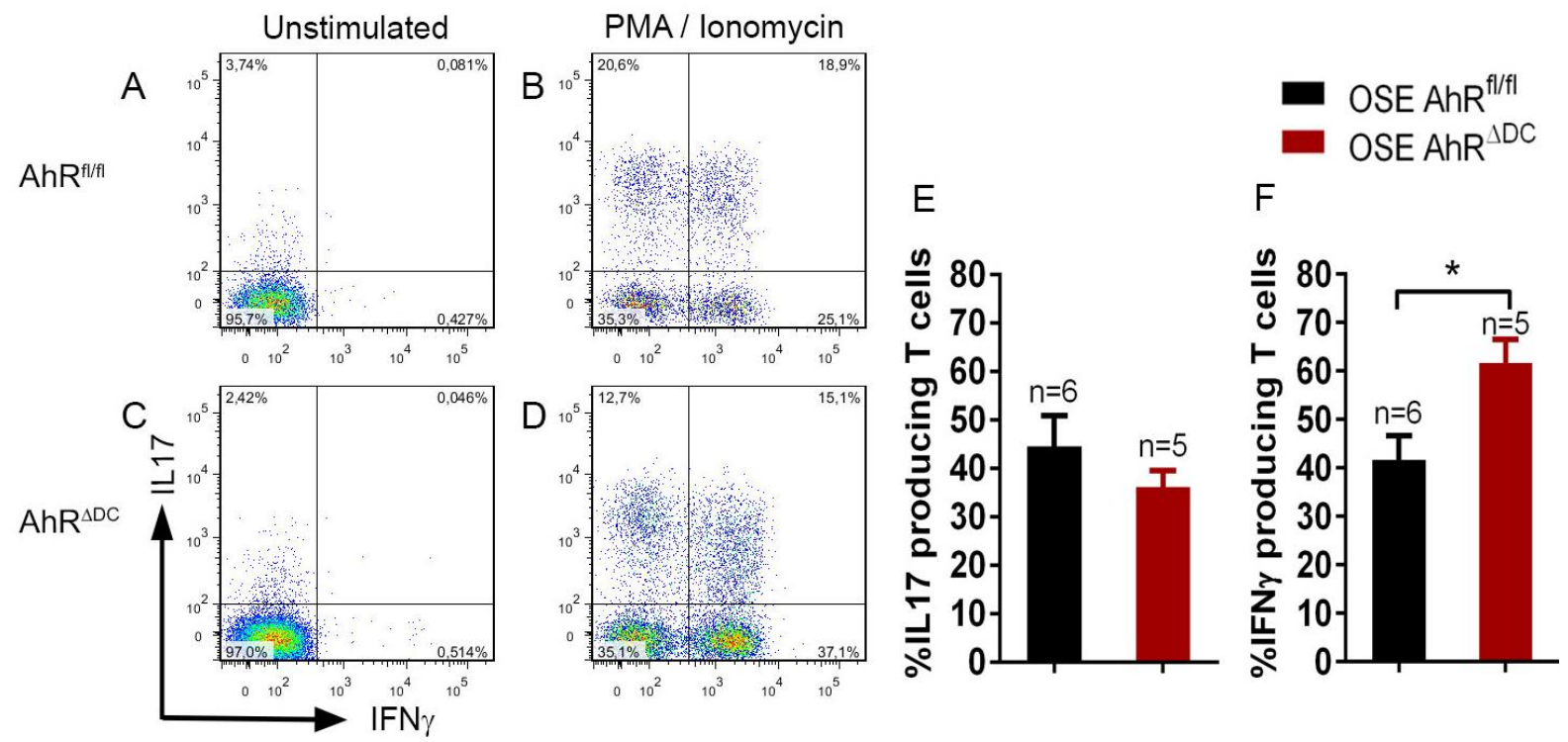

Figure 14. OSE $A h R^{\triangle D C}$ mice have significantly higher frequencies of IFN $\gamma$ producing MOG specific $T$ cells in the lamina propria of the small intestines. (A, B) Representative flow cytometry analysis of intestinal Va3.2 CD4+ $\mathrm{T}$ cells obtained from the small intestines of OSE AhR ${ }^{\mathrm{fl} / \mathrm{ll}}$ control mice and (C, D) OSE AhR ${ }^{\triangle D C}$ littermates. (E) The production of IL17 and (F) IFNY was quantified ex vivo by flow cytometry after stimulation with PMA and ionomycin. Data are presented as percentage of the total number of transgenic CD4+ $T$ cells and shown as mean \pm SEM. ${ }^{*} p=0.038$, Mann-Whitney U-test.

Cytokine secretion was blocked with Golgi Stop and intracellular detection of IL17 and IFNy was performed by flow cytometry in Va3.2 ${ }^{+} \mathrm{MOG}$ specific TCR transgenic CD4+ ${ }^{+} \mathrm{T}$ cells (described in section 2.4.8.3). A significantly higher frequency of IFNy (figure 14B, D and F) but not IL17 (figure 14B, D and E) producing transgenic CD4 ${ }^{+} \mathrm{T}$ cells were detected in response to stimulation with PMA and lonomycin in OSE $A h R^{\Delta D C}$ animals compared to OSE $A H R^{f / f l}$ control littermates. 


\subsubsection{OSE AhR ${ }^{\triangle D C}$ mice have significantly higher MOG specific IgG2a antibody titers}

IFNy is known to promote isotype switching to $\lg G 2 a$ production ${ }^{279}$. Thus, anti-MOG $\lg G 1$ and $\operatorname{lgG} 2 a$ antibody titers were quantified in the sera of OSE $A h R^{\Delta D C}$ and OSE $A H R^{f / / f l}$ mice by ELISA performing 5-fold serial dilutions starting at 1:500 as described in section 2.4.13. Significantly higher MOG specific $\lg G 2 a$ (figure 15B) but not $\lg G 1$ antibody titers (15A) were found in OSE AhR ${ }^{\Delta D C}$ compared to OSE $A H R^{f / / f l}$ mice at 1:500 $\left({ }^{* *} \mathrm{p}=0.008\right)$ and 1:2500 dilutions $\left({ }^{*} \mathrm{p}=0.012\right)$.

A

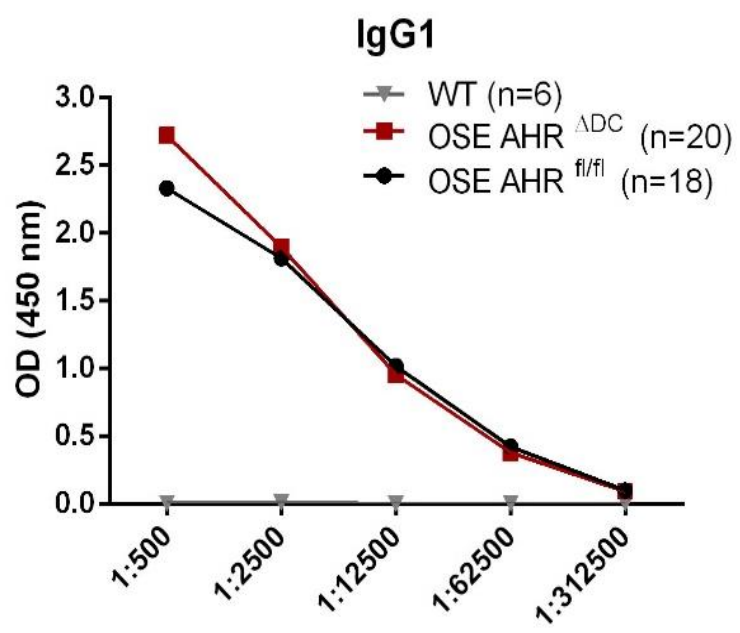

Dilution
B

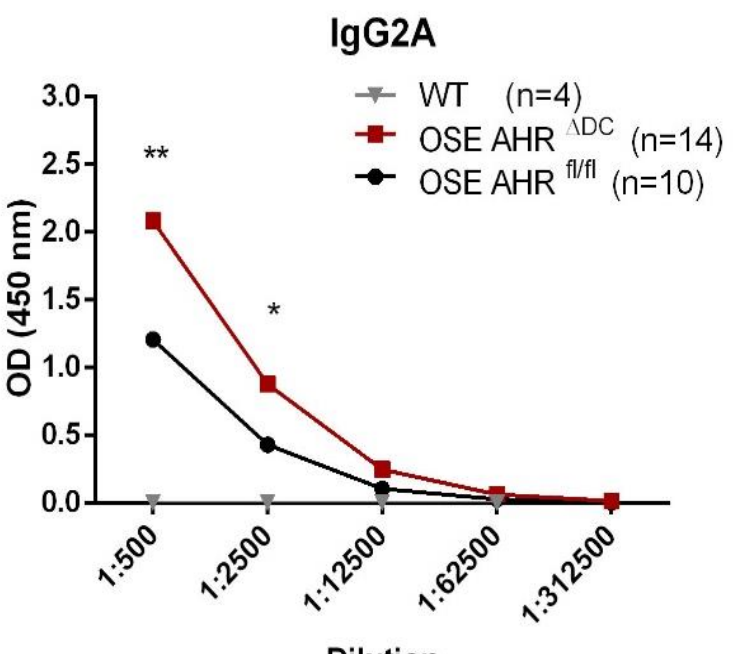

Dilution

Figure 15. Quantification of MOG specific antibody titers in the sera of OSE $A h R^{\triangle D C}$ and OSE AHR $^{\mathrm{fl} / \mathrm{fl}}$ mice by ELISA. (A) $\lg \mathrm{G} 1$ and (B) $\lg \mathrm{g} 2 \mathrm{~A}$ anti-MOG antibody concentrations were measured in the serum of sick OSE $A H R^{\Delta D C}$ and OSE $A h R^{f / / f l}$ mice by indirect ELISA. Serum obtained from healthy WT animals was used as a negative control. Nonspecific binding to BSA was subtracted from all values to calculate the mean absorbance $(\mathrm{OD} 450 \mathrm{~nm})$ and compared by multiple $t$ tests. ${ }^{*} p<0.05,{ }^{* \star} p<0.01$.

\subsection{AhR competent DC are relevant for Laquinimod to suppress EAE}

Laquinimod, a quinoline-3-carboxamide derivative, is an oral DMT with moderate efficacy against RRMS ${ }^{280}$. Previous EAE experiments have suggested that the immunomodulatory properties of Laquinimod might be attributed to its ability of promoting the shift of proinflammatory immune cells towards less immunogenic and more regulatory phenotypes.

Daily oral treatment with Laquinimod from the day of immunization ameliorates or completely abolishes acute EAE development in C57BL/6 mice ${ }^{183}$. In particular, Laquinimod 
treatment decreases the immunogenicity of $\mathrm{DC}$, reduces the frequency of proinflammatory IFNy and IL17 producing $\mathrm{T}$ cells and increases the percentage of $\mathrm{T}_{\text {regs }}{ }^{182}$. In addition, the modulation of nonimmune cells such as astrocytes ${ }^{189}$ and endothelial cells ${ }^{192}$ might be relevant for Laquinimod's therapeutic efficacy in EAE.

Recent results demonstrated that Laquinimod's ability to suppress EAE is greatly decreased in AhR KO mice ${ }^{193,194}$. Therefore, the therapeutic efficacy of Laquinimod was evaluated in cell specific AhR deficient mice immunized with $\mathrm{MOG}_{35-55}$.

\subsubsection{Laquinimod's therapeutic effect cannot be attributed to a single AhR competent}

\section{cell type}

EAE was actively induced by $\mathrm{MOG}_{35-55}$ immunization (as described in section 2.4.2) in $\mathrm{AhR}^{\Delta \mathrm{CD} 4}$, $A h R^{\Delta T r e g}, A h R^{\Delta A s t r o} A h R^{\Delta D C}$ and $A h R^{f / / f l}$ control mice treated with Laquinimod ( $25 \mathrm{mg} / \mathrm{kg}_{\text {body weight }}$ ) or vehicle from the day of immunization (section 2.4.4). EAE incidence, onset and maximum disease score were recorded for all transgenic lines in table 22. Animals were handled and scored as explained in 2.4 .3 (scoring scale described in table 20).

\begin{tabular}{|c|c|c|c|c|c|c|}
\hline & \multicolumn{3}{|c|}{ Vehicle } & \multicolumn{3}{|c|}{ Laquinimod } \\
\hline & Incidence & $\begin{array}{l}\text { Max. } \\
\text { Score }\end{array}$ & $\begin{array}{c}\text { Disease } \\
\text { Onset }\end{array}$ & Incidence & $\begin{array}{l}\text { Max. } \\
\text { Score }\end{array}$ & $\begin{array}{c}\text { Disease } \\
\text { Onset }\end{array}$ \\
\hline$A h R^{\mathrm{fl} / \mathrm{fl}}$ & $28 / 41$ & $2.92 \pm 0.84$ & $16.03 \pm 4.17$ & $3 / 44$ & $2.83 \pm 0.58$ & $23.00 \pm 1.73$ \\
\hline$A h R^{\Delta D C}$ & $9 / 10$ & $3.06 \pm 0.73$ & $17.00 \pm 4.18$ & $7 / 11$ & $2.42 \pm 0.53$ & $23.00 \pm 2.28$ \\
\hline$A h R^{\Delta A s t r o}$ & $20 / 20$ & $3.37 \pm 0.55$ & $15.45 \pm 3.16$ & $5 / 20$ & $3.25 \pm 0.50$ & $17,4 \pm 1.81$ \\
\hline $\mathrm{AhR}^{\Delta \text { Treg }}$ & $12 / 18$ & $3.37 \pm 0.70$ & $14.33 \pm 3.17$ & $1 / 16$ & 3 & 22 \\
\hline $\mathrm{AhR} \mathrm{R}^{\Delta \mathrm{CD} 4}$ & $7 / 12$ & $2 \pm 1$ & $17.28 \pm 5.61$ & $2 / 11$ & $2.75 \pm 0.35$ & $19 \pm 7.07$ \\
\hline
\end{tabular}

Table 22. EAE incidence, maximum disease score and EAE onset. Cell specific AhR deficient mice were immunized with $\mathrm{MOG}_{35-55}$ and treated with Laquinimod or vehicle. Incidence, maximum disease score of clinically affected mice and EAE onset were assessed for 30 days post immunization and presented as mean $\pm \mathrm{SD}$. AhR ${ }^{\mathrm{fl} / \mathrm{fl}}$ littermates were used as controls.

Vehicle treated $\mathrm{AhR}^{\mathrm{fl} / \mathrm{fl}}$ control mice developed EAE in $68 \%$ of the cases (28/41). The EAE incidence in vehicle treated $A h R^{\Delta C D 4}, A h R^{\Delta T r e g}, A h R^{\Delta D C}, A h R^{\triangle A s t r o}$ varied between $58 \%$ $\left(A h R^{\Delta C D 4}\right), 67 \%\left(A h R^{\Delta T r e g}\right), 90 \%\left(A h R^{\Delta D C}\right)$ or $100 \%\left(A h R^{\Delta A s t r o}\right)$ respectively and was significantly different between vehicle treated $A h R^{\Delta A s t r o}$ and $A h R^{f / / f l}$ controls (figure $18 B$ ). 

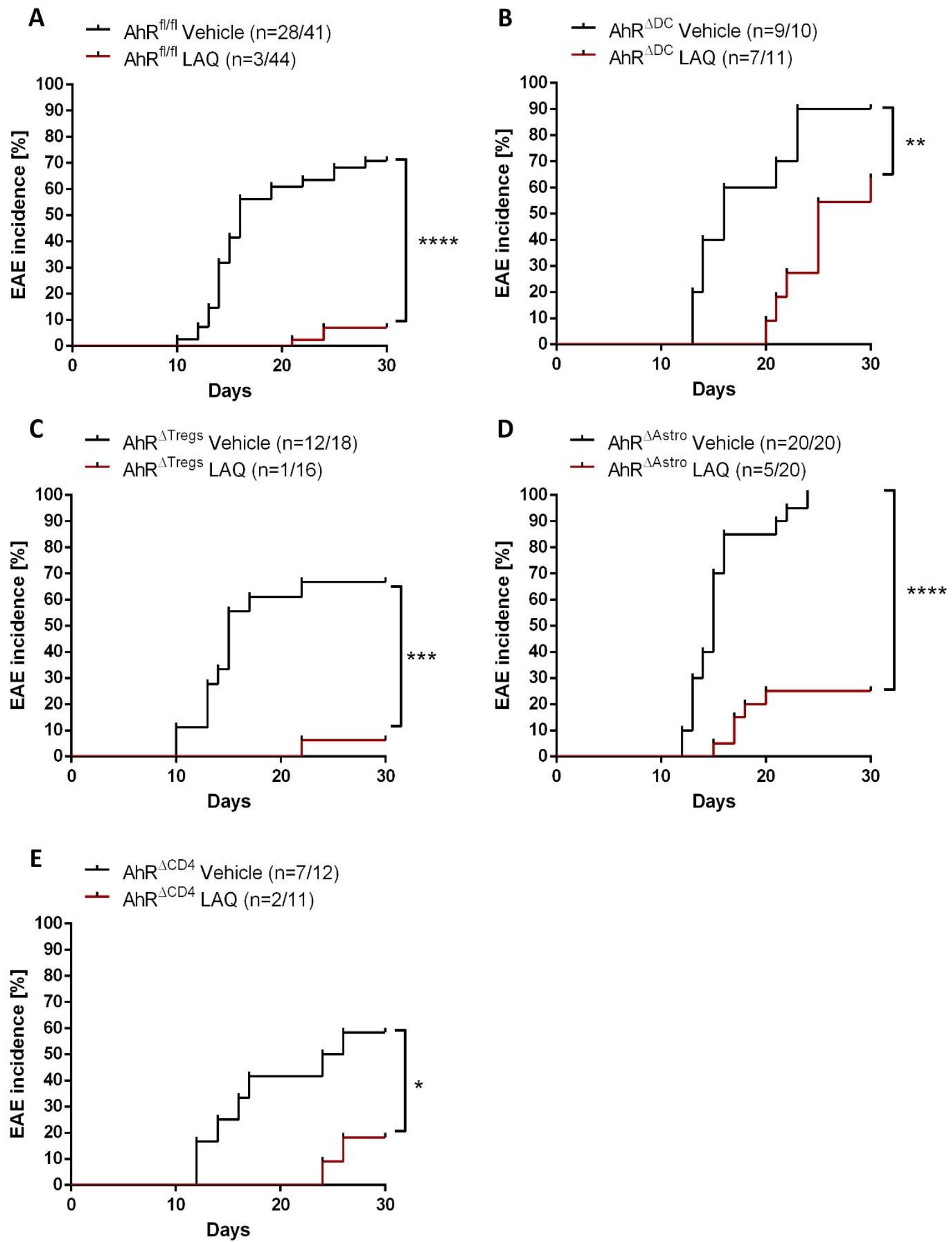

Figure 16. The Laquinimod mediated $E A E$ incidence decrease is less sustained in $A h R^{\triangle D C}$ mice. (A) EAE incidence curve of $A h R^{\text {fl/fl }}$ control group, (B) $A h R^{\Delta D C}$, (C) $A h R^{\Delta T r e g, ~(D) ~} A h R^{\Delta A s t r o}$ and (E) $A h R^{\Delta C D 4}$ animals. AhR was deleted in specific cell populations including DC (CD11c Cre), $\mathrm{T}_{\text {regs }}$ (FoxP3Cre), astrocytes (GFAPCre) and CD4+ T cells (CD4Cre) using the Cre lox system. Mice were daily monitored and treated with Laquinimod ( $25 \mathrm{mg} / \mathrm{kg}$ body weight) or vehicle from the day of immunization to day $30 \mathrm{p.i.}$ Data are shown as mean \pm SEM and are representative of three to five independent experiments. ${ }^{*} p<0.05,{ }^{* *} p<0.01,{ }^{* * *} p<0.001,{ }^{* * * *} p<0.0001$, Log-rank (Mantel-Cox) test. 
The disease onset was comparable between all vehicle treated cell specific AhR deficient mice and vehicle treated $\mathrm{AhR}^{\mathrm{fl} / \mathrm{fl}}$ controls. The maximum disease scores of the affected animals were slightly higher in mice with AhR deficiency in astrocytes and $T_{\text {regs. }}$

Laquinimod administration delayed the development of EAE symptoms and decreased the $\mathrm{EAE}$ incidence in $\mathrm{AhR}^{\mathrm{ffl} / \mathrm{l}}$ control animals and in all cell specific $\mathrm{AhR}$ deficient mice compared to littermates treated with water. However, this protective effect was less sustained in $A h R^{\Delta A s t r o}$ (figure $16 \mathrm{D}$ ) and particularly in $\mathrm{Ah} \mathrm{R}^{\Delta \mathrm{DC}}$ mice (figure $16 \mathrm{~B}$ ). In descending order, $64 \%$ of $A h \mathrm{R}^{\Delta \mathrm{DC} \text {, }}$ $25 \%$ of $A h R^{\Delta A s t r o}, 18 \%$ of $A h R^{\Delta C D 4}$ and $6 \%$ of $A h R^{\Delta T r e g}$ mice developed disease if treated with laquinimod compared to $6.8 \%$ of mice in $\mathrm{AhR}^{\mathrm{fl} / \mathrm{fl}}$ controls.

\subsubsection{AhR competent DC contribute to Laquinimod's protection against $E A E$}

Laquinimod significantly protected $A h R^{\Delta D C}$ mice against $E A E$ induced by active immunization evidenced by a delayed disease onset (EAE onset of vehicle treated $A h R^{\Delta D C}$ mice at day $17 \pm$ 4.18 and EAE onset of Laquinimod treated $\mathrm{AhR}^{\triangle \mathrm{DC}}$ mice at day $23 \pm 2.28$ ) and a reduction of the mean maximum score of the clinically affected animals compared to vehicle treated $A h R^{\Delta D C}$ mice $($ vehicle treated $=3.06 \pm 0.73$ and Laquinimod treated $=2.42 \pm 0.53$ )

Nonetheless, the protective effect of Laquinimod was not as sustained as in Laquinimod treated $A h R^{f / f / l}$ mice (figure $16 \mathrm{~A}$ and $17 \mathrm{~A}$ ) and a significant number of $A h R^{\Delta D C}$ animals developed mild EAE symptoms during the last 10 days of the observation period (figure 16B, 17B and 18G).

Laquinimod was also therapeutically effective in $A h R^{\Delta A s t r o}$ mice (figure $16 D$ and 17D). Of note, vehicle treated $A h R^{\Delta A \text { stro }}$ mice harbored more severe $E A E$ than vehicle treated $A h R^{f / f l}$ mice (figure 18B and F). Therefore, the slight increase of unprotected Laquinimod treated $A h R^{\Delta A s t r o}$ mice compared to Laquinimod treated $A h R^{\mathrm{fl} / \mathrm{fl}}$ mice might reflect an increased susceptibility of $A h R^{\triangle A s t r o}$ mice to develop $E A E$ rather than a necessity of the astrocytic AhR mediating the protective effect of Laquinimod (figure 18D and $\mathrm{H}$ ).

Laquinimod treatment protected $\mathrm{AhR}^{\Delta \mathrm{CD} 4}$ (figure $16 \mathrm{E}$ and $17 \mathrm{E}$ ) and $\mathrm{AhR}^{\Delta \mathrm{Treg}}$ mice (figure 16C and 17C) compared to $A \mathrm{Ah}^{\mathrm{f} / \mathrm{fl}}$ littermates. As shown in table 22, the disease onset 
was delayed from day $14.33 \pm 3.17$ (control group) to 22 in the $A h R^{\Delta T r e g}$ Laquinimod treated group and there was a slight reduction of the mean maximum score of the diseased mice $\left(A h R^{\Delta T r e g}\right.$ vehicle treated $=3.37 \pm 0.70$ and Laquinimod treated $\left.=3\right)$.

A

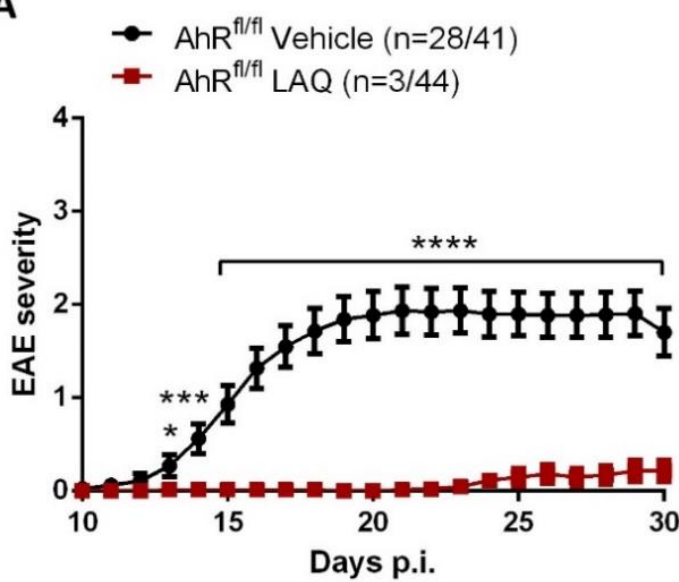

C

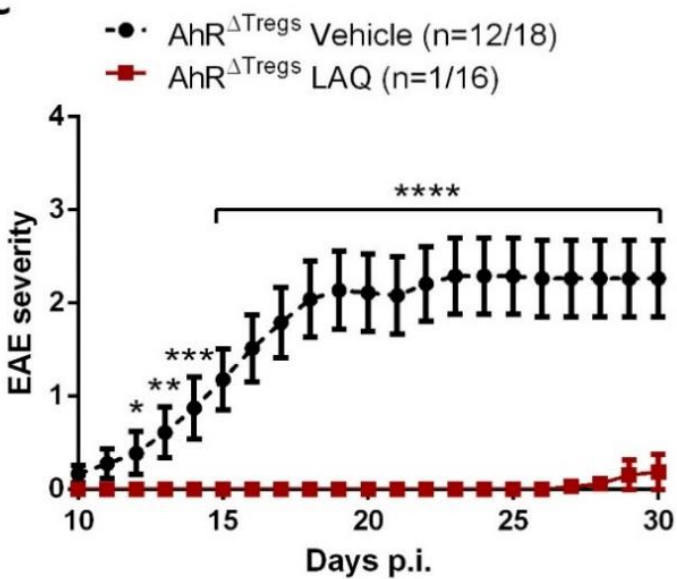

$\mathbf{E}$

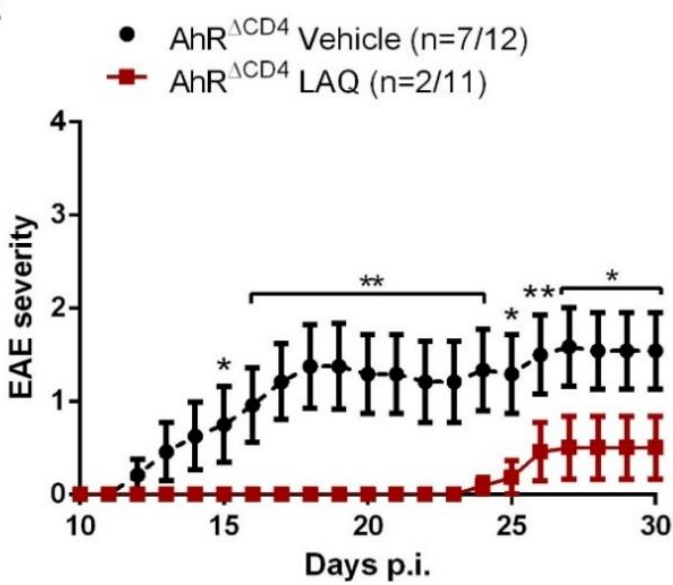

B

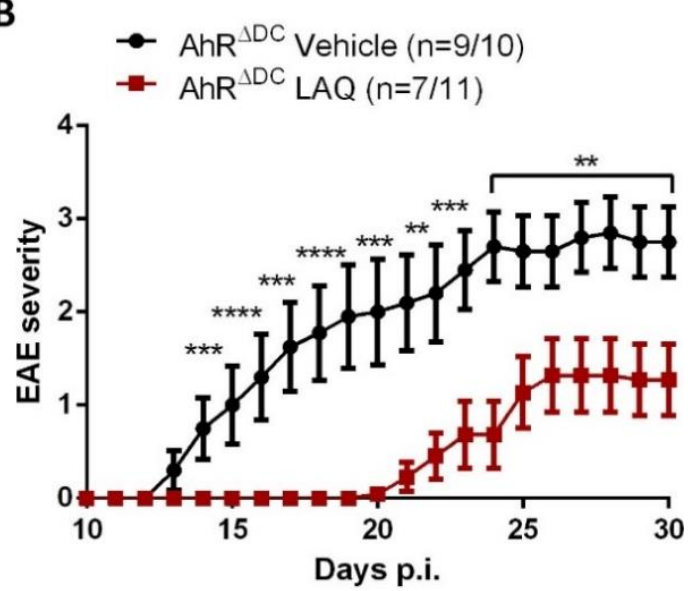

D

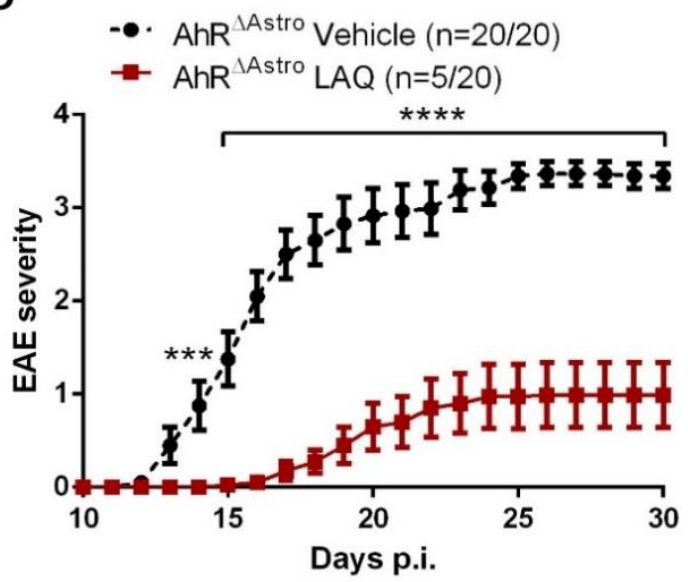

Figure 17. Expression of AhR on DC, $T_{\text {regs }}$ and astrocytes is not essential for Laquinimod mediated decrease of EAE severity. Cell specific AhR KO mice were MOG $35-55$ immunized and daily treated with Laquinimod (25 mg/kgbody weight). Oral administration of the drug or vehicle started on the day of immunization to day 30 p.i. (A) Disease severity curves of $A h R^{f / / f l}$ control mice, (B) $A h R^{\Delta D C},(C)$ $A h R^{\Delta T r e g}$ and $(D) A h R^{\Delta A s t r o}$ mice. Data are shown as mean \pm SEM and represent three independent experiments. AhR ${ }^{f / / 1}$ mice were used as control group $(A) .{ }^{*} p<0.05,{ }^{* *} p<0.01,{ }^{* * *} p<0.001$ and ${ }^{* * * *} p<0.0001$. All severity curves were analyzed using multiple $t$ tests. 

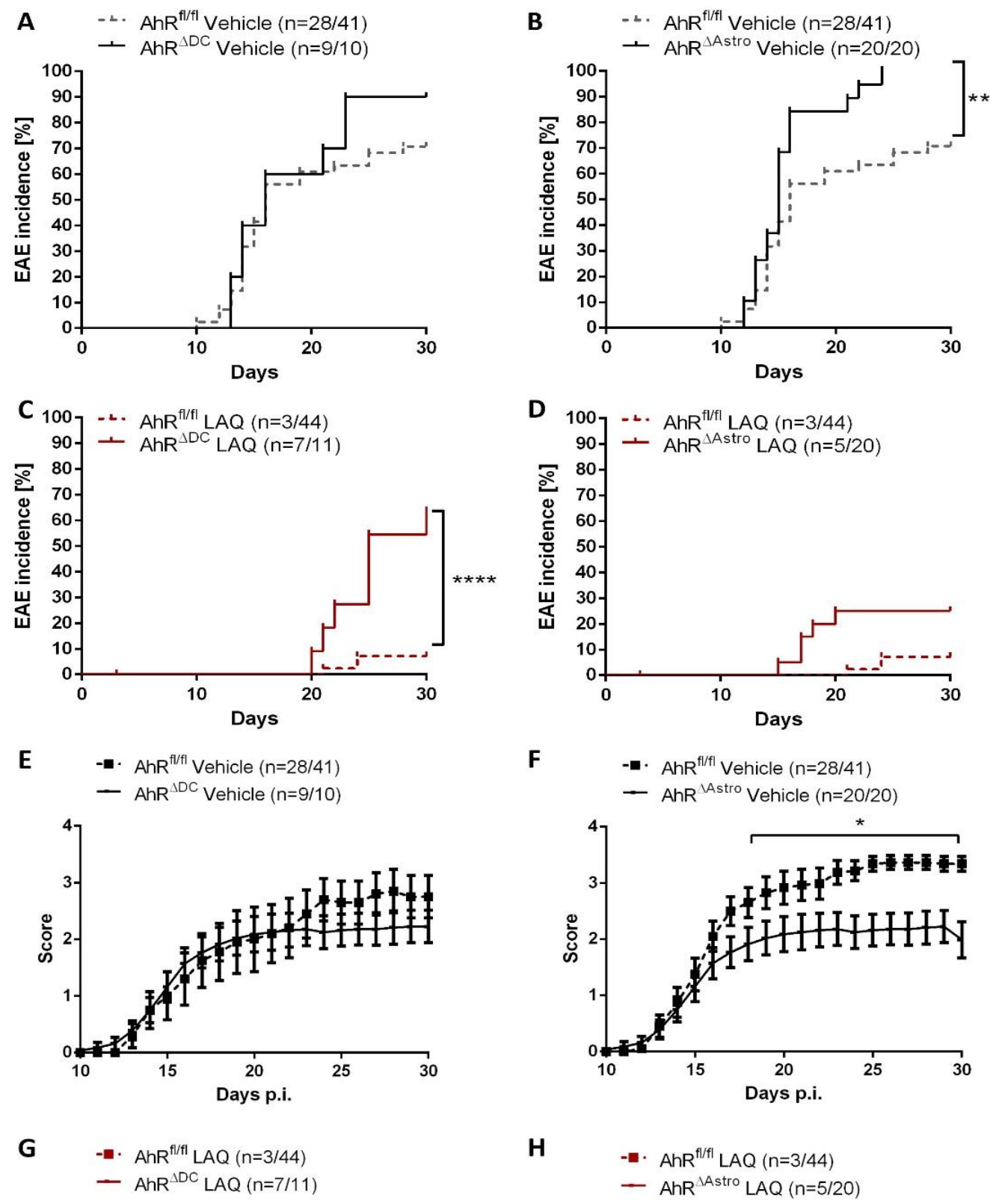

H

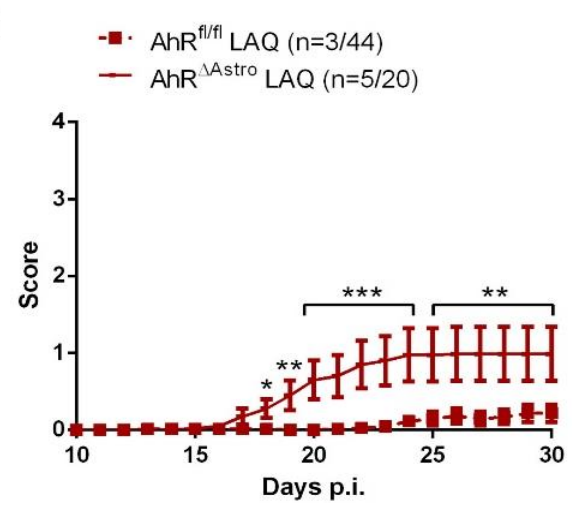

Figure 18. Laquinimod's effect on $\mathbf{A h} \mathbf{R}^{\Delta A s t r o}$ and $\mathbf{A} \mathbf{R}^{\Delta \mathrm{DC}}$. (A) $E A E$ incidence curves corresponding to vehicle treated $A h R^{\triangle D C}$, $(B)$ vehicle treated $A h R^{\triangle A s t r o}$. AhR deficiency in GFAP+ but not in $C D 11 c^{+}$cells potentiates EAE incidence and does not affect Laquinimod's protective effect. (C) Graphs representing the $E A E$ incidence of Laquinimod treated $A h R^{\triangle D C}$ and $(D)$ Laquinimod treated $A h R^{\triangle A s t r o}$. AhR expression in $\mathrm{CD} 11 \mathrm{C}^{+}$cells is not essential but plays a role in the Laquinimod mediated EAE inhibition, while AhR deficiency in GFAP+ cells is not required. (E) EAE severity curves obtained from Laquinimod treated $A h R^{\triangle D C}$ and $(F)$ vehicle treated $A h R^{\triangle A s t r o}$. Data are shown as mean $\pm S E M$ and represent three to four independent experiments. AhR competent $\left(A h R^{1 / 1 / 1}\right)$ mice were used as control group and are represented with dotted lines. The $E A E$ incidence curves of $A h R^{\triangle A s t r o}$ and $A h R^{\triangle D C}$ mice are depicted with solid lines. ${ }^{* *} p<0.01,{ }^{* * *} p<0.0001$, Log-rank (Mantel-Cox) test. The EAE severity curves of $A h R^{\triangle A s t r o}$ and $A h R^{\triangle D C}$ mice were analyzed by multiple $t$ tests. ${ }^{*} p<0.1,{ }^{* *} p<0.01$ and ${ }^{* * * *} p<0.0001$. 
Laquinimod was able to significantly reduce EAE in all cell specific AhR KO lines compared to vehicle treated littermates. Even though Laquinimod significantly protected $A h R^{\triangle D C}$ mice against $E A E$ compared to $A h R^{f / / f l}$ littermates $(p=0.001)$, fewer number of animals were fully protected, arguing for a moderate effect of AhR competent DC mediating the therapeutic efficacy of Laquinimod.

\subsubsection{Laquinimod treatment reduces the percentage of $\mathrm{CD}_{11 \mathrm{c}^{+} \mathrm{MHCII}}{ }^{\text {high }} \mathrm{DC}$ cells in}

\section{$\mathrm{AhR}^{\Delta \mathrm{DC}}$ mice}

To date, different mechanisms have been proposed to describe how Laquinimod could suppress EAE. Previous results obtained in C57BL/6 mice suggested that APCs such as $C D 11 c^{+} C D 11 b^{+} C D 4^{+} D C$ were reduced and $C D 11 b+$ cells were modulated towards an antiinflammatory phenotype ${ }^{180,182}$.

Ex vivo and in vivo experiments displayed a reduction of $\mathrm{MHCll}$, costimulatory molecules (CD80, CD86) and the activation marker CD40 on DC and macrophages after Laquinimod therapy ${ }^{281}$, suggesting that $\mathrm{T}$ cell activation and proliferation might be indirectly impaired ${ }^{282}$. Hence, it was tested if a reduction of $\mathrm{CD} 11 \mathrm{c}^{+} \mathrm{MHCII}^{\text {high }} \mathrm{DC}$ can be still observed in Laquinimod treated $A h R^{\Delta D C}$ mice, but also in $A h R^{\Delta C D 4}, A h R^{\Delta A s t r o}$ and $A h R^{\Delta T r e g}$ mice.

All Cre lines and $A h R^{f / f l}$ controls were treated with vehicle or Laquinimod from the day of immunization. At day 10 splenic $\mathrm{CD} 11 \mathrm{c}^{+} \mathrm{MHCI}^{\text {high }} \mathrm{DC}$ were evaluated ex vivo by flow cytometry as explained in 2.4.8.

All Laquinimod treated mice, including $A h R^{\Delta D C}$ animals, had reduced $D C$ frequencies compared to control litermates. $A h R^{\Delta D C} p=0.036, A h R^{\Delta T r e g} p=0.009, A h R^{\Delta A s t r o}: p=0.001$, $A h R^{\Delta C D 4} p=0.003$, corresponding to figure $19 B, C, D$ and $E$. $A h R^{f / / 1}$ animals were used as controls (figure 19A, $p=0.002$ ). 
On CD45+CD19- cells

A

$A H R^{f / f f l}$

B

$\mathrm{AHR}^{\triangle \mathrm{DC}}$

C

$\mathrm{AHR}^{\Delta \mathrm{Treg}}$
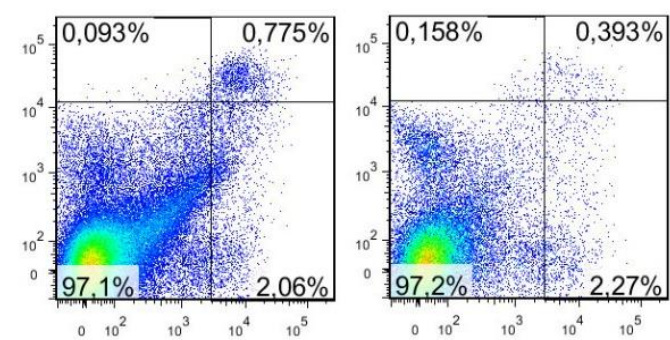

D

AHR $\triangle$ Astro
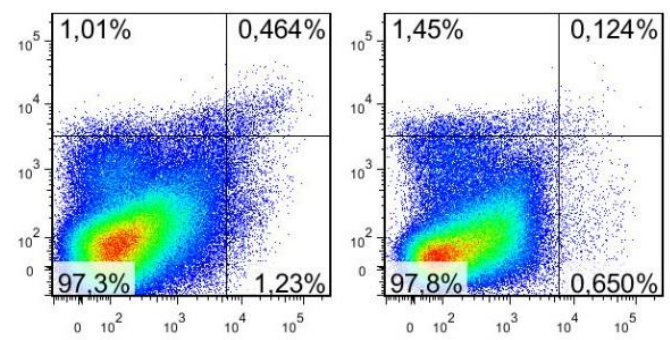

$E$

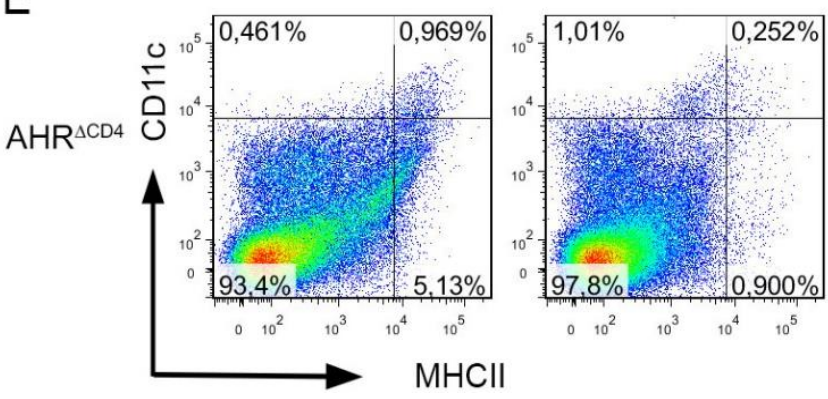

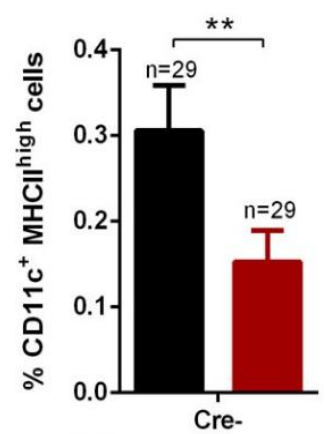
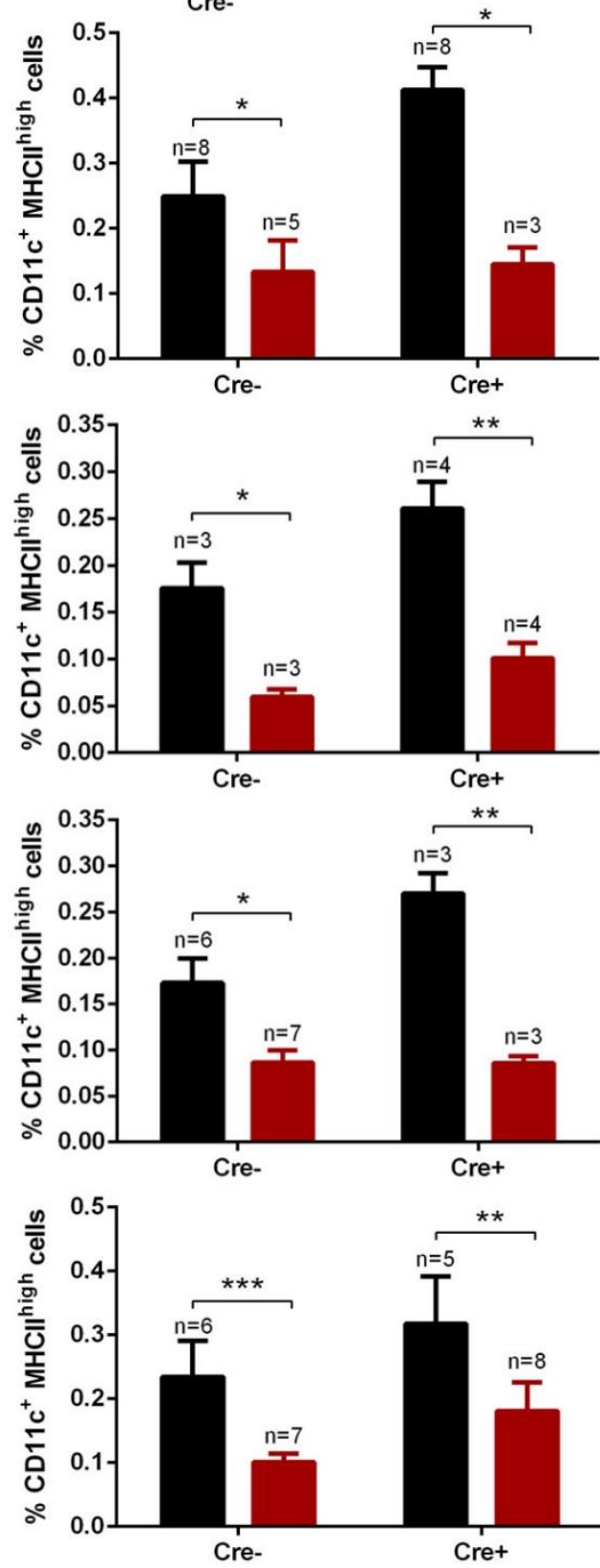

Figure 19. Laquinimod decreases the percentage of $C D 11 c^{+} M H C I^{\text {high }} D C$ in $A h R^{\Delta D C}$ mice. Representative dot plots of $\mathrm{CD} 11 \mathrm{C}$ and MHCll expression in CD45+ CD19- cells of MOG $35-55$-immunized (A) $A h R^{\text {fl/fll }}$, (B) $A h R^{\Delta D C},(C) A h R^{\Delta T r e g}$, (D) $A h R^{\Delta A s t r o}$ and (E) $A h R^{\Delta C D 4}$ mice, which were treated daily with Laquinimod ( $25 \mathrm{mg} / \mathrm{kg}$ body weight) or vehicle from the day of immunization to day 10 p.i. Bar graphs depict the percentage of $\mathrm{CD} 11 \mathrm{c}^{+} \mathrm{MHCl|}$ high cells among total CD45+ cells. Data are shown as mean \pm SEM.. ${ }^{*} p<0.05,{ }^{* *} p<0.01$. Mann-Whitney U-test. 


\subsubsection{Laquinimod requires AhR competent DC to reduce the frequency of Th17 cells}

Previous studies performed in Laquinimod treated mice showed that the frequency of proinflammatory Th1 or Th17 CD4+ $\mathrm{T}$ cells decreases whereas the numbers of $\mathrm{T}_{\text {regs }}$ increase in the periphery ${ }^{182}$ and $\mathrm{CNS}^{196}$.

In addition, it was demonstrated that $\mathrm{AhR}$ is involved in the development of Th17 cells, as well as in the production of IL17 and IL22 cytokines ${ }^{283}$. Until now, it remains unclear if Laquinimod directly interacts with $\mathrm{T}$ cells or if the shift towards anti-inflammatory $\mathrm{T}$ cell populations is indirectly induced by the drug.

Splenocytes were ex vivo stimulated with PMA and ionomycin to induce cytokine production. Monensin and brefeldin were added to the cultures in order to block protein transport and to promote cytokine accumulation in the Golgi complex. Intracellular staining of IL17 and IFNy was analyzed by flow cytometry in splenic CD45+CD19 - CD3 ${ }^{+}$CD4 ${ }^{+} \mathrm{T}$ cells as explained in section 2.4.8.3.

Preventive treatment with Laquinimod significantly decreased 3 to 4 -fold the number of IL17 producing $\mathrm{CD}^{+} \mathrm{T}$ cells in $\mathrm{AhR}^{\mathrm{fl} / \mathrm{fl}}$ control mice $(\mathrm{p}=0.004)$, as well as in $A h \mathrm{R}^{\mathrm{Astro}},(0.002)$ and $\mathrm{AhR}^{\mathrm{CD4}}(p=0.004)$ corresponding to figure $20 \mathrm{~A}, \mathrm{C}$ and $\mathrm{D}$.

Interestingly, Laquinimod failed to significantly decrease the percentage of IL17 producing $\mathrm{CD}^{+} \mathrm{T}$ cells in $\mathrm{AhR} \mathrm{R}^{\triangle \mathrm{DC}}$ mice (figure 20B; $\mathrm{p}=0.1$ ), suggesting that the reduction of proinflammatory cytokine producing $\mathrm{CD}^{+} \mathrm{T}$ cells is indirectly mediated via AhR competent DC. 


\section{A}

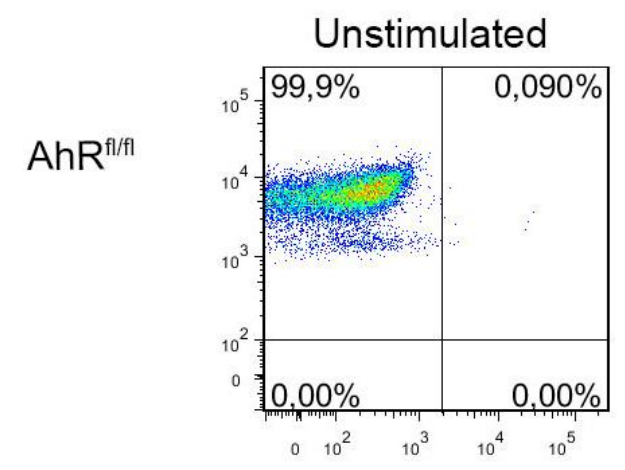

B

$\mathrm{AhR}^{\Delta \mathrm{DC}}$

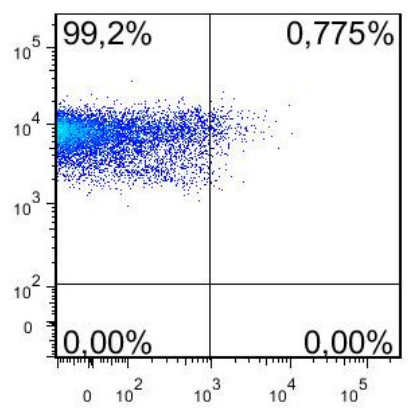

C

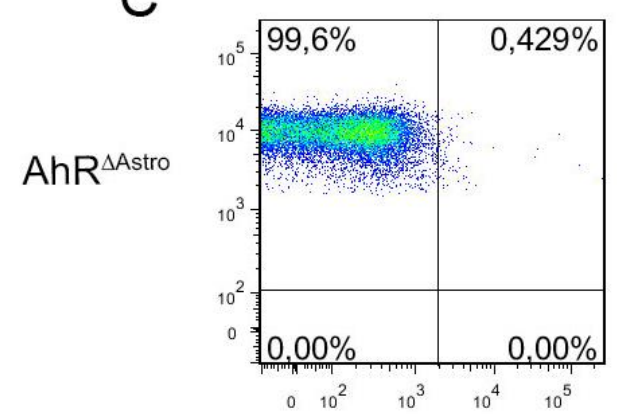

D

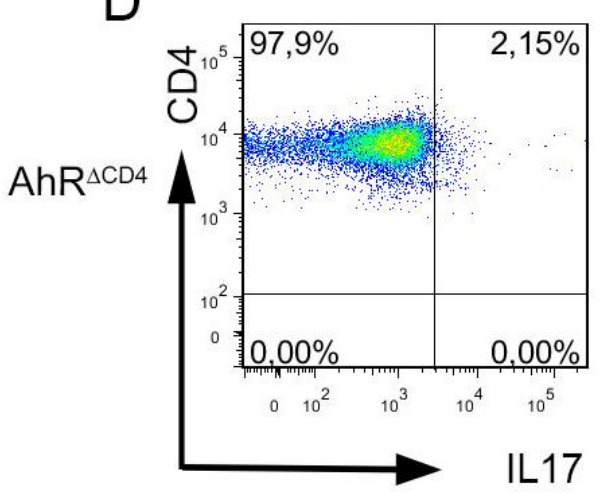

$\mathrm{PMA} /$ lonomycin
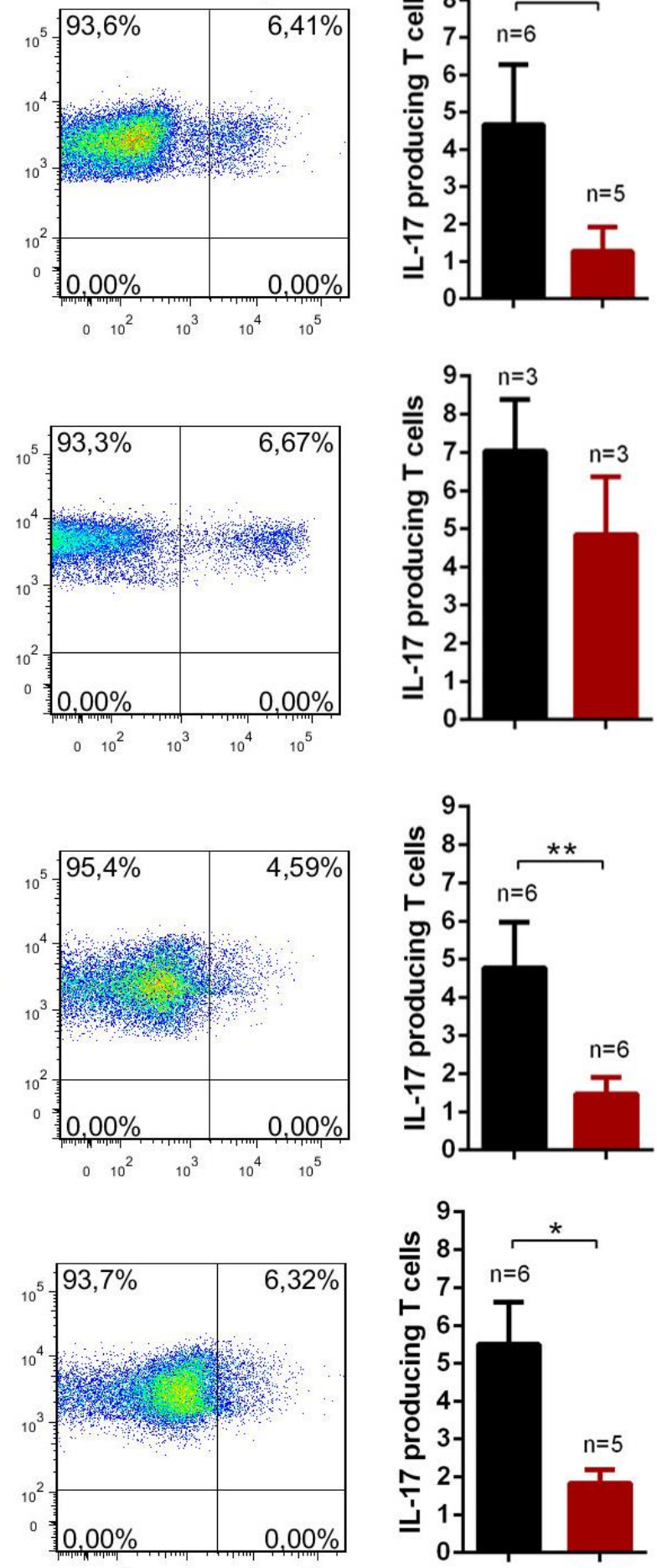

Figure 20. Laquinimod fails to decrease IL17 producing $C D 4^{+} T$ cells in $\mathrm{AhR}^{\triangle \mathrm{DC}}$ mice but not in $\mathrm{AhR}^{\Delta \mathrm{CD} 4}$ and $A \mathrm{AR}^{\Delta \mathrm{Astro}}$. Representative flow cytometry analysis of the IL17 producing $\mathrm{CD} 4^{+} \mathrm{T}$ cells isolated from (A) $A h R^{\mathrm{fl} / \mathrm{fl}}$ control mice, (B) $A h R^{\Delta D C}$, (C) $A h R^{\triangle A \text { stro }}$ and (D) $A h R^{\Delta C D 4}$ animals treated daily with Laquinimod ( $25 \mathrm{mg} / \mathrm{kg}$ body weight) or vehicle from the day of immunization to day 10 p.i. IL17 producing T cells were ex vivo analyzed by flow cytometry following stimulation with PMA and ionomycin. Data are presented as percentage from the total number of $\mathrm{CD} 4^{+} \mathrm{T}$ cells shown as mean \pm SEM and are representative from three different experiments. ${ }^{*} p<0.1,{ }^{* *} p<0.01$, Mann-Whitney U-test. 


\subsubsection{The AhR-IDO-1 axis does not mediate Laquinimod's protective effect in the EAE}

\section{model}

AhR signaling is required for the expression of indoleamine 2,3 dioxygenase (IDO) in DC, an immunosuppressive enzyme that catabolizes tryptophan into kynurenine ${ }^{168,174,284}$. Furthermore, the absence of the AhR in bone marrow derived DC skewed the differentiation of naïve T cells towards Th17 and inhibited the differentiation into $\mathrm{T}_{\text {regs }}{ }^{285}$.

To assess whether the AhR-IDO-1 signaling loop contributes to the efficacy of Laquinimod to suppress EAE, IDO-1 KO mice and C57BL/6 controls were immunized with $\mathrm{MOG}_{35-55}$ and treated with vehicle or Laquinimod for 30 days from the day of immunization. Laquinimod inhibited EAE regardless of IDO-1 deletion. IDO- 1 competent ( $p=0.0003$ ), as well as IDO-1 KO mice ( $p=0.0007)$ were fully protected by Laquinimod administration from day 16 onwards compared to vehicle treated animals (figure 21).

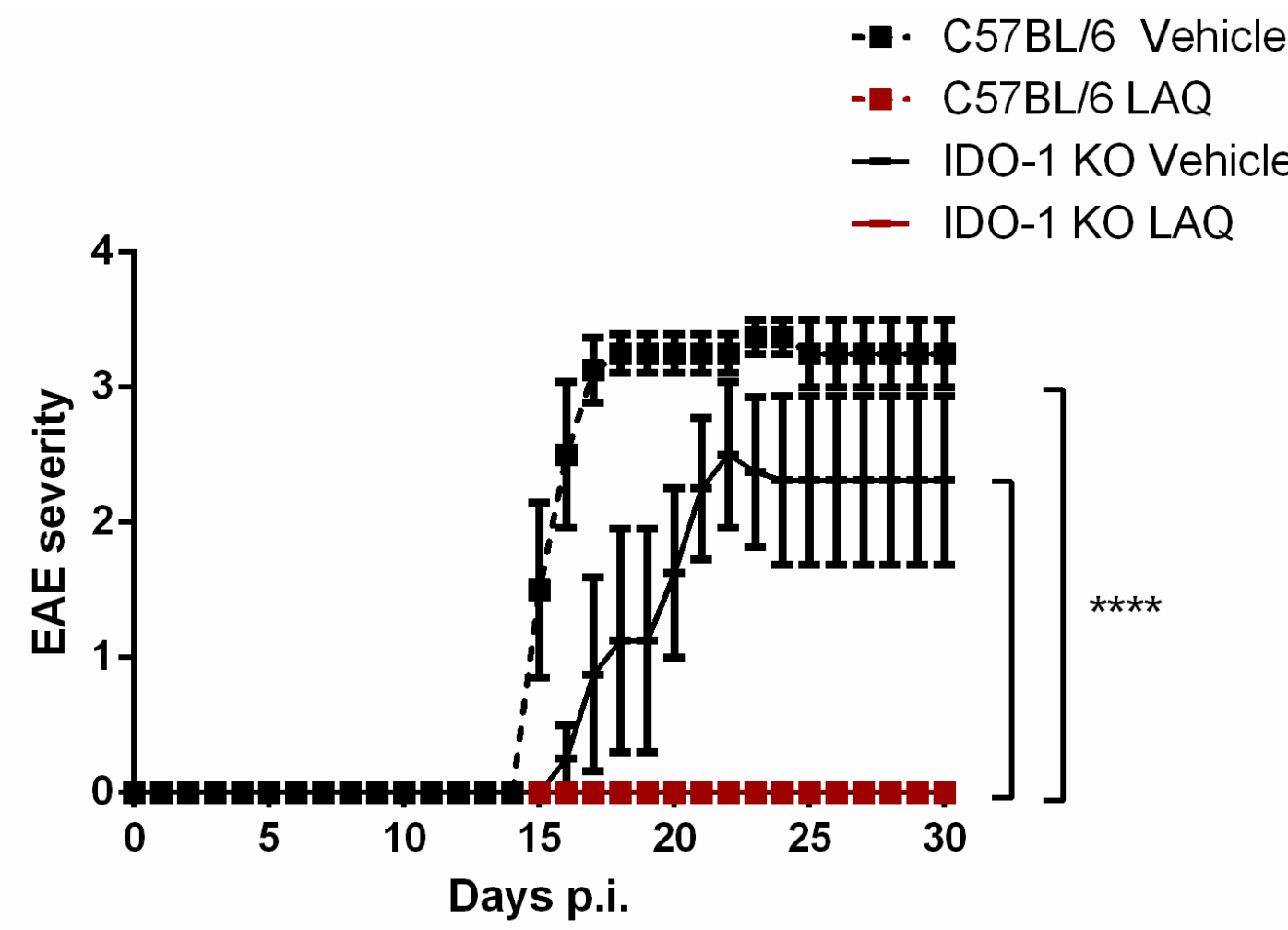

Figure 21. The lack of IDO-1 does not impair Laquinimod's protection against EAE. IDO-1 KO and C57BI/7 mice were immunized with $\mathrm{MOG}_{35-55}$ and treated daily with vehicle or Laquinimod $(25 \mathrm{mg} / \mathrm{kg}$ body weight) from the day of immunization to day 30 p.i. Data are shown as mean \pm SEM. ${ }^{* * * *} p<0.0001$, Laquinimod versus vehicle treated groups were analyzed by multiple $t$ tests. Control littermates were treated with water as vehicle. $n=10$ for each of the four experimental groups. 


\subsubsection{Laquinimod increases $\mathrm{CD}^{2} 5^{+}$FoxP3 ${ }^{+} \mathrm{T}$ cells in $\mathrm{AhR}^{\Delta \mathrm{CD} 4}$ and $A h \mathrm{R}^{\Delta \mathrm{Treg}}$ mice}

Laquinimod was previously shown to promote anti-inflammatory conditions by significantly decreasing Th1 and Th17 responses ${ }^{190}$ and favoring $T_{\text {regs }}$ differentiation and expansion in the $\mathrm{CNS}^{196}$ and periphery ${ }^{182}$.

Different groups have shown that acutely immunized mice with $\mathrm{MOG}_{35-55}$ and daily treated from the day of immunization with the AhR agonist, Laquinimod, present an elevation of the percentage of splenic $\mathrm{CD}^{+} \mathrm{CD}^{+} 5^{+} \mathrm{Foxp}^{+}$cells compared to vehicle treated animals ${ }^{194,196,286}$.

On the other hand, it is known that AhR signaling triggered by physiological ligands is an important regulator of murine and human $T_{\text {regs }}$ diferentiation ${ }^{137}$. Furthermore, Laquinimod treatment has been shown to be unable to alter $\mathrm{T}_{\text {regs }}$ frequencies in AhR KO mice compared to control littermates ${ }^{194}$.

As a subpopulation of $\mathrm{CD}^{+} \mathrm{T}$ cells, $\mathrm{T}_{\text {regs }}$ were defined by the expression of the transcription factor FoxP3 and the surface marker CD25 as shown in figure 22. Flow cytometry analysis (described in section 2.4.8.2) showed that Laquinimod treatment increased the percentage of $T_{\text {regs }}$ in EAE mice devoid of AhR in DC ( $\left.p=0.0007\right), T_{\text {regs }}(p=0.0002)$ and CD4 T cells ( $p=0.03$ ), corresponding to figure $22 \mathrm{~B}, \mathrm{C}$ and $\mathrm{D}$, as well as in $A h \mathrm{R}^{\mathrm{fl} / \mathrm{fl}}$ control animals (figure $22 A, p=0.005)$.

In contrast to an impaired suppression of Th17 cells in $\mathrm{AhR} \mathrm{R}^{\mathrm{DC}}$ mice treated with Laquinimod, AhR competent DC, CD4+ T cells or FoxP3+ $T$ cells were not required in Laquinimod treated mice to increase the percentage of $\mathrm{T}_{\text {regs. }}$ 


\section{On $\mathrm{CD}_{4} 5^{+} \mathrm{CD} 19 \mathrm{CD}^{+}$cells}
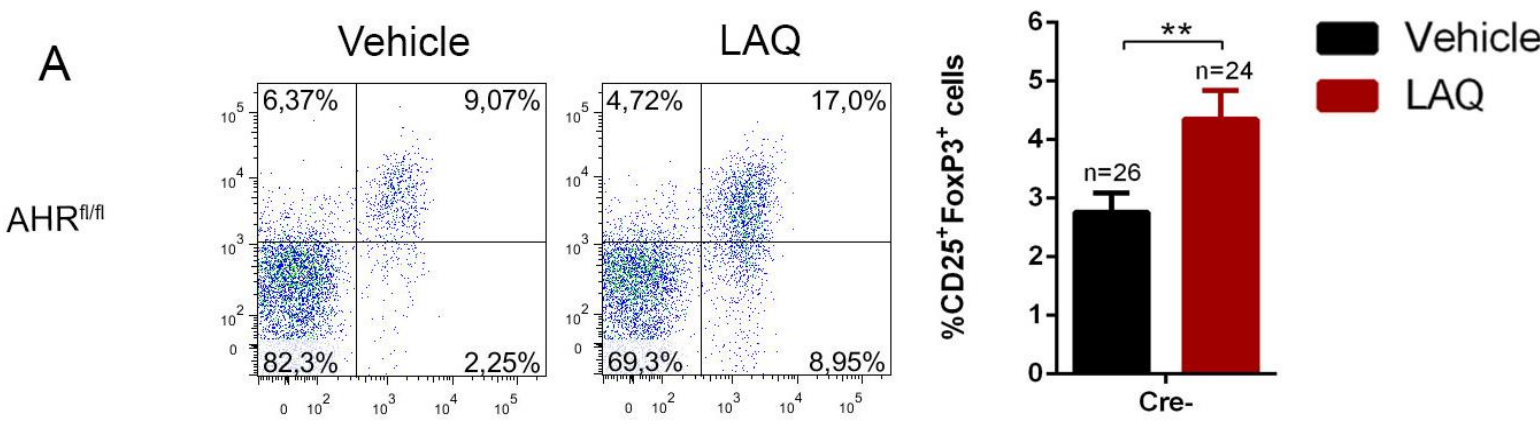

B

$\mathrm{AHR}^{\triangle \mathrm{DC}}$
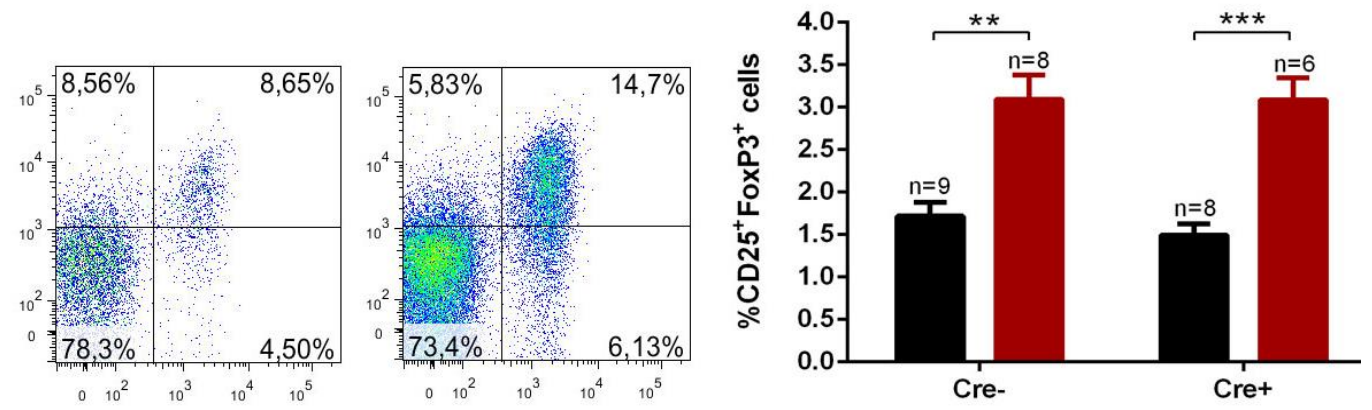

C

$\mathrm{AHR}^{\Delta \mathrm{Treg}}$
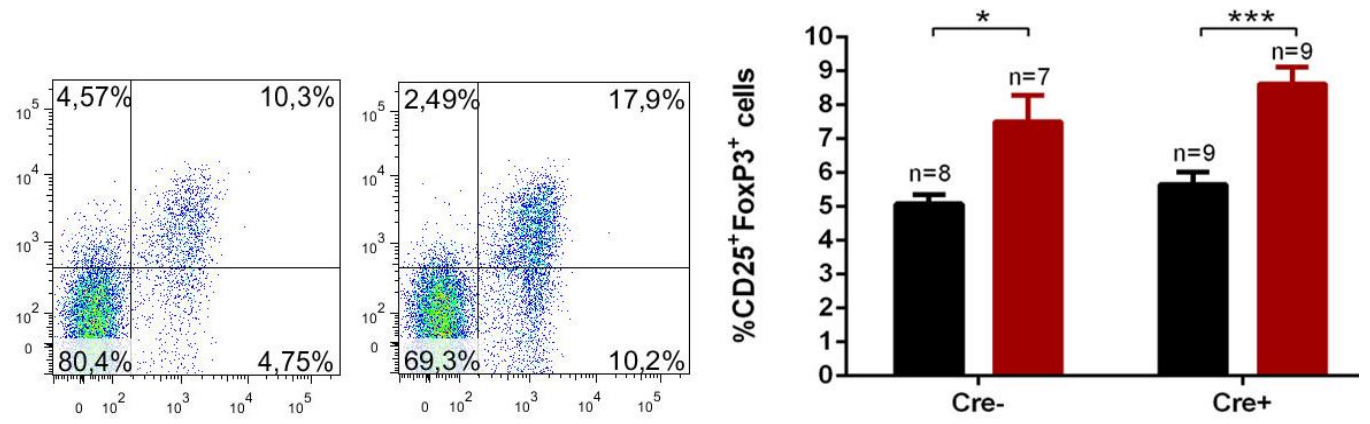

D
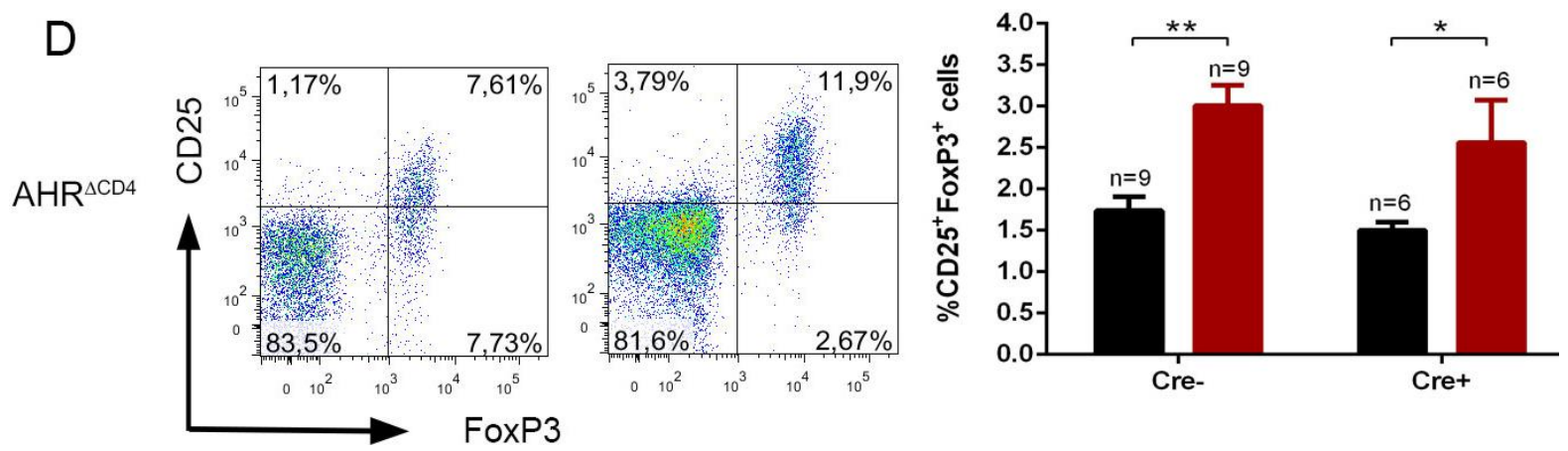

Figure 22. Laquinimod increases the percentage of $\mathrm{CD}^{2} 5^{+} \mathrm{FoxP} 3^{+}$cells in $\mathrm{AhR}^{\Delta \mathrm{DC}}, \mathrm{AhR}^{\Delta \mathrm{Treg}}$ and AhR ${ }^{\Delta C D 4}$ animals. Representative FACS dot plots showing the expression of CD25 and FoxP3 in T cells of (A) $A h R^{\text {fl/fl }}$ control mice, (B) $A h R^{\Delta D C}$, (C) $A h R^{\Delta T r e g}$ and (D) $A h R^{\Delta C D 4}$ animals treated with Laquinimod (25 mg/kgbody weight) or vehicle from the day of immunization to day 10 p.i. CD25+ FoxP3 ${ }^{+}$cells were ex vivo analyzed by flow cytometry and presented as percentage from the total lymphocyte count (CD45+

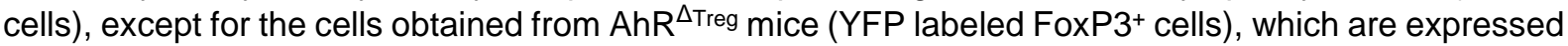
as a percentage of the CD19-CD3 ${ }^{+}$cells. Data are shown as mean \pm SEM and are pooled from three independent experiments. ${ }^{*} p<0.05,{ }^{* *} p<0.01,{ }^{* *} p<0.001$, Mann-Whitney U-test. 


\subsubsection{NK cell activation by Laquinimod is independent of AhR expression on DC and $\mathrm{CD4}^{+} \mathrm{T}$ cells}

NK cells are effectors of the innate immune system that constantly monitor stressed, infected or abnormally proliferating cells. NK cells belong to the innate lymphoid cell (ILC) family ${ }^{287}$, which has been shown to require AhR signaling in many of its subsets to differentiate and survive $^{288}$. It has been shown that $A h R$ activation through tryptophan derived ligands potentiates NK cell activation leading to cytokine production, cytolytic and tumor control activity $^{289}$.

The interplay between NK and DC potentially elicits cell activation and maturation of both cell types and impacts on $\mathrm{CD}^{+} \mathrm{T}$ cell responses ${ }^{290}$. Previous work from our group has shown that Laquinimod activates NK cells in vivo and in vitro and CD69 was among the NK cell markers upregulated by laquinimod treatment.

Ex vivo purified NK cells from Laquinimod treated mice killed B16F10 melanoma cells in vitro more efficiently than NK cells isolated from vehicle treated littermates. Furthermore, in a co-culture system with DC and MOG specific CD4+ ${ }^{+}$cells, NK cells from Laquinimod treated mice inhibited $\mathrm{T}$ cell proliferation better than NK cells from vehicle treated animals. This inhibition required cell to cell contact of NK cells with DC. Additionally, the depletion of NK cells impaired the efficacy of Laquinimod to suppress EAE [in revision].

In order to evaluate NK cell activation in response to Laquinimod administration and in the absence of $A h R$ in different immune cell players relevant for its signaling, expression of the activation marker CD69 was measured by flow cytometry in splenic NK cells obtained from $A h R^{\Delta D C}, A h R^{\Delta T r e g}$, and $A h R^{\Delta C D 4}$ mice immunized with $M O_{35-55 .}$

Laquinimod treatment increased the early activation marker CD69 in NK cells obtained from $A h R^{f l / f l}$ control mice (figure $23 \mathrm{~A}, \mathrm{p}=0.032$ ) and all cell specific AhR KO mice, including $\operatorname{AhR} R^{\Delta D C}(p=0.029), A h R^{\Delta T r e g}(p=0.015)$ and $A h R^{\Delta C D 4}$ mice $(p=0.006)$ corresponding to figure 23B, C and D, as well as in their corresponding AhR competent controls $(p=0.022,0.0003$, 0.022). 
On CD45+CD19- CD3-NK1.1 ${ }^{+}$cells

A

$\operatorname{AhR}^{\mathrm{fl} / f l}$

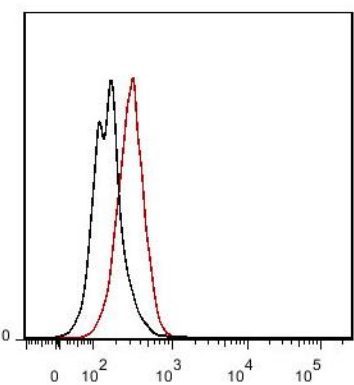

B

$\mathrm{AhR}^{\Delta \mathrm{DC}}$

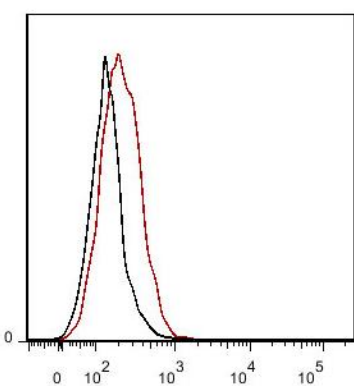

C

AhR ${ }^{\Delta T r e g}$

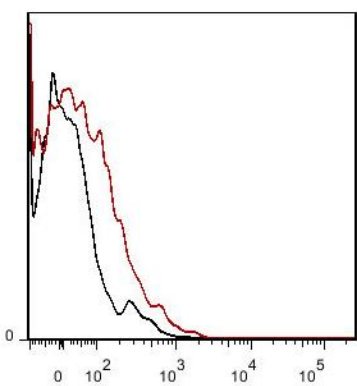

D

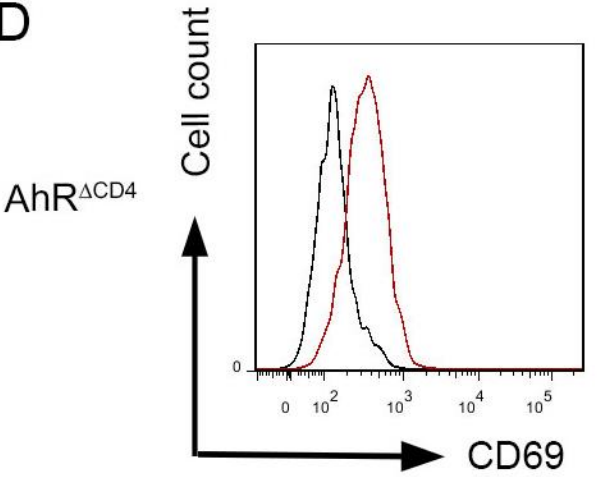

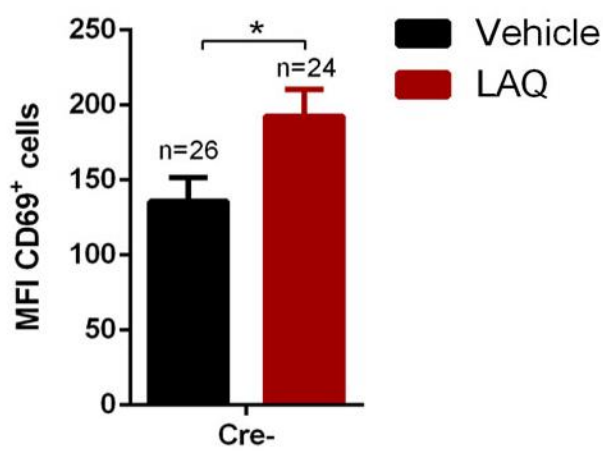
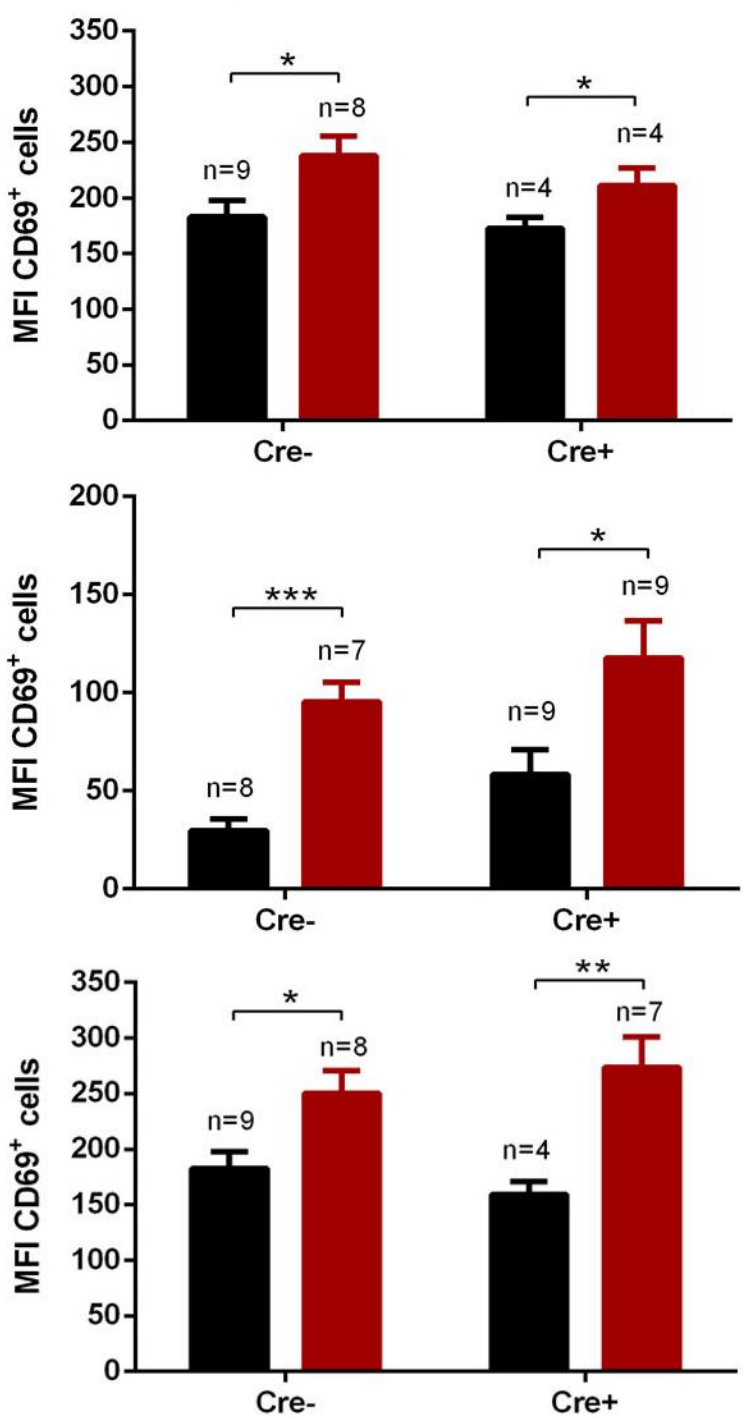

Figure 23. Laquinimod activates NK cells in the absence of AhR competent CD4+ $T$ cells or DC. FACS histograms of CD69 expression on the surface of splenic NK cells obtained from $(A) A h R^{f / / f l}$ control mice, (B) $A h R^{\Delta D C},(C) A h R^{\Delta T r e g}$ and (D) $A h R^{\Delta C D 4}$ animals treated with Laquinimod (25 mg/kg body weight) or vehicle from the day of immunization to day 10 p.i. The CD69 MFI of the bar graphs is depicted as mean \pm SEM pooled from 3 independent experiments. ${ }^{*} p<0.05,{ }^{* *} p<0.01,{ }^{* *} p<0.001$, Mann-Whitney U-test. 


\subsubsection{Laquinimod reduces pulmonary B16F10 metastases}

NK cells' antitumor functions have been extensively studied in different cancer models ${ }^{291}$. They are usually more effective impairing the metastatic spread of malignant cells in the blood stream than reducing the size of established tumors. In vivo and in vitro approaches have previously shown that AhR activation enhances the anti-tumor properties and cytolytic activity of NK cells in the murine model ${ }^{289,292}$.

Laqunimod mediated control of B16F10 melanoma metastases was evaluated in vivo using two experimental approaches. In a first model Laquinimod was preventively administrated to C57BL/6 and AhR KO mice before i.v. injection of B16F10 melanoma cells (figure 24A). In a second model the treatment of Laquinimod was initiated in C57BL/6 mice with established metastases 11 days after i.v. B16F10 melanoma cell injection (figure 24B).

\section{A Preventive treatment} or vehicle

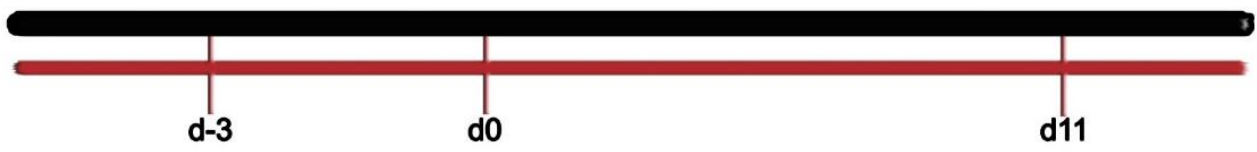

B Therapeutic treatment

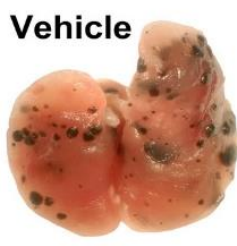

LAQ

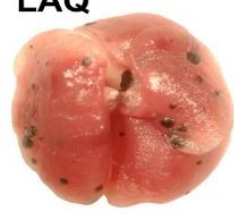

sacrifice

\section{d11}

LAQ $50 \mathrm{mg} / \mathrm{kg}$ or vehicle

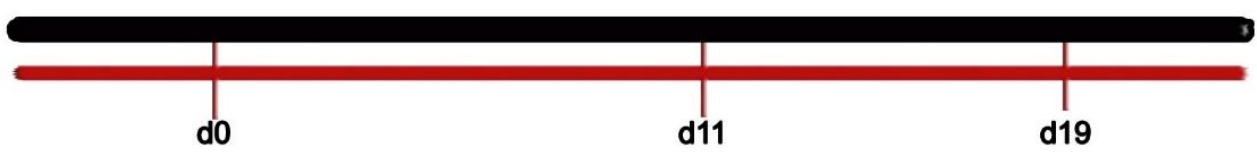

Figure 24. Preventive and therapeutic approaches used to study the efficacy of Laquinimod to suppress B16F10 melanoma metastases in vivo. Timelines corresponding to the $(A)$ preventive and (B) therapeutic approaches. Animals submitted to the preventive treatment received daily Laquinimod administration starting three days before the i.v. transfer with $0.5 \times 10^{6} \mathrm{~B} 16 \mathrm{~F} 10$ melanoma cells and the lungs were isolated 10 days after inoculation. Mice under a therapeutic regimen were sacrificed 19 days after i.v. injection of $0.2 \times 10^{6} \mathrm{~B} 16 \mathrm{~F} 10$ melanoma cells and Laquinimod treatment was started 11 days after tumor inoculation. 
Laquinimod was administrated in a dosis of $50 \mathrm{mg} / \mathrm{kg}_{\text {body weight }}$ and vehicle treated littermates were used as control. After preventive or therapeutic regimens the mice were sacrificed and the metastasic burden was quantified in the lungs as described in 2.4.12.3.

C57BL/6 animals preventively treated with Laquinimod showed a decrease in the number of metastasic colonies in the lungs (figure 25B) compared to vehicle treated mice $(p=0.04)$. These results were confirmed by assesing the total lung weight, showing that the lungs obtained from mice receiving Laquinimod weighted significantly less $(p=0.001)$ than those isolated from control animals (figure 25A).

When the same experiment was repeated with Laquinimod or vehicle treated AhR KO animals, the drug's protective effect was abolished. Vehicle treated AhR KO animals had less pulmonary metastases than vehicle treated C57BL/6 mice, which were not further reduced by laquinimod treatment. (figure 25D). In addition, Laquinimod was ineffective to reduce the number of already established pulmonary metastases (figure 25C).

A

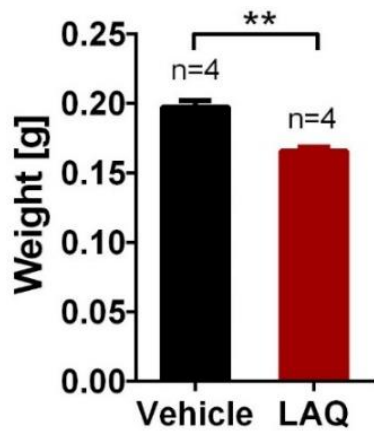

C

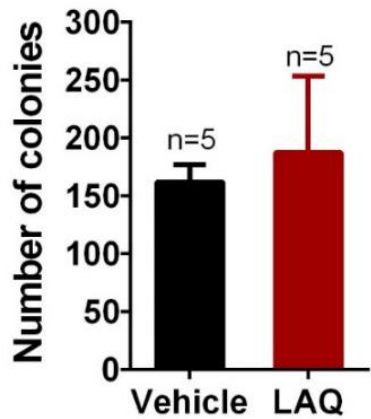

B

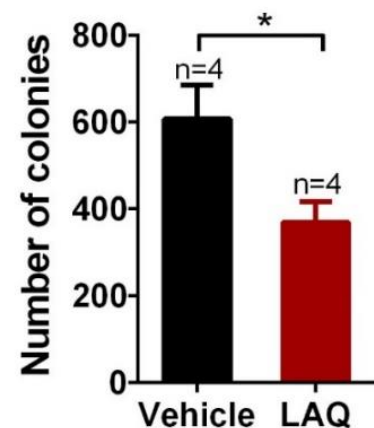

D

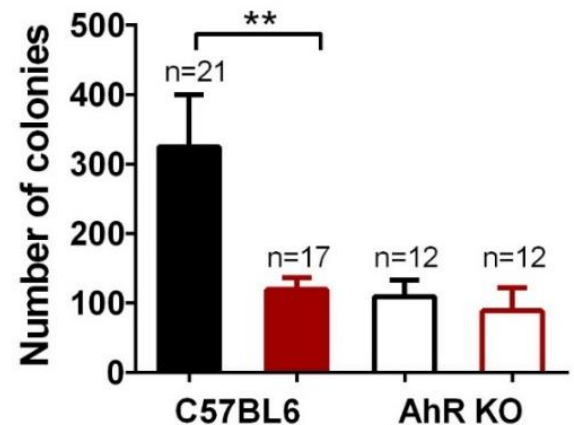

Figure 25. Laquinimod reduces the number of pulmonary B16F10 metastases if given preventively. (A) Pre-fixation total lung weight and (B) number of pulmonary metastatic colonies observed in WT mice receiving preventive daily oral gavage of Laquinimod $50 \mathrm{mg} / \mathrm{kg}$ body compared to water treated controls. (C) Number of pulmonary B16F10 metastases of mice submitted to the therapeutic regimen. (D) Number of pulmonary metastases in B16F10 melanoma cell-transferred $\mathrm{C} 57 \mathrm{BL} / 6 \mathrm{~J}$ and $\mathrm{AhR}^{-1-}$ mice treated with Laquinimod or vehicle prior to the tumor cell challenge. 


\section{DISCUSSION}

There is increasing evidence that the gut microbiome found in demyelinating CNS diseases such as MS and NMO might differ from the gut microbiome found in healthy controls ${ }^{293-296}$. While the causality of these findings needs to be clarified in the light of potential confounders from comorbidity to concomitant medications, growing experimental evidence from a number of transgenic animal models shows that the germ status of the animal facility influences the incidence of spontaneous autoimmunity as in MBP TCR transgenic mice ${ }^{297}$. Dysbiosis of the gastrointestinal microflora promotes the differentiation of proinflammatory $\mathrm{T}$ cells and organspecific autoimmunity ${ }^{118,121}$. OSE mice raised in germ-free conditions are impervious to spontaneous $\mathrm{EAE}^{103}$, suggesting that the intestinal microbiome contributes to the priming of pathogenic transgenic T cells.

The AhR is a ligand activated transcription factor that participates in broad molecular interactions, including the interplay of the immune system, diet and microbiome. The last two provide a wide range of AhR ligands leading to different effects on immune homeostasis such as control of $\mathrm{T}_{\text {regs }}$ and Th17 responses, dampen of DC maturation and regulation of gastrointestinal tolerance or inflammation mechanisms ${ }^{74}$. The present study is mainly focused on the influence of AhR expression in CNS autoimmunity and its modulation by natural ligands that can be ingested through the diet.

In the first part, a dramatic decrease in the spontaneous EAE incidence was observed in the OSE mouse model after altering one AhR ligand in their diet. Next, the repercussions of the specific AhR deletion in astrocytes and immune cells, such as DC, CD4 ${ }^{+} T$ cells and $T_{\text {regs, }}$, were evaluated in the spontaneous EAE incidence, maximum disease scores and EAE severity of the OSE mice. Due to the effect of AhR deletion in DC, which significantly increased the disease incidence in this transgenic line, a closer look was taken into the APCs compartment and the $\mathrm{CD} 4^{+} \mathrm{T}$ cell proinflammatory cytokines production of the OSE mice. 


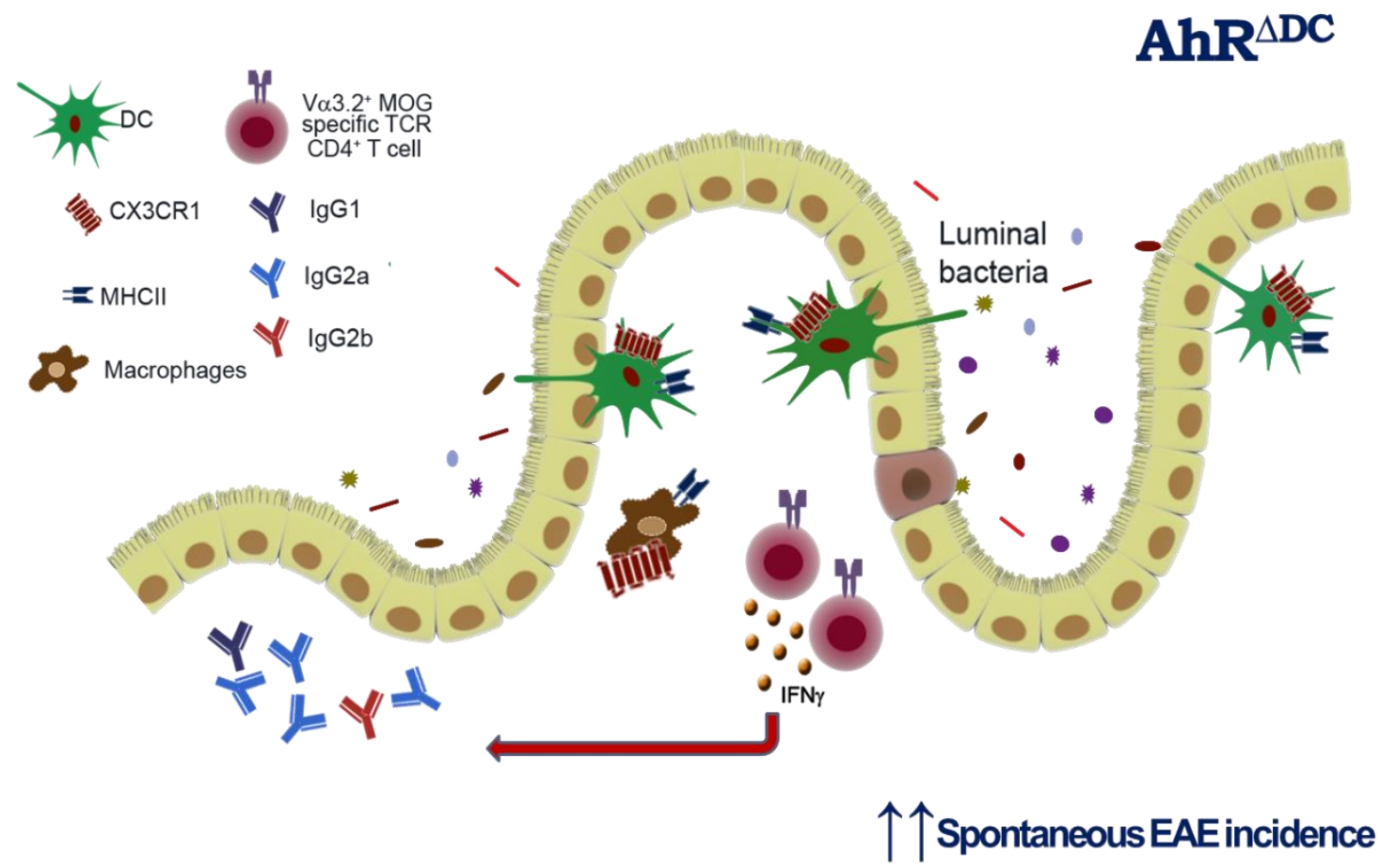

Figure 26. Graphical summary of the observed effects in the OSE mouse model harboring an AhR deletion in DC. Schematic representation of the small intestines of OSE AhR $\mathrm{R}^{\mathrm{fl} / \mathrm{fl}} \mathrm{CX} 3 \mathrm{CR} 1_{\mathrm{EGFP} /+}$. OSE mice lacking AhR in DC showed higher frequencies of LP CX3CR $1^{\text {int }} \mathrm{DC}$ (depicted in green) and IFNy producing $\mathrm{Va} 3.2^{+} \mathrm{MOG}$ specific TCR $\mathrm{CD} 4^{+} \mathrm{T}$ cells (depicted in red-brown). Isotype switching towards IgG2a secretion was enhanced and the spontaneous EAE incidence in OSE $A h R^{\Delta D C}$ CX3CR1 1 GFF/+ mice doubled in comparison to their OSE AhR competent littermates. DC might capture luminal antigens by extending transepithelial dendrites.

As shown in the graphical summary (figure 26), the specific AhR deletion in CD11c ${ }^{+}$ cells led to an increase in the frequencies of $\mathrm{CX} 3 \mathrm{CR} 1^{\text {int }} \mathrm{DC}$ compared to CX3CR1-DC measured in the $\mathrm{LP}$ of the OSE $A h R^{\triangle \mathrm{DC}} \mathrm{CX} 3 \mathrm{CR} 1^{\mathrm{EGFP} /+}$ reporter mice. Besides, higher expression of $\mathrm{MHCll}$ was quantified in $\mathrm{CX} 3 \mathrm{CR} 1^{\text {int }} \mathrm{DC}$, suggesting that OSE $A h R^{\triangle D C}$ CX3CR1 ${ }^{\mathrm{EGFP} /+}$ might exhibit DC that are better prepared for antigen presentation. In addition, a discrete increase of the IFNy producing Va3.2+ MOG specific TCR CD4+ ${ }^{+}$cells was shown in the LP of these transgenic animals, which supports the increase of lgG2a secretion measured in the OSE mice sera.

In the last part, Laquinimod, a presumed AhR ligand known by its immunomodulatory effects in DC and $\mathrm{CD}^{+} \mathrm{T}$ cells, was tested in AhR specific $\mathrm{KO}$ animals. Laquinimod's therapeutic effect seemed to be attenuated by AhR expression in DC. On the one hand, all transgenic mice with AhR deletion in $\mathrm{DC}, \mathrm{CD} 4^{+} \mathrm{T}$ cells, $\mathrm{T}_{\text {regs }}$ or astrocytes, were protected from 
78 Discussion

$E A E$ by the drug, even though in a less sustained way in $A h R^{\triangle D C}$ mice. On the other hand, the frequencies of IL17 producing CD4 ${ }^{+} \mathrm{T}$ cells were reduced in mice lacking $\mathrm{AhR}$ in $\mathrm{CD} 4^{+} \mathrm{T}$ cells but not in animals devoid of AhR in DC.

\subsection{AhR deletion in DC doubles disease incidence in the OSE mouse model}

Research conducted in AhR KO mice has shown important implications on Th17 and $\mathrm{T}_{\text {regs }}$ responding to AhR signals. Yet there was no previous evidence on a spontaneous EAE model reporting the particular repercussions of $A h R$ specific deletion in DC, astrocytes and CD4+ cells.

The data presented in figure $7 \mathrm{~A}$ showed that the lack of $A h R$ in $D C$ doubles the occurrence of spontaneous CNS autoimmunity in the OSE mice. This results support that physiological AhR ligands in the regular animal diet influence the development of spontaneous CNS autoimmunity via AhR competent DC 288 .

AhR ablation in $\mathrm{CD}_{11 \mathrm{C}^{+}}$(figure $7 \mathrm{~A}$ ) cells but not in $\mathrm{GFAP}^{+}$and $\mathrm{CD}^{+}$(figure $6 \mathrm{~A}$ and $\mathrm{D}$ ) led to a significant increase in the spontaneous EAE incidence suggesting important regulatory functions of AhR signaling in DC and certain macrophages subsets.

DC are the most potent APCs modulating immune responses and they express high AhR protein levels ${ }^{131}$. Intestinal DC have important functions maintaining the integrity of the epithelial barrier by continuously sensing gut lumen antigens. Due to their close proximity to commensal bacteria, the activation status of intestinal DC and APCs has to be tightly regulated. Imbalanced APCs might contribute to the development of gut specific autoimmunity ${ }^{298,299}$.

AhR in DC has been demonstrated to act through the Wnt signaling regulating mucosal immunity and development. For example, AhR deficient DC have a direct effect in the intestine morphogenesis affecting the differentiation of secretory epithelial cells, such as goblet and Paneth cells ${ }^{173}$. Impairment of AhR in DC is enough to elicit gut epithelium dysfunction and to increase the propensity to bowel inflammation. The disruption of the intestinal epithelium's 
integrity is considered an early EAE event, which may support disease progression and worsening ${ }^{300}$.

$\mathrm{AhR}^{\mathrm{fl} /+} \mathrm{CD} 11 \mathrm{c}^{\mathrm{Cre}+} \mathrm{R} 26 \mathrm{R}^{\mathrm{YYFP}}$ and $\mathrm{AhR}^{\mathrm{fl} /-} \mathrm{CD} 11 \mathrm{c}^{\mathrm{Cre}+} \mathrm{R} 26 \mathrm{R}^{\mathrm{eYFP}}$ mice were generated in order to sort out AhR competent and AhR deficient DC ex vivo. More than $90 \%$ of the MACS purified DC were YFP labeled. Besides, CYP1A1, a prototypic AhR regulated gene, is readily induced by FICZ in sorted YFP+ DC of $\mathrm{AhR}^{\mathrm{fl} /+} \mathrm{CD} 11 \mathrm{c}^{\mathrm{Cre}+} \mathrm{R} 26 \mathrm{R}^{\mathrm{eYFP}}$ mice (AhR competent), but not in YFP+ DC purified from $A h R^{\mathrm{fl} /-} \mathrm{CD} 11 \mathrm{c}^{\mathrm{Cre}+} \mathrm{R} 26 \mathrm{R}^{\mathrm{eYFP}}$ mice (AhR deficient). Thus, this model might be valuable to further dissect the DC phenotype and to generate functional data with AhR competent or deficient DC.

\subsection{Evaluation of intestinal $A P C s$ in the OSE $A H R^{\Delta D C}$ mice}

Taking a closer look into the intestinal APCs compartment, AhR deficient and AhR competent $D C$ were characterized in OSE $A H R^{\triangle D C}$ and OSE $A H R^{f / f / l}$ mice, respectively. Since the LP is the mucosal effector site where most of the APCs reside and contribute to the gastrointestinal immune system, DC were obtained and characterize from this compartment.

DC have a unique feature that allows them to migrate from the intestine to the mesenteric lymph nodes in the vicinity starting adaptive immune responses by priming naive T cells. Macrophages are LP residents and thus, unlikely to play a major role in the priming of naive cells. As innate effector cells, macrophages engulf and clear bacteria, secrete cytokines, and maintain intestinal homeostasis They are also very abundant and express CD11 $\mathrm{c}^{+}$in some subsets, which is considered a prototypical DC marker ${ }^{301-304}$.

Besides the ability to migrate, the intestinal APCs can be differentiated by the expression of cell surface markers. The chemokine receptor CX3CR1 (fractalkine receptor) and the high affinity IgG receptor FcyR CD64 were used to evaluate the different APCs population through a consistent gating approach. The fractalkine receptor (CX3CR1) is often used to characterize functionally and phenotypically different subsets of the intestinal immune cells, being present in the LP DC (CX3CR $\left.1^{\text {int }}\right)$ and macrophages (CX3CR $\left.1^{\text {high }}\right)^{301,302,305,306}$. 
The lack of AhR in DC affected the composition of the APCs compartment in the lamina propria of the OSE $A h R^{\triangle D C} C X 3 C R 1^{E G F P /+}$ reporter mice by increasing the percentage of CX3CR $1^{\text {int }} D C$ while decreasing the percentage of CX3CR $1^{-} \mathrm{DC}$.

Initial studies using $\mathrm{CX} 3 \mathrm{CR} 1^{\mathrm{EGFP} /+}$ reporter mice suggested that $\mathrm{DC}$ could extend transepithelial dendrites (TED) through tight junctions in the epithelium to capture luminal bacteria $^{307}$. Further studies proposed that TED formation was CX3CR1 dependent ${ }^{308}$

In addition, CD64 expression was used to distinguish DC from macrophages within the lymphocytes isolated from the gut (figure 8). Until now, CD64 seems to be the most reliable intestinal macrophage marker in the small and large bowel of humans and mice, under inflammation or steady state ${ }^{306,309}$ to unambiguously discriminate CX3CR1 ${ }^{\text {int }}$ (CD64) DC from $\mathrm{CD} 11 \mathrm{c}^{+}\left(\mathrm{CD} 64^{+}\right)$macrophages.

Furthermore, the murine receptor $\mathrm{F} 4 / 80$ expressed in most tissue resident macrophages ${ }^{310}$ was used to further characterize intestinal APCs, even though it is present in some DC subtypes, such as CD103- CD11 b+ DC 311.

Of note, CX3CR $1^{\text {int }} \mathrm{DC}$ showed higher expression of MHCIl by flow cytometry than CX3CR1- DC. Also the $\mathrm{CD} 64^{+} \mathrm{F} 4 / 80^{+} \mathrm{CX}_{3} \mathrm{CR} 1^{\text {high }}$ macrophage population in the OSE $\mathrm{AhR} \mathrm{R}^{\Delta \mathrm{DC}}$ CX3CR1 $1^{\mathrm{EGFP} /+}$ mice expressed higher levels of $\mathrm{MHCll}$ and lower levels of F4/80 compared to the $\mathrm{CD}_{64}{ }^{+} \mathrm{F} 4 / 80^{+} \mathrm{CX}{ }_{3} \mathrm{CR} 1^{\text {high }}$ macrophages of OSE $\mathrm{AhR}^{\mathrm{fl/fl}} \mathrm{CX}{ }_{3} \mathrm{CR} 1^{\mathrm{EGFP} /+}$ mice, suggesting that macrophages are more activated in the OSE $A h R^{\triangle D C} C X 3 C R 1^{E G F P /+}$ mice than in control animals.

During this project CD11 $\mathrm{c}^{\text {tdTomato }} \mathrm{CX} 3 \mathrm{CR} 1^{\text {eGFP }}$ reporter mice were generated in order to visualize the APC populations in situ, which were described by flow cytometry after tissue digestion. CD11 $\mathrm{c}^{\text {tdTomato }}$ single and CD11 $\mathrm{c}^{\text {tdTomato }} \mathrm{CX} 3 \mathrm{CR} 1{ }^{\text {eGFP }}$ double positive cells were mainly found in the LP of the small intestines while EGFP single positive cells were sparse (figure 10). Single TED were visualized using the same mice (figure 11). 
81 Discussion

\subsection{OSE AHR ${ }^{\triangle D C}$ mice produce higher amounts of IgG2a MOG antibody titers} and IFNY

The protective effect of ITE in EAE was attributed to the generation of tolerogenic DC, which secreted less proinflammatory cytokines but expressed similar $\mathrm{MHCl}, \mathrm{MHCI}, \mathrm{CD} 40$ or CD80 levels compared to DC obtained from vehicle treated controls.

It was tempting to speculate that the lack of AhR in DC might increase CX3CR1 $1^{\text {int }} \mathrm{DC}$ populations, which might be better equipped for luminal bacterial sampling. Thereby, the microbiological cues in the LP could increase and MOG specific $\mathrm{CD} 4^{+} \mathrm{T}$ cells could be better activated.

Therefore, it was next assessed if the frequency of MOG specific CD4 ${ }^{+} \mathrm{T}$ cells that produce proinflammatory cytokines is higher in the lamina propria of OSE $A h R^{\triangle D C}$ mice compared to OSE AhR $\mathrm{R}^{\mathrm{fl} / \mathrm{l}}$ control littermates.

Ex vivo analysis of $C D 4^{+} T$ cells isolated from that OSE $A H R^{\triangle D C}$ mice showed a moderate increase of IFNy but not IL17 producing MOG specific T cells (figure 14D and F). Additionally, higher MOG specific IgG2a antibody titers were found in the serum of OSE $\mathrm{AHR}^{\Delta \mathrm{DC}}$ mice compared to control animals. These results correlate well with the higher production of IFNy, known to influence immunoglobulin isotypes. Previous studies have shown that IFNy inhibits $\lg G 3, \lg G 2 b, \lg G 1$ and $\lg E$ secretion, whereas $\lg G 2 a$ production is enhanced 279,312 .

IFNy producing T cells seem to be particular relevant for the OSE mouse model, since the IFNy, but not the IL17 transcripts were increased in CNS lesions of these animals. Furthermore, in vitro stimulation of OSE splenocytes with MOG led to the secretion of IFNY and IL17 to a lesser extent ${ }^{101}$.

Interestingly, studies using AhR KO mice showed an increase of IFNy production compared to AhR competent animals. Similar results were found at mRNA level, when AhR 
KO lymphocytes were analyzed and presented higher IFNY levels than the WT ones, suggesting an AhR mediated downregulation of IFNY ${ }^{313}$.

\subsection{AhR effect on T cell differentiation}

The lack of $\mathrm{AhR}$ in $\mathrm{CD}^{+}{ }^{+} \mathrm{T}$ cells in the OSE mice did not change spontaneous $\mathrm{EAE}$ development and severity, suggesting that physiological amounts of AhR ligands do not modulate MOG specific CD4+ $\mathrm{T}$ cells directly or effectively enough to change spontaneous EAE. However, different publications have suggested a direct effect of the AhR on $T$ cell differentiation.

It has been shown that AhR activation modulates in vitro Th17 differentiation and thus, IL17 and IL22 secretion, in splenic CD4 ${ }^{+} T$ cells $^{283}$ and intestinal $\gamma \delta T$ cells ${ }^{133}$. The first publication showed that $\mathrm{T}$ cells express the AhR under Th17 polarizing conditions, whereas AhR deficiency reduces IL17 production of splenic naïve CD4 ${ }^{+} \mathrm{T}$ cells in vitro. In the second paper, it was shown a higher production of IL17 in AhR deficient $ү \delta$ T cells. Moreover, results obtained in a model of skin inflammation support these findings showing increased IL17 levels in the skin of AhR KO mice ${ }^{314}$.

The AhR has been shown to play complex roles in the differentiation of $\mathrm{T}_{\text {regs }}{ }^{142}$ and Th17 by modulating the activation of Stat $1^{283}$ and through the generation of kynurenines by IDO in DC scattered within the gut microenvironment ${ }^{135}$. Possibly, due to the strong implications of AhR signaling in IL17 producing T cells, it was unlikely that Th17 were increased in mice lacking AhR in DC.

\subsection{AhR repercussions on astrocytes}

Similarly, OSE mice which lacked AhR in astrocytes did not show any differences in the incidence of spontaneous EAE. Thus, the results presented in 3.1 .2 disagree with Rothhammer and colleagues ${ }^{126}$, who report that astrocytes can be exploited to suppress EAE if activated by AhR ligands. 
83 Discussion

As shown in figure $18 \mathrm{~b}$, an increased EAE susceptibility of vehicle treated $A h R^{\triangle A s t r o}$ mice was observed compared to vehicle treated $A h R^{f / / f l}$ mice in our Laquinimod experiments performed with $\mathrm{MOG}_{35-55}$ immunized animals, suggesting that the relevance of the astrocytic AhR in EAE might be model dependent.

\subsection{EAE incidence can be altered by modifying AhR ligands in the diet}

Although the AhR was exhaustively studied for its actions mediating the toxicity of certain xenobiotics, different physiological functions have been slowly unraveled in response to endogenous AhR ligands obtained from commensal bacteria and the diet.

Altering the composition of one natural AhR ligand, indol-3-carbinol (I3C), the disease incidence significantly dropped in a spontaneous EAE model. It was also shown that the OSE animals submitted to the $\mathrm{I} 3 \mathrm{C}$ enriched diet possess the necessary immune elements to start an immune response and are fully susceptible to develop EAE if immunized (figure 5A and B).

Previous reports treating EAE immunized mice with potent AhR agonists obtained conflicting results with different outcomes depending on the mode of ligand application. For example, systemic administration of the high affinity AhR agonist FICZ (6-formylindolo[3,2b]carbazole) by i.p. injection suppressed $\mathrm{EAE}^{142}$, whereas FICZ injection (incorporated to the antigen and CFA emulsion) exacerbated EAE pathology and promoted a Th17 response ${ }^{159}$.

In contrast, the i.p. injection of the endogenous AhR ligand 2-(1'H-indole-3'carbonyl)thiazole-4-carboxylic acid methyl ester (ITE) suppressed EAE ${ }^{174}$ and the addition of tryptophan to the diet, which is metabolized to a number of AhR ligands by gut microbiota, ameliorates actively induced $E A E$ as well ${ }^{126}$. Ingestion of indole metabolites, phytochemicals and tryptophan seemed to unequivocally help to homeostasis maintenance at epithelial barriers by producing a vast variety of AhR ligands ${ }^{125,275}$. 


\subsection{AhR mediated effect of Laquinimod on EAE}

Laquinimod, a quinoline-3-carboxamide with immunomodulatory properties ${ }^{315}$, has been presumed an AhR agonist based on the induction of CYP1A1 and AhRR (AhR repressor), two prototypical AhR regulated genes, in a number of tissues including the CNS ${ }^{194}$.

Daily oral treatment with Laquinimod completely abolishes the development of murine EAE in an AhR dependent manner, as shown by Kaye and collaborators using AhR KO and bone marrow chimeras ${ }^{194}$. It was previously demonstrated that the presence of AhR in the immune system is sufficient and necessary for Laquinimod's actions ${ }^{193,194}$. However, the exact immune population that mediates Laquinimod's therapeutic effect remains to be demonstrated. Furthermore, there is no evidence that AhR expression is directly required one single cell type.

Cell specific AhR knockout mice were used in order to define which cellular players are relevant mediators of the therapeutic efficacy of Laquinimod, including mice devoid of AhR in $\mathrm{DC}, \mathrm{CD} 4^{+} \mathrm{T}$ cells, $\mathrm{T}_{\text {regs }}$ and astrocytes (AhR $\mathrm{R}^{\Delta \mathrm{DC}}, \mathrm{AhR}^{\Delta \mathrm{CD} 4}, \mathrm{AhR}^{\Delta \mathrm{Treg}}$, and $\left.A h \mathrm{R}^{\Delta \mathrm{Astro}}\right)$.

All cell specific AhR KO mice were significantly protected by the drug as evidenced by a lack or delay of EAE symptoms in treated animals. In particular, Laquinimod treated $A h R^{\triangle C D 4}$, $\mathrm{AhR}^{\Delta \mathrm{Treg}}$, and $A h R^{\Delta A s t r o}$ mice were protected against $\mathrm{EAE}$ similarly to Laquinimod treated $A h \mathrm{f}^{\mathrm{fl} / \mathrm{fl}}$ controls. The initial protection of $A h R^{\Delta D C}$ mice against $E A E$ was less sustained over time and $2 / 3$ of the animals developed EAE symptoms compared to $7 \%$ of the $A h R^{\mathrm{fl} / \mathrm{fl}}$ mice.

If animals treated with Laquinimod developed clinical EAE at later time points, the mean maximum disease scores were not significantly different from water treated controls. This suggests that Laquinimod works better in the priming than the effector phase of EAE.

Previous experiments using C57BL/6 mice indicate that Laquinimod directly or indirectly regulates $T$ cells through its influence on APCs ${ }^{179,181-183}$. Thus, DC and T cells were the first compartments to be evaluated in all cell specific AhR KO mice treated with Laquinimod from the day of immunization. 
Splenic $T_{\text {regs }}$ were comparably induced in $A h R^{\Delta T r e g}, A h R^{\Delta C D 4}$ and $A h R^{f / / f l}$ mice by Laquinimod treatment. Decreased percentages of $\mathrm{CD}^{+} \mathrm{T}$ cells producing proinflammatory cytokines could be demonstrated equally well in Laquinimod treated $A h R^{\Delta C D 4}$ and $A h R^{f / f / l}$ mice. Nevertheless, their reduction was less impressive in $A h R^{\Delta D C}$ mice, suggesting that $A h R$ competent DC might be required for Laquinimod to lower the percentage of $\mathrm{CD}^{+} \mathrm{T}$ cells producing proinflammatory cytokines, such as IL17. This indirect effect was astonishing given that Laquinimod reduced the percentage of $\mathrm{CD} 11 \mathrm{c}^{+} \mathrm{MHCI}{ }^{\text {high }} \mathrm{DC}$ in all Cre lines including treated $\mathrm{AhR}^{\Delta \mathrm{DC}}$ mice.

AhR activation in DC has been shown to promote a tolerogenic phenotype and the TCCD mediated activation of the AhR induced the expression of the potent immunosuppressive enzyme IDO in $\mathrm{DC}^{316}$. Laquinimod therapy completely abolished $\mathrm{EAE}$ development in IDO deficient mice, demonstrating that a functional IDO1-AhR axis was not required.

The absence of AhR in astrocytes did not significantly impair the efficacy of the drug suppressing EAE. As mentioned in the previous section, $A h R^{\triangle A \text { stro }}$ mice that were $M O G$ immunized and vehicle treated developed more severe EAE compared to vehicle treated $\mathrm{AhR}^{\mathrm{fl} / \mathrm{l} l}$ mice, arguing for a higher susceptibility to develop EAE.

Supporting these data (table 22 and figure 18B), Rothhammer et al ${ }^{126}$ has previously shown that $A h R^{\triangle A s t r o}$ mice experience worsening of the $E A E$ scores compared to control animals. Additionally, they used a lentivirus construct with an AhR targeting shRNA expressed under the control of the GFAP promoter to prove that the increase of the disease severity was due to lack of the expression of AhR in astrocytes and not in $\mathrm{GFAP}^{+}$cells outside the CNS. 


\subsubsection{Laquinimod effect on NK cell cytotoxicity}

Previous results of our group demonstrated that Laquinimod effectively activates NK cells in vivo and in vitro. NK cells contribution to Laquinimod's therapeutic efficacy has been observed in vivo by a marked reduction of the drug's protective effect in EAE after NK cell depletion. Additionally, Laquinimod improved NK cell mediated killing of B16F10 melanoma cells in vitro.

Figure 20 shows a consistent elevation of the activation marker CD69 in NK1.1+ cells obtained from Laquinimod treated mice from the day of immunization. However, AhR competent $\mathrm{DC}$ and $\mathrm{CD} 4^{+} \mathrm{T}$ cells were not required for NK cell activation after Laquinimod treatment.

Next, the ability of Laquinimod to suppress B16F10 melanoma cell metastases was evaluated in vivo using preventive and therapeutic approaches. Daily oral Laquinimod treatment significantly decreased lung metastasis if given before B16F10 melanoma cells were i.v. transferred.

Even though AhR KO mice developed less metastases than C57BL/6 controls, Laquinimod failed to reduce the number of B16F10 metastases further, suggesting the AhR mediated activation of NK cells might contribute to B16F10 metastasis control.

It has been shown that AhR modulates the differentiation and activation of murine ${ }^{289}$ and human ${ }^{317}$ NK cells. In humans, CD56 ${ }^{\text {bright }}$ NK cells were shown as highly sensitive to AhR ligands, which modulate their activation, receptor expression, cytokine production and antitumor capacity ${ }^{317}$. Besides, the expression of AhR in NK cell developmental intermediates regulates their interaction with conventional DC within secondary lymphoid tissue modulating mucosal immunity during infection 292

In mice, NK cell tumor control is significantly enhanced in vivo by administering endogenous AhR ligands in WT mice inoculated with murine lymphoma RMA-S cells. Such inhibition of tumor growth is AhR dependent because its protection is completely abolished in AhR KO mice. Besides, AhR deficient NK cells have reduced cytolytic activity and antitumor 
effector functions ${ }^{289}$ and liver resident NK cells lacking AhR have an impairment of their maintenance and memory ${ }^{318}$.

\subsubsection{Final remarks on AhR mediated Laquinimod's effect}

Taking all these data together leads to different possible hypotheses. For instance, Laquinimod's protection could require downstream targets of $A h R$ signaling. Due to its promiscuity, the AhR signaling network is involved in different cellular processes and it is able to activate different pathways depending on the agonist that triggered the cascade ${ }^{319}$ For example, Laquinimod induction of $\mathrm{T}_{\text {regs }}$ responses is probably occurring through different mechanisms to the AhR signaling activated by tryptophan metabolites (which induce IDO expression in DC and lead as well to $T_{\text {regs }}$ responses) ${ }^{131,285,298,320}$.

An alternative hypothesis would consider that Laquinimod's protection is not limited by one single cell player expressing AhR but rather regulated by the interplay of different AhR competent cells. It is also possible that Laquinimod's therapeutic efficacy might require AhR competent macrophages or B cells, which were not approached in the present thesis.

In summary, the most likely scenario is that additional cell types are involved in mediating the protective efficacy of Laquinimod and that the AhR is not the only receptor mediating the protective effect of the drug. 


\section{OUTLOOK}

The present thesis showed that AhR deletion in DC augments spontaneous CNS autoimmunity, elevates the percentage of LP CX3CR $1^{\text {int }} \mathrm{DC}$ and induces a moderate increase of IFNy producing MOG specific CD4+ $\mathrm{T}$ cells. It was also shown that dietary supplementation with I3C, an AhR ligand present in cruciferous vegetables, effectively suppresses spontaneous CNS autoimmunity of AhR competent OSE mice. In further experiments newly developed tools will allow us to understand the aforementioned observations better:

In order to clarify if the AhR deficiency in DC leads to local or more disseminated changes in the APCs compartment, their analysis in the OSE $A h R^{\triangle \mathrm{DC}} \mathrm{CX} 3 \mathrm{CR} 1^{\mathrm{EGFP} /+}$ and OSE

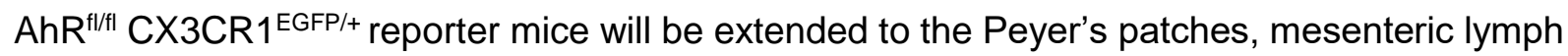
nodes and spleen.

Subsequently, it would be interesting to characterize in more detail the $A h R^{f / /+}$ $\mathrm{CD} 11 \mathrm{c}^{\mathrm{Cre}+} \mathrm{R} 26 \mathrm{R}^{\mathrm{eYFP}}$ and $A h R^{\mathrm{fl} /-} \mathrm{CD} 11 \mathrm{c}^{\mathrm{Cre}+} \mathrm{R} 26 \mathrm{R}^{\mathrm{eYFP}}$ mice and to further confirm the AhR deficiency in $\mathrm{YFP}^{+} \mathrm{DC}$ in the latter. AhR competent or AhR deficient $\mathrm{YFP}^{+} \mathrm{DC}$ could be sorted and used for RNA sequencing analyses or functional ex vivo studies with naïve MOG specific T cells as responders.

Due to the changes observed in the APCs compartment of the OSE $A H R^{\triangle D C}$ CX3CR1 $1^{\mathrm{EFP} /+}$ reporter mice, in vitro and in vivo functional studies would be desirable to test the APCs immunogenic capacity to prime T cells. In vivo, adoptive transfer of MOG specific RFP labeled $\mathrm{Va} 3.2^{+} \mathrm{CD}^{+} \mathrm{T}$ cells into $\mathrm{AhR}^{\mathrm{fl} /-} \mathrm{CD} 11 \mathrm{c}^{\mathrm{Cre}+} \mathrm{R} 26 \mathrm{R}^{\mathrm{eYFP}}$ mice or OSE $\mathrm{AHR}^{\triangle \mathrm{DC}}$ CX3CR1 $1^{\mathrm{EGFP} /+}$ animals to analyze if MOG specific T cells colocalize with LP DC and differentiate into better cytokine producers in mice expressing AhR deficient DC. In vitro, cocultures of MOG specific RFP labeled Va3.2 ${ }^{+} \mathrm{CD} 4^{+} \mathrm{T}$ cells and intestinal DC sorted from $\mathrm{AhR}^{\mathrm{fl} /-}$ CD11c ${ }^{\mathrm{Cre}+} \mathrm{R} 26 \mathrm{R}^{\mathrm{eYFP}}$ mice would allow to measure $\mathrm{T}$ cell activation and proliferation.

This work provided compelling evidence of the regulatory role of the AhR in spontaneous CNS autoimmunity. It was shown that the increase of one single AhR ligand (I3C) 
dramatically diminished disease incidence in a model of spontaneous EAE. Having available the molecular tools, it would be interesting to evaluate which are the most relevant cells mediating AhR's actions through the diet. Therefore, following experiments aim to study the effect of the chemically defined diet (E1500) supplemented with $13 C^{2 \mathrm{mg} / \mathrm{kg}}$ in the cell specific AhR KO mice (OSE $A h R^{\Delta D C}$, OSE $A h R^{\Delta C D 4}$ and OSE $A h R^{\triangle A s t r o}$ transgenic lines). Furthermore, it will be investigated if the I3C supplied in the chow decreases the percentage of LP CX3CR $1^{\text {int }}$ DC obtained from the small intestines.

Furthermore, spontaneous stool samples and the contents of the small intestines of OSE mice (kept under a regular, chemically defined or $13 C^{2 \mathrm{mg} / \mathrm{kg}}$ enriched chemically defined diet) have been snap frozen during this project. The next step will be to use the samples to characterize the composition and differences between the gut microbiomes.

The results obtained in this thesis indicated that Laquinimod's protection is either supported by additional cell types apart from the ones studied or is conferred by an effect on multiple cell types simultaneously. That is why it would be necessary to test mice with AhR deleted in further cell types, such as $B$ cells, macrophages and NK cells (AhR ${ }^{\Delta M a c}, A_{h} R^{\Delta B c e l l}$ and $A h R^{\Delta N K c e l l}$ ) using the corresponding Cre lines (LysM ${ }^{\text {Cre }}, N K p 46^{\text {Cre }}$ and $\mathrm{mb}^{\text {Cre }}$ mice). Furthermore, it is likely that AhR independent effects contribute to Laquinimod's protection from autoimmunity. 


\section{CONCLUSIONS}

CNS autoimmune diseases are likely caused by a complex interplay of genetic and environmental factors. One of the well-established environmental sensors is the aryl hydrocarbon receptor $(\mathrm{AhR})$, which is widely expressed in the immune and central nervous system (CNS). The AhR is not only activated by pollutants such as TCDD but also by a number of physiological ligands of the diet, the commensal flora and diverse metabolites produced by the host.

This study assessed if the incidence and severity of spontaneous EAE in OSE mice are modified by the selective deletion of AhR in immune cells (including DC, CD4 ${ }^{+} \mathrm{T}$ cells and $\mathrm{T}_{\text {regs }}$ ) or in CNS resident cells, such as astrocytes. AhR deletion in CD11c cells significantly increased spontaneous EAE incidence in the OSE mice. In contrast, OSE animals lacking AhR competent $\mathrm{CD}^{+}{ }^{+} \mathrm{T}$ cells, $\mathrm{T}_{\text {regs }}$ or astrocytes did not differ to OSE $\mathrm{AhR}^{\mathrm{fl} / \mathrm{fl}}$ control littermates in their ability to mount a CNS autoimmune response.

Using OSE AhR ${ }^{\triangle D C}$ CX3CR1 $1^{\mathrm{EGFP} /+}$ reporter mice, it was demonstrated that $\mathrm{AhR}$ deficiency led to changes in the intestinal APCs by upregulating the percentage of DC intermediately expressing CX3CR1 (CX3CR $\left.1^{\text {int }} \mathrm{DC}\right)$ in the lamina propria (LP) of OSE mice. CX3CR1 ${ }^{+}$DC expressed higher levels of MHCII compared to CX3CR1- DC. Therefore, they might be better equipped to mount a CD4 ${ }^{+} \mathrm{T}$ cell response.

Generating CD11 $\mathrm{c}^{\text {tdTomato }} \mathrm{CX} 3 \mathrm{CR} 1^{\text {eGFP }}$ transgenic mice, the presence of $\mathrm{CD} 11 \mathrm{c}^{+}$and $\mathrm{CD} 11 \mathrm{C}^{+} \mathrm{CX} 3 \mathrm{CR} 1^{+}$double positive DC was confirmed in histological sections of the intestinal LP. Interestingly, a number of previous studies emphasized the unique ability of CX3CR $1^{+} \mathrm{DC}$ in the LP to sample gut bacteria.

The ablation of AhR competent DC in OSE mice increased the frequency of IFNY producing MOG specific CD4+ ${ }^{+}$cells in the LP and led to higher titers of MOG specific $\lg G 2 a$ antibodies in the sera of the mice. 
Demonstrating the therapeutic potential of AhR targeted medications, the spontaneous EAE was almost completely abolished in OSE mice by increasing the dietary intake of one single AhR ligand present in cruciferous vegetables, the indol-3-carbinol (I3C).

While AhR deletion in astrocytes did not influence spontaneous autoimmunity in the OSE mouse model, it worsened $\mathrm{EAE}$ in $\mathrm{MOG}_{35-55}$ immunized $\mathrm{AhR}^{\mathrm{AAstro}}$ mice suggesting that the relevance of astrocytic AhR might be model dependent.

Laquinimod is a presumed AhR agonist, which was moderately effective in reducing relapse rates in clinical trials with RRMS patients. Cell specific AhR knock out mice were generated in order to analyze which cell type is relevant for the therapeutic efficacy of Laquinimod to suppress EAE. Laquinimod treatment protected all cell specific AhR deficient mice against EAE. However, its protective effect was less sustained in $A h R^{\Delta D C}$ mice. Moreover, Laquinimod reduced the percentage of IL17 producing CD4 ${ }^{+} \mathrm{T}$ cells in $\mathrm{AhR}^{\triangle \mathrm{CD} 4}$ mice but not in $A h R^{\triangle D C}$ animals, arguing for a rather indirect effect of the drug on $T$ cells.

In summary, it was demonstrated that physiological concentrations of AhR ligands modulate spontaneous autoimmunity via AhR competent DC. Additionally, MS patients might benefit from increasing their dietary uptake of AhR ligands 


\section{REFERENCES}

1. Filion, L. G., Graziani-Bowering, G., Matusevicius, D. \& Freedman, M. S. Monocytederived cytokines in multiple sclerosis. Clin. Exp. Immunol. 131, 324-334 (2003).

2. Noseworthy, J. H., Lucchinetti, C., Rodriguez, M. \& Weinshenker, B. G. Multiple sclerosis. N. Engl. J. Med. 343, 938-952 (2000).

3. Compston, A. \& Coles, A. Multiple sclerosis. Lancet 372, 1502-1517 (2008).

4. Leray, E., Moreau, T., Fromont, A. \& Edan, G. Epidemiology of multiple sclerosis. Rev. Neurol. (Paris). 172, 3-13 (2016).

5. Feigin, V. L. et al. Global, regional, and national burden of neurological disorders during 1990-2015: a systematic analysis for the Global Burden of Disease Study 2015. Lancet Neurol. 16, 877-897 (2017).

6. Kingwell, E. et al. Incidence and prevalence of multiple sclerosis in Europe: a systematic review. BMC Neurol. 13, 128 (2013).

7. Wade, B. J. Spatial Analysis of Global Prevalence of Multiple Sclerosis Suggests Need for an Updated Prevalence Scale. Mult. Scler. Int. 1-7 (2014).

8. Höer, A. et al. Multiple sclerosis in Germany: data analysis of administrative prevalence and healthcare delivery in the statutory health system. BMC Health Serv. Res. 14, 381 (2014).

9. Ahlgren, C., Odén, A. \& Lycke, J. High nationwide incidence of multiple sclerosis in Sweden. PLoS One 9, (2014).

10. Harbo, H. F., Gold, R. \& Tintoré, M. Sex and gender issues in multiple sclerosis. Ther. Adv. Neurol. Disord. 6, 237-248 (2013).

11. Gomes, M. da M. \& Engelhardt, E. Jean-Martin Charcot, father of modern neurology: an homage 120 years after his death. Arq. Neuropsiquiatr. 71, 815-817 (2013).

12. Reich, D. S., Lucchinetti, C. F. \& Calabresi, P. A. Multiple Sclerosis. N. Engl. J. Med. 378, 169-180 (2018).

13. Watson, C. T., Disanto, G., Breden, F., Giovannoni, G. \& Ramagopalan, S. V. Estimating the proportion of variation in susceptibility to multiple sclerosis captured by common SNPs. Sci. Rep. 2, 770 (2012).

14. Baranzini, S. E. \& Oksenberg, J. R. The Genetics of Multiple Sclerosis: From 0 to 200 in 50 Years. Trends Genet. 33, 960-970 (2017).

15. Dyment, D. A., Dessa Sadnovich, A. \& Ebers, G. C. Genetics of multiple sclerosis. Hum. Mol. Genet. 6, 1693-1698 (1997).

16. Willer, C. J., Dyment, D. A., Risch, N. J., Sadovnick, A. D. \& Ebers, G. C. Twin concordance and sibling recurrence rates in multiple sclerosis. Proc. Natl. Acad. Sci. 100, 12877-12882 (2003).

17. Hawkes, C. H. \& Macgregor, A. J. Twin studies and the heritability of MS: A conclusion. Mult. Scler. 15, 661-667 (2009).

18. Rejdak, K., Jackson, S. \& Giovannoni, G. Multiple sclerosis: A practical overview for clinicians. Br. Med. Bull. 95, 79-104 (2010).

19. Handunnetthi, L., Handel, A. E. \& Ramagopalan, S. V. Contribution of genetic, 
epigenetic and transcriptomic differences to twin discordance in multiple sclerosis. Expert Rev. Neurother. 10, 1379-1381 (2010).

20. Souren, N. Y. P. et al. Mitochondrial DNA Variation and Heteroplasmy in Monozygotic Twins Clinically Discordant for Multiple Sclerosis. Hum. Mutat. 37, 765-775 (2016).

21. Sadovnick, A. D. \& Ebers, G. C. Epidemiology of Multiple Sclerosis: A Critical Overview. Can. J. Neurol. Sci. / J. Can. des Sci. Neurol. 20, 17-29 (1993).

22. Ebers, G. C. \& Sadovnick, a D. The role of genetic factors in multiple sclerosis susceptibility. J. Neuroimmunol. 54, 1-17 (1994).

23. Schapira, K., Poskanzer, D. C. \& Miller, H. Familial and conjugal multiple sclerosis. Acta Neurol. Scand. 42, 83-84 (1966).

24. Nielsen, N. M. et al. Familial risk of multiple sclerosis: A nationwide cohort study. Am. J. Epidemiol. 162, 774-778 (2005).

25. Koch, M. W. et al. Progression in familial and nonfamilial MS. Mult. Scler. 14, 300-306 (2008).

26. Hoppenbrouwers, I. A. et al. Familial clustering of MS in a Dutch genetic isolate. Neurology 64, A85-A85 (2005).

27. Ebers, G. C., Yee, I. M., Sadovnick, A. D. \& Duquette, P. Conjugal multiple sclerosis: population-based prevalence and recurrence risks in offspring. Canadian Collaborative Study Group. Ann. Neurol. 48, 927-31 (2000).

28. Barcellos, L. F. et al. Heterogeneity at the HLA-DRB1 locus and risk for multiple sclerosis. Hum. Mol. Genet. 15, 2813-2824 (2006).

29. Ramagopalan, S. V., Knight, J. C. \& Ebers, G. C. Multiple sclerosis and the major histocompatibility complex. Curr. Opin. Neurol. 22, 219-225 (2009).

30. Tiwari, J. L. \& Terasaki, P. I. HLA-DR and disease associations. Prog Clin Biol Res (1981).

31. Bergamaschi, L. et al. Association of HLA class I markers with multiple sclerosis in the Italian and UK population: Evidence of two independent protective effects. J. Med. Genet. 48, 485-492 (2011).

32. Wang, Z. et al. Nuclear Receptor NR1H3 in Familial Multiple Report Nuclear Receptor NR1H3 in Familial Multiple Sclerosis. Neuron 90, 948-954 (2016).

33. Gregory, S. G. et al. Interleukin 7 receptor $\alpha$ chain (IL7R) shows allelic and functional association with multiple sclerosis. Nat. Genet. 39, 1083-1091 (2007).

34. Wallentin, L. et al. Risk Alleles for Multiple Sclerosis Identified by a Genomewide Study. N. Engl. J. Med. 357, 851-862 (2007).

35. De Jager, P. L. et al. Meta-analysis of genome scans and replication identify CD6, IRF8 and TNFRSF1A as new multiple sclerosis susceptibility loci. Nat. Genet. 41, 776-782 (2009).

36. Pierrot-Deseilligny, C. \& Souberbielle, J.-C. Contribution of vitamin D insufficiency to the pathogenesis of multiple sclerosis. Ther. Adv. Neurol. Disord. 6, 81-116 (2013).

37. Marrie, R. A. Environmental risk factors in multiple sclerosis aetiology. Lancet. Neurol. 3, 709-18 (2004).

38. Kurtzke, J. F. Multiple sclerosis: changing times. Neuroepidemiology (1991). doi:10.1159/000110240 
39. Kurtzke, J. F. Epidemiologic contributions to multiple sclerosis: an overview. Neurology 30, 61-79 (1980).

40. Makhani, N. et al. MS incidence and prevalence in Africa, Asia, Australia and New Zealand: A systematic review. Mult. Scler. Relat. Disord. 3, 48-60 (2014).

41. Koch-Henriksen, N. \& Sørensen, P. S. The changing demographic pattern of multiple sclerosis epidemiology. Lancet Neurol. 9, 520-532 (2010).

42. Rosati, G. The prevalence of multiple sclerosis in the world: an update. Neurol. Sci. 22, 117-139 (2001).

43. Rojas, J. I., Romano, M., Patrucco, L. \& Cristiano, E. A systematic review about the epidemiology of primary progressive multiple sclerosis in Latin America and the Caribbean. Mult. Scler. Relat. Disord. 22, 1-7 (2018).

44. Pugliatti, M. et al. The epidemiology of multiple sclerosis in Europe. Eur. J. Neurol. 13, 700-722 (2006).

45. Sun, H. Temperature dependence of multiple sclerosis mortality rates in the United States. Mult. Scler. J. 23, 1839-1846 (2017).

46. Pandit, L. et al. Association of vitamin D and multiple sclerosis in India. Mult. Scler. J. 19, 1592-1596 (2013).

47. Simpson, S., Blizzard, L., Otahal, P., Van Der Mei, I. \& Taylor, B. Latitude is significantly associated with the prevalence of multiple sclerosis: A meta-analysis. J. Neurol. Neurosurg. Psychiatry 82, 1132-1141 (2011).

48. Kragt, J. et al. Higher levels of 25-hydroxyvitamin D are associated with a lower incidence of multiple sclerosis only in women. Mult. Scler. J. 15, 9-15 (2009).

49. Langer-Gould, A. et al. Vitamin D, pregnancy, breastfeeding, and postpartum multiple sclerosis relapses. Arch. Neurol. 68, 310-313 (2011).

50. Holick, M. F. Vitamin D Deficiency. N. Engl. J. Med. 357, 266-281 (2007).

51. Norval, M. Effects of solar radiation on the human immune system. Compr. Ser. Photosciences 3, 91-113 (2001).

52. Duthie, M. S., Kimber, I. \& Norval, M. The effects of ultraviolet radiation on the human immune system. Br. J. Dermatol. 140, 995-1009 (1999).

53. Gouras, G. K. et al. Intraneuronal A 342 accumulation in human brain. Am. J. Pathol. 156, 15-20 (2000).

54. Alharbi, F. M. Update in vitamin D and multiple sclerosis. Neurosciences 20, 329-335 (2015).

55. Christakos, S., Dhawan, P., Verstuyf, A., Verlinden, L. \& Carmeliet, G. Vitamin D: Metabolism, Molecular Mechanism of Action, and Pleiotropic Effects. Physiol. Rev. 96, 365-408 (2016).

56. Dörr, J., Döring, A. \& Paul, F. Can we prevent or treat multiple sclerosis by individualised vitamin D supply? EPMA J. 4, 4 (2013).

57. Mostafa, W. Z. \& Hegazy, R. A. Vitamin D and the skin: Focus on a complex relationship: A review. J. Adv. Res. 6, 793-804 (2013).

58. Swank, R. L., Lerstad, O., Strøm, A. \& Backer, J. Multiple Sclerosis in Rural Norway. N. Engl. J. Med. 246, 721-728 (1952).

59. Esposito, S., Bonavita, S., Sparaco, M., Gallo, A. \& Tedeschi, G. The role of diet in 
multiple sclerosis: A review. Nutr. Neurosci. (2017). doi:10.1080/1028415X.2017.1303016

60. Swank, R. L. \& Dugan, B. B. Effect of low saturated fat diet in early and late cases of multiple sclerosis. Lancet 336, 37-39 (1990).

61. Swank, R. L. \& Grimsgaard, A. Multiple sclerosis: the lipid relationship. Am. J. Clin. Nutr. 48, 1387-1393 (1988).

62. Farez, M. F., Fiol, M. P., Gaitán, M. I., Quintana, F. J. \& Correale, J. Sodium intake is associated with increased disease activity in multiple sclerosis. J. Neurol. Neurosurg. Psychiatry 86, 26-31 (2015).

63. McDonald, J. et al. A case-control study of dietary salt intake in pediatric-onset multiple sclerosis. Mult. Scler. Relat. Disord. 6, 87-92 (2016).

64. Wilck, N. et al. Salt-responsive gut commensal modulates TH17 axis and disease. Nature 551, 585-589 (2017).

65. Lauer, K. Diet and multiple sclerosis. Neurology 49, S55 LP-S61 (1997).

66. Riccio, P. \& Rossano, R. Nutrition facts in multiple sclerosis. ASN Neuro 7, 1-20 (2015).

67. Mische, L. J. \& Mowry, E. M. The Evidence for Dietary Interventions and Nutritional Supplements as Treatment Options in Multiple Sclerosis: a Review. Curr. Treat. Options Neurol. 20, 8 (2018).

68. Gardener, H. Mediterranean Diet and White Matter Hyperintensity Volume in the Northern Manhattan Study. Arch. Neurol. 69, 251 (2012).

69. Hubbard, T. . et al. Dietary broccoli impacts microbial community structure and attenuates chemically induced colitis in mice in an Ah receptor dependent manner. $J$. Funct. Foods (2017). doi:10.1016/J.JFF.2017.08.038

70. Berer, K. \& Krishnamoorthy, G. Commensal gut flora and brain autoimmunity: a love or hate affair? Acta Neuropathol. 123, 639-51 (2012).

71. Sedaghat, F., Jessri, M., Behrooz, M., Mirghotbi, M. \& Rashidkhani, B. Mediterranean diet adherence and risk of multiple sclerosis: A case-control study. Asia Pac. J. Clin. Nutr. 25, 377-384 (2016).

72. Ye, J. et al. The Aryl Hydrocarbon Receptor Preferentially Marks and Promotes Gut Regulatory T Cells. Cell Rep. 21, 2277-2290 (2017).

73. Macdonald, T. T. \& Monteleone, G. Immunity, inflammation, and allergy in the gut. Science 307, 1920-5 (2005).

74. Zelante, T. et al. Tryptophan feeding of the IDO1-AhR axis in host-microbial symbiosis. Front. Immunol. 5, 1-4 (2014).

75. Kiss, E. A. \& Diefenbach, A. Role of the aryl hydrocarbon receptor in controlling maintenance and functional programs of RORyt+ innate lymphoid cells and intraepithelial lymphocytes. Front. Immunol. 3, 1-11 (2012).

76. Hooper, L. V. You AhR what you eat: Linking diet and immunity. Cell 147, 489-491 (2011).

77. Benson, J. M. \& Shepherd, D. M. Dietary ligands of the aryl hydrocarbon receptor induce anti-inflammatory and immunoregulatory effects on murine dendritic cells. Toxicol. Sci. 124, 327-338 (2011).

78. Altowaijri, G., Fryman, A. \& Yadav, V. Dietary Interventions and Multiple Sclerosis. Curr. 
Neurol. Neurosci. Rep. 17, 28 (2017).

79. Guerrero-García, J. D. J. et al. Multiple Sclerosis and Obesity: Possible Roles of Adipokines. Mediators Inflamm. 2016, (2016).

80. Hedström, A. K. et al. Interaction between adolescent obesity and HLA risk genes in the etiology of multiple sclerosis. Neurology 82, 865-872 (2014).

81. Langer-Gould, A., Brara, S. M., Beaber, B. E. \& Koebnick, C. Childhood obesity and risk of pediatric multiple sclerosis and clinically isolated syndrome. Neurology 80, 548-552 (2013).

82. Payne, a. Nutrition and diet in the clinical management of multiple sclerosis. J Hum Nutr Diet 14, 349-357 (2001).

83. Weinstock-Guttman, B. et al. Serum lipid profiles are associated with disability and MRI outcomes in multiple sclerosis. J Neuroinflammation 8, 127 (2011).

84. Hubbard, E. A., Motl, R. W. \& Fernhall, B. Sedentary Behavior and Blood Pressure in Patients with Multiple Sclerosis. Int. J. MS Care 20, 1-8 (2018).

85. Virtanen, J. O. \& Jacobson, S. Viruses and multiple sclerosis. CNS Neurol. Disord. Drug Targets 11, 528-44 (2012).

86. Leibovitch, E. C. \& Jacobson, S. Evidence linking HHV-6 with multiple sclerosis: an update. Curr. Opin. Virol. 9, 127-33 (2014).

87. Pender, M. P. \& Burrows, S. R. Epstein-Barr virus and multiple sclerosis: potential opportunities for immunotherapy. Clin. Transl. Immunol. 3, e27 (2014).

88. Lassmann, H., Niedobitek, G., Aloisi, F. \& Middeldorp, J. M. Epstein-Barr virus in the multiple sclerosis brain: A controversial issue-report on a focused workshop held in the Centre for Brain Research of the Medical University of Vienna, Austria. Brain 134, 27722786 (2011).

89. Owens, G. P., Gilden, D., Burgoon, M. P., Yu, X. \& Bennett, J. L. Viruses and Multiple Sclerosis. Neurosci. 17, 659-676 (2011).

90. Levin, L. I., Munger, K. L., O’Reilly, E. J., Falk, K. I. \& Ascherio, A. Primary infection with the Epstein-Barr virus and risk of multiple sclerosis. Ann. Neurol. 67, 824-830 (2010).

91. Libbey, J. E., McCoy, L. L. \& Fujinami, R. S. B. T.-I. R. of N. Molecular Mimicry in Multiple Sclerosis. in The Neurobiology of Multiple Sclerosis 79, 127-147 (Academic Press, 2007).

92. Constantinescu, C. S., Farooqi, N., O’Brien, K. \& Gran, B. Experimental autoimmune encephalomyelitis (EAE) as a model for multiple sclerosis (MS). Br. J. Pharmacol. 164, 1079-106 (2011).

93. McCarthy, D. P., Richards, M. H. \& Miller, S. D. Mouse Models of Multiple Sclerosis: Experimental Autoimmune Encephalomyelitis and Theiler's Virus-Induced Demyelinating Disease. 900, 381-401 (2012).

94. Contarini, G., Giusti, P. \& Skaper, S. D. Active induction of experimental autoimmune encephalomyelitis in C57BL/6 mice. Methods in Molecular Biology 1727, (2018).

95. Tuohy, V. K., Sobel, R. A., Lu, Z., Laursen, R. A. \& Lees, M. B. Myelin proteolipid protein: minimum sequence requirements for active induction of autoimmune encephalomyelitis in SWR/J and SJL/J mice. J. Neuroimmunol. 39, 67-74 (1992).

96. Mendel, I., de Rosbo, N. K. \& Ben-Nun, A. A myelin oligodendrocyte glycoprotein peptide induces typical chronic experimental autoimmune encephalomyelitis in $\mathrm{H}-2 \mathrm{~b}$ 
mice: Fine specificity and T cell receptor V $\beta$ expression of encephalitogenic $T$ cells. Eur. J. Immunol. 25, 1951-1959 (1995).

97. Amor, S. et al. Identification of epitopes of myelin oligodendrocyte glycoprotein for the induction of experimental allergic encephalomyelitis in SJL and Biozzi AB/H mice. $J$. Immunol. 153, 4349-4356 (1994).

98. Ando, D. G., Clayton, J., Kono, D., Urban, J. L. \& Sercarz, E. E. Encephalitogenic T cells in the B10.PL model of experimental allergic encephalomyelitis (EAE) are of the Th-1 lymphokine subtype. Cell. Immunol. 124, 132-143 (1989).

99. Stojković, A., Maslovarić, I., Kosanović, D. \& Vučetić, D. Pertussis vaccine-induced experimental autoimmune encephalomyelitis in mice. Transl. Neurosci. 5, 57-63 (2014).

100. Mannara, F. et al. Passive experimental autoimmune encephalomyelitis in C57BL/6 with MOG: evidence of involvement of B cells. PLoS One 7, e52361 (2012).

101. Krishnamoorthy, G., Lassmann, H., Wekerle, H. \& Holz, A. Spontaneous opticospinal encephalomyelitis in a double-transgenic mouse model of autoimmune $\mathrm{T}$ cell/B cell cooperation. J. Clin. Invest. 116, 2385-92 (2006).

102. Bettelli, E., Baeten, D., Jäger, A., Sobel, R. a \& Kuchroo, V. K. Myelin oligodendrocyte glycoprotein-specific T and B cells cooperate to induce a Devic-like disease in mice. J. Clin. Invest. 116, 2393-402 (2006).

103. Berer, K. et al. Commensal microbiota and myelin autoantigen cooperate to trigger autoimmune demyelination. Nature 479, 538-41 (2011).

104. Ransohoff, R. M. A mighty mouse: Building a better model of multiple sclerosis. J. Clin. Invest. 116, 2313-2316 (2006).

105. Ley, R. E., Peterson, D. A. \& Gordon, J. I. Ecological and evolutionary forces shaping microbial diversity in the human intestine. Cell 124, 837-848 (2006).

106. Pereira, F. C. \& Berry, D. Microbial nutrient niches in the gut. Environ. Microbiol. 19, 1366-1378 (2017).

107. Eckburg, P. B. et al. Diversity of the human intestinal microbial flora. Science 308, 16358 (2005).

108. Shi, N., Li, N., Duan, X. \& Niu, H. Interaction between the gut microbiome and mucosal immune system. Mil. Med. Res. 4, 14 (2017).

109. Magrone, T. \& Jirillo, E. The Interplay between the Gut Immune System and Microbiota in Health and Disease: Nutraceutical Intervention for Restoring Intestinal Homeostasis. Curr. Pharm. Des. 19, 1329-1342 (2012).

110. Cheroutre, H. Starting at the Beginning: New Perspectives on the Biology of Mucosal T Cells. Annu. Rev. Immunol. 22, 217-246 (2004).

111. Cheroutre, H., Lambolez, F. \& Mucida, D. The light and dark sides of intestinal intraepithelial lymphocytes. Nat. Rev. Immunol. 11, 445-56 (2011).

112. Qiu, Y., Peng, K., Liu, M., Xiao, W. \& Yang, H. CD8aa TCRaß Intraepithelial Lymphocytes in the Mouse Gut. Dig. Dis. Sci. 61, 1451-1460 (2016).

113. Ruddle, N. H. \& Akirav, E. M. Secondary lymphoid organs: responding to genetic and environmental cues in ontogeny and the immune response. J. Immunol. 183, 2205-12 (2009).

114. Jung, C., Hugot, J.-P. \& Barreau, F. Peyer's Patches: The Immune Sensors of the Intestine. Int. J. Inflam. 2010, 1-12 (2010). 
115. Wu, T. H. et al. Progression of cancer from indolent to aggressive despite antigen retention and increased expression of interferon-gamma inducible genes. Cancer Immun. a J. Acad. Cancer Immunol. 11, 2 (2011).

116. van der Meulen, T. et al. The microbiome-systemic diseases connection. Oral Dis. 22, 719-734 (2016).

117. Mazmanian, S. K., Cui, H. L., Tzianabos, A. O. \& Kasper, D. L. An immunomodulatory molecule of symbiotic bacteria directs maturation of the host immune system. Cell 122, 107-118 (2005).

118. Ivanov, I. I. et al. Induction of intestinal Th17 cells by segmented filamentous bacteria. Cell 139, 485-98 (2009).

119. Kuwahara, T. et al. The lifestyle of the segmented filamentous bacterium: A nonculturable gut-associated immunostimulating microbe inferred by whole-genome sequencing. DNA Res. 18, 291-303 (2011).

120. Atarashi, K. et al. Induction of colonic regulatory $\mathrm{T}$ cells by indigenous Clostridium species. Science 331, 337-41 (2011).

121. Atarashi, K. et al. Treg induction by a rationally selected mixture of Clostridia strains from the human microbiota. Nature 500, 232-236 (2013).

122. Schmidt, J. V \& Bradfield, C. a. Ah receptor signaling pathways. Annu. Rev. Cell Dev. Biol. 12, 55-89 (1996).

123. Esser, C. \& Rannug, A. The Aryl Hydrocarbon Receptor in Barrier Organ Physiology, Immunology, and Toxicology. Pharmacol. Rev. 67, 259-279 (2015).

124. Zhou, L. AHR Function in Lymphocytes: Emerging Concepts. Trends Immunol. 37, 1731 (2016).

125. Li, Y. et al. Exogenous stimuli maintain intraepithelial lymphocytes via aryl hydrocarbon receptor activation. Cell 147, 629-640 (2011).

126. Rothhammer, V. et al. Type I interferons and microbial metabolites of tryptophan modulate astrocyte activity and central nervous system inflammation via the aryl hydrocarbon receptor. Nat. Med. 22, 586-97 (2016).

127. Williamson, M. A., Gasiewicz, T. A. \& Opanashuk, L. A. Aryl hydrocarbon receptor expression and activity in cerebellar granule neuroblasts: Implications for development and dioxin neurotoxicity. Toxicol. Sci. 83, 340-348 (2005).

128. Esser, C., Rannug, A. \& Stockinger, B. The aryl hydrocarbon receptor in immunity. Trends Immunol. 30, 447-54 (2009).

129. Quintana, F. J. Regulation of central nervous system autoimmunity by the aryl hydrocarbon receptor. Semin. Immunopathol. 35, 627-635 (2013).

130. Veldhoen, M. et al. The aryl hydrocarbon receptor links TH17-cell-mediated autoimmunity to environmental toxins. Nature 453, 106-9 (2008).

131. Jux, B., Kadow, S. \& Esser, C. Langerhans Cell Maturation and Contact Hypersensitivity Are Impaired in Aryl Hydrocarbon Receptor-Null Mice. J. Immunol. 182, 6709-6717 (2009).

132. Marcus, R. S., Holsapple, M. P. \& Kaminski, N. E. Lipopolysaccharide activation of murine splenocytes and splenic B cells increased the expression of aryl hydrocarbon receptor and aryl hydrocarbon receptor nuclear translocator. J. Pharmacol. Exp. Ther. 287, 1113-8 (1998). 
133. Martin, B., Hirota, K., Cua, D. J., Stockinger, B. \& Veldhoen, M. Interleukin-17-Producing үठ T Cells Selectively Expand in Response to Pathogen Products and Environmental Signals. Immunity 31, 321-330 (2009).

134. Villa, M. et al. Aryl hydrocarbon receptor is required for optimal B-cell proliferation. EMBO J. 36, 116-128 (2017).

135. Stockinger, B., Hirota, K., Duarte, J. \& Veldhoen, M. External influences on the immune system via activation of the aryl hydrocarbon receptor. Semin. Immunol. 23, 99-105 (2011).

136. Stockinger, B., Meglio, P. Di, Gialitakis, M. \& Duarte, J. H. The Aryl Hydrocarbon Receptor: Multitasking in the Immune System. Annu. Rev. Immunol. 32, 403-432 (2014).

137. Quintana, F. J. The aryl hydrocarbon receptor: A molecular pathway for the environmental control of the immune response. Immunology 138, 183-189 (2013).

138. Hahn, M. E., Allan, L. L. \& Sherr, D. H. Regulation of constitutive and inducible AHR signaling: Complex interactions involving the AHR repressor. Biochem. Pharmacol. 77, 485-497 (2009).

139. Murray, I. A., Nichols, R. G., Zhang, L., Patterson, A. D. \& Perdew, G. H. Expression of the aryl hydrocarbon receptor contributes to the establishment of intestinal microbial community structure in mice. Sci. Rep. 6, 33969 (2016).

140. Wheeler, M. A., Rothhammer, V. \& Quintana, F. J. Control of immune-mediated pathology via the aryl hydrocarbon receptor. J. Biol. Chem. 292, 12383-12389 (2017).

141. Pallotta, M. T., Fallarino, F., Matino, D., Macchiarulo, A. \& Orabona, C. AhR-mediated, non-genomic modulation of IDO1 function. Front. Immunol. 5, 1-6 (2014).

142. Quintana, F. J. et al. Control of $T(r e g)$ and $T(H) 17$ cell differentiation by the aryl hydrocarbon receptor. Nature 453, 65-71 (2008).

143. Behnsen, J. \& Raffatellu, M. Keeping the peace: Aryl hydrocarbon receptor signaling modulates the mucosal microbiota. Immunity 39, 206-207 (2013).

144. Li, S., Bostick, J. \& Zhou, L. Regulation of Innate Lymphoid cells by Aryl Hydrocarbon Receptor. Front. Immunol. - Rev. 8, (2017).

145. Sabatino, J. J. \& Zamvil, S. S. Aryl hydrocarbon receptor activity may serve as a surrogate marker for MS disease activity. Neurol. - Neuroimmunol. Neuroinflammation 4, e366 (2017).

146. Fernandez-Salguero, P. et al. Immune system impairment and hepatic fibrosis in mice lacking the dioxin-binding Ah receptor. Science 268, 722-6 (1995).

147. Lahvis, G. P. \& Bradfield, C. A. Ahr null alleles: Distinctive or different? Biochem. Pharmacol. 56, 781-787 (1998).

148. Mimura, J. et al. Loss of teratogenic response to 2,3,7,8-tetrachlorodibenzo-p-dioxin (TCDD) in mice lacking the Ah (dioxin) receptor. Genes Cells 2, 645-654 (1997).

149. Schmidt, J. V, Su, G. H., Reddy, J. K., Simon, M. C. \& Bradfield, C. A. Characterization of a murine Ahr null allele: involvement of the Ah receptor in hepatic growth and development. Proc. Natl. Acad. Sci. U. S. A. 93, 6731-6736 (1996).

150. Esser, C. The immune phenotype of AhR null mouse mutants: not a simple mirror of xenobiotic receptor over-activation. Biochem. Pharmacol. 77, 597-607 (2009).

151. Singh, K. P., Garrett, R. W., Casado, F. L. \& Gasiewicz, T. A. Aryl hydrocarbon receptor- 
null allele mice have hematopoietic stem/progenitor cells with abnormal characteristics and functions. Stem Cells Dev. 20, 769-84 (2011).

152. Gonzalez, F. J. \& Fernandez-Salguero, P. The aryl hydrocarbon receptor: studies using the AHR-null mice. Drug Metab. Dispos. 26, 1194-8 (1998).

153. Shackleford, G. et al. Involvement of Aryl hydrocarbon receptor in myelination and in human nerve sheath tumorigenesis. Proc. Natl. Acad. Sci. 115, E1319-E1328 (2018).

154. Hubbard, T. D., Murray, I. a \& Perdew, G. H. Indole and Tryptophan Metabolism: Endogenous and Dietary Routes to Ah Receptor Activation. Drug Metab. Dispos. 43, 1522-1535 (2015).

155. Lee, J. S., Cella, M. \& Colonna, M. AHR and the Transcriptional Regulation of Type17/22 ILC. Front. Immunol. 3, 10 (2012).

156. Shertzer, H. G. \& Senft, A. P. The micronutrient indole-3-carbinol: Implications for disease and chemoprevention. Drug Metabol. Drug Interact. (2000).

157. Hammerschmidt-Kamper, C. et al. Indole-3-carbinol, a plant nutrient and AhR-Ligand precursor, supports oral tolerance against OVA and improves peanut allergy symptoms in mice. PLoS One 12, 1-17 (2017).

158. Artis, D. \& Spits, H. The biology of innate lymphoid cells. Nature 517, 293-301 (2015).

159. Duarte, J. H., Di Meglio, P., Hirota, K., Ahlfors, H. \& Stockinger, B. Differential influences of the aryl hydrocarbon receptor on Th17 mediated responses in vitro and in vivo. PLoS One 8, e79819 (2013).

160. Veldhoen, M., Hirota, K., Christensen, J., O'Garra, A. \& Stockinger, B. Natural agonists for aryl hydrocarbon receptor in culture medium are essential for optimal differentiation of Th17 T cells. J. Exp. Med. 206, 43-9 (2009).

161. Veldhoen, M. \& Duarte, J. H. The aryl hydrocarbon receptor: fine-tuning the immuneresponse. Curr. Opin. Immunol. 22, 747-752 (2010).

162. Trifari, S., Kaplan, C. D., Tran, E. H., Crellin, N. K. \& Spits, H. Identification of a human helper $\mathrm{T}$ cell population that has abundant production of interleukin 22 and is distinct from TH-17, TH1 and TH2 cells. Nat. Immunol. 10, 864-871 (2009).

163. Sonnenberg, G. F., Fouser, L. A. \& Artis, D. Border patrol: Regulation of immunity, inflammation and tissue homeostasis at barrier surfaces by IL-22. Nat. Immunol. 12, 383-390 (2011).

164. Spits, H. \& Mjösberg, J. The Aryl Hydrocarbon Receptor: A Sentinel Safeguarding the Survival of Immune Cells in the Gut. Immunity 36, 5-7 (2012).

165. Spits, H. \& Di Santo, J. P. The expanding family of innate lymphoid cells: Regulators and effectors of immunity and tissue remodeling. Nat. Immunol. 12, 21-27 (2011).

166. Lee, H. U., McPherson, Z. E., Tan, B., Korecka, A. \& Pettersson, S. Host-microbiome interactions: the aryl hydrocarbon receptor and the central nervous system. J. Mol. Med. 95, 29-39 (2017).

167. Lamas, B. et al. CARD9 impacts colitis by altering gut microbiota metabolism of tryptophan into aryl hydrocarbon receptor ligands. Nat. Med. 22, 598-605 (2016).

168. de Araújo, E. F. et al. The IDO-AhR axis controls Th17/Treg immunity in a pulmonary model of fungal infection. Front. Immunol. 8, (2017).

169. Bessede, A. et al. Aryl hydrocarbon receptor control of a disease tolerance defence pathway. Nature 511, 184-190 (2014). 
170. Kawajiri, K. et al. Aryl hydrocarbon receptor suppresses intestinal carcinogenesis in ApcMin/+ mice with natural ligands. Proc. Natl. Acad. Sci. 106, 13481-13486 (2009).

171. Ohtake, F., Fujii-Kuriyama, Y. \& Kato, S. AhR acts as an E3 ubiquitin ligase to modulate steroid receptor functions. Biochem. Pharmacol. 77, 474-484 (2009).

172. Ohtake, F. et al. Dioxin receptor is a ligand-dependent E3 ubiquitin ligase. Nature 446, 562-566 (2007).

173. Chng, S. H. et al. Ablating the aryl hydrocarbon receptor (AhR) in CD11c+ cells perturbs intestinal epithelium development and intestinal immunity. Sci. Rep. 6, 23820 (2016).

174. Quintana, F. J. et al. An endogenous aryl hydrocarbon receptor ligand acts on dendritic cells and T cells to suppress experimental autoimmune encephalomyelitis. Proc. Natl. Acad. Sci. U. S. A. 107, 20768-20773 (2010).

175. Mahiout, S. et al. Toxicological characterisation of two novel selective aryl hydrocarbon receptor modulators in Sprague-Dawley rats. Toxicol. Appl. Pharmacol. 326, 54-65 (2017).

176. Helmersson, S., Sundstedt, A., Deronic, A., Leanderson, T. \& Ivars, F. Amelioration of experimental autoimmune encephalomyelitis by the quinoline-3-carboxamide paquinimod: reduced priming of proinflammatory effector CD4(+) T cells. Am. J. Pathol. 182, 1671-80 (2013).

177. Deronic, A., Tahvili, S., Leanderson, T. \& Ivars, F. The anti-tumor effect of the quinoline3-carboxamide tasquinimod: blockade of recruitment of CD11b(+) Ly6C(hi) cells to tumor tissue reduces tumor growth. BMC Cancer 16, 440 (2016).

178. He, D. et al. Laquinimod for multiple sclerosis. Cochrane database Syst. Rev. 8, CD010475 (2013).

179. Kieseier, B. C. Defining a role for laquinimod in multiple sclerosis. Ther. Adv. Neurol. Disord. 7, 195-205 (2014).

180. Thöne, J. \& Linker, R. Laquinimod in the treatment of multiple sclerosis: a review of the data so far. Drug Des. Devel. Ther. 1111 (2016). doi:10.2147/DDDT.S55308

181. Varrin-Doyer, M., Zamvil, S. S. \& Schulze-Topphoff, U. Laquinimod, an up-and-coming immunomodulatory agent for treatment of multiple sclerosis. Exp. Neurol. 262, 0-5 (2014).

182. Schulze-Topphoff, U. et al. Laquinimod, a quinoline-3-carboxamide, induces type II myeloid cells that modulate central nervous system autoimmunity. PLoS One 7, e33797 (2012).

183. Brunmark, C. et al. The new orally active immunoregulator laquinimod (ABR-215062) effectively inhibits development and relapses of experimental autoimmune encephalomyelitis. J. Neuroimmunol. 130, 163-172 (2002).

184. Karussis, D. M., Lehmann, D. \& Linde, A. Treatment of secondary progressive multiple sclerosis with the immunomodulator linornide : 341-346 (1996).

185. Andersen, $\mathrm{O}$. et al. Linomide reduces the rate of active lesions in relapsing-remitting multiple sclerosis. Neurology 47, 895-900 (1996).

186. Tuvesson, $\mathrm{H}$. et al. Cytochrome P450 3A4 is the major enzyme responsible for the metabolism of laquinimod, a novel immunomodulator. Drug Metab. Dispos. 33, 866-72 (2005).

187. Fernández, O. Tratamiento oral con laquinimod en la esclerosis múltiple. Neurologia 26, 
111-117 (2011).

188. Brück, W. \& Wegner, C. Insight into the mechanism of laquinimod action. J. Neurol. Sci. 306, 173-179 (2011).

189. Brück, W. et al. Reduced astrocytic NF-KB activation by laquinimod protects from cuprizone-induced demyelination. Acta Neuropathol. 124, 411-424 (2012).

190. Wegner, C. et al. Laquinimod interferes with migratory capacity of T cells and reduces IL-17 levels, inflammatory demyelination and acute axonal damage in mice with experimental autoimmune encephalomyelitis. J. Neuroimmunol. 227, 133-143 (2010).

191. Yang, J. S., Xu, L. Y., Xiao, B. G., Hedlund, G. \& Link, H. Laquinimod (ABR-215062) suppresses the development of experimental autoimmune encephalomyelitis, modulates the Th1/Th2 balance and induces the Th3 cytokine TGF- $\beta$ in Lewis rats. J. Neuroimmunol. 156, 3-9 (2004).

192. Lühder, F. et al. Laquinimod enhances central nervous system barrier functions. Neurobiol. Dis. 102, 60-69 (2017).

193. Berg, J. et al. The immunomodulatory effect of laquinimod in CNS autoimmunity is mediated by the aryl hydrocarbon receptor. J. Neuroimmunol. 298, 9-15 (2016).

194. Kaye, J. et al. Laquinimod arrests experimental autoimmune encephalomyelitis by activating the aryl hydrocarbon receptor. Proc. Natl. Acad. Sci. U. S. A. 201607843 (2016). doi:10.1073/pnas.1607843113

195. Thöne, J. et al. Modulation of autoimmune demyelination by laquinimod via induction of brain-derived neurotrophic factor. Am. J. Pathol. 180, 267-274 (2012).

196. Aharoni, R. et al. Oral treatment with laquinimod augments regulatory T-cells and brainderived neurotrophic factor expression and reduces injury in the CNS of mice with experimental autoimmune encephalomyelitis. J. Neuroimmunol. 251, 14-24 (2012).

197. Moore, S. et al. Therapeutic laquinimod treatment decreases inflammation, initiates axon remyelination, and improves motor deficit in a mouse model of multiple sclerosis. Brain Behav. 3, 664-682 (2013).

198. Polman, C. et al. Treatment with laquinimod reduces development of active MRI lesions in relapsing MS. Neurology 64, 987 LP-991 (2005).

199. Comi, G. et al. Effect of laquinimod on MRI-monitored disease activity in patients with relapsing-remitting multiple sclerosis: a multicentre, randomised, double-blind, placebocontrolled phase Ilb study. Lancet 371, 2085-2092 (2008).

200. Filippi, M. et al. Placebo-controlled trial of oral laquinimod in multiple sclerosis: MRI evidence of an effect on brain tissue damage. J. Neurol. Neurosurg. Psychiatry 85, 8518 (2014).

201. Comi, G. et al. Placebo-Controlled Trial of Oral Laquinimod for Multiple Sclerosis. N. Engl. J. Med. 366, 1000-1009 (2012).

202. Vollmer, T. L. et al. A randomized placebo-controlled phase III trial of oral laquinimod for multiple sclerosis. J. Neurol. 261, 773-783 (2014).

203. Stasiolek, M., Linker, R. a., Hayardeny, L., Bar Ilan, O. \& Gold, R. Immune parameters of patients treated with laquinimod, a novel oral therapy for the treatment of multiple sclerosis: results from a double-blind placebo-controlled study. Immunity, Inflamm. Dis. 3, 45-55 (2015).

204. Comi, G. et al. Baseline characteristics of patients enrolled in CONCERTO - a study of 
0.6 and $1.2 \mathrm{mg} /$ day oral laquinimod for relapsing-remitting multiple sclerosis (P7.216). Neurology 84, (2015).

205. Myhr, K. M. \& Mellgren, S. I. Corticosteroids in the treatment of multiple sclerosis. Acta Neurol. Scand. 120, 73-80 (2009).

206. Cortese, I. et al. Evidence-based guideline update: Plasmapheresis in neurologic disorders Report of the Therapeutics and Technology Assessment. Neurology 76, 294300 (2011).

207. Tumani, H. Corticosteroids and plasma exchange in multiple sclerosis. J. Neurol. 255, 36-42 (2008).

208. Torkildsen, O., Myhr, K. M. \& Bø, L. Disease-modifying treatments for multiple sclerosis - a review of approved medications. Eur. J. Neurol. 23, 18-27 (2016).

209. Jacobs, L. D. et al. Intramuscular Interferon Beta-1A Therapy Initiated during a First Demyelinating Event in Multiple Sclerosis. N. Engl. J. Med. 343, 898-904 (2000).

210. Kinkel, R. P. IM interferon $\beta-1$ a delays definite multiple sclerosis 5 years after a first demyelinating event. Neurology (2006). doi:10.1212/01.wnl.0000200778.65597.ae

211. Paty, D. W. \& Li, D. K. B. Interferon beta- 1 b is effective in relapsing-remitting multiple sclerosis: II. MRI analysis results of a multicenter, randomized, double-blind, placebocontrolled trial. Neurology 43, 662-662 (1993).

212. Comi, G. et al. Effect of early interferon treatment on conversion to definite multiple sclerosis: A randomised study. Lancet 357, 1576-1582 (2001).

213. Perini, P. et al. Interferon-beta (INF-beta) antibodies in interferon-beta1a- and interferon-beta1b-treated multiple sclerosis patients. Prevalence, kinetics, crossreactivity, and factors enhancing interferon-beta immunogenicity in vivo. Eur. Cytokine Netw. (2001).

214. Barkhof, F. et al. Magnetic Resonance Imaging Effects of Interferon Beta-1b in the BENEFIT Study. Arch. Neurol. 64, 1292 (2007).

215. Freedman, M. S. Evidence for the efficacy of interferon beta-1b in delaying the onset of clinically definite multiple sclerosis in individuals with clinically isolated syndrome. Ther. Adv. Neurol. Disord. 7, 279-288 (2014).

216. Kappos, L. et al. Treatment with interferon beta-1b delays conversion to clinically definite and McDonald MS in patients with clinically isolated syndromes. Neurology 67, 1242 LP-1249 (2006).

217. Hurwitz, B. J. et al. Tolerability and safety profile of $12-$ to 28 -week treatment with interferon beta-1b 250 and $500 \mu \mathrm{g}$ QOD in patients with relapsing-remitting multiple sclerosis: A multicenter, randomized, double-blind, parallel-group pilot study. Clin. Ther. 30, 1102-1112 (2008).

218. Gaindh, D. et al. The effect of interferon beta-1b on size of short-lived enhancing lesions in patients with multiple sclerosis. Expert Opin. Biol. Ther. 8, 1823-1829 (2008).

219. Johnson, K. et al. Copolymer 1 reduces relapse rate and improves disability in relapsingremitting multiple sclerosis: results of a phase III multicenter, double-blind, placebocontrolled trial. Neurology (1995). doi:10.1212/WNL.45.7.1268

220. Boneschi, F. M. et al. Effects of glatiramer acetate on relapse rate and accumulated disability in multiple sclerosis: meta-analysis of three double-blind, randomized, placebo-controlled clinical trials. Mult. Scler. J. 9, 349-355 (2003). 
221. Comi, G., Filippi, M. \& Wolinsky, J. S. European/Canadian multicenter, double-blind, randomized, placebo-controlled study of the effects of glatiramer acetate on magnetic resonance imaging-measured disease activity and burden in patients with relapsing multiple sclerosis. Ann. Neurol. 49, 290-297 (2001).

222. Comi, G. et al. Effect of glatiramer acetate on conversion to clinically definite multiple sclerosis in patients with clinically isolated syndrome (PreCISe study): a randomised, double-blind, placebo-controlled trial. Lancet 374, 1503-1511 (2009).

223. Wolinsky, J. S. et al. GLACIER: An open-label, randomized, multicenter study to assess the safety and tolerability of glatiramer acetate $40 \mathrm{mg}$ three-times weekly versus $20 \mathrm{mg}$ daily in patients with relapsing-remitting multiple sclerosis. Mult. Scler. Relat. Disord. 4, 370-376 (2015).

224. O'Connor, P. et al. Randomized Trial of Oral Teriflunomide for Relapsing Multiple Sclerosis. N. Engl. J. Med. 365, 1293-1303 (2011).

225. O'Connor, P. et al. Long-term safety and efficacy of teriflunomide. Neurology 86, 920 $930(2016)$

226. Miller, A. E. et al. Oral teriflunomide for patients with a first clinical episode suggestive of multiple sclerosis (TOPIC): A randomised, double-blind, placebo-controlled, phase 3 trial. Lancet Neurol. 13, 977-986 (2014).

227. Confavreux, C. et al. Oral teriflunomide for patients with relapsing multiple sclerosis (TOWER): A randomised, double-blind, placebo-controlled, phase 3 trial. Lancet Neurol. 13, 247-256 (2014).

228. Fox, R. J. et al. Placebo-Controlled Phase 3 Study of Oral BG-12 or Glatiramer in Multiple Sclerosis. N. Engl. J. Med. 367, 1087-1097 (2012).

229. Fox, R. J. et al. Efficacy and Tolerability of Delayed-release Dimethyl Fumarate in Black, Hispanic, and Asian Patients with Relapsing-Remitting Multiple Sclerosis: Post Hoc Integrated Analysis of DEFINE and CONFIRM. Neurol. Ther. 6, 175-187 (2017).

230. Gold, R. et al. Sustained Effect of Delayed-Release Dimethyl Fumarate in Newly Diagnosed Patients with Relapsing-Remitting Multiple Sclerosis: 6-Year Interim Results From an Extension of the DEFINE and CONFIRM Studies. Neurol. Ther. 5, 45-57 (2016).

231. Everage, N. J. et al. Safety and Efficacy of Delayed-release Dimethyl Fumarate in Multiple Sclerosis Patients Treated in Routine Medical Practice: Interim Analysis of ESTEEM (P6.333). Neurology 88, (2017).

232. Rudick, R. A. et al. Natalizumab plus Interferon Beta-1a for Relapsing Multiple Sclerosis. N. Engl. J. Med. 354, 911-923 (2006).

233. Voloshyna, N. et al. Natalizumab improves ambulation in relapsing-remitting multiple sclerosis: Results from the prospective TIMER study and a retrospective analysis of AFFIRM. Eur. J. Neurol. 22, 570-577 (2015).

234. Balcer, L. J. et al. Low-contrast acuity measures visual improvement in phase 3 trial of natalizumab in relapsing MS. J. Neurol. Sci. 318, 119-124 (2012).

235. Polman, C. H. et al. A randomized, placebo-controlled trial of natalizumab for relapsing multiple sclerosis. N. Engl. J. Med. 354, 899-910 (2006).

236. Cohen, J. A. et al. Long-term (up to 4.5 years) treatment with fingolimod in multiple sclerosis: Results from the extension of the randomised TRANSFORMS study. $J$. Neurol. Neurosurg. Psychiatry 87, 468-475 (2016). 
237. Cohen, J. A. et al. Oral Fingolimod or Intramuscular Interferon for Relapsing Multiple Sclerosis. N. Engl. J. Med. 362, 402-415 (2010).

238. Khatri, B. et al. Comparison of fingolimod with interferon beta-1a in relapsing-remitting multiple sclerosis: A randomised extension of the TRANSFORMS study. Lancet Neurol. 10, 520-529 (2011).

239. Khatri, B. O. et al. Effect of prior treatment status and reasons for discontinuation on the efficacy and safety of fingolimod vs. interferon $\beta-1$ a intramuscular: Subgroup analyses of the Trial Assessing Injectable Interferon vs. Fingolimod Oral in Relapsing-Remitting Multiple Sclerosis (TRANSFORMS). Mult. Scler. Relat. Disord. 3, 355-363 (2014).

240. Devonshire, V. et al. Relapse and disability outcomes in patients with multiple sclerosis treated with fi ngolimod: subgroup analyses of the double-blind, randomised, placebocontrolled FREEDOMS study. Lancet Neurol. 11, 420-428 (2012).

241. Kappos, L. et al. A placebo-controlled trial of oral fingolimod in relapsing multiple sclerosis. N. Engl. J. Med. 362, 387-401 (2010).

242. Calabresi, P. A. et al. Safety and efficacy of fingolimod in patients with relapsingremitting multiple sclerosis (FREEDOMS II): A double-blind, randomised, placebocontrolled, phase 3 trial. Lancet Neurol. 13, 545-556 (2014).

243. Cuker, A. et al. A distinctive form of immune thrombocytopenia in a phase 2 study of alemtuzumab for the treatment of relapsing-remitting multiple sclerosis. Blood 118, 6299-305 (2011).

244. CAMMS223 Trial Investigators et al. Alemtuzumab vs. interferon beta-1a in early multiple sclerosis. N. Engl. J. Med. 359, 1786-801 (2008).

245. Cohen, J. A. et al. Alemtuzumab versus interferon beta 1a as first-line treatment for patients with relapsing-remitting multiple sclerosis: A randomised controlled phase 3 trial. Lancet 380, 1819-1828 (2012).

246. Coles, A. J. et al. Alemtuzumab for patients with relapsing multiple sclerosis after disease-modifying therapy: A randomised controlled phase 3 trial. Lancet 380, 18291839 (2012).

247. Bernitsas, E., Wei, W. \& Mikol, D. D. Suppression of mitoxantrone cardiotoxicity in multiple sclerosis patients by dexrazoxane. Ann. Neurol. 59, 206-209 (2006).

248. van de Wyngaert FA D'Hooghe MB, Dooms G, Lissoir F, Carton H, Sindic CJ, B. C. A double-blind clinical trial of mitoxantrone versus methylprednisolone in relapsing, secondary progressive multiple sclerosis. Acta Neurol. Belg. 101, 210 (2001).

249. Marriott, J. J., Miyasaki, J. M., Gronseth, G. \& O'Connor, P. W. Evidence Report: The efficacy and safety of mitoxantrone (Novantrone) in the treatment of multiple sclerosis. Neurology 74, 1463-1470 (2010).

250. Gajofatto, A. \& Benedetti, M. D. Treatment strategies for multiple sclerosis: When to start, when to change, when to stop? World J. Clin. Cases 3, 545 (2015).

251. Grand'Maison, F. et al. Sequencing of disease-modifying therapies for relapsingremitting multiple sclerosis: a theoretical approach to optimizing treatment. Curr. Med. Res. Opin. 7995, 1-38 (2018).

252. Litzenburger, T. et al. B lymphocytes producing demyelinating autoantibodies: development and function in gene-targeted transgenic mice. J. Exp. Med. 188, 169-180 (1998).

253. Bettelli, E. et al. Myelin oligodendrocyte glycoprotein-specific T cell receptor transgenic 
mice develop spontaneous autoimmune optic neuritis. J. Exp. Med. 197, 1073-81 (2003).

254. Caton, M. L., Smith-Raska, M. R. \& Reizis, B. Notch-RBP-J signaling controls the homeostasis of CD8 ${ }^{-}$dendritic cells in the spleen. J. Exp. Med. 204, 1653-1664 (2007).

255. Srinivas, S. et al. Cre reporter strains produced by targeted insertion of EYFP and ECFP into the ROSA26 locus. BMC Dev. Biol. 1, 4 (2001).

256. Walisser, J. a, Glover, E., Pande, K., Liss, A. L. \& Bradfield, C. a. Aryl hydrocarbon receptor-dependent liver development and hepatotoxicity are mediated by different cell types. Proc. Natl. Acad. Sci. U. S. A. 102, 17858-17863 (2005).

257. Lee, P. P. et al. A critical role for Dnmt1 and DNA methylation in T cell development, function, and survival. Immunity 15, 763-74 (2001).

258. Sawada, S., Scarborough, J. D., Killeen, N. \& Littman, D. R. A lineage-specific transcriptional silencer regulates CD4 gene expression during $\mathrm{T}$ lymphocyte development. Cell 77, 917-929 (1994).

259. Jung, S. et al. Analysis of Fractalkine Receptor CX3CR1 Function by Targeted Deletion and Green Fluorescent Protein Reporter Gene Insertion. Mol. Cell. Biol. 20, 4106-4114 (2000).

260. Rubtsov, Y. P. et al. Regulatory T Cell-Derived Interleukin-10 Limits Inflammation at Environmental Interfaces. Immunity 28, 546-558 (2008).

261. Garcia, A. D. R., Doan, N. B., Imura, T., Bush, T. G. \& Sofroniew, M. V. GFAPexpressing progenitors are the principal source of constitutive neurogenesis in adult mouse forebrain. Nat. Neurosci. 7, 1233-1241 (2004).

262. Madisen, L. et al. A robust and high-throughput Cre reporting and characterization system for the whole mouse brain. Nat. Neurosci. 13, 133-40 (2010).

263. Pan, D., Das, A., Liu, D., Veazey, R. S. \& Pahar, B. Isolation and characterization of intestinal epithelial cells from normal and SIV-infected rhesus macaques. PLoS One 7, (2012).

264. Yin, Y., Mitson-Salazar, A. \& Prussin, C. Detection of intracellular cytokines by flow cytometry. Curr. Protoc. Immunol. (2015). doi:10.1002/0471142735.im0624s110

265. Zola, H. Detection of cytokine receptors by flow cytometry. Curr. Protoc. Immunol. (2001). doi:10.1002/0471142735.im0621s26

266. Freer, G. \& Rindi, L. Intracellular cytokine detection by fluorescence-activated flow cytometry: Basic principles and recent advances. Methods (2013). doi:10.1016/j.ymeth.2013.03.035

267. Foster, B., Prussin, C., Liu, F., Whitmire, J. K. \& Whitton, J. L. Detection of Intracellular Cytokines by Flow Cytometry BT - Current Protocols in Immunology. Curr. Protoc. Immunol. (2001). doi:10.1002/0471142735.im0624s78

268. Shi, S. R., Cote, R. J. \& Taylor, C. R. Antigen retrieval techniques: current perspectives. J. Histochem. Cytochem. 49, 931-7 (2001).

269. Shi, S. R., Chaiwun, B., Young, L., Cote, R. J. \& Taylor, C. R. Antigen retrieval technique utilizing citrate buffer or urea solution for immunohistochemical demonstration of androgen receptor in formalin-fixed paraffin sections. J. Histochem. Cytochem. 41, 1599-1604 (1993).

270. Faget, L. \& Hnasko, T. S. Tyramide Signal Amplification for Immunofluorescent 
Enhancement. Methods Mol. Biol. (2015). doi:10.1007/978-1-4939-2742-5_16

271. Fidler, I. J. Selection of Successive Tumour Lines for Metastasis. Nat. New Biol. 242, 148-149 (1973).

272. Fidler, I. J. \& Fidler, J. Biological Behavior of Malignant Melanoma Cells Correlated to Their Survival in Vivo Biological Behavior of Malignant Melanoma Cells Correlated to Their Survival in vitro. 35, 218-224 (1975).

273. Baniyash, M., Netanel, T. \& Witz, I. P. Differences in cell density associated with differences in lung-colonizing ability of B16 melanoma cells. Cancer Res. 41, 433-437 (1981).

274. Overwijk, W. W. \& Restifo, N. P. B16 as a mouse model for human melanoma. Current protocols in immunology / edited by John E. Coligan ... [et al.] Chapter 20, (2001).

275. Gutiérrez-Vázquez, C. \& Quintana, F. J. Regulation of the Immune Response by the Aryl Hydrocarbon Receptor. Immunity 48, 19-33 (2018).

276. Nguyen, L. P. \& Bradfield, C. A. The search for endogenous activators of the aryl hydrocarbon receptor. Chem. Res. Toxicol. 21, 102-16 (2008).

277. Fletcher, J. M., Lalor, S. J., Sweeney, C. M., Tubridy, N. \& Mills, K. H. G. T cells in multiple sclerosis and experimental autoimmune encephalomyelitis. Clin. Exp. Immunol. 162, 1-11 (2010).

278. Berer, K. et al. Dietary non-fermentable fiber prevents autoimmune neurological disease by changing gut metabolic and immune status. Sci. Rep. 8, 10431 (2018).

279. Snapper, C. M., Peschel, C. \& Paul, W. E. IFN-gamma stimulates IgG2a secretion by murine B cells stimulated with bacterial lipopolysaccharide. J. Immunol. 140, 2121-7 (1988).

280. Preiningerova, J. Oral laquinimod therapy in relapsing multiple sclerosis. Expert Opin. Investig. Drugs 18, 985-989 (2009).

281. Lourenço, E. V., Wong, M., Hahn, B. H., Palma-Diaz, M. F. \& Skaggs, B. J. Laquinimod delays and suppresses nephritis in lupus-prone mice and affects both myeloid and lymphoid immune cells. Arthritis Rheumatol. 66, 674-685 (2014).

282. Jolivel, V. et al. Modulation of dendritic cell properties by laquinimod as a mechanism for modulating multiple sclerosis. Brain 136, 1048-1066 (2013).

283. Kimura, A., Naka, T., Nohara, K., Fujii-Kuriyama, Y. \& Kishimoto, T. Aryl hydrocarbon receptor regulates Stat1 activation and participates in the development of Th17 cells. Proc. Natl. Acad. Sci. 105, 9721-9726 (2008).

284. Jin, G.-B., Winans, B., Martin, K. C. \& Lawrence, B. P. New insights into the role of the aryl hydrocarbon receptor in the function of CD11c + cells during respiratory viral infection. Eur. J. Immunol. 44, 1685-1698 (2014).

285. Nguyen, N. T. et al. Aryl hydrocarbon receptor negatively regulates dendritic cell immunogenicity via a kynurenine-dependent mechanism. Proc. Natl. Acad. Sci. 107, 19961-19966 (2010).

286. Varrin-Doyer, M. et al. Treatment of spontaneous EAE by laquinimod reduces Tfh, B cell aggregates, and disease progression. Neurol. Neuroimmunol. Neurolnflammation 3, 1-11 (2016).

287. Spits, H., Bernink, J. H. \& Lanier, L. NK cells and type 1 innate lymphoid cells: partners in host defense. Nat. Immunol. 17, 758 (2016). 
288. Schiering, C. et al. Feedback control of AHR signalling regulates intestinal immunity. Nature 542, 242-245 (2017).

289. Shin, J. H. et al. Modulation of natural killer cell antitumor activity by the aryl hydrocarbon receptor. Proc. Natl. Acad. Sci. 110, 12391-12396 (2013).

290. Valentin-Torres, A., Ramirez Kitchen, C. M., Haller, H. S. \& Bernstein, H. B. Bidirectional NK/DC interactions promote CD4 expression on NK cells, DC maturation, and HIV infection. Virology 433, 203-215 (2012).

291. Gras Navarro, A., Björklund, A. T. \& Chekenya, M. Therapeutic potential and challenges of natural killer cells in treatment of solid tumors. Front. Immunol. 6, 202 (2015).

292. Hughes, T. et al. Interleukin-1 $\beta$ selectively expands and sustains interleukin-22+ immature human natural killer cells in secondary lymphoid tissue. Immunity $32,803-$ 814 (2010).

293. Cree, B. A. C., Spencer, C. M., Varrin-Doyer, M., Baranzini, S. E. \& Zamvil, S. S. Gut microbiome analysis in neuromyelitis optica reveals overabundance of Clostridium perfringens. Ann. Neurol. 80, 443-7 (2016).

294. Rumah, K. R., Linden, J., Fischetti, V. A. \& Vartanian, T. Isolation of Clostridium perfringens type $B$ in an individual at first clinical presentation of multiple sclerosis provides clues for environmental triggers of the disease. PLoS One 8, e76359 (2013).

295. Jangi, S. et al. Alterations of the human gut microbiome in multiple sclerosis. Nat. Commun. 7, (2016).

296. Tremlett, H. et al. Gut microbiota in early pediatric multiple sclerosis: a case-control study. Eur. J. Neurol. 23, 1308-1321 (2016).

297. Goverman, J. et al. Transgenic mice that express a myelin basic protein-specific T cell receptor develop spontaneous autoimmunity. Cell (1993). doi:10.1016/00928674(93)90074-Z

298. Vogel, C. F. A., Goth, S. R., Dong, B., Pessah, I. N. \& Matsumura, F. Aryl hydrocarbon receptor signaling mediates expression of indoleamine 2,3-dioxygenase. Biochem. Biophys. Res. Commun. 375, 331-5 (2008).

299. Vojdani, A. A potential link between environmental triggers and autoimmunity. Autoimmune Dis. 2014, (2014).

300. Nouri, M., Bredberg, A., Weström, B. \& Lavasani, S. Intestinal barrier dysfunction develops at the onset of experimental autoimmune encephalomyelitis, and can be induced by adoptive transfer of auto-reactive T cells. PLoS One 9, (2014).

301. Cerovic, V., Bain, C. C., Mowat, A. M. \& Milling, S. W. F. Intestinal macrophages and dendritic cells: What's the difference? Trends Immunol. 35, 270-277 (2014).

302. Schulz, O. et al. Intestinal CD103+, but not CX3CR1+, antigen sampling cells migrate in lymph and serve classical dendritic cell functions. J. Exp. Med. 206, 3101-3114 (2009).

303. Pabst, O. \& Bernhardt, G. The puzzle of intestinal lamina propria dendritic cells and macrophages. Eur. J. Immunol. 40, 2107-2111 (2010).

304. Flannigan, K. L., Geem, D., Harusato, A. \& Denning, T. L. Intestinal Antigen-Presenting Cells: Key Regulators of Immune Homeostasis and Inflammation. Am. J. Pathol. 185, 1809-1819 (2015).

305. Bogunovic, M. et al. Origin of the Lamina Propria Dendritic Cell Networkc Access. 
Immunity 31, 513-525 (2009).

306. Tamoutounour, S. et al. CD64 distinguishes macrophages from dendritic cells in the gut and reveals the Th1-inducing role of mesenteric lymph node macrophages during colitis. Eur. J. Immunol. 42, 3150-3166 (2012).

307. Rescigno, M. et al. Dendritic cells express tight junction proteins and penetrate gut epithelia...: EBSCOhost. Nat. Immunol. 2, 361-368 (2001).

308. Niess, J. H. et al. CX3CR1-mediated dendritic cell access to the intestinal lumen and bacterial clearance. Science 307, 254-8 (2005).

309. De Calisto, J., Villablanca, E. J. \& Mora, J. R. FcyRI (CD64): an identity card for intestinal macrophages. Eur. J. Immunol. 42, 3136-40 (2012).

310. Lin, H.-H. et al. The macrophage F4/80 receptor is required for the induction of antigenspecific efferent regulatory T cells in peripheral tolerance. J. Exp. Med. 201, 1615-1625 (2005).

311. Merad, M., Sathe, P., Helft, J., Miller, J. \& Mortha, A. The dendritic cell lineage: ontogeny and function of dendritic cells and their subsets in the steady state and the inflamed setting. Annu. Rev. Immunol. 31, 563-604 (2013).

312. Bossie, A. \& Vitetta, E. S. IFN-y enhances secretion of IgG2a from IgG2a-committed LPS-stimulated murine B cells: Implications for the role of IFN-y in class switching. Cell. Immunol. (1991). doi:10.1016/0008-8749(91)90257-C

313. Rodríguez-Sosa, M. et al. Over-production of IFN-y and IL-12 in AhR-null mice. FEBS Lett. 579, 6403-6410 (2005).

314. DiMeglio, P. et al. Activation of the aryl hydrocarbon receptor dampens the severity of inflammatory skin conditions. Immunity 40, 989-1001 (2014).

315. Kim, W., Zandoná, M. E., Kim, S. H. \& Kim, H. J. Oral disease-modifying therapies for multiple sclerosis. J. Clin. Neurol. 11, 9-19 (2015).

316. Simones, T. \& Shepherd, D. M. Consequences of AhR activation in steady-state dendritic cells. Toxicol. Sci. 119, 293-307 (2011).

317. Moreno-Nieves, U. Y., Mundy, D. C., Shin, J. H., Tam, K. \& Sunwoo, J. B. The aryl hydrocarbon receptor modulates the function of human CD56 bright NK cells. Eur. J. Immunol. (2018). doi:10.1002/eji.201747289

318. Zhang, L. H., Shin, J. H., Haggadone, M. D. \& Sunwoo, J. B. The aryl hydrocarbon receptor is required for the maintenance of liver-resident natural killer cells. J. Exp. Med. jem.20151998 (2016). doi:10.1084/jem.20151998

319. Yelamanchi, S. D. et al. Signaling network map of the aryl hydrocarbon receptor. J. Cell Commun. Signal. 10, 341-346 (2016).

320. Lanz, T. V. et al. Tryptophan-2,3-Dioxygenase (TDO) deficiency is associated with subclinical neuroprotection in a mouse model of multiple sclerosis. Sci. Rep. 7, 1-13 (2017). 


\section{CURRICULUM VITAE}

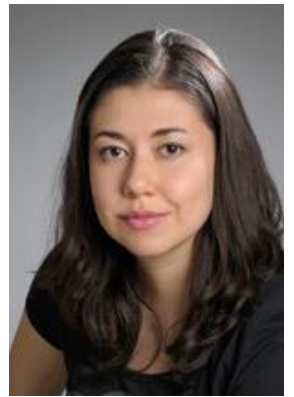

\section{Erika Avendaño Guzmán}

e.avendanoguzman@gmail.com

\begin{tabular}{l|l} 
Nationality & Mexican \\
Date of birth & May 6th, 1988 \\
Place of birth & Tlalnepantla de Baz, México
\end{tabular}

- EDUCATION:

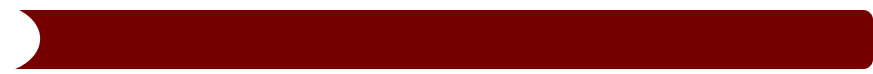

$2014-2018$

PhD student Institute for Neuropathology, University of Göttingen, IMPRS (member of the International Max Planck Research School). Neuroscience graduate program, Göttingen, Germany.

$2012-2014$

M.Sc. student University of Göttingen, IMPRS Neuroscience graduate program, Göttingen, Germany.

$2007-2011$ B.Sc. (Biology) Honorific Mention. (Class rank: 2 of 1,756) Universidad Nacional Autónoma de México, Mexico City, Mexico.

$2004-2007 \quad$ High school Honorific Mention. (Class rank: 3 of $\sim 1000$ ) Instituto Tecnológico de Monterrey, Mexico City, Mexico.

$2000-2004$ Secondary school. Honorific Mention. (Class rank: 1 of 52) Liceo Ibérico Americano, Mexico City, Mexico.

- PROJECTS / RESEARCH:

09/2014-10/2018 Evaluating the function of the Aryl Hydrocarbon Receptor in CNS autoimmunity. PhD project at the Neuropathology department (Prof. Wolfgang Brück) of the University Medical Center Göttingen (UMG), Göttingen, Germany.

10/2013-07/2014 Role of N-truncated $\mathbf{A} \beta 4-x$ and $\mathbf{A} \beta 5-x$ in Alzheimer's disease. Master's project at the division of Molecular Psychiatry (Prof. Thomas Bayer) of the UMG, Göttingen, Germany.

05/2013 - 06/2013 Activity dependent expression of TRPV1 in hippocampal neurons. Lab rotation at the Trans-synaptic signaling department (Camin Dean, $\mathrm{PhD}$ ) of the European Neuroscience Institute, Göttingen, Germany.

03/2013-05/2013 Evaluation of antibody signal intensity and specificity in colorimetric and fluorescent protein microarray applications. Lab rotation at the R\&D Diagnostic Membranes department (Dr. Denise van Rossum) of Sartorius Stedim Biotech GmbH, Göttingen, Germany.

01/2013-03/2013 Involvement of synaptic molecules in synapse formation and maturation. Lab rotation at the Anatomy and Embryology department (Prof. Thomas Dresbach) of the Center for Anatomy, UMG, Göttingen, Germany.

08/2010-02/2012 Role of reactive oxygen species in BDNF and NMDA trophic actions using cerebellar granule cells. Bachelor's thesis project at the Neurodevelopment and Physiology department (Prof. Julio Morán Andrade) of the Universidad Nacional Autónoma de Mexico, Mexico City, Mexico.

03/2011-09/2011 Mechanisms or neuronal death. Internship at the Neurodevelopment and Physiology department (Prof. Julio Morán Andrade) of the Universidad Nacional Autónoma de Mexico, Mexico City, Mexico. 
- SCIENTIFIC PUBLICATIONS:

Original publication:

2018 Ott $\mathrm{M}^{1}$, Avendaño-Guzmán $\mathrm{E}^{1}$, Ullrich E, Dreyer $\mathrm{C}$, Strauss J, Harden $\mathrm{M}$, Schön $\mathrm{M}$, Schön MP, Bernhardt G, Stadelmann C, Wegner C, Brück W, Nessler S. Quinoline-3carboxamides utilize a CD155-mediated NK/DC interaction to suppress CNS autoimmunity. 2018 [in revision].

2014 Avendaño-Guzmán E, Bouter Y, Richard BC, Lannfelt L, Ingelsson M, Paetau A, Verkkoniemi-Ahola A, Wirths O, Bayer TA.. Mol Neurodegener. 2014; 9: 13.

Poster presentations:

2017 Avendaño-Guzmán E, Ott M, Wegner C, Hayardeny L, Ullrich E, Schoen M, Brück W, Nessler S. Laquinimod is a potent aryl hydrocarbon receptor dependent activator of natural killer cells. American Academy of Neurology, Boston, 2017.

2016 Avendaño-Guzmán E, Barrette B, Theiss R, Lagumersindez - Denis N, Hayardeny L, Stadelmann-Nessler C, Nave KA, Brück W, Nessler S. A new rodent model of progressive demyelination and neurodegeneration mimicking progressive MS. 13th International Congress of Neuroimmunology, Jerusalem, 2016.

2015 Avendaño-Guzmán E, Stadelmann-Nessler C, Brück W, Nessler S. Evaluating the function of MOG specific-TCR CD8 ${ }^{+} \mathrm{T}$ cells in CNS autoimmunity. 6th biennial neuroscience conference Neurizons, Göttingen, 2015.

${ }^{1}$ Co-first author 